UNIVERSIDADE DE SÃO PAULO

FACULDADE DE ECONOMIA, ADMINISTRAÇÃO E CONTABILIDADE DEPARTAMENTO DE ADMINISTRAÇÃO PROGRAMA DE PÓS-GRADUAÇ̃̃o EM ADMINISTRAÇÃo

A ORGANIZAÇÃO DE OBJETIVOS ESTRATÉGICOS CORPORATIVOS: UM ESTUDO SOBRE A ESTRUTURAÇÃO DOS OBJETIVOS E SUA RELAÇÃO COM A IMPLEMENTAÇÃO

Daniel Estima de Carvalho

Orientador: Prof. Dr. James Terence Coulter Wright 
Prof. Dr. Marco Antonio Zago

Reitor da Universidade de São Paulo

Prof. Dr. Reinaldo Guerreiro

Diretor da Faculdade de Economia, Administração e Contabilidade

Prof. Dr. Roberto Sbragia

Chefe do Departamento de Administração

Prof. Dr. Lindolfo Galvão de Albuquerque

Coordenador do Programa de Pós-Graduação em Administração 


\section{A ORGANIZAÇÃO DE OBJETIVOS ESTRATÉGICOS CORPORATIVOS: UM ESTUDO SOBRE A ESTRUTURAÇÃO DOS OBJETIVOS E SUA RELAÇÃO COM A IMPLEMENTAÇÃO}

Tese apresentada ao Programa de PósGraduação em Administração da Faculdade de Economia, Administração e Contabilidade da Universidade de São Paulo, para a obtenção do título de Doutor em Ciências.

Orientador: Prof. Dr. James Terence Coulter Wright

Versão Corrigida

(versão original disponível na Faculdade de Economia, Administração e Contabilidade)

\section{SÃO PAULO}




\section{Carvalho, Daniel Estima de}

A organização de objetivos estratégicos corporativos: um estudo sobre a estruturação dos objetivos e sua relação com a implementação / Daniel Estima de Carvalho. -- São Paulo, 2014.

$189 \mathrm{p}$.

Tese (Doutorado) - Universidade de São Paulo, 2014.

Orientador: James Terence Coulter Wright.

1. Estratégia organizacional 2. Objetivos organizacionais 3. Administracão estratégica 4. Administração executiva I. Universidade de São Paulo. Faculdade de Economia, Administração e Contabilidade II. Título.

$$
\text { CDD - } 658.401
$$


À memória de meu pai, exemplo de força, dedicação, automotivação e equilíbrio referência para sempre. 
Agradeço, primeiramente, a meu orientador, o professor James T. C. Wright. O privilégio de sua orientação foi fundamental para chegar-se aos resultados alcançados neste trabalho. E sua compreensão, no período mais difícil de minha vida, essencial para conseguir chegar até o final.

Agradeço também seu apoio, por meio do Programa de Estudos do Futuro (PROFUTURO), que tornou viável a aplicação da pesquisa e produção desta tese. $\mathrm{E}$ aproveito para agradecer ao apoio e incentivo dos colegas que lá trabalham, em especial, Cristiane Oliveira e Ivana Franco, e aos professores Carlos Honorato Teixeira, Leandro Fraga e Nelson D. Yoshida.

Aos Professores da FEA-USP, cujas aulas tive o prazer e o privilégio de participar, em especial aos professores Martinho Almeida e Hamilton Corrêa pelas valorosas contribuições na banca de qualificação.

A toda a equipe da Secretaria do Programa de Pós-Graduação do Departamento de Administração, da Secretaria de Pós-graduação da FEA e da Biblioteca FEA, pelo suporte e presteza.

A todos os participantes da pesquisa de campo, que foram fundamentais para esta tese, compartilhando informações valiosas das empresas em que trabalham, além de outros tantos, que, mesmo na impossibilidade de contribuir para a pesquisa, registraram sua torcida pelo sucesso deste trabalho.

A toda equipe da Faculdade FIA de Administração e Negócios (professores, funcionários e alunos), em especial, a seu diretor, professor Leandro Morilhas, e aos colegas e amigos Claudia Ivonciac, Eduardo Armando, Marcio Fedichina, Marcos Gaspar, Maurício Tsuruta e Renira Cirelli, pelo interesse e motivação para com este trabalho.

Um agradecimento especial à Reni, ao amigo Léo Seki, e à minha irmã Daiane, pelo apoio na revisão do trabalho e pelas discussões estatísticas.

Às minhas famílias Estima, Carvalho (desde sempre), Burgudji e Porsani (desde 2008), em especial à minha mãe Vandi, pelo carinho e compreensão, neste período de raro convívio familiar.

À minha esposa Carolina, que partilhou comigo os momentos de tristezas e alegrias, nesses anos de Doutorado. E que, a partir de agora, os momentos de alegria sejam ainda mais frequentes.

E, novamente, a meu pai: o maior incentivador desta realização. 


\section{RESUMO}

Uma correta organização de objetivos estratégicos pode assegurar um caminho da implementação mais adequado, tornando possível, assim, aumentar a satisfação dos responsáveis pela definição da estratégia corporativa. O objetivo desta tese é a proposição de uma tipologia de técnicas para organização de objetivos estratégicos e a análise do uso de elementos dessa tipologia na implementação de estratégias corporativas. Foram estudados diversos autores que abordavam conceitos para organizar objetivos estratégicos que, agrupados em cinco técnicas, foram organizadas segundo uma tipologia que abrange, em um primeiro eixo, o nível de participação dos diversos níveis organizacionais na aplicação da técnica e no processo estratégico, e no outro eixo, o nível de formalização e estruturação da técnica. As técnicas elencadas para organização de objetivos estratégicos corporativos são: Administração por Objetivos (APO), Balanced Scorecard (BSC), Objetivos essencialmente Financeiros, Processo Intuitivo / Criativo e Processo Participativo. Na pesquisa de campo, que obteve 289 respostas válidas, todos os respondentes escolheram uma das cinco opções da tipologia como técnica para organização de objetivos estratégicos em sua empresa, reforçando a abrangência e utilidade da tipologia. Das cinco técnicas, o BSC foi a mais indicada. Apesar de a amostra indicar seu uso em todo porte de empresa, o BSC obteve destaque pela maior presença em empresas com faturamento acima de $\mathrm{R} \$ 1$ bilhão. Características como divulgação da estratégia para toda a organização, contribuição da técnica para a comunicação, maior abrangência dos objetivos, dentre outros, também puderam ser comprovadas. A APO, mesmo sendo a técnica mais antiga estudada nesta tese, destacou-se por estar entre as técnicas com o maior número de objetivos estratégicos implementados com sucesso, enquanto que a técnica de Objetivos Financeiros foi a segunda mais indicada pelos respondentes e a sua característica principal foi reforçada na pesquisa, já que é a técnica que mais usa os objetivos de "Geração de Valor". As características da técnica Participativa que puderam ser comprovadas na pesquisa foram a participação dos respondentes em todo o processo estratégico e a divulgação da estratégia para toda a organização, que recebe o reforço pela ampla participação no processo estratégico. A técnica Participativa, adicionalmente, apresentou, como resultado, um dos maiores números de objetivos estratégicos implementados com sucesso. Por fim, a técnica Intuitiva caracterizou-se como a mais usada por respondentes de empresas com faturamento abaixo de $\mathrm{R} \$ 1$ bilhão e pelo menor número de objetivos estratégicos estabelecidos. A pesquisa pôde mostrar o quanto o uso de objetivos auxilia a implementação estratégica, e em especial, mostrar quais são as características mais relevantes de cada técnica da tipologia e como elas estão sendo aplicadas nas corporações. 


\begin{abstract}
A proper organization of the strategic objectives can ensure the most appropriate implementation, thus increasing the satisfaction of those responsible for setting corporate strategy. This doctoral dissertation aims to propound a typology of techniques for organizing strategic objectives and analyse the use of elements of this typology in the implementation of corporate strategies. Several authors addressed concepts for organizing strategic objectives that allowed grouping five techniques according to the central concepts that best represented what authors reported. The techniques considered for organizing corporate strategic objectives are: Management by Objectives (MBO), Balanced Scorecard (BSC), essentially Financial Goals, Intuitive/Creative Process and Participatory Process. These five techniques were organized according to a typology that covers, in a first axis, the level of participation of different organizational levels in the application of technical and strategic process, and on the other axis, the level of formalization and structuring technique. In the field survey, conducted with 289 valid responses, all respondents chose one of the five options of typology as a technique for organizing strategic objectives for their business, enhancing the scope and usefulness of the typology. Of the five techniques, the BSC was the most utilized. Although the sample indicates its use in all sizes of enterprise, the BSC was highlighted by being most used in companies with revenues exceeding $R \$ 1$ billion. Features such as dissemination of the strategy throughout the organization, contribution to communication, broader range of objectives, among others, could also be proven. The MBO, the oldest technique studied in this dissertation, was highlighted by the largest number of strategic objectives successfully implemented, while the technique of Financial Objectives was the second most indicated by respondents and its main feature was as the technique that uses more "Value Generation" goals. The characteristics of the Participatory technique confirmed in the survey were the participation of respondents in all the strategic process and the dissemination of the strategy throughout the organization, which is boosted by the broad participation in the strategic process. Furthermore, this technique presented as a result, a larger number of strategic objectives implemented successfully. Finally, the Intuitive technique was characterized as the most used by respondents from companies with revenue under BRL $\$ 1$ billion and the smallest number of strategic objectives. The research was able to show that the use of objective aids strategic implementation, and in particular, could show the most relevant characteristics of each type of technique and how they are being applied in corporations.
\end{abstract}




\section{SUMÁRIO}

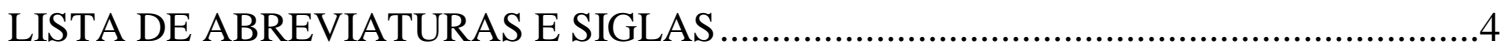

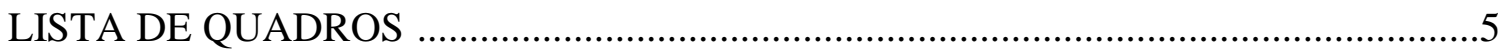

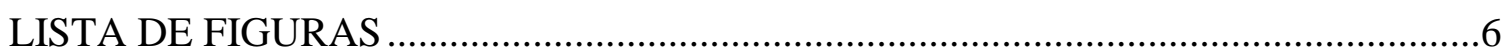

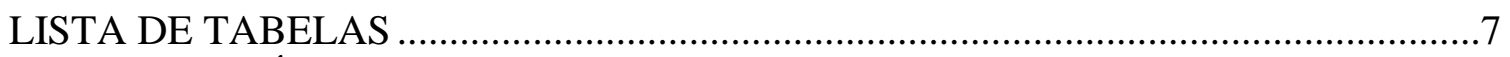

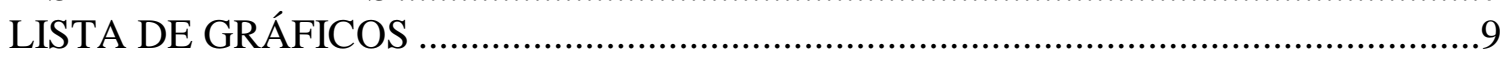

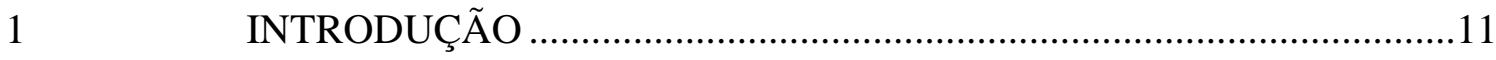

$1.1 \quad$ O desafio da administração estratégica ..............................................11

1.2 O problema da organização dos objetivos estratégicos corporativos....12

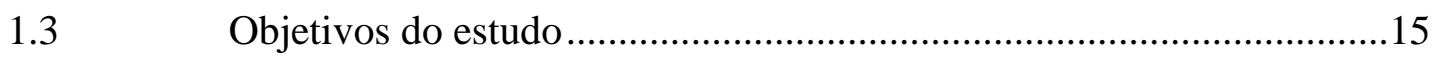

1.4 Definições teóricas e operacionais da pesquisa....................................15

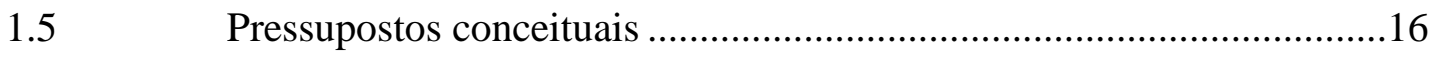

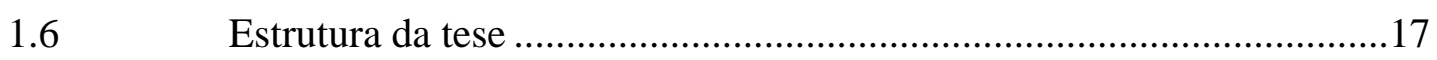

2 A ADMINISTRAÇÃO ESTRATÉGICA E A ORGANIZAÇÃO DE OBJETIVOS ESTRATÉGICOS CORPORATIVOS …............................19

2.1 A estratégia como preparação para o futuro........................................19

a) Do planejamento estratégico à administração estratégica ................22

b) As escolas de pensamento estratégico ...........................................24

2.2 As grandes etapas da administração estratégica...................................29

a) A separação entre formulação e implementação estratégica .............33

b) Aspectos críticos para o sucesso da implementação estratégica .......35

2.3 As definições de objetivos estratégicos..............................................42

2.4 As diversas visões a sobre organização de objetivos estratégicos ........46

a) O Balanced Scorecard (BSC) de Kaplan e Norton ..........................46

i) $\quad \mathrm{O}$ mapa de sucesso de Bourne e Bourne ..................................52

b) A Administração por Objetivos (APO) de Drucker ...........................55

i) Os objetivos estratégicos de Ansoff .......................................60

ii) Os objetivos essenciais de Chatterjee.....................................61

iii) $\quad$ Fatores críticos de sucesso ..................................................64

iv) Definição de objetivos de Alogan e Yetis ................................66

v) O processo hoshin kanri .........................................................68

c) $\quad \mathrm{O}$ uso de Objetivos essencialmente Financeiros ...........................70

d) Processo Intuitivo/Criativo desenvolvido a partir da alta direção....75

e) Processo Participativo por meio da discussão em grupos de baixo

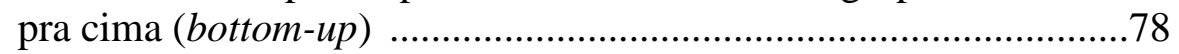

2.5 Proposição de uma tipologia de organização de objetivos estratégicos

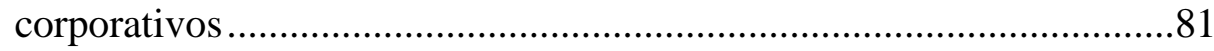

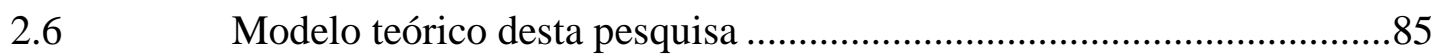

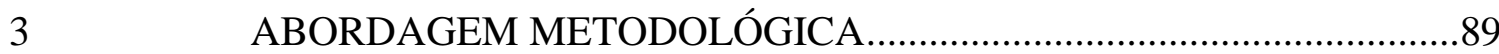

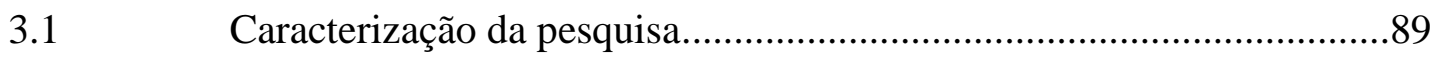

3.2 Definição do universo e amostra de pesquisa .....................................91 
3.3 Estratégia de coleta dos dados .92

3.4 Escalas de mensuração e técnicas de tratamento estatístico dos dados.94

3.6 Limitações do método de pesquisa......................................................97

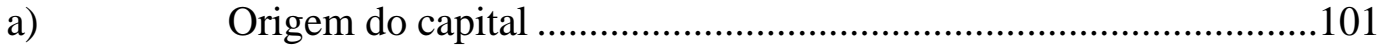

b) Setor de atuação das organizações ..............................................102

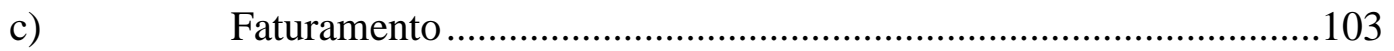

4.3 Características da estratégia corporativa ...........................................104

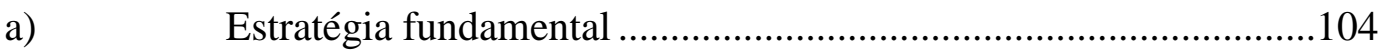

b) Nível de participação do respondente na definição da estratégia...104

c) Técnicas que organizam os objetivos estratégicos corporativos ....105

d) Pontos fortes e recomendações de aprimoramento das técnicas:

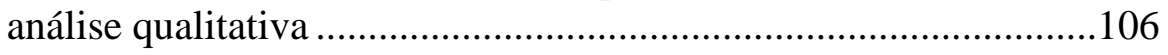

e) Níveis organizacionais que recebem a divulgação dos objetivos estratégicos

4.4 Estudo de elementos de influência na técnica adotada pelas organizações ....

e) Característica fundamental da estratégia ....................................117

f) Quantidade de reuniões para definição da estratégia.

g) Dias de preparação prévia para a definição da estratégia empresarial

h) Divulgação dos objetivos estratégicos para os níveis organizacionais

i) Nível de participação na definição da estratégia ............................120

j) Número de objetivos estratégicos ...............................................123

k) Nível organizacional responsável pela definição de elementos da

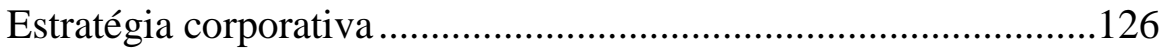

1) Percepção de satisfação dos respondentes em relação aos aspectos

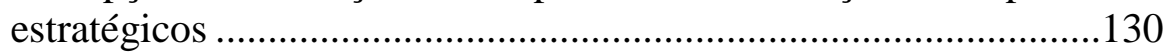

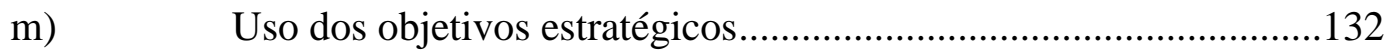

n) Ordem das etapas do processo estratégico ..................................137

o) Resumo das diferenças estatisticamente significativas encontradas entre as técnicas.... 
5.1 Principais resultados encontrados na pesquisa de campo

Considerações sobre as técnicas de organização de objetivos estratégicos ................................................................................. 150

5.3 Observações sobre os objetivos específicos da pesquisa ....................154

5.4 Limitações da pesquisa e sugestões para estudos futuros ....................157

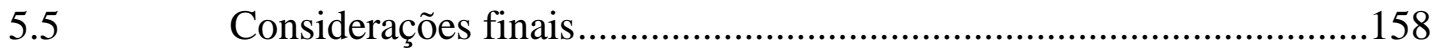

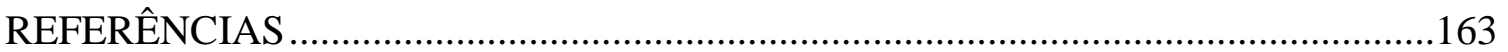

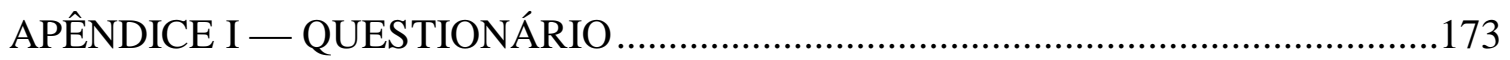

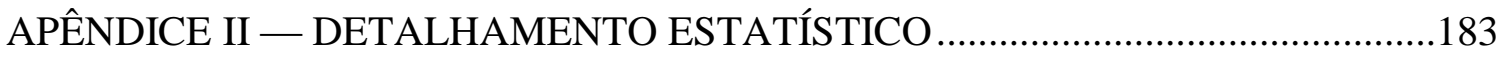




\section{LISTA DE ABREVIATURAS E SIGLAS}

APO: Administração por Objetivos

BNDES: Banco Nacional de Desenvolvimento Econômico e Social

BSC: Balanced Scorecard

FCS: Fatores Críticos de Sucesso

KPI: Key Performance Indicators (Indicadores Chave de Desempenho)

PDCA: Plan-Do-Check-Act (Planejar, Executar, Verificar e Agir)

PE: Planejamento Estratégico

PEST: Política, Econômica, Social e Tecnológica

ROA: Return on Assest (retorno sobre o ativo)

ROE: Return on Equity (retorno sobre o patrimônio líquido)

ROI: Return on Investment (retorno sobre o investimento)

SMART: Specific, Measurable, Achievable, Realistic, Time-related (Específico, Mensurável, Atingível, Realista e Relacionado com o tempo)

SWOT: Strengths, Weaknesses, Opportunities, Threats (Pontos Fortes, Fracos, Oportunidades e Ameaças)

UEN: Unidade Estratégica de Negócios 


\section{LISTA DE QUADROS}

Quadro 1 - Diferenças entre planejamento e administração estratégica.........................23

Quadro 2 - Características das escolas de pensamento estratégico ..................................27

Quadro 3 - Combinações das escolas de pensamento estratégico ...................................28

Quadro 4 - Técnicas que organizam objetivos estratégicos ..........................................81

Quadro 5 - Blocos de questões do levantamento .........................................................93

Quadro 6 - Integração metodológica entre os elementos da tese....................................96

Quadro 7 - Outras técnicas de organização de objetivos citadas pelos respondentes .106

Quadro 8 - Principais pontos fortes, fracos e sugestões de aprimoramento para as

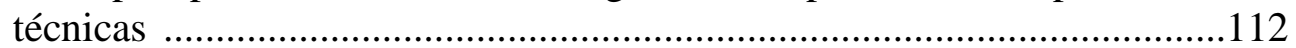

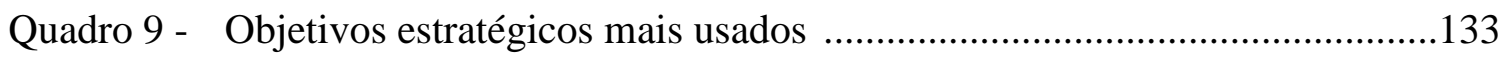

Quadro 10 - Variáveis agrupadas em fatores ...........................................................136

Quadro 11 - Diferenças estatisticamente relevantes entre as técnicas ...........................141

Quadro 12 - Principais diferenças entre as técnicas ....................................................156 


\section{LISTA DE FIGURAS}

Figura 1 - Diagrama simplificado do processo estratégico .........................................13

Figura 2 - Modelo de administração estratégica ..................................................29

Figura 3 - Diagrama simplificado do processo estratégico com dois estágios: formulação e implementação .....................................................................34

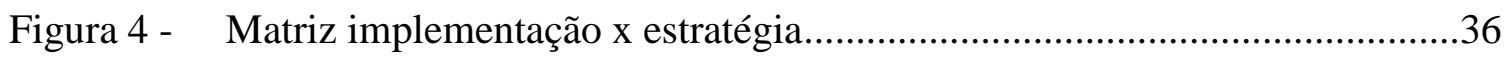

Figura 5 - Relacionamento entre objetivos estratégicos e a estratégica.........................44

Figura 6 - Relação entre estratégia, BSC e mapas estratégicos ....................................47

Figura 7 - Mapa estratégico padrão.........................................................................48

Figura 8 - Componentes do BSC e do mapa estratégico para um fragmento de estratégia para uma companhia aérea .........................................................50

Figura 9 - Exemplo do processo "o que/como" (what / how) .....................................52

Figura 10 - Exemplo de mapa de sucesso para uma empresa de treinamentos ...............53

Figura 11 - O mapa de sucesso derivado em um Balanced Scorecard .............................54

Figura 12 - Iniciativas em andamento cruzadas com os objetivos do mapa .....................55

Figura 13 - Hierarquia geral de objetivos ...............................................................61

Figura 14 - O modelo COAR ...................................................................................63

Figura 15 - Processo de definição de objetivos, FCS e KPIs, a partir da missão ...........64

Figura 16 - Fluxo do processo de gestão estratégica .....................................................67

Figura 17 - Esquema do processo hoshin kanri .......................................................69

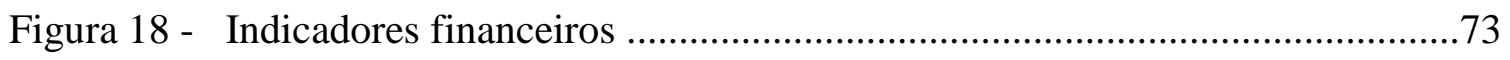

Figura 19 - Esquema da discussão apresentada por Bower .........................................80

Figura 20 - Tipologia de estruturação de técnicas de organização de objetivos estratégicos .................................................................................... 83

Figura 21 - O papel da definição de objetivos estratégicos, do planejamento à

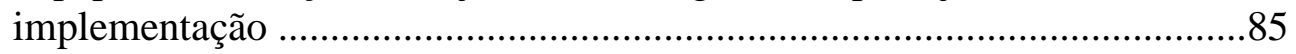

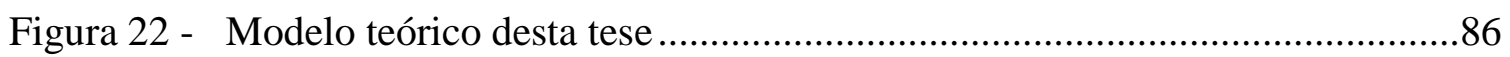

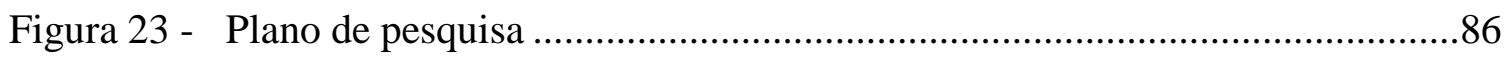

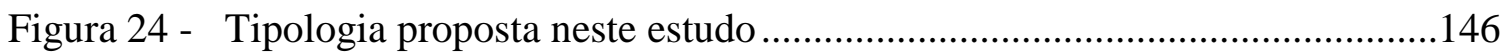

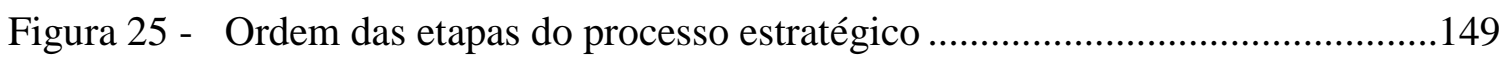




\section{LISTA DE TABELAS}

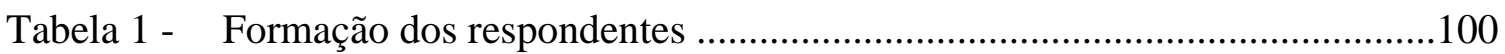

Tabela 2 - Nível de decisão dos respondentes........................................................101

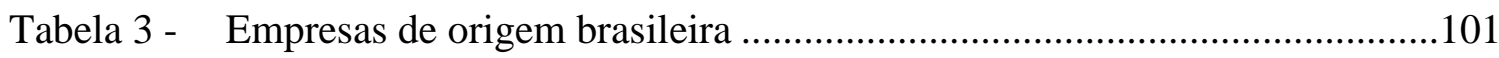

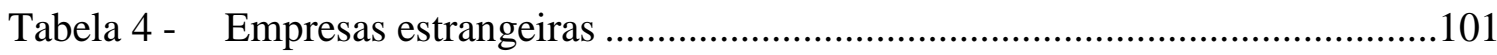

Tabela 5 - Origem das empresas $x$ capital aberto no Brasil ........................................102

Tabela 6 - Detalhamento do setor de atuação do respondente ....................................102

Tabela 7 - Agrupamento dos setores entre indústria e serviços ..................................103

Tabela 8 - Faturamento das organizações ................................................................104

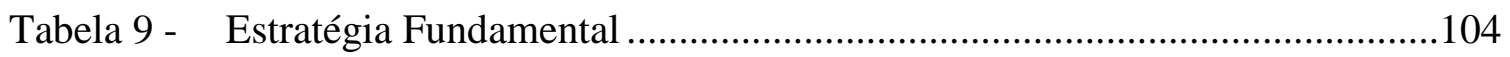

Tabela 10 - Nível de participação do respondente na definição da estratégia................105

Tabela 11 - Técnicas para organização de objetivos estratégicos corporativos .............105

Tabela 12 - Níveis organizacionais que recebem os objetivos estratégicos ...................114

Tabela 13 - Origem de capital e técnicas de organização de objetivos estratégicos

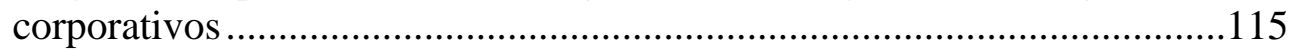

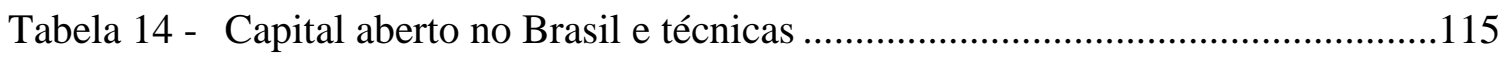

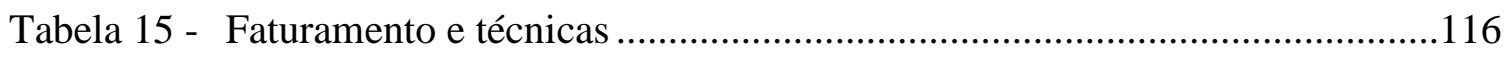

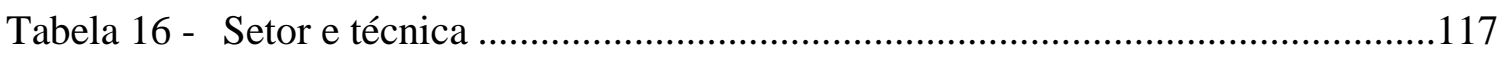

Tabela 17 - Característica fundamental da estratégia e técnica...................................118

Tabela 18 - Quantidade de reuniões e técnicas (médias e medianas) ............................118

Tabela 19 - Quantidade de reuniões e técnicas (números absolutos) ...........................119

Tabela 20 - Dias de preparação prévia e técnicas.........................................................119

Tabela 21 - Divulgação dos objetivos e técnicas..............................................................120

Tabela 22 - Nível de participação e técnica..................................................................121

Tabela 23 - Nível de participação do respondente e faturamento da organização ........123

Tabela 24 - Número de objetivos estabelecidos e técnicas .........................................124

Tabela 25 - Número de objetivos implementados com sucesso e técnicas ...................124

Tabela 26 - Razão entre objetivos implementados com sucesso e objetivos estabelecidos

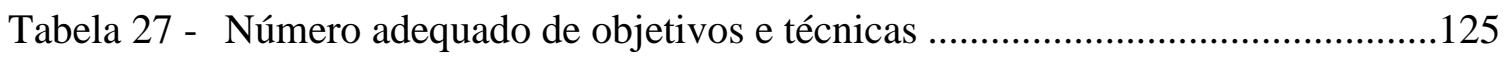

Tabela 28 - Número de objetivos individuais e técnicas .............................................126

Tabela 29 - Responsáveis pela definição da estratégia e as técnicas..............................125

Tabela 30 - Responsáveis pela definição de objetivos estratégicos e as técnicas .........126

Tabela 31 - Responsáveis pela definição de metas e as técnicas...................................129

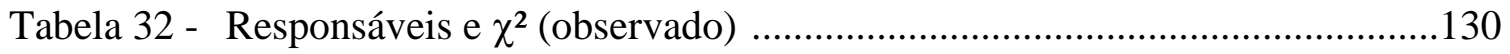

Tabela 33 - Prova de Kruskal-Wallis para comparação das técnicas em relação à satisfação do respondente.....................................................................132

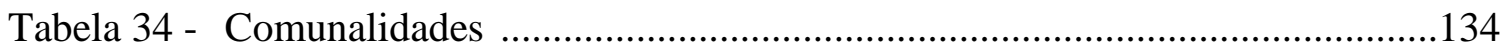

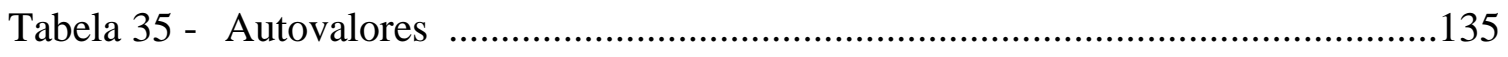

Tabela 36 - Prova de Kruskal-Wallis frente aos fatores .............................................137

Tabela 37 - Quantidade de etapas do processo estratégico .........................................138 
Tabela 38 - Sequência das etapas do processo estratégico

Tabela 39 - Nível de participação na definição estratégia e tamanho da organização .144

Tabela 40 - Uso das técnicas de organização de objetivos estratégicos corporativos ..147

Tabela 41 - Porte da empresa e uso da técnica de organização de objetivos estratégicos corporativos

Tabela 42 - Origem do capital das empresas e uso da técnica de organização de objetivos estratégicos

Tabela 43 - Divulgação dos objetivos para a organização e uso da técnica de organização de objetivos estratégicos corporativos

Tabela 44 - Satisfação do respondente com relação a contribuição do objetivo para a comunicação estratégica 


\section{LISTA DE GRÁFICOS}

Gráfico 1 - Faturamento das organizações e técnica usada ........................................116

Gráfico 2 - Participação na estratégia e uso da técnica ...............................................122

Gráfico 3 - Responsáveis pela definição da estratégia corporativa e as técnicas ........127

Gráfico 4 - Responsáveis pela definição de objetivos estratégicos e as técnicas ........128

Gráfico 5 - Responsáveis pela definição de metas e as técnicas ...................................129

Gráfico 6 - Resumo das responsabilidades .................................................................130

Gráfico 7 - Percepção de satisfação dos respondentes em relação aos aspectos

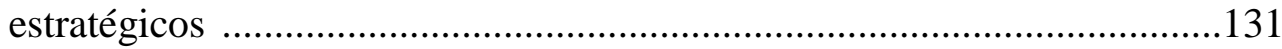

Gráfico 8 - Contribuição da técnica para a comunicação estratégica ….......................132

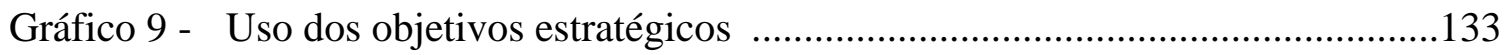

Gráfico 10 - Teste scree para identificação de número de fatores .................................135

Gráfico 11 - Pontuação das etapas e as técnicas ............................................................138

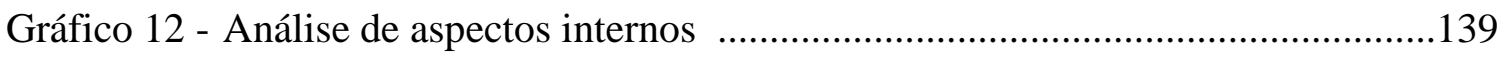




\section{INTRODUÇÃO}

\subsection{O desafio da administração estratégica}

Definir e comunicar os objetivos estratégicos de uma organização é um desafio perene para os administradores. A formulação e priorização dos objetivos estratégicos de uma organização deve levar em conta a velocidade das mudanças no ambiente competitivo, o desenvolvimento tecnológico e a complexidade dos mercados, que são alguns dos aspectos que impactam a rotina de uma organização. Aspectos como situação econômica e política dos países onde a organização desempenha atividades, o desenvolvimento da tecnologia, seja ela empresarial ou produtiva, o acompanhamento de possíveis ameaças, oriundos de novos entrantes ou do surgimento de novos produtos ou serviços substitutos em seu mercado de atuação, devem ser monitorados, acompanhados, entendidos e enfrentados.

É necessário que os gestores analisem o ambiente que os cerca para entender as condições de mercado, a movimentação da concorrência e as novas tecnologias que podem impactar sua realidade - o que contribui para o aumento da complexidade da gestão. Este conjunto de incertezas que afetam a realidade das organizações exige uma postura proativa, em termos de ações que posicionem uma empresa em relação ao mercado em que atua, perante seus concorrentes, parceiros, clientes e demais stakeholders. Todos esses itens são externos ao controle e à interferência direta da organização, que pode, no máximo, tentar influenciar partes desse quebra-cabeça e preparar-se para as mudanças das condições competitivas.

Em adição às ameaças externas, temos a administração interna de recursos da empresa como a gestão das pessoas, a produção, o fluxo de custos e recebimentos, entre outros aspectos que devem ser monitorados e, neste caso, geridos, pois são elementos que fazem parte da organização e que devem funcionar para atender a missão que a empresa se propõe. Neste ponto, entender e gerenciar todas as atividades críticas de sua cadeia de valor é importante para potencializar suas competências e diferenciar-se perante o mercado.

Além do acompanhamento do que acontece externamente à organização, da gestão de seus recursos e de sua rotina, é necessário pensar, também, em seu futuro. Como a empresa atenderá a visão que almeja? Quais são e como alcançar os objetivos definidos pela 
organização? Essas questões são importantes para direcionar a análise da empresa e possibilitar uma postura proativa em relação ao mercado. Esta reflexão é necessária para evitar que todos os esforços concentrem-se somente na situação atual da empresa, sem preparar-se para os próximos passos que devem ser dados, pensando na continuidade da empresa e dos negócios. E integrando todos os pontos citados, deve-se analisar como a organização deverá trabalhar para aproveitar melhor seus recursos em oportunidades detectadas no mercado, ao mesmo tempo em que se defende das ameaças externas.

A administração estratégica é a disciplina da área de Administração que apresenta e organiza ferramentas que buscam analisar o ambiente em que a organização está envolvida; define como a empresa irá posicionar-se e portar-se face às oportunidades e ameaças identificadas; de que maneira irá aproveitar seus recursos e de que forma será feita a gestão de todos estes aspectos, para garantir a execução que permita que tudo o que foi planejado seja alcançado no futuro. Dessa maneira, espera-se que a empresa de sucesso vislumbre e aproveite oportunidades em seu ambiente, obtendo melhores resultados do que seus concorrentes e garantindo sua competitividade.

O sucesso da implementação estratégica é fundamental para a realização da estratégia planejada. Mais do que analisar uma situação e conceber um plano, é necessário acompanhar se os desdobramentos imaginados estão se realizando a contento. Neste sentido, o uso de objetivos que possam ser organizados, definidos e detalhados em metas e indicadores, é essencial para uma adequada gestão da implementação estratégica. Estes objetivos, relacionados à divisão da estratégia em partes menores, fazem a integração entre os elementos que foram analisados e planejados com o caminho delineado para a realização da estratégia de forma sistêmica.

\subsection{O problema da organização dos objetivos estratégicos corporativos}

O objetivo desta tese é a proposição de uma tipologia de abordagens para organização de objetivos estratégicos e a análise do uso de elementos dessa tipologia na implementação de estratégias corporativas. Com isso, tem-se a intenção de estudar esta parte pouco explorada de um processo de administração estratégica, que faz a ligação entre as etapas de análise e formulação da estratégia com a sua implementação, conforme a Figura 1 apresenta, a seguir. 


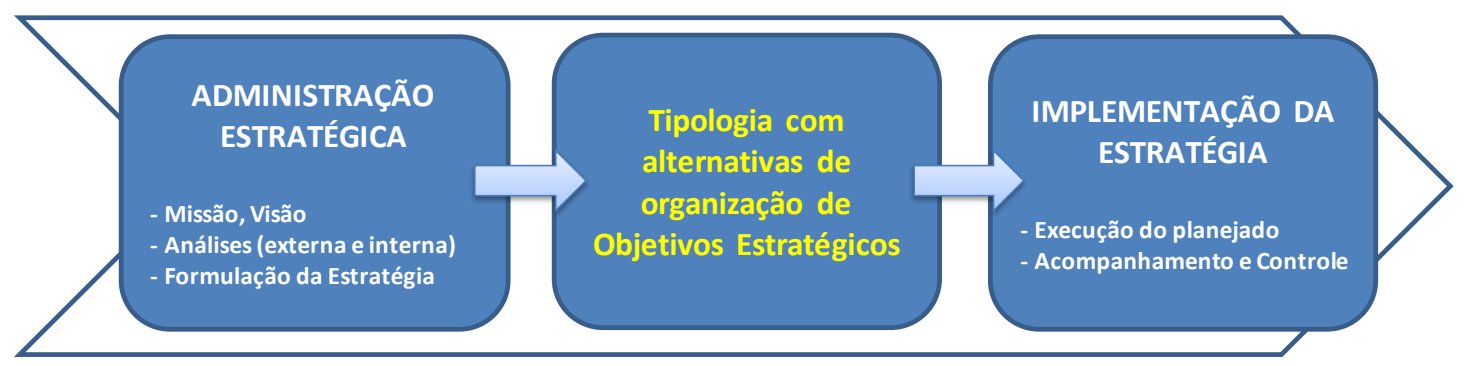

Figura 1 - Diagrama simplificado do processo estratégico

FONTE: baseado em Almeida (2010) e Kaplan e Norton (2008).

O processo de administração estratégica engloba, de modo geral, etapas que incluem a reflexão acerca da missão e da visão da organização, as análises externa e interna, a formulação da estratégia, e por fim, a implementação do plano estratégico definido. Após as etapas de análise, é realizada a etapa da formulação do caminho a ser seguido com o posicionamento, para atender a missão e a visão de uma organização. Para Almeida (2010) e Kaplan e Norton (2008), após a definição e a formulação da estratégia, são estabelecidos os objetivos estratégicos corporativos. Com isso, entende-se que a estratégia é representada por grandes objetivos, que, ao serem alcançados na etapa de implementação, resultam na execução bem sucedida da estratégia planejada.

Os objetivos estratégicos detalham a estratégia em partes menores e, de preferência, mensuráveis. Por sua vez, os objetivos permitem ser detalhados por meio de metas intermediárias e indicadores para sua mensuração, o que pode assegurar um caminho de implementação melhor. Desta forma, é possível direcionar os esforços da empresa para alcançar, controlar e acompanhar o desenvolvimento de cada objetivo estratégico, possibilitando a correção dos rumos, caso algum não esteja no caminho almejado.

A divisão da estratégia em objetivos menores realizáveis e controláveis também pode trazer benefícios, em termos de comunicação. Um conjunto de objetivos bem definidos podem clarificar os papéis esperados das diversas áreas de uma empresa e aumentar o alinhamento necessário para a realização da estratégia corporativa. Estruturar e organizar um conjunto de objetivos estratégicos alinhados com a estratégia concebida, a missão e a visão da organização podem trazer maiores chances de sucesso na sua implementação e melhor satisfação com os resultados de desempenho da organização. 
A administração estratégica é uma das disciplinas mais estudadas da gestão em geral, porém, não encontramos grande número de referências para a definição e organização de objetivos estratégicos, como estão disponíveis referências sobre outras etapas do processo estratégico, como as análises interna e externa à organização, a definição de estratégia ou seu acompanhamento e controle. Essa carência é maior, especialmente, no caso de estudos que envolvam empresas com atuação no Brasil.

São conhecidas diversas ferramentas relacionadas à análise de ambiente, assim como também existem conceitos que discutem as possibilidades de posicionamento e da implementação estratégica. No entanto, existe pouca discussão acerca de técnicas para apoiar a estruturação dos objetivos estratégicos e a respectiva satisfação com sua efetividade por parte dos responsáveis pela implementação estratégica.

Mesmo com a disponibilidade de ferramentas e conceitos para obter-se sucesso em uma estratégia, pesquisas como a de Neilson et al. (2008) indicam que existem oportunidades a serem estudadas na integração entre as análises, a formulação e a efetividade da estratégia colocada em prática. Mintzberg (2004) destaca que, com exceção de impressões genéricas na literatura, a ligação entre a fixação de objetivos e a criação de estratégias permanece indefinida.

Desta forma, a questão que norteia esta pesquisa é: quais são as principais alternativas de organização de objetivos estratégicos corporativos e suas possíveis contribuições para a implementação e administração da estratégia empresarial?

Para responder a questão proposta foi conduzida uma pesquisa exploratória-descritiva, com vistas a buscar informações acerca do processo estratégico e do papel dos objetivos em organizações com atuação no Brasil. Essas informações, obtidas por meio de questionário, colheu percepções sobre a caracterização e o uso de objetivos estratégicos no processo estratégico, especialmente na implementação, além da satisfação dos respondentes em relação ao uso dessas ferramentas.

A melhor compreensão sobre esta questão da administração estratégica pode trazer uma contribuição ao processo estratégico das corporações, especialmente ao uso de objetivos 
estratégicos e à eficácia da implementação. Vislumbrar a oportunidade de expandir os estudos realizados no Mestrado, focado na comparação de métodos para construção de mapas estratégicos de objetivos, e a carência de estudos no exterior, e, sobretudo, no Brasil, sobre esta importante ponte entre a formulação da estratégia e sua implementação, foram os motivadores desta tese.

\subsection{Objetivos do estudo}

O objetivo geral desta tese é a proposição de uma tipologia de organização de objetivos estratégicos corporativos e a análise de seu uso na implementação estratégica, contribuindo para o desenvolvimento do conhecimento sobre organização dos objetivos estratégicos. Em termos de objetivos específicos deste trabalho, é discutida a relação entre as diferentes formas de organização de objetivos e as características da organização. Além disto, aspectos relacionados à implementação, comunicação e esforço despendido com a estratégia também são analisados.

Os objetivos específicos desta tese são detalhados, a seguir:

- Delimitar uma tipologia de técnicas para organização de objetivos estratégicos.

- Identificar diferenças no uso de técnicas de organização de objetivos estratégicos, entre organizações de características diferentes, quanto ao volume de faturamento, da origem de seu capital e do esforço despendido no processo estratégico.

- Caracterizar o nível de satisfação de executivos em relação aos objetivos estratégicos de suas organizações, à implementação e à comunicação da estratégia, de acordo com a técnica utilizada.

\subsection{Definições teóricas e operacionais da pesquisa}

São apresentadas, a seguir, as definições teóricas e as respectivas definições operacionais dos principais tópicos desenvolvidos nesta tese.

- Administração Estratégica: para Fischmann e Almeida (1991), a administração estratégica 
é o processo de tornar a organização capaz de integrar as decisões administrativas e operacionais com as estratégicas, procurando dar, ao mesmo tempo, maior eficiência e eficácia à organização. Operacionalmente, nesta pesquisa, este conceito foi utilizado com os participantes do levantamento e avaliado por meio da análise da sequencia do processo de administração estratégica.

- Objetivos estratégicos: elaborados a partir da definição da estratégia empresarial, compõem uma declaração expressa do que a organização pretende alcançar e realizar com sua estratégia (KAPLAN e NORTON, 2004). Este conceito foi operacionalizado por meio da pesquisa em que os participantes foram convidados a identificar que técnica assemelhase à forma que sua corporação organiza seus objetivos estratégicos. A partir do referencial teórico, descrito no capítulo 2, pôde-se propor uma tipologia de objetivos estratégicos, a partir da qual, os respondentes analisaram os objetivos estratégicos corporativos em uso em suas respectivas organizações.

- Tipologia: caracterização de realidades considerada em um estudo. Descrição geral desses tipos em cada caso (MICHAELIS, 2009). Nesta pesquisa, esse conceito foi utilizado na caracterização e proposição de uma tipologia de técnicas de organização de objetivos estratégicos corporativos.

- Satisfação: qualidade ou estado de satisfeito, contentamento. Sensação que sentimos quando as coisas correm à nossa vontade ou cumprem-se a nosso contento (MICHAELIS, 2009). Foi utilizado nesta pesquisa como parâmetro para colher e avaliar a percepção dos pesquisados sobre sua satisfação em relação a aspectos da formulação e implementação da estratégia e de objetivos estratégicos.

\subsection{Pressupostos conceituais}

Como pressupostos para a realização desta tese, consideramos que os seguintes pontos são determinantes para o alcance dos objetivos da pesquisa.

- Os objetivos estratégicos corporativos são derivados de uma estratégia formulada. Por meio de um objetivo estratégico, é feita a ligação entre o planejamento e a implementação. Atingir os objetivos estratégicos é o caminho para implementar e realizar a estratégia planejada.

- Foram consideradas técnicas aquelas abordagens ou ferramentas de gestão que lidam com 
objetivos estratégicos de alto nível, cujos desdobramentos estão relacionados com a implementação estratégica.

- O foco desta pesquisa é o uso das técnicas de organização de objetivos estratégicos e sua relação com o processo estratégico. Não será discutida a operacionalização destes métodos.

- Não são consideradas técnicas de organização de objetivos estratégicos os chamados modelos de mensuração de desempenho, pois a implementação destes modelos inicia-se a partir da identificação dos objetivos.

- Embora esta pesquisa analise a satisfação com a estratégia e sua relação com os objetivos da empresa, entende-se que o resultado da implementação estratégica pode ser influenciado por outros aspectos que não apenas os itens estudados nesta tese.

- Esta pesquisa limita-se à percepção de satisfação do respondente e não analisa o desempenho efetivo das empresas por entender que o resultado empresarial pode ser influenciado por variáveis incontroláveis à organização - tema que não é objeto desta tese.

\subsection{Estrutura da tese}

Esta pesquisa divide-se em cinco capítulos: este capítulo (Capítulo 1) apresenta uma introdução do tema de pesquisa, seus objetivos e pressupostos que nortearão os capítulos seguintes.

O Capítulo 2 reúne a fundamentação teórica necessária para o delineamento da pesquisa. São ressaltados os principais conceitos relacionados à administração estratégica e aos objetivos estratégicos.

O Capítulo 3 apresenta a técnica empregada na pesquisa, com a definição do método de pesquisa, a amostra utilizada, os instrumentos para coleta de dados, bem como as limitações do método de pesquisa.

O Capítulo 4 apresenta e analisa o resultado do levantamento realizado de acordo com a técnica de pesquisa adotada.

O Capítulo 5 discute as conclusões e as implicações da tese à luz do modelo de pesquisa 
proposto, as limitações da pesquisa, as sugestões e recomendações adicionais para próximas pesquisas.

Ao final, encontram-se as Referências Bibliográficas utilizadas nesta tese, e os Apêndices. 


\section{A ADMINISTRAÇÃO ESTRATÉGICA E A ORGANIZAÇÃO DE OBJETIVOS ESTRATÉGICOS CORPORATIVOS}

O objetivo deste item é apresentar a discussão dos conceitos que embasam e que foram citados no capítulo anterior desta tese.

\subsection{A estratégia como preparação para o futuro}

O ambiente empresarial aliado a desafios advindos da globalização, integração de blocos econômicos e da tecnologia aumenta a complexidade de ações necessárias para uma organização vencer no mercado e realizar sua missão, e alcançar sua visão empresarial. Os aspectos citados acima estão alinhados ao conceito de estratégia empresarial e a importância que esta disciplina possui no contexto atual no ambiente acadêmico e das organizações.

Hitt et al. (2008) definem estratégia como um conjunto integrado e coordenado de compromissos e ações, definido para explorar competências essenciais e obter vantagens competitivas. Na visão desses autores, uma empresa possui vantagem competitiva quando implementa uma estratégia que os concorrentes não conseguem copiar.

Kaplan e Norton (2004) observam que, na prática, adotam-se numerosas abordagens para formular estratégias. E dessas abordagens resultam estratégias diferentes, pelas quais as empresas buscam diferenciar-se de seus concorrentes. Segundo os autores, a essência da estratégia está nas atividades: executar certas atividades de maneira diferente ou executar atividades diferentes das dos concorrentes. É mais difícil para um concorrente copiar várias atividades entrelaçadas do que apenas uma atividade isolada que gere diferenciação, e desta forma os autores afirmam que o encaixe estratégico entre muitas atividades é fundamental para gerar e sustentar a vantagem competitiva.

Por sua vez, Porter (1996) enfatiza que o sucesso da estratégia depende de conseguir integrar e executar muito bem tais ações. Os diversos autores citados até aqui destacam a importância de combinar e integrar a execução de uma série de atividades para o sucesso da estratégia de uma empresa. Porter (1996) complementa e afirma que faz parte da estratégia atingir a 
eficiência operacional de um conjunto de atividades, em vez de apenas uma atividade - o que, na visão do autor, não seria estratégia, pois não haveria sustentabilidade da vantagem competitiva, já que os concorrentes poderiam copiar uma atividade isolada, fácil e rapidamente.

De acordo com Porter (2012) para uma estratégia de sucesso é necessário que a equipe gerencial trabalhe em grupo e trace a estratégia em conjunto, tratando a estratégia como algo para a empresa como um todo. Além disto, a comunicação é muito importante. Para Porter (2012) a estratégia deve alinhar todos na organização e ajudar a tomar boas decisões todos os dias.

Quinn (2006) afirma que uma estratégia bem formulada ajuda a ordenar e alocar os recursos de uma organização, com base em suas competências e deficiências internas, e auxilia a lidar com mudanças e antecipações, providenciando ações contingenciais em relação a atos de um oponente inteligente. Quando definem uma estratégia, as empresas escolhem alternativas para competir e alcançar um futuro planejado. Nesse sentido, a estratégia escolhida indica o que a empresa pretende e o que não pretende fazer. Após a concepção da estratégia, a empresa deve assegurar que sua implementação tenha sido realizada tal qual planejada. Para Fischmann (1987), quando a estratégia é apropriada e a implementação excelente, o sucesso é esperado. Montgomery (2012), por sua vez, destaca que formulação e implementação são dois aspectos importantes e inter-relacionados, uma vez que todas as empresas buscam estratégias bem formuladas com execuções bem realizadas. No caso desta tese, como vários autores já citados, analisamos esta relação entre formulação e execução para melhor ilustrar e comentar cada fase do processo estratégico.

Para Hitt et al. (2008), a estratégia deve ajudar a empresa a preparar-se para o futuro, a pensar como a organização continuará gerando valor a seus stakeholders e como continuará enfrentando seus concorrentes por meio de análises do monitoramento dos ambientes competitivos externos e dos aspectos internos. A estratégia deve ser integradora, buscando contemplar todas as competências da empresa e unir todas as suas unidades e áreas em busca de um distinto caminho para o futuro. Hitt et al. (2008) analisa dois modelos possíveis com relação a etapas de elaboração de uma estratégia. Um dos modelos é chamado de modelo de organização industrial (também conhecido como modelo I/O) e o segundo é o modelo baseado em recursos (RBV). O modelo de organização industrial parte do pressuposto que o 
ambiente externo exerce uma grande pressão no mercado intensificando a concorrência entre empresas que possuem recursos bem parecidos. Estas empresas procuram oportunidades em suas ações estratégicas para obter retornos superiores à média do mercado a partir de características do setor e do ambiente competitivo. Para estes autores, as empresas que desenvolvem ou adquirem as habilidades internas necessárias para implantar as estratégias exigidas pelo ambiente externo provavelmente serão bem-sucedidas. Este modelo constata que os retornos são determinados basicamente por características externas, e não somente pelos recursos e capacidades internos exclusivos de uma empresa.

Uma proposta diferente do modelo de organização industrial (ou modelo I/O) e também discutida por Hitt et al. (2008) é o modelo baseado em recursos (RBV). São buscados os setores que mais podem potencializar o uso dos recursos da empresa para que sejam obtidos retornos acima da média de mercado. Este modelo pressupõe que as empresas possuam recursos diferentes com base na maneira como os combinam e os utilizam. De acordo com Hitt et al. (2008) o modelo baseado em recursos pressupõe que a singularidade dos recursos da empresa é base para sua estratégia. As diferenças nos desempenhos das empresas ao longo do tempo se devem aos recursos internos e não as características estruturais de um setor.

Por outro lado, existem autores que alertam quanto a riscos que envolvem o planejamento estratégico. Hax e Majluf (1984) destacam o risco de excessiva burocratização e o perigo de falta de interação com outros sistemas administrativos formais - além desses, um projeto grandioso versus o incrementalismo lógico, o planejamento formal versus o planejamento oportunista, e possível inconveniência do processo de planejamento estratégico conduzido por um calendário, também são desvantagens do planejamento estratégico.

Mintzberg (2004), por sua vez, alerta que estratégias eficazes combinam duas características de maneira que reflitam as condições existentes no ambiente competitivo: a capacidade de planejar e também a necessidade de reagir a eventos inesperados, por meio de estratégias emergentes. Para ele, uma estratégia emergente é aquela em que ações e padrões realizados não foram expressamente formalizados em um plano.

Montgomery (2012) alerta para o risco de relegar a estratégia a um mero exercício lógico e tático, sem conexão com o dia a dia da empresa e com sua visão de futuro. A autora destaca a 
importância do alinhamento da estratégia, dos planos futuros e das pessoas para que se tenha sucesso na implementação do que foi planejado.

Já, Robinson (1986) identifica quatro paradoxos que ocorrem no processo de planejamento estratégico:

- Identificação de objetivos: a atividade do planejador não é estabelecer objetivos, mas, sim, propiciar condições para a alta administração identificá-los.

- Compreensão do futuro: a atividade do planejador não é prever o futuro, mas, sim, auxiliar a compreendê-lo.

- Decisão quanto à estratégia: a atividade do planejador não é tomar decisão, mas ajudar a alta administração no processo decisório.

- Desenvolvimento do plano: a atividade do planejador não é produzir um plano, mas, sim, conduzir o processo de planejamento.

Assim, a visão sistêmica do processo estratégico, com a discussão de papéis, a gestão de mudanças, e em especial, um modelo para suportar a gestão de objetivos, são importantes, para que a estratégia seja formulada e implementada com sucesso.

Na sequência deste capítulo, serão discutidas a evolução do conceito da estratégia e algumas visões e escolas de pensamento estratégico. Serão estudados ainda os principais itens de um processo de administração estratégica, enfatizando a organização de objetivos e a implementação estratégica. No bloco final deste capítulo, serão discutidas as técnicas relacionadas à organização de objetivos estratégicos e seu papel no processo estratégico, de acordo com os respectivos autores. Encerrando o capítulo, a proposição de uma tipologia destacará semelhanças e diferenças entre as técnicas levantadas.

\section{a) Do planejamento estratégico à administração estratégica}

A evolução do planejamento estratégico para a administração estratégica passou a incorporar o ferramental do administrador. Deve-se disseminar, por toda a organização, a consciência de que ela deve trabalhar em função de uma visão e um pensamento estratégico (maior, sistêmico) e não apenas em função de negócios isolados ou independentes de oportunidades. 
Para Fischmann e Almeida (1991), o planejamento estratégico é uma técnica administrativa que, por meio da análise do ambiente de uma organização, cria a consciência de suas oportunidades e ameaças e de seus pontos fortes e fracos para o cumprimento de sua missão, e por meio desta consciência, estabelece o propósito de direção que a organização deverá seguir para aproveitar as oportunidades e evitar riscos. Este conceito evoluiu, segundo Fischmann e Almeida (1991), para a administração estratégica, que é o processo de tornar a organização capaz de integrar as decisões administrativas e operacionais com as estratégicas, procurando dar, ao mesmo tempo, maior eficiência e eficácia à organização.

A administração estratégica surge para superar algumas deficiências inerentes ao próprio processo de planejamento estratégico (FISCHMANN, 1987). A administração estratégica tem como objetivo máximo o desenvolvimento dos valores da corporação, sua capacitação gerencial, suas responsabilidades como organização dentro da sociedade e seus sistemas administrativos que interligam o processo de tomada de decisão estratégica e operacional em todos os níveis hierárquicos, tanto em diversos negócios, quanto entre as diferentes linhas de autoridade funcional - chegando a este nível de desenvolvimento, eliminando os conflitos entre o desenvolvimento, em longo prazo, e a lucratividade, em curto prazo.

O termo administração estratégica refere-se a um processo contínuo e ininterrupto. O termo reflete a necessidade de não separar a estratégia em grandes blocos sequenciais e independentes. Nas discussões de Fischmann (1987), é apresentado um quadro de Gaj (1987), com o resumo das diferenças entre planejamento estratégico e administração estratégica (Quadro 1).

Quadro 1 - Diferenças entre planejamento e administração estratégica

\begin{tabular}{|l|l|}
\hline \multicolumn{1}{|c|}{ Planejamento estratégico } & \multicolumn{1}{c|}{ Administração estratégica } \\
\hline Estabelece uma postura em relação ao ambiente & Acresce a capacitação estratégica \\
\hline Lida com fatos, ideias, probabilidade & $\begin{array}{l}\text { Adiciona aspirações das pessoas, e lida com mudanças } \\
\text { rápidas do ambiente e da empresa }\end{array}$ \\
\hline Termina com um plano estratégico & Termina com um novo comportamento \\
\hline Caracteriza-se mais como sistema de planejamento & $\begin{array}{l}\text { Incorpora o sistema de ações ao sistema de } \\
\text { planejamento }\end{array}$ \\
\hline
\end{tabular}

FONTE: Fischmann (1987), baseado em Gaj (1987).

Para Zacarelli (2003), a difusão deste assunto, até então conhecido como planejamento estratégico, começou mais intensamente na década de 1970. De acordo com o autor, passouse a uma nova fase, na qual o termo "estratégia" foi amadurecendo e ganhando destaque, em 
detrimento do termo "planejamento estratégico".

Degen (1986, apud Fischmann, 1987) informa que a evolução do planejamento estratégico, no Brasil, até a década de 1970, resumia-se ao orçamento anual. A partir do início dos anos de 1970, passou-se a falar em planejamento em longo prazo, sendo que, no início da década de 1980, começou-se a falar em planejamento estratégico, e partir daí, até surgir a administração estratégica.

De acordo com Lobato et al.(2006) a partir da década de 90 buscou-se um enfoque mais sistêmico para a estratégia, equilibrando as demandas entre ambiente externo e aspectos internos, com a integração de todas as áreas da organização com o intuito de atingir seus objetivos. E, como próximo passo para a estratégia, Lobato et al.(2006) analisa que o pensamento estratégico deveria se proliferar por toda a organização, assumindo um processo de aprendizagem, estimulando uma postura empreendedora e a ação integrada de gestão, promovendo assim, um processo mais participativo de formulação e implementação estratégica.

\section{b) As escolas de pensamento estratégico}

Mintzberg et al. (2000) classificaram dez diferentes escolas, que, para eles, significam processos diferentes de fazer estratégia. Estas dez escolas foram agrupadas em dois grandes blocos. O primeiro grande bloco agrupa as escolas de pensamento que indicam análises, prescrições e ações em seus modelos estratégicos. No segundo bloco estão as chamadas escolas descritivas, que trazem uma abordagem mais conceitual e que buscam antes inspirar do que prescrever estratégias.

\section{$\underline{\text { Primeiro bloco - as escolas analíticas e prescritivas }}$}

\section{Design}

Propõe um modelo de formulação da estratégia que busca atingir uma adequação entre as capacidades internas, classificadas em pontos fortes e fracos da organização, e as possibilidades externas, classificadas em oportunidades e ameaças. De acordo com aqueles autores, este pensamento foi dominante nas décadas de 1960 e de 1970. Mintzberg (2004) complementa que esta escola não se desenvolveu de forma a surgir variantes; ao contrário: ela combinou-se com outras visões, em contextos bem diferentes. 


\section{Planejamento}

Desenvolvida concomitantemente com a escola do design, baseia-se em procedimento, treinamento e análise - todos formais. A estratégia devia ser guiada por um quadro de planejamento estratégico com acesso direto ao executivo principal. De acordo com Mintzberg (2006), esta escola nasceu na década de 1960, e continua a ser um ramo importante da literatura atual.

\section{Posicionamento}

Predominante nos anos de 1980, graças a Michael Porter, embora aceitasse a maior parte das premissas das escolas do design e planejamento, enfatiza que o estrategista é, sobretudo, um analista. A escola do posicionamento, afirmou que poucas estratégias (genéricas), como posições no mercado, são desejáveis, em um determinado setor, e podem ser defendidas contra concorrentes atuais e futuros. Mintzberg (2004) ressalva que apesar do crescimento desta escola, incluindo outras técnicas e conceitos, sempre se baseia na inclinação analítica.

\section{$\underline{\text { Segundo bloco - as escolas inspiradoras }}$}

\section{Empreendedorismo}

Conceito central baseado na visão formulada pelo líder, em sua intuição e capacidade de controlar a implementação de suas ideias. Esta visão serve como inspiração e também como guia.

\section{Cognitiva}

Compreender o processo mental das pessoas e do estrategista, na forma que a realidade é percebida. A estratégia emerge como perspectivas, em forma de conceitos, mapas e esquemas.

\section{Aprendizado}

Parte do pressuposto que a formulação e a implementação da estratégia não podem estar separadas. A estratégia é um processo emergente e os estrategistas podem estar presentes em toda parte da empresa, já que o aprendizado é coletivo.

Poder

A formação de estratégia é parte de um processo aberto de influência, enfatizando o uso do 
poder e da política para negociar estratégias favoráveis a determinados interesses. Enxerga disputas internas pelo poder, nas empresas e parcerias, ou inter-relacionamentos, para que a organização obtenha resultados de seu interesse.

\section{Cultura}

Considera a estratégia como um processo social baseada na cultura, tratando dos interesses comuns e da integração. Trata da influência da cultura como inibidora de mudanças estratégias.

\section{Ambiental}

Estuda-se a liberdade da empresa para movimentar-se dentro de seu ambiente, bem como quais são as demandas deste meio ambiente. São estudadas a teoria da contingência (respostas esperadas em determinadas condições) e a teoria institucional (as pressões institucionais enfrentadas pelas organizações).

\section{Configuração}

Mais abrangente e interativa que as demais escolas, compreende dois grandes aspectos. $\mathrm{O}$ primeiro entende a empresa como uma configuração para cada situação, integrando diferentes visões de cada escola. O segundo, mais prescritivo, vê as mudanças como transformações dramáticas de um estado para outro.

O Quadro 2 apresenta um resumo das características de cada escola de pensamento, bem como os exemplos de autores enquadrados em cada escola. 
Quadro 2 - Características das Escolas de Pensamento Estratégico

\begin{tabular}{|c|c|c|c|}
\hline Escola de Pensamento & $\begin{array}{c}\text { Visão do Processo de } \\
\text { Formulação da Es tratégia }\end{array}$ & Exemplo de Autores & Mensagem Pretendida \\
\hline \multicolumn{4}{|c|}{ Prescristivas } \\
\hline Design & Processo de Concepção & $\begin{array}{c}\text { Selznick; Newman; } \\
\text { Andrews }\end{array}$ & $\begin{array}{c}\text { Ajuste da empresa ao } \\
\text { ambiente }\end{array}$ \\
\hline Planejamento & Processo Formal & Ansoff & $\begin{array}{c}\text { Formalize o processo de } \\
\text { ajuste ao ambiente }\end{array}$ \\
\hline Posicionamento & Processo Analítico & Porter; Shendel; Hatten & $\begin{array}{c}\text { Analise o mercado e o } \\
\text { setor }\end{array}$ \\
\hline \multicolumn{4}{|c|}{ Descritivas } \\
\hline Empreendedorismo & Processo Visionário & Shumpeter; Cole & Visione / Vis lumbre \\
\hline Cognitivo & Processo Mental & Simon; March & Crie \\
\hline Aprendizado & Processo Emergente & $\begin{array}{l}\text { Lindblom; Cyert \& } \\
\text { March; Weick; Quinn; } \\
\text { Prahalad \& Hamel }\end{array}$ & Aprenda \\
\hline Poder & Processo de Negociação & $\begin{array}{l}\text { Allis on (micro); Pfeffer \& } \\
\text { Salancik; Astley (macro) }\end{array}$ & Promova \\
\hline Cultural & Processo Social & Rhenman \& Normann & Combine \\
\hline Ambiental & Processo Reativo & $\begin{array}{c}\text { Hanna \& Freeman; Pugh } \\
\text { et al. }\end{array}$ & Reaja \\
\hline Configuração & $\begin{array}{c}\text { Processo de } \\
\text { Transformação }\end{array}$ & $\begin{array}{l}\text { Chandler; Mintzberg; } \\
\text { Miller; Miles; Snow }\end{array}$ & Integre, trans forme \\
\hline
\end{tabular}

FONTE: Adaptado de Carvalho e Laurindo (2007) e Barbero (2008), baseado em Mintzberg et al. (2000).

Das escolas elencadas, nota-se que as prescritivas, em especial, a de Planejamento e de Posicionamento possuem uma estruturação em que os objetivos estratégicos são componentes fundamentais do processo.

Em complemento, a classificação que propuseram Mintzberg et al. (2000) destaca novas abordagens para a formação de estratégias resultantes das combinações de aspectos das dez escolas, como mostra o Quadro 3. De acordo com Carvalho e Laurindo (2007), estas combinações reforçam a ideia de que as escolas podem ser complementares e que podem contribuir para novas abordagens, mostrando que, se, por um lado, as ideias sobre estratégia continuam a evoluir, por outro lado, o conhecimento pregresso não é desprezado. 
Quadro 3 - Combinações das Escolas de Pensamento Estratégico

\begin{tabular}{|c|c|}
\hline Abordagem & Escolas de Pensamento \\
\hline Capacidades dinâmicas & Design, Aprendizado \\
\hline Teoria baseada nos recursos & Cultural, Aprendizado \\
\hline Análise de cenário e análise de stakeholders & Planejamento, Aprendizado, Poder \\
\hline Construcionismo & Cognitivo, Cultural \\
\hline Caos e teoria evolucionária & Aprendizado, Ambiental \\
\hline Teoria institucional & Ambiental, Poder, Cognitiva \\
\hline Intrapreneurship (risco) & Ambiental, Empreendedorismo \\
\hline Mudança revolucionária & Configuração, Empreendedorismo \\
\hline Estratégia negociada & Poder, Posicionamento \\
\hline Estratégia de manobras (ou de desenvolvimento) & Posicionamento, Poder \\
\hline
\end{tabular}

FONTE: Carvalho e Laurindo (2007), adaptado de Mintzberg et al. (2000).

E para Mintzberg (2004), lidar com todas essas características faz parte da complexidade do processo estratégico. Ademais, o processo pode pender para a direção de uma escola ou de outra, dependendo do estágio do processo ou das condições em que a organização encontrase. Mintzberg et al. (2006) ressaltam que nenhuma organização pode funcionar apenas com estratégias emergentes, da mesma forma, que também não poderia atuar apenas com estratégias deliberadas, sempre. Uma abordagem puramente unilateral pode significar de falta de análises conscientes até falta de flexibilidade, dependendo do extremo escolhido.

Para Carvalho e Laurindo (2007), outras correntes de pensamento estratégico estão ganhando destaque, pois enfocam a implementação e não somente a formulação. Esses conceitos, dentre outros que não foram destacados pelos autores, são o Balanced Scorecard de Kaplan e Norton, e a destruição criativa de Foster e Kaplan e os Modelos disruptivos de Christensen. A estes conceitos também podemos destacar outras abordagens que obtiveram destaque e não são abordadas na obra de Mintzberg et al. (2000), como as Disciplinas de valor, Modelo Delta, Estratégia baseada em recursos, Estratégia do Oceano Azul, dentre outras. Após a discussão sobre os conceitos de estratégia, veremos, a seguir, a descrição das principais etapas de um processo de administração estratégica. 


\subsection{As grandes etapas da administração estratégica}

Baseado na visão comum de diversos autores e na experiência de treinamento e consultorias Almeida (2010) propõe um diagrama com o seu modelo de administração estratégica (Figura 2) alertando que existem várias formas de se desenvolver a estratégia. Como observado por Bethlem (1998), a maior parte desses modelos é constituída pelas mesmas ideias básicas que também levarão ao estabelecimento da estratégia.

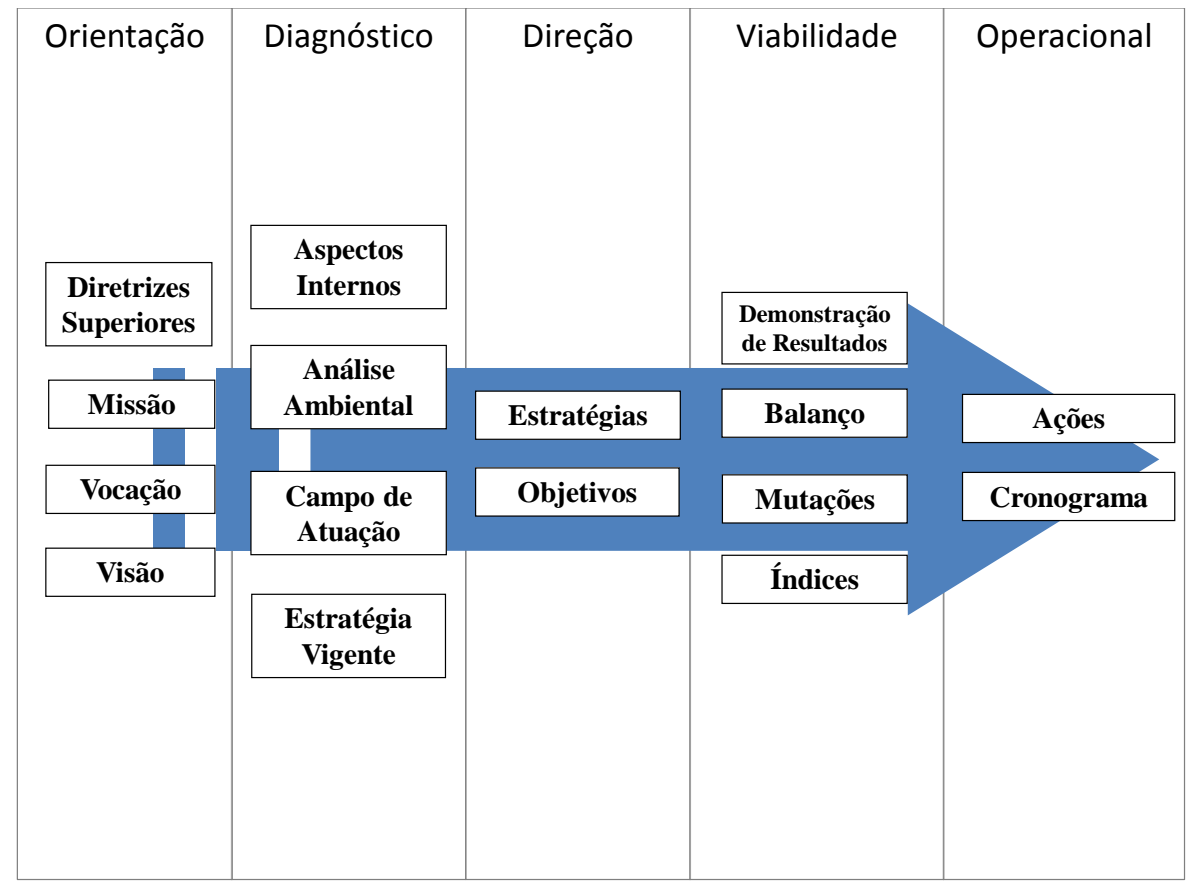

Figura 2 - Modelo de administração estratégica

FONTE: baseado em Almeida (2010).

Para Almeida (2010), o processo de planejamento estratégico é composto de cinco grandes etapas, apresentadas na Figura 2 e descritas a seguir.

\section{$\underline{\text { Orientação }}$}

Esta etapa busca estabelecer a missão, vocação e visão da empresa, todas orientadas por diretrizes superiores. Ou seja, para Almeida (2010), na etapa de orientação se analisa a razão de ser da organização, a capacidade que a empresa tem para desenvolver determinadas atividades e o que ela espera tornar-se. Esta etapa estabelece a referência da empresa no que tange a verificar se existem atividades que são feitas na organização, mas não condizem com 
sua orientação, ou, se ocorre o inverso. Bethlem (1998) convencionou chamar de "primeiro exercício" as atividades intelectuais e comportamentais que têm por objetivo não só estabelecer um nível de conhecimento adequado e uniforme do conteúdo da estratégia e dos princípios norteadores da organização (missão e visão), mas também desenvolver a confiança e estimular a participação de todos os envolvidos no processo.

\section{Diagnóstico}

Nesta etapa analisam-se tanto os aspectos internos como os externos da organização, onde fatores críticos de sucesso na área de atuação da empresa são destacados, assim como a comparação com outras empresas de referência no setor. Também, analisam-se as ameaças e as oportunidades decorrentes do ambiente e o campo de atuação que a empresa deve estar operando, sempre de acordo com sua orientação. Para Almeida (2010), após estas análises, pode ser avaliada a estratégia vigente na organização e que será aprimorada ou descontinuada nas etapas seguintes. Nessa fase, as contribuições de Porter $(1986,1989)$ podem ser aplicadas como a análise das cinco forças, para analisar o ambiente externo, a cadeia de valor (para os aspectos internos) e a estrutura das estratégias genéricas para a análise e definição do posicionamento da organização, para analisar a estratégia vigente. A visão de Certo (2010), baseada em diversos autores, traz um processo ligeiramente diferente: somente após análise ambiental é que os administradores serão capazes de formulação uma missão organizacional e estabelecer objetivos organizacionais a esta missão (dentro da etapa de diretrizes). Para isso, o autor sugere um processo da administração estratégica de 5 etapas (análise de ambiente, diretrizes organizacionais, formulação, implementação e controle) com feedback. Fischmann e Almeida (1991) destacam que a sequência de etapas de uma estratégia não é algo rígido, variando tanto entre autores como entre empresas. Embora os planos possuam referência de tempo, eles devem ser refeitos, periodicamente, para incluir as alterações que acontecerem no ambiente.

\section{Direção}

Aqui são definidas as estratégias e os objetivos que nortearão a organização. Nesta fase, é importante sintetizar e dar um sentido geral ao material produzido nas etapas anteriores, para que os resultados desta etapa sejam identificados com um conjunto de estratégias coesas, assim como os objetivos que dela resultarão. Almeida (2010) reforça que, nas etapas anteriores, as possíveis estratégias são levantadas e aqui deverão ser organizadas em um conjunto que deve ser a estratégia adotada. Para Fischmann (1987), as estratégias são 
selecionadas segundo critérios estabelecidos, para que seus projetos sejam detalhados, seus pressupostos reexaminados e, depois, sejam operacionalizadas. Almeida (2010) destaca que os conceitos de estratégia e objetivos estão intimamente ligados, já que a estratégia mostra o caminho e o objetivo indica aonde se deseja chegar. Para Almeida (2010), o objetivo é o ponto concreto que se quer atingir, deve ter parâmetros numéricos e datas a serem alcançadas. Deve-se ressaltar que, de acordo com Almeida, a meta é a segmentação de um objetivo, e nesse conceito, o aspecto quantitativo tem importância maior, apresentando valores e prazos precisos.

\section{$\underline{\text { Viabilidade }}$}

É a etapa de avaliação dos objetivos em termos de valores e de desempenho. São analisados fluxos de caixa, para verificar a liquidez de determinados projetos e estratégias. Na medida do possível, busca-se estabelecer uma "fotografia" da situação, no final do período, verificando, inclusive, a contribuição de cada ação para a estratégia da empresa. Assim, os objetivos tornam-se mensuráveis facilitando, inclusive, a etapa seguinte.

\section{Operacional}

Etapa de implementação do plano por meio de ações detalhadas, contemplando cronogramas e controles. Almeida (2010) destaca que é necessário integrar aquilo que é planejado em nível estratégico, e que seja refletido para os níveis administrativo e operacional, para que as ações ocorram, de fato, como planejado, e sejam controladas e acompanhadas pelos níveis competentes.

Almeida (2010) destaca que neste processo descrito optou-se por chegar à estratégia e em decorrência dela, estabelecer os objetivos - enquanto alguns outros autores adotam a opção contrária. A justificativa de Almeida (2010) está em entender que a estratégia é decorrente das atividades de análises anteriores, na etapa de diagnóstico, e assim, os objetivos não podem preceder à estratégia, mas, ter coerência com ela. Almeida (2010) observa, também, que o processo estratégico não é estabelecido de forma linear, ou seja, revisões dos blocos anteriores são necessárias para a coerência do plano. Almeida (2010) destaca que os termos, em planejamento estratégico, variam de autor para autor, com muitos termos assumindo conotações diferentes, mesmo em autores consagrados.

Hitt et al. (2008) recomendam, baseados em diversos autores clássicos da estratégia, um 
modelo parecido, em que a empresa deve avaliar tanto o aspecto interno quanto o externo e planejar suas ações de forma coordenada e organizada, para que atinja os objetivos para os quais se propôs, atendendo a sua missão e visão, e desta forma, alcançando melhores resultados, em termos das expectativas de clientes, mercados, finanças, acionistas, sociedade e outras partes interessadas em geral. A quantidade de stakeholders a serem atendidos mostra a necessidade de a estratégia funcionar como uma disciplina integradora, tanto externa como internamente, já que, para atingir seus resultados e objetivos, a empresa deve buscar integrar todas suas áreas (inclusive, de apoio), para alcançar e realizar a estratégia planejada.

Além de analisar e propor uma estratégia, é necessário entender quais características são importantes para determinar um resultado de sucesso. Quinn (2006) lista os elementos críticos da estratégia, que, segundo ele, são fatores que ajudam a determinar os resultados finais de uma estratégia, além de sorte, ou de uma ótima implementação, ou ainda, de uma falha do concorrente. Tais fatores são:

- Objetivos claros o suficiente para gerar continuidade e coesão das escolhas táticas durante o horizonte de tempo da estratégia. Devem ser claros e dirigidos, ou seja, se forem atingidos, devem assegurar viabilidade e vitalidade contínua da organização, frente a frente a seus oponentes.

- Manter a iniciativa, para aumentar a probabilidade de sucesso e assegurar independência e continuidade, além de evitar a postura reativa que resulta em inquietação e baixo moral.

- Flexibilidade e capacidade de manobra frente aos concorrentes, reservando capacidades e reposicionamentos quando necessários.

- Liderança coordenada e comprometida com cada objetivo - estratégias bem-sucedidas exigem comprometimento, não apenas aceitação.

- Surpresa, para atacar rapidamente os oponentes e obter sucesso.

- Segurança, para evitar surpresas internas (como falta de recursos) ou externas (como ações dos oponentes).

Na visão de Magretta (2012), que analisou algumas implicações estratégicas com base nos conceitos de Porter, alguns aspectos essenciais sobre a estratégia complementam o levantamento de Quinn, sendo que o principal é estabelecer uma estratégia com uma proposição de valor bem definida. Essa proposição de valor deve resultar em lucro para a 
empresa e não, simplesmente, crescimento de mercado. Um sinal de uma estratégia bem estabelecida é a definição do que a empresa não fará - mesmo que isso deixe alguns clientes insatisfeitos. É destacado por Magretta (2012), baseada nos conceitos de Porter, que estabelecer trade-offs possibilita construir uma vantagem competitiva possível e sustentável. Além disto, a autora destaca que uma boa estratégia depende de várias escolhas (não apenas uma) e das conexões entre elas. Para Magretta (2012) uma competência essencial sozinha raramente produz uma vantagem competitiva sustentável.

Por fim, Rumelt (2006), dentre alguns pontos que usa para avaliar a estratégia, lembra que um tipo avaliação de consistência estratégica a ser feita está entre os objetivos organizacionais e os valores do grupo gerencial. Deve-se verificar se a direção futura da empresa exige alterações que conflitam com os valores gerenciais. O autor recomenda que ajustes devem ser realizados na estratégia para solucionar esses conflitos.

\section{a) A separação entre formulação e implementação estratégica}

Montgomery (2012) e Andrews (2006) reforçam que, para fins de análise, podemos abstrair do processo estratégico dois aspectos importantes, que estão inter-relacionados, na vida real, mas, separados, aqui, para fins de entendimento: a formulação e a implementação. Para Magretta (2012) a importância da execução de uma estratégia não pode ser desprezada. Sem a devida atenção a este aspecto, uma estratégia brilhante poderá falhar.

Andrews (2006) destaca que, na etapa de formulação, antes de se fazer a escolha da estratégia é importante avaliar as forças e fraquezas da empresa, além dos recursos disponíveis. Sua capacidade real ou potencial de aproveitar as oportunidades encontradas e evitar os riscos identificados é o que o autor denomina de estratégia econômica. $\mathrm{O}$ autor afirma que saber se pretendem assumir riscos altos ou baixos depende dos objetivos de lucro: quanto mais alto for esse objetivo, mais a empresa está disposta a assumir o risco correspondentemente alto.

Andrews (2006) dá sequência a seu modelo, afirmando que, na fase de implementação da estratégia, se o objetivo é determinado, então se pode mobilizar os recursos para atingi-lo. $\mathrm{O}$ autor afirma que os processos de avaliação de desempenho, remuneração, desenvolvimento devem ser voltados para o tipo de comportamento exigido pelo objetivo organizacional. Quando estes e outros aspectos de estrutura organizacional estiverem analisados, a empresa entenderá em que ponto estará preparada para lidar com a interdependência da formulação e 
implementação do objetivo corporativo.

O diagrama de Fischmann (1987) ilustra bem a ideia de separar, em modelos, os blocos de formulação e implementação, o que torna a demonstração das etapas mais fácil, conforme apresenta a Figura 3:

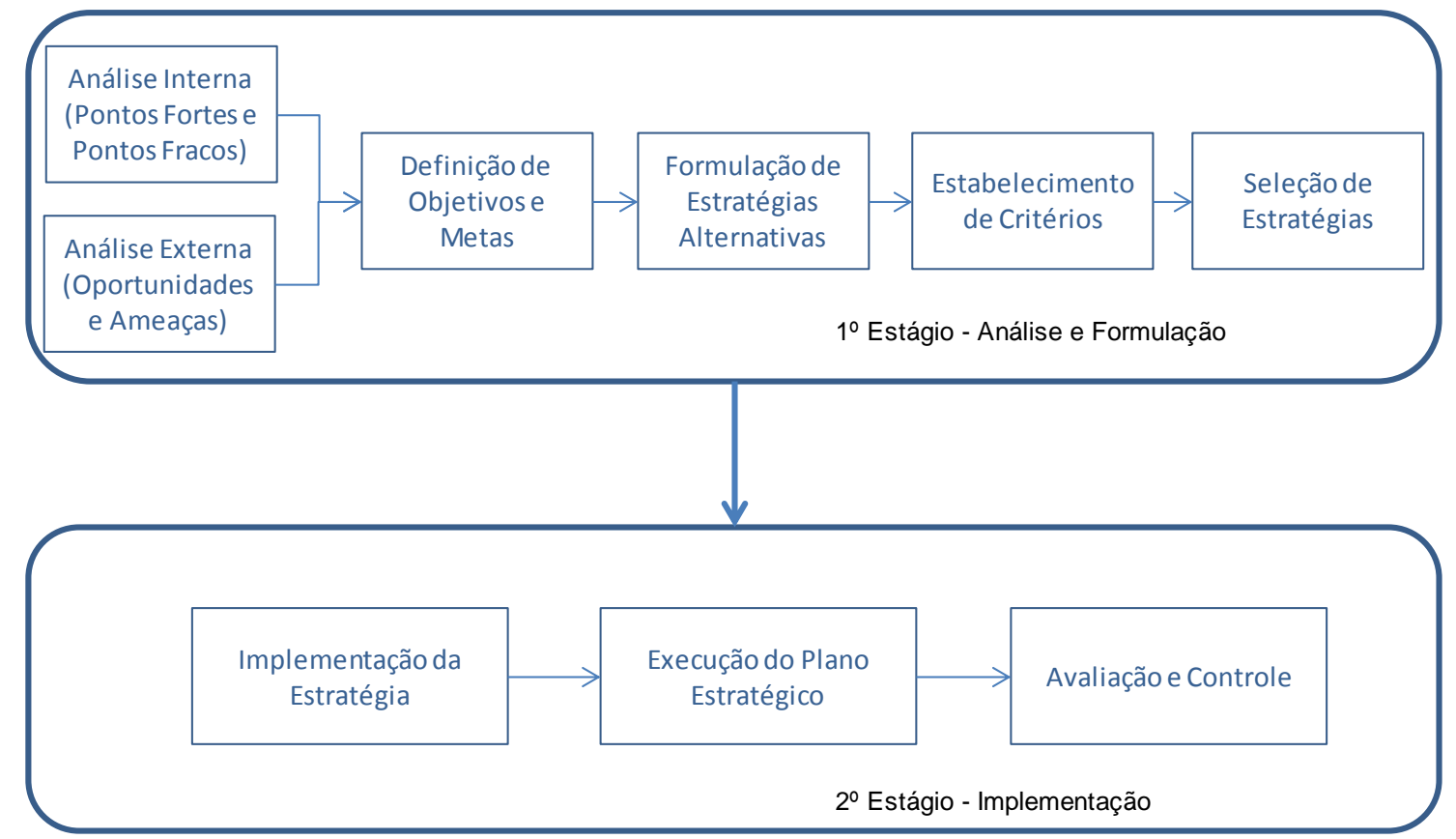

Figura 3 - Diagrama simplificado do processo estratégico com dois estágios: formulação e implementação FONTE: baseado em Fischmann (1987).

O diagrama de Fischmann (1987) é dividido em dois grandes blocos: o estágio do planejamento e formulação estratégica, e o estágio da implementação e execução. Antes do primeiro bloco, Fischmann (1987) sugere analisar a missão da empresa e avaliar a estratégia vigente até então. A fixação de objetivos e metas surge como balizador de resultados esperados, em decorrência das estratégias a serem implementadas. No modelo de Fischmann, após o diagnóstico ambiental e os objetivos pretendidos, obtêm-se as condições para a composição das estratégias alternativas.

O bloco seguinte do modelo de Fischmann (1987) diz respeito à implementação estratégica, que, na visão de Fischmann, é a etapa de transição entre o planejamento e a operacionalização. De acordo com este autor, são identificados e providenciados os ajustes de estrutura organizacional, definidos os orçamentos, dentre outras providências necessárias para 
buscar o êxito das estratégias selecionadas.

A execução é o próprio cumprimento do que foi planejado, e na parte final do processo, avaliação e controle, são elementos que devem acontecer, em todo momento, para buscar acompanhar o que está sendo desenvolvido, reforçar o que está dando certo e ajustando ou eliminando o que não está dando certo.

Outro aspecto importante na execução da estratégia planejada são os aspectos da comunicação da estratégia, conforme esclarecem Carvalho e Laurindo (2007), que pode ser relacionado a um painel de gestão estratégica, ligando os objetivos estratégicos aos pessoais, constituindo um processo em cascata. Deve-se evitar que os incentivos individuais priorizem as metas de curto prazo, alinhando-os à estratégia da organização. Este conceito também é reforçado por Almeida (2010), que considera a gestão estratégica realizada por indicadores, projetos de aperfeiçoamento e projetos de mudança.

\section{b) Aspectos críticos para o sucesso da implementação estratégica}

Lupoli Junior (2006) mostra que um dos grandes problemas da implementação é o fato de a visão dos gestores ser segmentada e setorizada. É recomendável, de acordo com esse autor, que se desenvolva uma visão sistêmica das organizações, que permita observar as relações de causa e efeito entre os recursos captados e os resultados alcançados. Nessa mesma linha de raciocínio, para Kronmeyer Filho et al. (2004), a concepção e implantação da estratégia é um processo transdisciplinar, e sua complexidade necessita de outros elementos, como liderança e comunicação, além de um suporte tecnológico, para ser realizada com sucesso.

Para Bradley et al. (2011), muitas boas estratégias falham na implementação pela falta de convicção na organização especialmente pelo alto escalão, onde apenas um ou dois descrentes são suficientes para matar uma mudança estratégica no nascedouro. Hrebiniak (2011) complementa esta afirmação acrescentando que a falta de concordância nos processos de formulação e implementação, a falta de habilidade para gerenciar mudança e uma pobre coordenação e integração de ações também são problemas que interferem na implementação estratégica.

Uma boa estratégia só de fato acontece após uma boa execução, mas, nem todas as empresas conseguem fazer o que se propõem (Neilson et al. 2008). Isso se dá, na visão de Fischmann 
(1987), pelo desbalanceamento entre excessiva atenção dada à formulação de estratégias, comparando à precariedade que cerca a implementação. A Figura 4 aponta a dependência mútua que a estratégia formulada possui da implementação (e vice-versa).

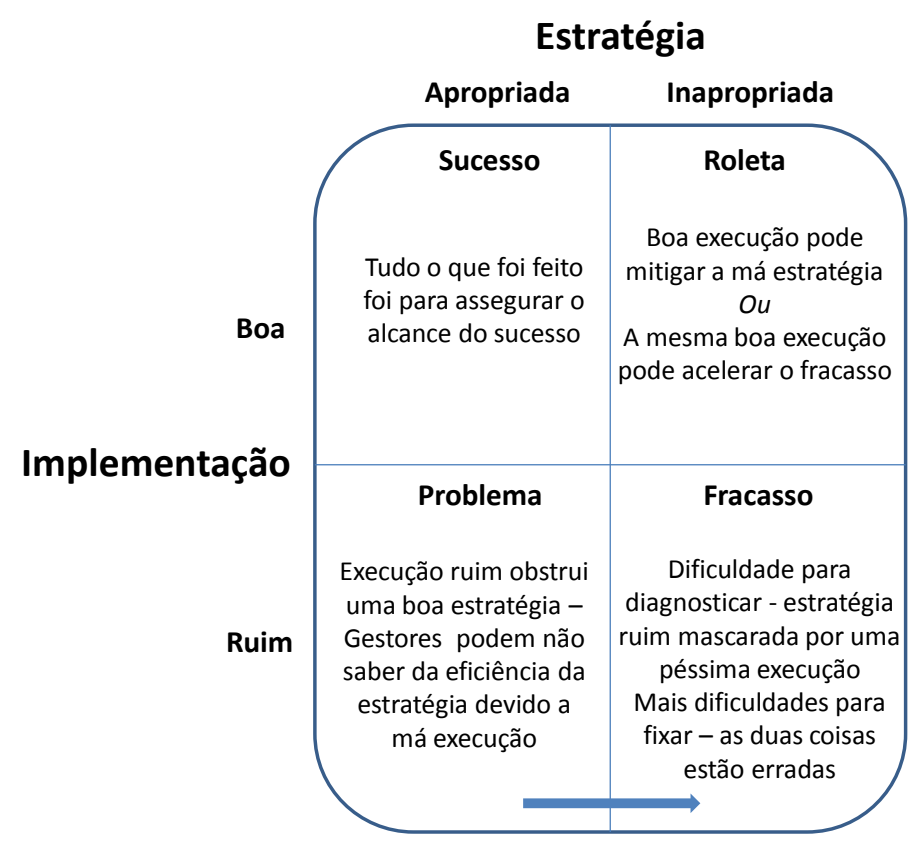

Figura 4 - Matriz implementação $x$ estratégia

FONTE: Fischmann (1987).

Na visão de Fischmann (1987), o sucesso da estratégia é assegurado se a formulação e a implementação forem adequadas. De acordo com Fischmann (1987), enquanto dá-se ênfase à formulação de estratégias compatíveis com o ambiente empresarial, e com os objetivos e as metas da organização, pouca atenção tem sido dirigida à implementação das mudanças estratégicas. $\mathrm{O}$ autor adverte que esse desequilíbrio pode contribuir para o insucesso de muitos planos, pois, muitas vezes, a organização não está preparada para as consequências, na prática de adotar um plano que não funciona exatamente como seus autores pretendiam.

Em sua pesquisa com 117 empresas, Fischmann (1987) encontra problemas mais graves em relação à implementação estratégica:

- Variáveis incontroláveis do ambiente externo tiveram um impacto adverso.

- Surgimento de grandes problemas no ambiente externo e que não foram identificados antecipadamente. 
- Sistemas de informação usados para monitorar e implementar não eram adequados.

- Tarefas e atividades críticas de implementação não foram definidas com detalhamento suficiente.

Destaque para as condições do ambiente externo, fato que é ressaltado por Fischmann, onde a influência do ambiente político e econômico do Brasil, no final da década de 1980, contava com uma tendência intervencionista do governo. Por outro lado, Fischmann (1987) também investigou as medidas facilitadoras, aquelas que foram consideradas as mais críticas para obter-se sucesso em uma implementação estratégica:

- Reuniões de divulgação de objetivos

- Reuniões de acompanhamento de desempenho controle e revisão de planos

- Treinamento oferecido à alta e média administração

- Estruturação e utilização de sistemas de informação

- Melhor definição de estrutura organizacional (adequação de organograma as estratégias)

- Criação de área específica responsável pela coordenação do planejamento estratégico

- Especificação de unidades estratégicas de negócios (UEN)

A pesquisa de Neilson et al. (2008) enfatiza, como aspectos fundamentais para o sucesso de uma implementação, um bom fluxo de informações e uma correta distribuição de papéis. A importância da comunicação se dá nos dois itens, uma vez que se trata da comunicação entre todas as partes envolvidas com a execução, e também com a correta comunicação e entendimento de papéis e funções.

Os autores, em sua pesquisa com 26 mil funcionários, em 31 empresas, identificaram traços que tornam uma organização eficaz para implementar suas estratégias:

1. Todos têm uma boa noção das decisões e dos atos que são de sua responsabilidade (81 pontos entre 100);

2. Informações importantes sobre o ambiente corporativo chegam rapidamente à matriz (68 pontos entre 100).

De acordo com Hamel (2006), para engajar toda uma organização, a alta gerência necessita: 
- Reforçar um senso de urgência ou quase crise, para não permitir a falta de ação;

- Desenvolver o foco competitivo em todos os níveis, para que os funcionários meçam esforços contra os concorrentes;

- Fornecer as habilidades que os funcionários necessitam;

- Evitar que iniciativas internas concorrentes sobrecarreguem a organização com mudanças de prioridade;

- Estabelecer marcos claros, para acompanhar o progresso e assegurar o reconhecimento interno.

Hrebiniak (2006) aponta a administração da mudança como um dos condicionantes que influenciam o processo de administração estratégica. Na visão do autor, qualquer decisão a ser implementada é um processo de mudança. Portanto, é preciso que as organizações entendam o tamanho e o impacto da mudança e preparem-se para gerenciá-la.

Neste sentido, implementar uma estratégia envolve mudança organizacional, mobilizar recursos e alinhar a empresa para realizar as alterações necessárias, para atingirem-se os objetivos traçados e chegar ao futuro desejado. Para Montgomery (2012) para manter uma estratégia sustentável deve-se se antecipar às mudanças e levar a empresa para onde ela precisa ir. Na visão da autora isto é um papel fundamental do estrategista que está conduzindo a empresa. Kotter (1997) sugere oito fases de um processo de mudança que se aderem bem à implementação de estratégias, e também, apontam as razões de muitas organizações falharem, ao colocar seus planos em prática.

Fase 1: definir um senso de urgência - evitar a complacência excessiva que não tira as pessoas da zona de conforto e impele as pessoas a empreenderem um esforço extra, necessário em um projeto de mudança. Líderes talentosos falham, ao iniciar um projeto de mudança, sem a devida comunicação, conscientização e cobrança da urgência das ações.

Fase 2: criar parcerias fortes - o projeto precisa da participação da liderança, do suporte e da parceria de gestores-chave (em função, em reputação, em habilidades de comunicação e relacionamento), que aumentarão a credibilidade das ações, a participação e o envolvimento de quantidades cada vez maiores de colaboradores. 
Fase 3: criar uma visão - é a criação da estratégia inspiradora. Os funcionários devem identificar-se nela e comprometer-se com os resultados. Esta inspiração deve gerar algum tipo de desconforto, pois deve ser desafiadora e trazer inovação.

Fase 4: comunicar a visão de forma contundente - a visão que descreve uma iniciativa de mudança deve ser descrita em menos de cinco minutos, e não deve provocar compreensão e interesse. Do contrário, não seria uma visão de mudança.

Fase 5: permitir que obstáculos não bloqueiem a visão — às vezes o obstáculo é a própria estrutura da empresa. Os sistemas de compensação, de avaliação de desempenho, as categorias de emprego, alguns supervisores que aplaudem os esforços de mudança e que não alteram nem seu comportamento nem de seus subordinados, o receio de afastar pessoas talentosas e que são avessas à mudança. Qualquer um destes itens enfraquece o projeto e prejudica os resultados.

Fase 6: planejar e celebrar "vitórias de curto prazo" (quick-wins) — conforme Kotter (1997), "sem vitórias de curto prazo, muitos funcionários irão desistir ou resistir novamente". Alcançar objetivos parciais e celebrá-los serve para motivar as pessoas para continuar perseguindo o objetivo maior. Em projetos de resultados demorados, os níveis de urgência geralmente caem, colocando em risco o objetivo em si da gestão da mudança.

Fase 7: não declarar vitória prematuramente - celebrar as primeiras conquistas é importante, mas, não se deve dar a ideia de que grande parte do trabalho já foi, então, concluído.

Fase 8: mude a cultura corporativa - é importante que as pessoas, na organização, liguem determinados comportamentos a casos de sucesso, e estabeleçam uma relação entre um comportamento e as atitudes, alinhada às mudanças com seu desempenho bem sucedido na corporação. Deve-se, então, rever critérios de promoção e reconhecimento, de forma que sejam consistentes com a nova cultura corporativa.

Essas etapas funcionam como um mapa e auxiliam na discussão sobre transformação e seus problemas estratégicos. Enfatizam, também, o papel da liderança como mecanismo que conduz à mudança e à implementação de objetivos estratégicos, e por consequência, à estratégia formulada. 
Uma vez que uma implementação é iniciada (a etapa de execução), além de cumprir as oito etapas de Kotter (1997), é necessário conhecer os aspectos desaceleradores de um processo de mudança (freios da mudança), estudados por Miles (2010), onde o aspecto tempo é crítico para que sejam contornados.

Conforme Miles (2010), a maior dificuldade da transformação corporativa é fazer com que uma organização execute suas mais arrojadas ideias de "forma rápida". O tempo, o timing e a velocidade são críticos, em processos de mudança. A seguir, listamos os seis freios e algumas recomendações de como evitá-los.

Freio 1: cultura de cautela - o medo de errar faz com que as pessoas evitem as grandes transformações e obviamente os grandes erros. Miles (2010) sugere algumas medidas para enfraquecer esta cultura de cautela: sinceridade — permita que a liderança e colaboradores sejam absolutamente sinceros em definir quais são as maiores fraquezas e sugestões de como eliminá-las; plano - defina, claramente, como cada um colaborará na transformação. $\mathrm{O}$ comprometimento começa desse ponto de partida; revisão - conduza uma entrevista com líderes-chave e entenda o que está dando certo ou não, e reavalie quais estratégias poderiam ser revisadas; confronto - faça um evento corporativo para confrontar as propostas de mudança com a realidade do negócio e trocar ideias com os líderes que vão conduzi-la. Estas etapas trazem à tona problemas invisíveis e auxiliam na definição e distribuição de recursos para o projeto de mudança. Elas também fazem olhar de frente os problemas na gestão de mudança e auxiliam a enfrentá-los, de forma bem sucedida.

Freio 2: dificuldade de a mudança entrar no processo atual - a rotina diária não permite que haja dedicação para um projeto de mudança. A solução é criar um processo de lançamento (da implantação) curto e que rode, paralelamente, aos sistemas e processos atuais. Assim, o processo atual do negócio convive com os novos processos de mudança, e isso fará com que os líderes aumentem a tração da transformação.

Freio 3: travar iniciativas por falta de priorização - se os diversos programas da empresa não forem priorizados, então, a capacidade de execução dos colaboradores ficará comprometida. Projetos de transformação bem sucedidos têm um plano de execução simples, com, no máximo, quatro objetivos claros, com métricas de desempenho. 
Freio 4: executivos indecisos - não tomar nenhuma atitude significa correr o risco de enfraquecer o lançamento do projeto e de enviar uma mensagem errada para o resto da empresa (de que se pode optar por não fazer parte do processo de mudança). $\mathrm{O}$ alinhamento parcial da liderança da empresa desacelera o processo de mudança.

Freio 5: colaboradores negligentes — a recomendação é executar um plano rápido que envolva todos os níveis da empresa, comunicando a estratégia global, e ir descendo, até atingir a base da pirâmide organizacional. A negligência dos colaboradores é evitada com informações claras do que é esperado de cada um deles.

Freio 6: perda de foco na execução - prioridades definidas no lançamento do plano serão desafiadas pelas atividades do dia a dia, e pela pressão imediatista de atingir metas táticas da operação. A liderança precisa estar presente, ao longo de toda a execução, para garantir que haja foco, energia e alto desempenho na transformação.

A discussão de ferramentas relacionadas à mudança é importante para fortalecer a execução de uma estratégia. Muitas vezes, as dificuldades de uma implementação estratégica não se dá pelo conteúdo do plano ou pelos objetivos firmados, mas, sim, pelas resistências enfrentadas na condução de mudanças exigidas na implementação de um plano estratégico.

As grandes etapas definidas por Fischmann (1987), formulação e execução, podem ser ligadas pela definição dos objetivos estratégicos. Este elemento, definido a partir da formulação estratégica, é o primeiro item da execução de estratégia, pois traz consigo a direção e as metas que devem ser alcançadas, da mesma forma que os objetivos estratégicos são destacados no modelo de Almeida (2010). No item, a seguir, são aprofundadas as definições de objetivos estratégicos e são apresentadas algumas visões de autores que trabalham com objetivos estratégicos de diversas maneiras. 


\subsection{As definições de objetivos estratégicos}

De acordo com Fischmann e Almeida (1991), objetivos estratégicos são aspectos concretos que a organização deverá alcançar para seguir a estratégia estabelecida. Já, metas são valores definidos dos objetivos a serem alcançados ao longo do tempo. Para Ansoff (1991), os objetivos são metas a alcançar e a estratégia indica o caminho a percorrer para chegar-se a tais metas. Alcançar os objetivos pactuados é um dos aspectos motivacionais mais fortes para contribuir com o desenvolvimento de profissionais e organizações. Alogan e Yetiş (2006) destacam que os objetivos estratégicos são ferramentas necessárias para operacionalizar os movimentos desejados por uma organização. Eles são a chave para alinhar estratégia com o desempenho dos processos.

Quinn (2006) afirma que os principais objetivos da organização, aqueles que afetam a direção geral e a viabilidade da organização, são chamados de objetivos estratégicos. Já, a estratégia define uma base contínua para ordenar a organização em direção a objetivos concebidos de forma mais ampla. Almeida (2010), nessa mesma linha de raciocínio, destaca que os conceitos de estratégia e objetivos estão intimamente ligados, já que a estratégia mostra o caminho e o objetivo indica aonde se deseja chegar. De acordo com Almeida (2010), objetivo é o ponto concreto que se quer atingir; deve ter parâmetros numéricos e datas a serem alcançadas. Deve-se ressaltar que, de acordo com Almeida, a meta é a segmentação de um objetivo e que, nesse conceito, o aspecto quantitativo tem importância maior com valores e prazos precisos. Na visão de Montgomery (2012), os objetivos orientam a empresa em direção ao que realmente importa enquanto que as metas auxiliam a medir resultados e indicar se a estratégia está funcionando. Para O’Donnell (1963), a identificação e a descrição de objetivos é a primeira etapa em um planejamento, e é essencial para o sucesso em qualquer plano. Esta identificação de objetivos vem do propósito de uma organização para poder criar seus objetivos. $\mathrm{O}$ autor recomenda a criação de planos mestres a serem seguidos.

Para Hamel e Prahalad (2006), objetivo estratégico é a obsessão de uma empresa em vencer em todos os níveis da organização. Os autores destacam que o objetivo estratégico é mais do que simplesmente uma ambição: é um conceito que engloba a gestão ativa do foco de atenção da organização, motivação, alocação de recursos, ao mesmo tempo em que deixa espaço para contribuições da equipe. Podemos interpretar que a definição de Hamel e Prahalad é outra maneira de operacionalizar a visão corporativa e manter o alinhamento da empresa para o 
cumprimento de objetivos, e consequentemente, da estratégia corporativa.

Um exemplo crítico de falta de alinhamento vem da pesquisa de Sa (2013), que aborda a relação da estratégia planejada e o sistema de desempenho. Foram consultados 208.841 colaboradores distribuídos em cinco níveis gerenciais de uma agência federal americana. Os resultados apresentaram que os empregados nos diversos níveis organizacionais possuem diferentes percepções da relação entre os componentes do planejamento estratégico e as dimensões do sistema de gestão de desempenho.

Os resultados demonstraram que o relacionamento com a estratégia difere de acordo com o nível gerencial do empregado. Segundo Sa (2013), os empregados nos diferentes níveis gerenciais relataram percepções e reportes diferentes sobre a ligação ou a correlação entre os componentes de gerenciamento estratégico e o sistema de gerenciamento de desempenho, e diferente percepção da capacidade para ajustar os componentes da estratégia de acordo com os níveis gerenciais para melhorar os sistemas e o desempenho organizacional.

De acordo com Hamel e Prahalad (2006), o objetivo estratégico possui algumas características:

- "capturar" a essência da vitória (uma afirmação ou visão única que a empresa vai perseguir).

- estabilidade para garantir consistência às ações de curto prazo, mas, deixando espaço para reinterpretações conforme o surgimento de novas oportunidades.

- estabelecimento de metas, que justifiquem esforço pessoal e comprometimento.

Empresas são criadas para objetivos específicos. Para Alogan e Yetis (2006), a visão organizacional é eficaz, quando define objetivos claros e explícitos para serem alcançados ao longo do tempo. As organizações podem acrescentar ou alterar objetivos ao longo dos anos. A Figura 5 ilustra o relacionamento dos objetivos estratégicos, com a definição de visão e missão organizacional. 


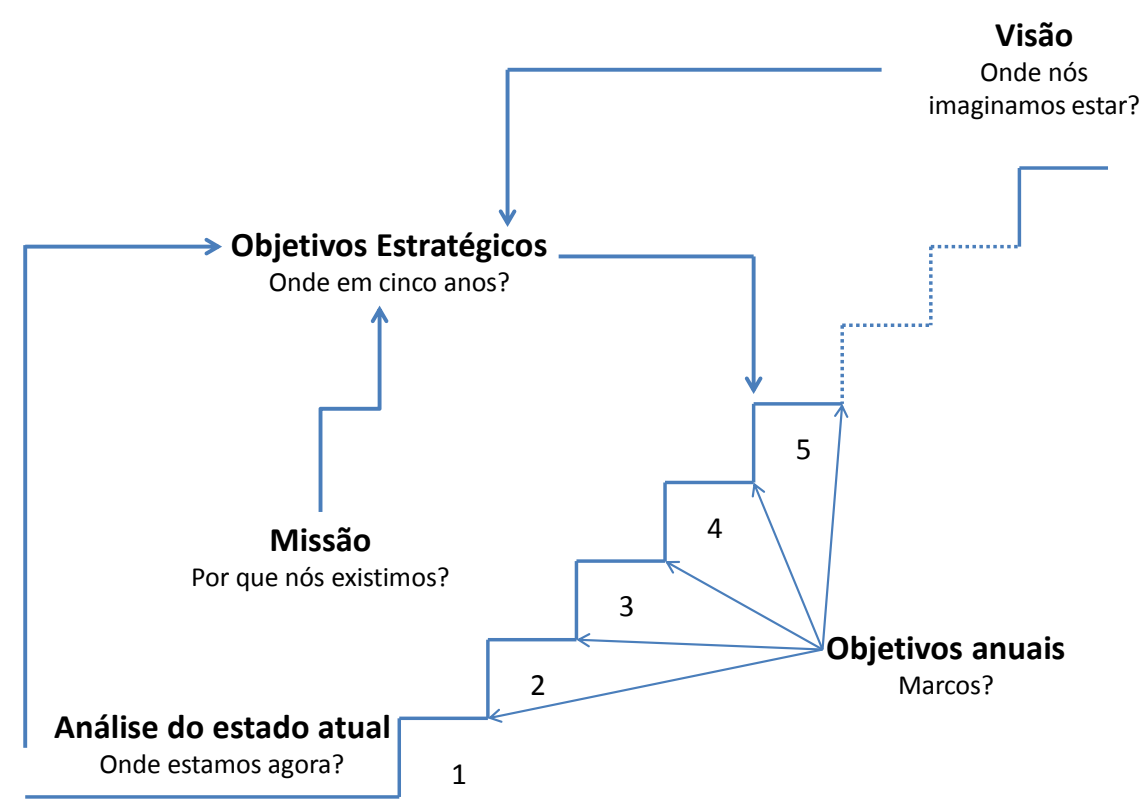

Figura 5 - Relacionamento entre objetivos estratégicos e a estratégica

FONTE: Alogan e Yetis (2006).

Almeida (2010) enfatiza que é a partir de estratégias que se chega aos objetivos. É importante estabelecer objetivos, para que se tenha claro aonde se deseja chegar. Alogan e Yetis (2006) esclarecem que existe uma controvérsia na literatura de administração estratégica, onde alguns sugerem "metas", outros, "objetivos", e ainda, há os que consideram estes termos sinônimos. Mintzberg (2004) também constata essa confusão, quando apresenta as definições de Ansoff e Lorange, e destaca: o que um chama de estratégia, o outro chama de objetivo.

De acordo com O’Donnell (1963), estes termos são frequentemente usados como sinônimos. Para deixar mais claro, o autor sugere usar "propósito" para descrever a razão de existência de uma organização, ou qualquer uma de suas divisões ou departamentos. Já, “metas”, termo originalmente emprestado de jogos, possui o intuito de ser resultado de um plano menor ou informal, enquanto que o termo "objetivos" descreve o fim para que um plano é designado.

Para Hrebiniak (2006), a estratégia de negócios deve ser traduzida em objetivos com métricas operacionais de curto prazo para executar a estratégia. Para alcançar os objetivos estratégicos, uma organização deve desenvolver objetivos mensuráveis de curto prazo que se relacionem de forma lógica e consistente com a estratégia de negócios e com a maneira em que a organização planejada concorrer. Almeida (2010) também destaca que pode haver uma árvore de objetivos com objetivos maiores e objetivos decorrentes. Os objetivos estratégicos devem 
virar objetivos estratégicos de curto prazo mensuráveis. Barbero (2008), em sua pesquisa com 354 empresas, identificou uma associação entre o crescimento do faturamento bruto das organizações e a apresentação de objetivos bem definidos.

Sem objetivo comunicado, uma organização pode tomar qualquer direção. Em geral, os objetivos são de curto (um a dois anos) ou de longo prazo (3 ou mais anos). Certo (2010) sugere que, na visão de Drucker, não se deve dar enfoque em apenas um objetivo. Deve se dar foco em oito áreas a serem abordadas pelos objetivos organizacionais: posicionamento no mercado, inovação, produtividade, níveis de recursos, lucratividade, desempenho e desenvolvimento, desempenho e atitude de funcionários, e responsabilidade social. Os objetivos devem possuir algumas características: serem específicos, exigentes de esforços, atingíveis, flexíveis, mensuráveis e consistentes a longo e a curto prazos.

No processo de definição dos objetivos estratégicos, é fundamental a definição de critérios quantificáveis (fatia de mercado, rentabilidade por produto, receita total, estratégicas por canal, custos de produtos, etc.), que possam ser operacionalizados em etapas de controle de processos.

Na visão de Etzioni (1976), os objetivos organizacionais possuem várias funções:

- Apresentam uma situação futura, indicando uma linha mestra que a organização deve seguir.

- Constituem uma fonte de legitimidade que justifica as atividades da organização, e na visão dos autores, justifica, até mesmo, sua existência.

- Servem como padrões, que todos os interessados podem usar para avaliar o êxito da organização, eficiência e desempenho em relação aos objetivos pretendidos.

- São unidades de medida, para que possam ser apuradas a produtividade e o sucesso da organização, seja em relação ao tempo ou em comparação com concorrentes.

- Funcionam como aglutinadores de esforços, ou seja, são elementos de convergência de atividades e direcionamento de esforços para que haja integração de maneira ordenada.

Objetivos comunicam interna e externamente para onde a empresa quer ir; legitimam as pretensões das empresas para seus stakeholders; focalizam a atenção em desafios pontuais; 
associados a planos, descrevem ações para a empresa alcançar.

Após a discussão conceitual de objetivos estratégicos, a seguir serão analisadas as formas de organização de objetivos destacadas com base pesquisa bibliográfica realizada.

\subsection{As diversas visões sobre a organização de objetivos estratégicos}

\section{a) O Balanced Scorecard (BSC) de Kaplan e Norton}

O Balanced Scorecard (BSC) é uma técnica que auxilia os gestores a avaliar se a estratégia está atingindo, de fato, seus objetivos e caminhando na direção que foi planejada pela organização. Enquanto o BSC permite acompanhar a estratégia, por meio da gestão dos objetivos, metas e indicadores, o mapa estratégico registra, de forma compacta, em uma única figura, a estratégia da corporação, apresentando os objetivos estratégicos em um diagrama com relações de causa e efeito, possibilitando levar a estratégia ao alcance de todos na organização. Estes conceitos serão detalhados a seguir.

Começaremos pelas definições sobre o mapa estratégico, pois ele representa o detalhamento da estratégia, concebido em forma gráfica, enquanto o BSC, por sua vez, organiza as métricas relacionadas a cada objetivo estratégico, conforme a Figura 6. Assim como o conceito de BSC prega que ele deve funcionar como ligação da estratégia com os indicadores e a parte operacional da empresa, o mapa estratégico também cumpre esse papel, demonstrando a relação de objetivos e estratégia de forma gráfica. 


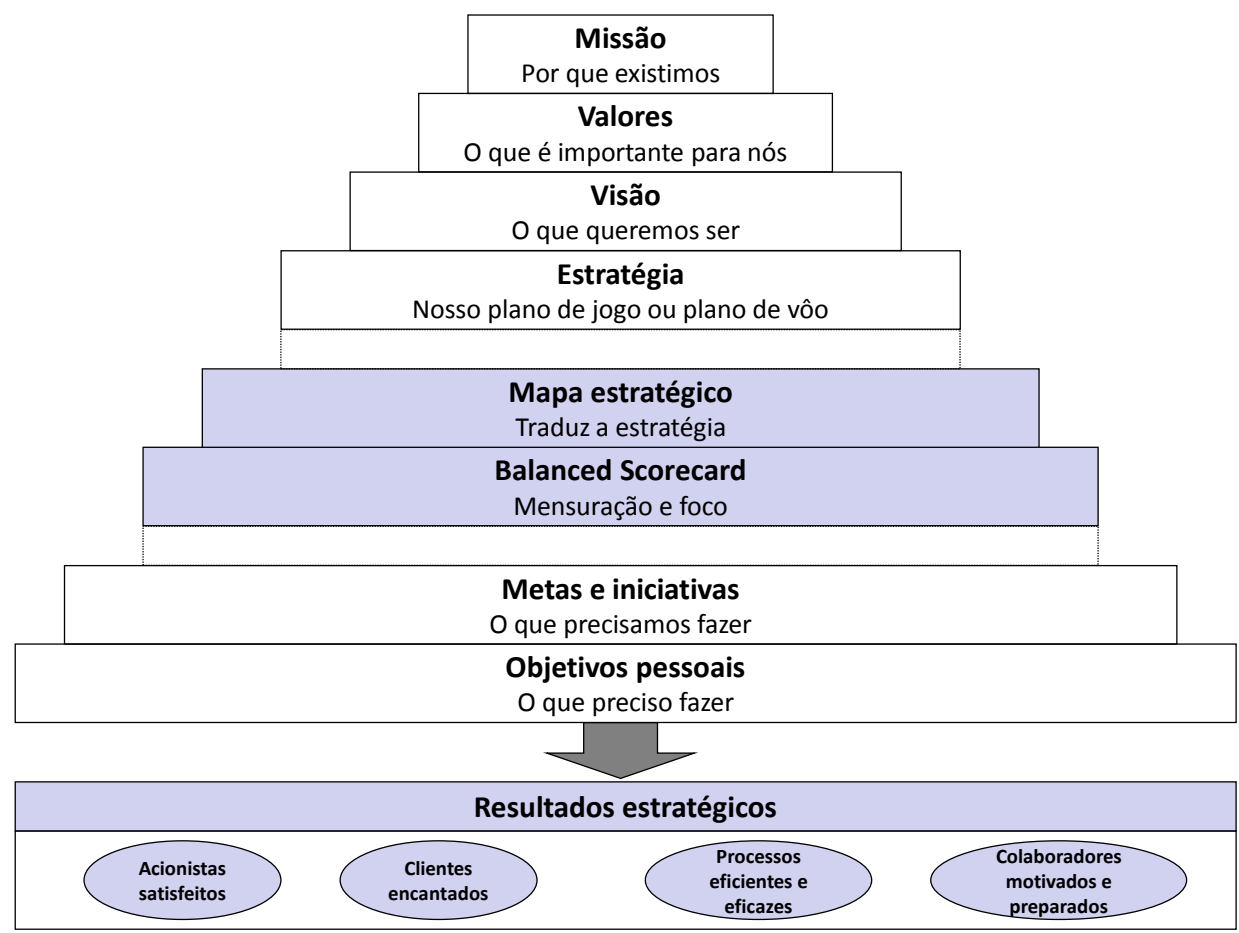

Figura 6 - Relação entre estratégia, BSC e mapas estratégicos

FONTE: Kaplan e Norton (2004).

O mapa estratégico é definido por Kaplan e Norton (2004) como a representação visual de causa e efeito entre os componentes da estratégia de uma organização, auxiliando, assim, a construção do BSC. Para Papalexandris et al. (2005), o mapa estratégico acrescenta uma camada de detalhes que ilustra a dinâmica da estratégia, melhorando a clareza e o foco. $\mathrm{O}$ desenvolvimento do mapa estratégico busca o entendimento da relação de causa e efeito entre os objetivos estratégicos. Kaplan e Norton (2004) contam que, nos primeiros workshops de mapas estratégicos com executivos, os objetivos estratégicos eram unidos, instintivamente, por setas, na medida em que eram distribuídos entre as quatro perspectivas, conforme a Figura 7 exemplifica, por meio do mapa estratégico padrão. 


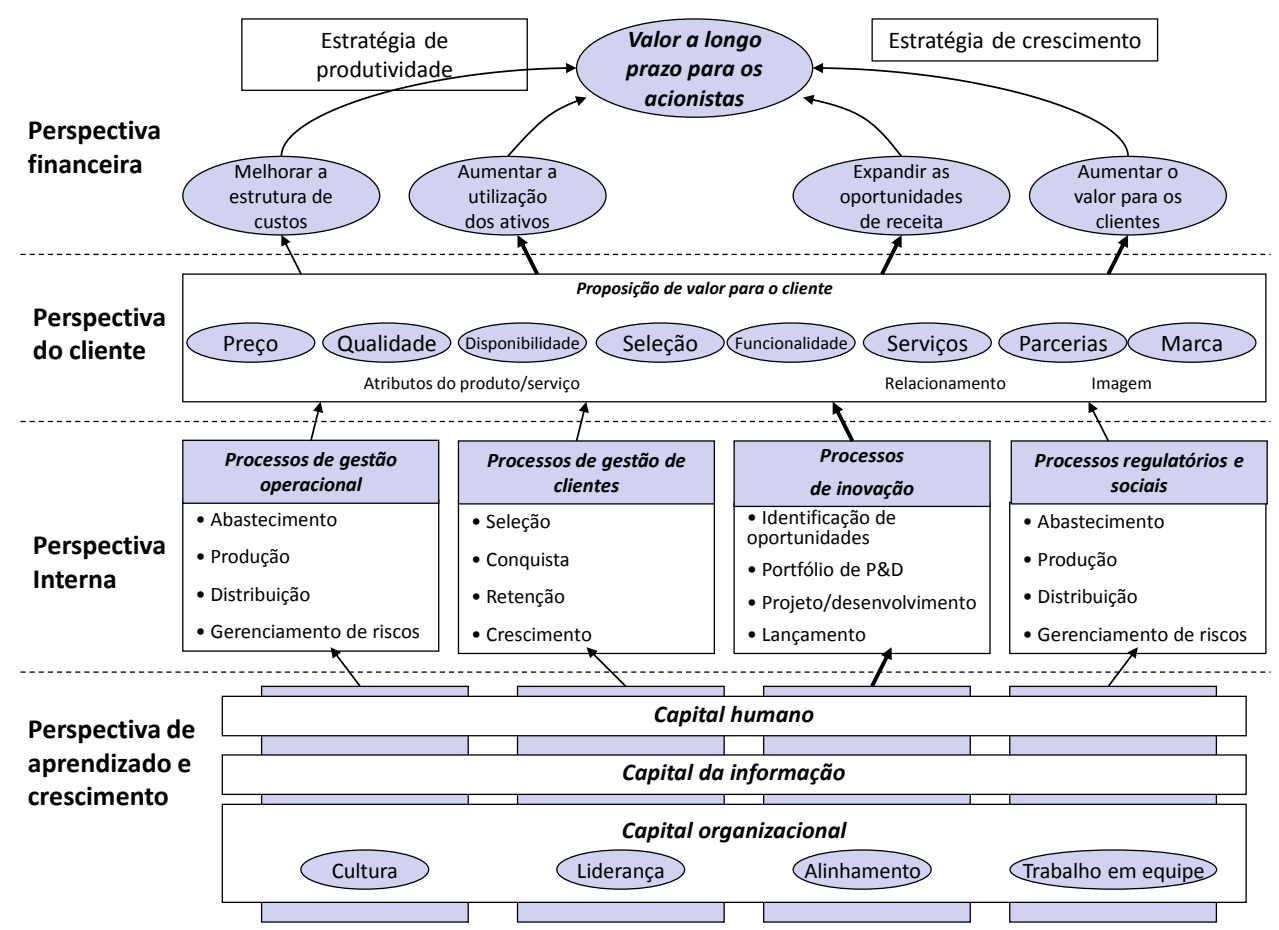

Figura 7 - Mapa estratégico padrão

FONTE: Kaplan e Norton (2004).

Para Niven (2005), as vinculações de causa e efeito apresentadas no desenho do mapa estratégico definem a trilha específica que a organização percorrerá para conquistar sua estratégia. Ou seja, conforme a Figura 7 apresenta, para atingir-se "valor em longo prazo para os acionistas", deve-se passar pelo cumprimento de objetivos financeiros, que, por sua vez, estão relacionados ao alcance do objetivo de proposição de valor ao cliente. Este item é apoiado pelo alcance de metas da perspectiva interna que só é atingida, se os indicadores da perspectiva de aprendizado e crescimento (que envolve as pessoas) obtiverem um bom desempenho. Dessa forma, os profissionais de todas as áreas da organização passam a ter uma visão geral da estratégia, compreendendo como os papéis se encaixam e como suas áreas contribuem com outras, chegando, assim, à compreensão da estratégia corporativa.

Com as definições de mapa estratégico apresentadas, é importante, agora, discutir os conceitos de Balanced Scorecard, que é a ferramenta central da obra de Kaplan e Norton, e que deu origem aos conceitos dos mapas. O Balanced Scorecard (BSC) surge como alternativa para acompanhamento de indicadores de todos os aspectos da empresa (e não somente os financeiros), auxiliando, dessa forma, a gestão estratégica da empresa. Uma das contribuições deste conceito está na ligação dos indicadores com objetivos estratégicos, que, se alcançados, levam a empresa a um patamar previsto na sua estratégia. 
Segundo Kaplan e Norton (1997), o BSC é uma ferramenta que traduz a missão e a estratégia da organização em um conjunto compreensível de medidas de desempenho, propiciando a formação de uma estrutura de mensuração estratégica e de um sistema de gestão eficiente. Com a utilização do BSC, pode-se esclarecer e traduzir melhor a visão e a estratégia da empresa, destacando-se, também, a forte ligação entre os indicadores e a estratégia, e permitindo que o gestor possa visualizar o comportamento das atividades consideradas fundamentais para o negócio.

Apesar da ênfase nos indicadores, pode-se dizer que o BSC mostra uma visão sobre o futuro e um caminho para chegar até ele. Os indicadores, a bem dizer, devem ser frutos dessa visão estratégica, desdobrada em objetivos a serem alcançados pelo bom desempenho dos indicadores.

Para Kaplan e Norton (1997, 2004), os objetivos do BSC são esclarecer e traduzir a visão e a estratégia de longo prazo, comunicar e associar objetivos e medidas estratégicas, planejar, estabelecer metas e alinhar iniciativas estratégicas e melhorar o feedback e o aprendizado estratégico.

A partir de uma visão integrada e balanceada da empresa, Kaplan e Norton (2004) afirmam que o BSC permite descrever a estratégia de forma clara, por meio de objetivos estratégicos, em quatro perspectivas, sendo todos eles relacionados entre si, em uma cadeia de relações de causa e efeito. Uma empresa que implementa o BSC sabe que é necessário ter bom desempenho em várias áreas, não somente no aspecto financeiro, para conseguir êxito em longo prazo. Além disso, o BSC promove o alinhamento dos objetivos estratégicos com indicadores de desempenho, metas e planos de ação, como exemplifica a Figura 8. Desta maneira, é possível gerenciar a estratégia de forma integrada e garantir que os esforços da organização estejam direcionados para a estratégia. 


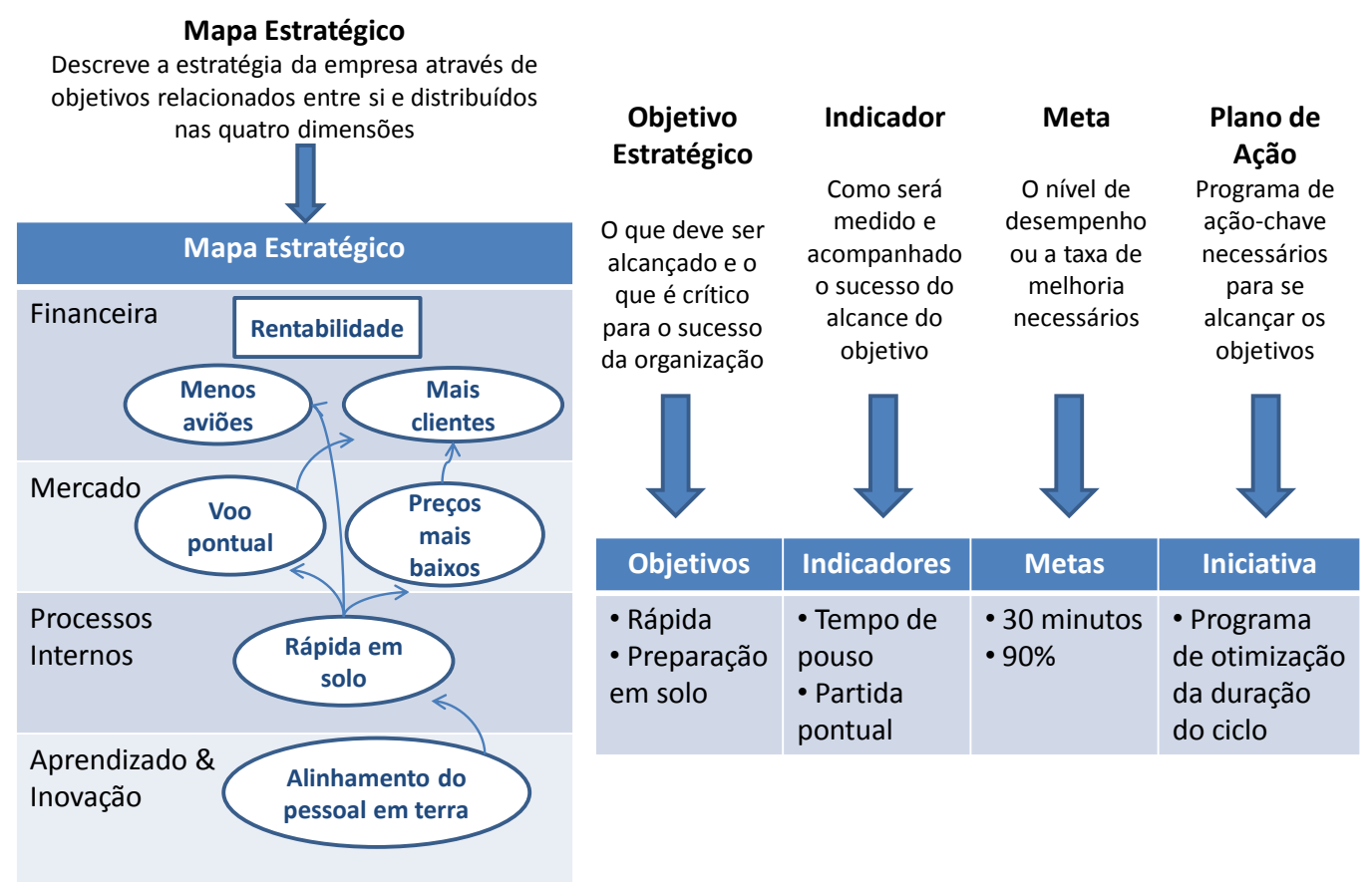

Figura 8 - Componentes do BSC e do mapa estratégico para um fragmento de estratégia para uma companhia aérea

FONTE: Kallás (2003).

A divisão do modelo em quatro perspectivas é uma característica importante do BSC, que possibilita uma análise correta e equilibrada do desempenho organizacional. As quatro perspectivas comumente utilizadas são: financeira, do cliente, dos processos internos e de aprendizado e crescimento. Se houver necessidade, é possível adicionar ou substituir alguma perspectiva por outra que faça mais sentido à realidade da organização. É o caso de organizações governamentais, empresas públicas, organizações sem fins lucrativos, entre outras.

Perspectivas clássicas e mais comuns do BSC:

- A perspectiva de finanças possibilita a identificação dos resultados financeiros da estratégia implementada. O BSC conserva a perspectiva financeira no topo do modelo, como consequência de todas as outras perspectivas, visto que as medidas financeiras são valiosas para sintetizar as consequências de ações consumadas. Exceções para este formato podem ser encontradas em alguns BSCs de organizações governamentais, ou do terceiro setor, nas quais a perspectiva financeira geralmente não fica no topo do modelo, ficando a perspectiva referente ao cliente (ou usuário ou contribuinte), em primeiro lugar, além de o 
caráter financeiro restringir-se à captação de recursos e sustentabilidade, em vez de foco em lucratividade e rentabilidade.

- A perspectiva dos clientes permite à administração estabelecer os segmentos e avaliar os desempenhos dos mercados e dos clientes para os quais a empresa atua, em função das expectativas dos clientes e do posicionamento mercadológico da organização.

- A terceira perspectiva, relacionada aos processos internos, possibilita aos executivos a identificação de pontos críticos nas atividades da empresa, em relação aos quais a organização tem de criar diferenciais para agregar valor aos clientes e satisfazer expectativas dos acionistas por meio dos objetivos financeiros da empresa.

- Por fim, a perspectiva de aprendizado e crescimento facilita a identificação da base ou da infraestrutura que a organização deve construir, para viabilizar o crescimento e a sobrevivência no longo prazo. O objetivo da perspectiva de aprendizado e crescimento é promover a capacitação da empresapara apresentar desempenho superior nas perspectivas anteriores.

$\mathrm{O}$ quadro de medidas organizadas, segundo as quatro perspectivas explicadas, obriga a direção da organização a fixar-se num pequeno número de indicadores fundamentais. $\mathrm{O}$ quadro de indicadores serve de prevenção contra o bom desempenho de uma área, em detrimento de outro setor da empresa. Apesar de destacar que as empresas não devem seguir quantidades fixas, as pesquisas de Niven (2005) indicam que as organizações utilizam em torno de 25 indicadores de desempenho, com um ou dois indicadores estão associados a um objetivo estratégico.

Embora originalmente criado como um sistema de medição de desempenho, o BSC transformou-se em um sistema de gestão estratégica, de acordo com Kaplan e Norton (2004), conduzindo a implementação, a comunicação e o acompanhamento de toda a estratégia corporativa por meio da gestão de seus objetivos e indicadores e do mapa estratégico. Os aspectos apresentados relacionados aos conceitos, características, funcionamento e implementação asseguram, para Kaplan, Norton e diversos pesquisadores que estudam e aplicam estes conceitos, que a ferramenta seja utilizada da melhor forma para gerenciar a estratégia de uma organização.

Outros métodos também são estudados, de maneira complementar, ao mapa estratégico ou ao BSC. A seguir, apresenta-se uma técnica para criar-se mapas, que pode funcionar como 
alternativa ao mapa estratégico, alertando para uma lacuna da obra de Kaplan e Norton, que não aborda a estruturação e a construção de mapas estratégicos.

\section{i) O mapa de sucesso de Bourne e Bourne}

De acordo com Bourne e Bourne (2011), uma forma de se capturarem os objetivos do negócio e definir de que forma medi-los, é por meio de um mapa de sucesso. Este conceito é apresentado, pelos autores, como um complemento para a organização de objetivos e sua consequente construção em mapas estratégicos.

Para criar o mapa do sucesso, os autores sugerem uma abordagem que consiste em aplicar duas perguntas: o que? / como? (what / how). A primeira pergunta é relacionada com o que a empresa precisa fazer, de forma a obter, como resposta, um objetivo organizacional. A segunda pergunta indica como a empresa deve alcançar o grande objetivo definido na pergunta anterior. A resposta à segunda pergunta deve ser objetivo do próximo item. Bourne e Bourne (2011) recomendam repetir o processo what / how sucessivas vezes, de forma a criar seu mapa de sucesso, conforme a Figura 9 ilustra:
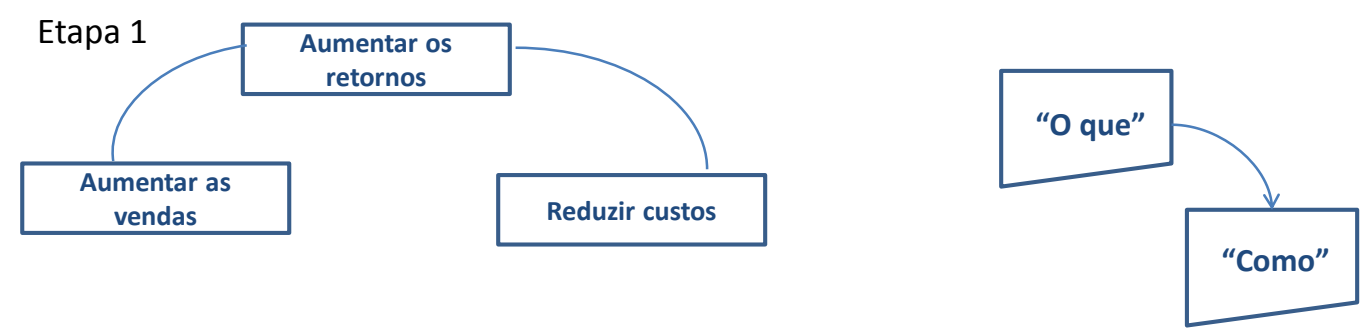

Etapa 2

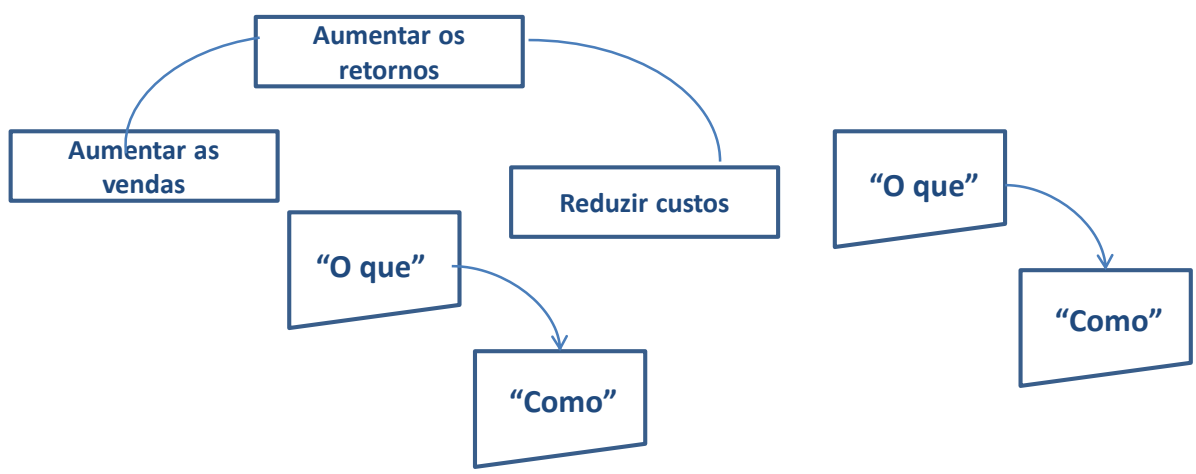

Figura 9 - Exemplo do processo "o que/como" (what / how)

FONTE: Bourne e Bourne (2011). 
Complementando o processo what / how, é recomendando pelos autores usar mais uma pergunta (why?/ por quê?), no sentido inverso do mapa de sucesso, de forma a testar o que foi desenhado e descobrir eventuais imperfeições ou correções na lógica de desdobramento dos objetivos. A verificação, usando mais uma pergunta, é importante para o entendimento de outros que precisam trabalhar com o mapa e compreender a relação entre os objetivos.

Ver a lógica das ações e como elas estão interligadas é muito mais fácil, no visual de um mapa, além de ser mais fácil para comunicar o que será feito e porque as pessoas estão envolvidas nisto. O mapa da Figura 10, exemplo de uma empresa de treinamentos, já mostra uma construção hierarquizada de acordo com as perspectivas de Kaplan e Norton sugeridas para o mapa estratégico.

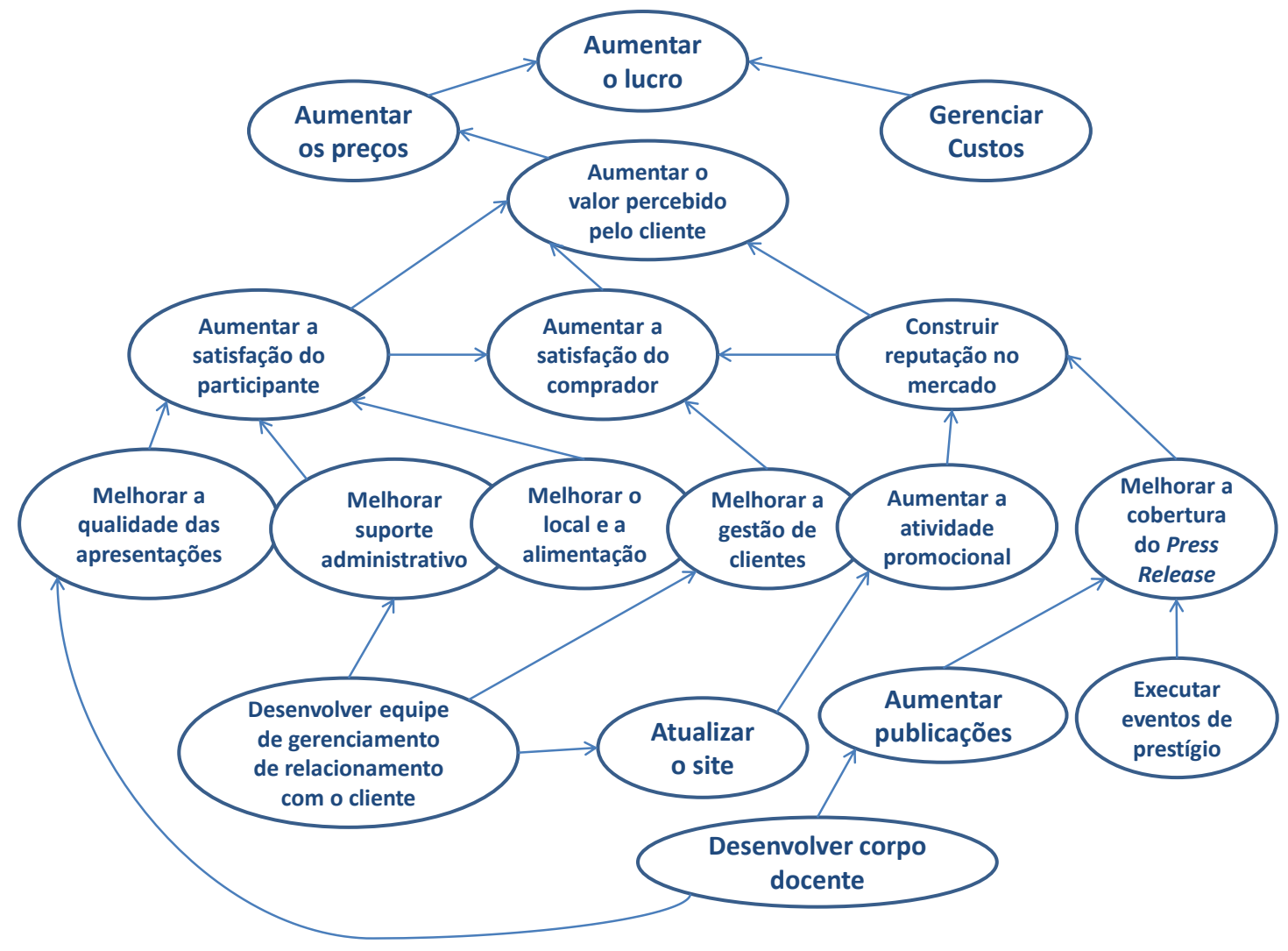

Figura 10 - Exemplo de mapa de sucesso para uma empresa de treinamentos

FONTE: Bourne e Bourne (2011).

Além da construção do mapa de sucesso, os autores exemplificam seu desdobramento em um Balanced Scorecard, em um conjunto de indicadores, metas e iniciativas relacionadas ao mapa construído e à estratégia delineada no caso estudado, conforme apresenta a Figura 11. 


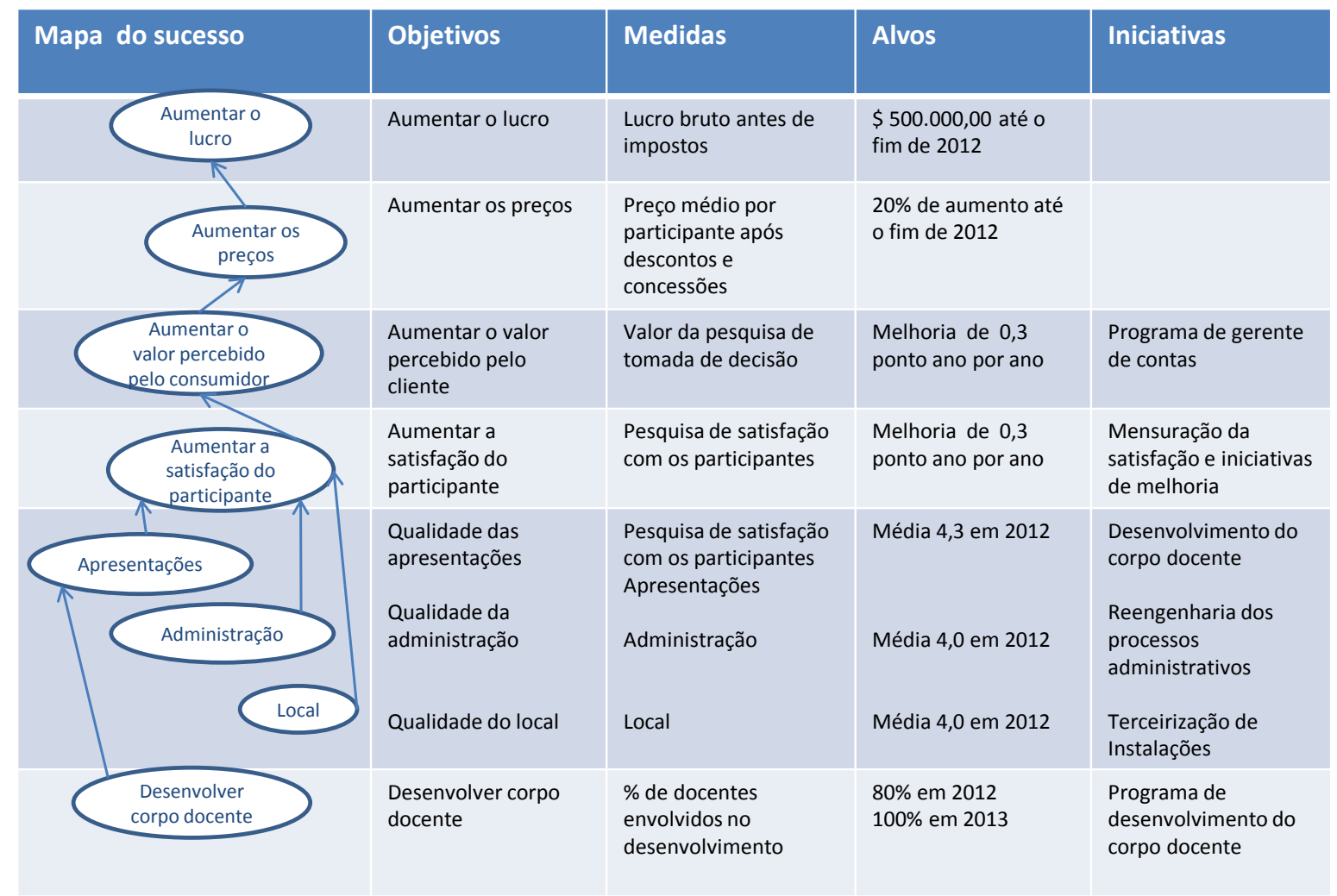

Figura 11 - O mapa de sucesso derivado em um Balanced Scorecard

FONTE: Bourne e Bourne (2011).

Outra contribuição de Bourne e Bourne (2011) se dá por meio de uma matriz (ilustrada na Figura 12), que une as iniciativas definidas da nova estratégia e as ações em curso na organização com os objetivos estratégicos, definidos anterioremente. Desta forma, é possivel entender se as ações em curso estão alinhadas com a nova definição estratégica e qual será a sua contribuição para os objetivos estratégicos definidos. De maneira análoga, pode-se supor que as iniciativas que não estejam alinhadas com os novos objetivos estratégicos deverão passar por uma análise em que sua descontinuidade será avaliada. 


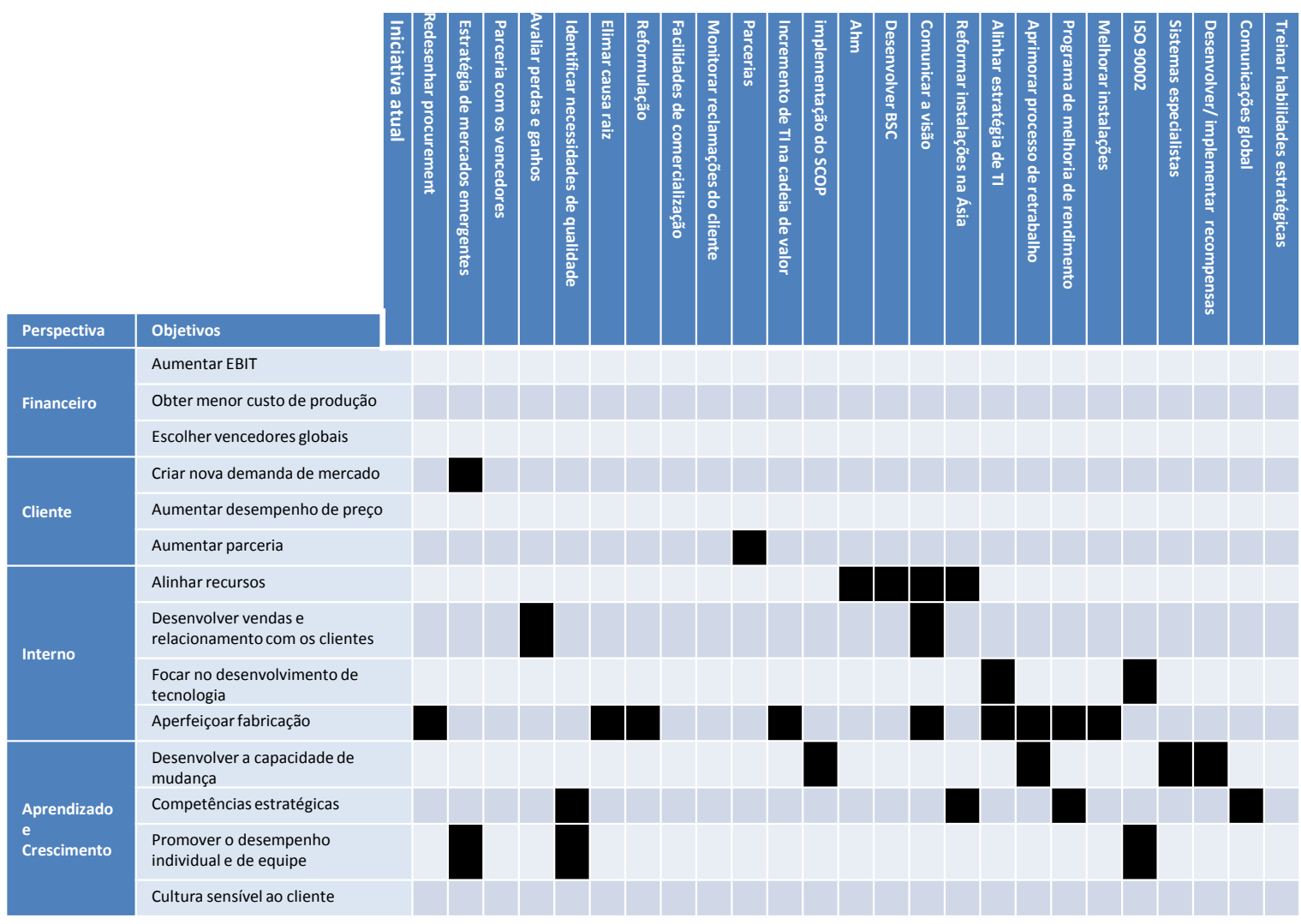

Figura 12 - Iniciativas em andamento cruzadas com os objetivos do mapa

FONTE: Bourne e Bourne (2011).

\section{b) A Administração por Objetivos (APO) de Drucker}

A Administração por Objetivos (ou Management by objectives) foi introduzida por Drucker, em seu livro The Practice of Management (1957). Esse conceito relaciona as metas organizacionais com o desempenho e desenvolvimento individual, por meio do envolvimento de todos os níveis administrativos. De acordo com Drucker (1981), a empresa deve organizarse numa verdadeira equipe e consolidar os esforços de cada um, num esforço comum. Todos devem contribuir para uma meta comum.

Define-se, também, como um processo pelo qual gerentes e subordinados identificam objetivos comuns, definem áreas de responsabilidade de cada um em termos de resultados esperados, e utilizam esses objetivos como guias para sua atividade. A ênfase passa a ser na eficácia dos resultados e não na eficiência.

Lodi (1977) define administração por objetivos como um método pelo qual os gestores de uma empresa estabelecem metas para suas operações em seu início do exercício fiscal em 
consonância com metas gerais da organização. Esses objetivos são planos de ação e melhoramentos que contribuem para alcançar resultados-chave para a empresa. $\mathrm{O}$ autor define como objetivos "uma declaração escrita o quanto possível com número, orientando o desempenho dos gerentes para atingir um resultado mensurável e de valor” (LODI, 1977).

A APO é uma técnica participativa de planejamento e avaliação, por meio da qual, superiores e subordinados definem, conjuntamente, aspectos prioritários, a saber:

- estabelecem objetivos (resultados) a serem alcançados, em um determinado período em termos quantitativos, dimensionando as respectivas contribuições.

- acompanham, sistematicamente, o desempenho para estabelecer as correções necessárias.

- enfatizam um conjunto de objetivos tangíveis e mensuráveis.

- deslocam o foco para as atividades meio (para chegar-se ao fim).

A APO funciona como uma abordagem amigável, democrática e participativa, servindo como base para novos esquemas de avaliação de desempenho humano, remuneração flexível, e sobretudo, para a compatibilização entre objetivos organizacionais e individuais.

A APO, para Daft (1999), apresenta as seguintes características:

1- Estabelecimento conjunto de objetivos entre executivo e seu superior;

2- Estabelecimento de objetivos para cada departamento ou cargo;

3- Interligação entre os vários objetivos departamentais;

4- Ênfase na mensuração e no controle dos resultados;

5- Contínua avaliação e revisão dos resultados;

6- Participação atuante das gerências;

Quem trabalha com a APO define metas comuns, especifica áreas de responsabilidade e responsáveis, e critérios para avaliação da atividade. Para Drucker (1981), todos os administradores, independentemente do nível hierárquico, precisam de objetivos bem definidos. A APO trabalha com a conversão dos objetivos da organização para objetivos específicos das unidades, gerando um efeito cascata (de cima para baixo), detalhando os objetivos estratégicos em táticos, e depois, em operacionais. De acordo com Drucker (1981), os objetivos de todos devem estipular qual sua parte para o alcance da meta da empresa, em 
todos os seus negócios. Como as empresas perseguem vários objetivos podem ser considerados três níveis de objetivos: estratégicos, táticos e operacionais.

a- Estratégicos — são os chamados objetivos organizacionais; são mais amplos, mostram as metas globais e são de longo prazo.

b- Táticos - são chamados de departamentais, sendo sua característica o médio prazo.

c- Operacionais - são os objetivos referentes a cada atividade ou tarefa e seu detalhamento a curto prazo.

Para Roth (2009), a APO começa quando empregados e seus supervisores imediatos discutem seus próximos objetivos. De acordo esse autor, esses objetivos estão focados em duas grandes áreas: a produtividade do empregado e de suas responsabilidades (vendas, erros, projetos, habilidades adquiridas etc.); e o caminho que o empregado desempenha (assume responsabilidade, toma decisões, trabalha em grupo, lida com clientes etc.).

Uma abordagem comum, para Roth (2009), é tanto o empregado como seu supervisor traçarem metas para o empregado, e depois, comparar e negociar o resultado, chegando a um acordo final, como um "contrato".

Após a escolha e fixação dos objetivos organizacionais, o próximo passo é saber como alcançá-los, isto é, estabelecer a estratégia empresarial a ser utilizada para alcançar os objetivos globais e quais táticas serão adotadas.

Os critérios para escolha dos objetivos, de acordo com Lodi (1977), são fixados de acordo com a prioridade e contribuição para o alcance dos resultados-chave da empresa:

1- Procurar atividades que tenham maior impacto sobre os resultados;

2- O objetivo dever ser claro, específico, mensurável, basear-se em dados concretos, e postos por escrito, para posterior acompanhamento.

3- Monitorar o desempenho, periodicamente, de acordo com o planejamento.

4- Focar os objetivos nas atividades e não nas pessoas.

5- Usar linguagem compreensível, indicando os resultados e os prazos a serem alcançados.

6- O objetivo deve ser difícil de ser atingido, requerendo esforço especial, mas, não a ponto de ser impossível de ser alcançado. 
Os objetivos devem traduzir as aspirações fundamentais da empresa e todos na empresa devem contribuir como parcela do esforço geral. O colaborador deve conhecer suas metas e a respectiva relação com os objetivos gerais da empresa; e o plano deve ser revisado e reformulado constantemente, de forma a se alinhar ao mercado. Drucker enfatiza que a APO requer uma hierarquia e um equilíbrio de metas, de forma a evitar um desempenho desordenado dos recursos humanos da empresa.

A definição de objetivos dá-se de maneira mais exata, usando os critérios representados pelo acrônimo SMART, que possui o seguinte significado:

- Specific (Específico)

- Measurable (Mensurável)

- Achievable (Atingível)

- Realistic (Realista)

- Time-related (Relacionado com o tempo)

O acrônimo SMART encontra-se disseminado, podendo apresentar pequenas variações, mas, sempre, com a finalidade de estabelecer uma orientação, para que os objetivos e metas sejam definidos corretamente. De acordo com Lodi (1977), os passos para fixar os objetivos de uma empresa são:

1. Analisar os alvos do negócio

2. Analisar as tarefas dos gerentes

3. Definir os objetivos

4. Determinar os padrões de medida de resultados

5. Selecionar os alvos específicos

6. Detalhar os objetivos até o último nível executivo

7. Conseguir a participação integrada de todas as áreas

Drucker (1981) propôs, originalmente, oito áreas que deveriam contemplar os objetivos da organização. A ênfase em cada setor dependeria do próprio setor ou do momento da organização, mas, em termos gerais, as dimensões propostas não seriam alteradas: 
1. Posição no mercado

2. Inovação

3. Produtividade

4. Recursos físicos e financeiros

5. Rentabilidade

6. Desempenho e desenvolvimento dos gerentes

7. Desempenho e atitude dos trabalhadores

8. Responsabilidade pública

Posteriormente, na continuidade da sua obra, Drucker (1998) passou a indicar as seguintes oito áreas, contemplando as áreas anteriores em um enquadramento visto até hoje no campo da Administração.

1. Marketing

2. Inovação

3. Recursos humanos

4. Recursos financeiros

5. Recursos físicos

6. Produtividade

7. Responsabilidade social

8. Lucro

Roth (2009) critica a APO, enfatizando que a técnica alimenta a competição entre os empregados, limita a capacidade deles, e restringe rápidas respostas das organizações. A chave para uma transição para além da APO é alterar o sistema de recompensas, que encoraja um sistema cooperativo e não competitivo, entre os colaboradores, revendo a tradicional cultura competitiva.

Dessa forma, a sugestão de Roth (2009) é a de que se considerem técnicas que possibilitem maior flexibilidade, trabalho em equipe, e outros aspectos mais alinhados às organizações atuais. Na opinião de Roth (2009), outras ferramentas organizacionais poderiam substituir a APO. No entanto existem relatos recentes de experiências de uso da APO em empresas de grande porte como a HP, conforme Hindle (2009), e a Intel, de acordo com Raj (2007). 


\section{i) Os objetivos estratégicos de Ansoff}

De acordo com Ansoff (1991), objetivos são "regras de decisão" que habilitam a administração a orientar e medir o desempenho da empresa na direção de seus fins. É um critério pelo qual se determina o sucesso (ou insucesso) de uma empresa. Contém três elementos: o atributo específico, como medida de satisfação, a unidade de medida (segundo o qual o atributo é mensurado), e a meta (valor que a empresa procura alcançar nessa escala).

Ansoff (1991) coloca que a primeira questão central, a ser respondida sobre objetivos da empresa, é saber o que ela empresa está perseguindo: lucro, riqueza do acionista, ou equilíbrio da satisfação dos grupos de interesse.

Os objetivos de uma instituição podem ser inferidos a partir de sua relação com o ambiente, da sua estrutura interna, das funções que executa e de sua história. Ansoff (1991) destaca que, embora as escolhas e prioridades sejam diferentes, a maioria das empresas tende a conter os seguintes objetivos:

- Objetivos econômicos — voltados para a otimização do processo de conversão dos recursos da empresa.

- Retorno sobre investimento no longo prazo - se o retorno não for atraente, os investidores abandonam a empresa; se o retorno for negativo, a empresa fechará.

- Objetivos sociais ou não-econômicos dos participantes na empresa.

- Objetivos de grupos externos de interesse (por exemplo, acionistas individuais ou fundos de pensão).

O sistema de fixação de objetivos, proposto por Ansoff (1991), leva em consideração relações de rentabilidade da empresa em longo prazo, e também a presença de objetivos nãoeconômicos. O modelo de Ansoff (Figura 13) mostra: a relação entre os objetivos que são mediados com a relação dos objetivos não-econômicos, e sua relação com os objetivos nãoeconômicos.

Conforme cita o autor, as influências não-econômicas também exercem efeito sobre a prioridade e os valores atribuídos às metas. Ele enfatiza a questão de externar as prioridades 
da empresa: isto afeta as disponibilidades de recursos para a empresa, e também suas prioridades. $\mathrm{O}$ ambiente econômico e o ambiente de produtos e mercados também exercem efeito sobre as prioridades.

Para o autor, objetivos realistas não devem ser decretados em uma sala de reunião, de modo arbitrário; devem ser resolvidos por uma interação continuada de objetivos e elementos da estratégia como análise da competitividade, o que ele chama de filosofia básica da estratégia e uma análise dos objetivos correntes.

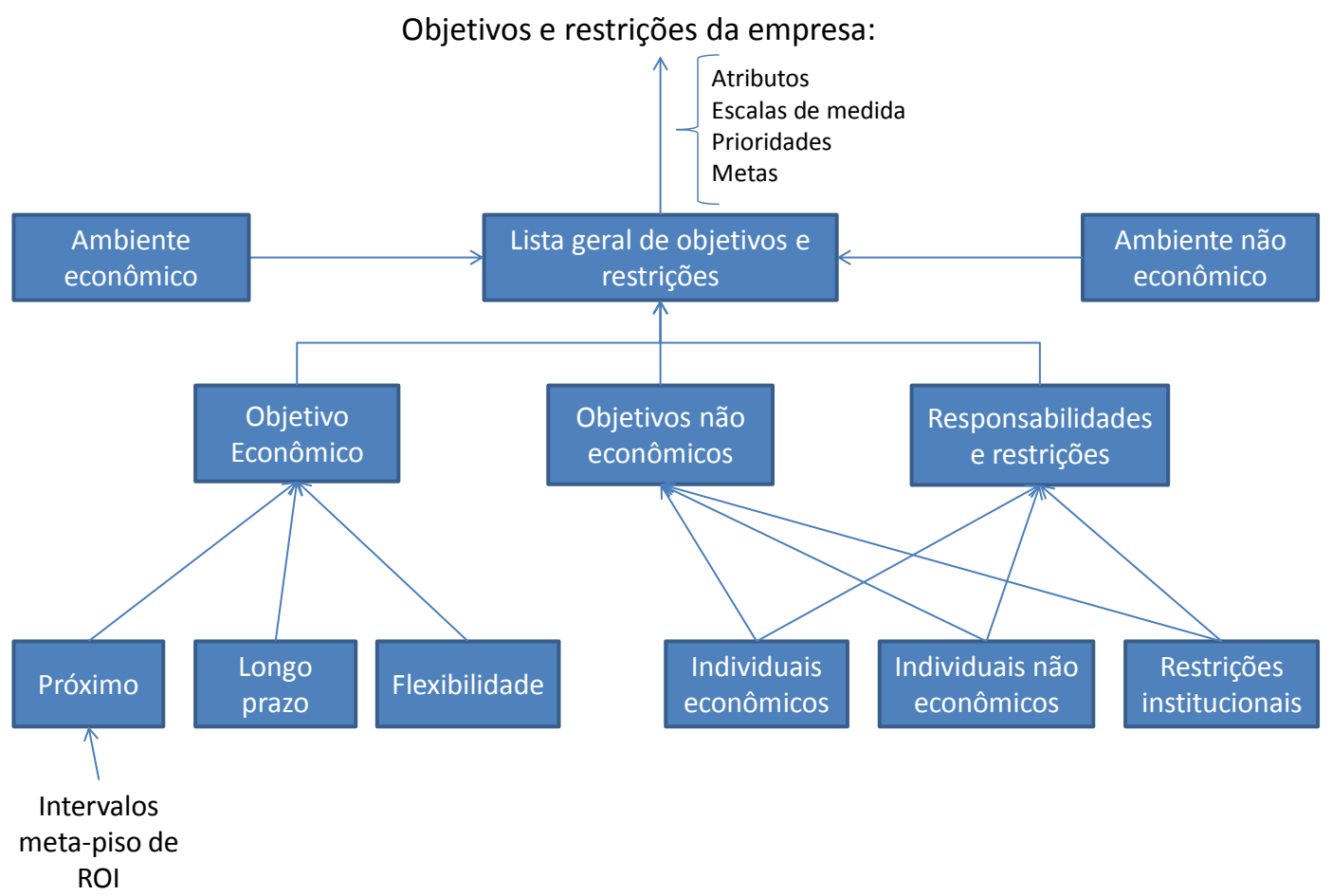

Figura 13 - Hierarquia geral de objetivos

FONTE: Ansoff (1991).

\section{ii) Os objetivos essenciais de Chatterjee}

Chatterjee (2005) argumenta que existem dois componentes para desenhar estratégias de sucesso: escolha e clareza. Para escolher um modelo de negócio, é necessário ter clareza nas capacitações que a organização possui, definindo-se o melhor caminho e evitando riscos.

De acordo com Chatterjee (2005), o processo de identificar poucos objetivos essenciais, que vão levar a empresa a obter uma vantagem competitiva, não é fácil, mas, coloca a organização 
em uma situação melhor para gerenciar riscos de falhas eventuais, se comparado com uma empresa tradicional. Adicionalmente, possuir poucos objetivos evita que a organização sofra de excesso de informação e facilita uma melhor comunicação e controle.

Um número menor de objetivos facilita o acompanhamento de objetivos que não estão com o desempenho satisfatório, e necessitam ações específicas. Chatterjee (2005) também enfatiza que um número otimizado de objetivos auxilia na melhor alocação de seus recursos evitando desperdiçar esforços. $\mathrm{O}$ autor alerta que trabalhar com objetivos estratégicos convencionais amplos não é suficiente, para antecipar os riscos de fracasso de uma estratégia. A explicação é que, por possuir um alto nível de abstração, esses objetivos não estão associados às capacitações necessárias para a realização consistente do objetivo. E o objetivo amplo não consegue trazer um nível de especificidade que capture a vantagem competitiva da organização.

Reduzir sua lista de objetivos também pode trazer a clareza que seu negócio necessita para operar. Para isso, de acordo com Chatterjee (2005), são necessários dois passos: primeiramente, a organização deve identificar quais objetivos de alto nível capturam a lógica competitiva do modelo de negócios adotado e, depois, desenvolver uma lista focada de um conjunto de objetivos que possa ser calibrada e rastreada em tempo real.

Os objetivos de alto nível a serem identificados na primeira etapa devem esclarecer de que forma a organização irá entregar o que seu consumidor deseja e procura, mas, também, os objetivos que os consumidores querem, mas nem imaginam. Estes objetivos amplos devem também mostrar-se como parte do valor e ser capturados para o acionista. Para Chatterjee (2005), os objetivos competitivos devem capturar o valor que o cliente pagaria a mais pela diferenciação no produto ou serviço.

Os resultados dos objetivos necessitam ser medidos em tempo real, são específicos dos negócios e precisamente mensuráveis. Os objetivos essenciais forçam a empresa a focar em poucas coisas, de forma a executá-las, excepcionalmente bem.

Muitas empresas acreditam possuir objetivos essenciais, mas, são metas amplas, como ROI, Market share, ou margem de lucro, que, de acordo com Chatterjee (2005), não são adequados para rastrear os verdadeiros riscos do negócio, pois essas métricas são bons sintomas do que 
já aconteceu na organização. O autor recomenda um sistema de indicadores que mostrem, em tempo real, se o modelo de negócios está funcionando ou não, antes de aparecer em um indicador amplo, se está sendo rentável ou não. Nas palavras do autor, uma métrica para um objetivo essencial deve "medir o pulso de uma organização, em tempo real".

Estratégia é trade-off, ou seja, tomar decisões em detrimento de outras; com os objetivos essenciais, é mais fácil identificar as trade-offs e tomar decisões. De forma a ilustrar o processo de ação, Chatterjee (2005) recomenda o processo COAR (ㄸustomer outcomes, core

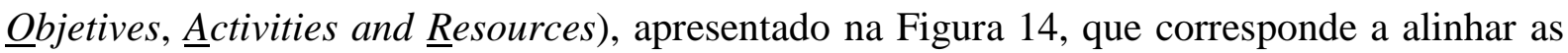
expectativas do cliente, e os objetivos essenciais da empresa, considerando suas capacitações, que o autor divide em atividades executadas pela empresa, usando os recursos corretos.

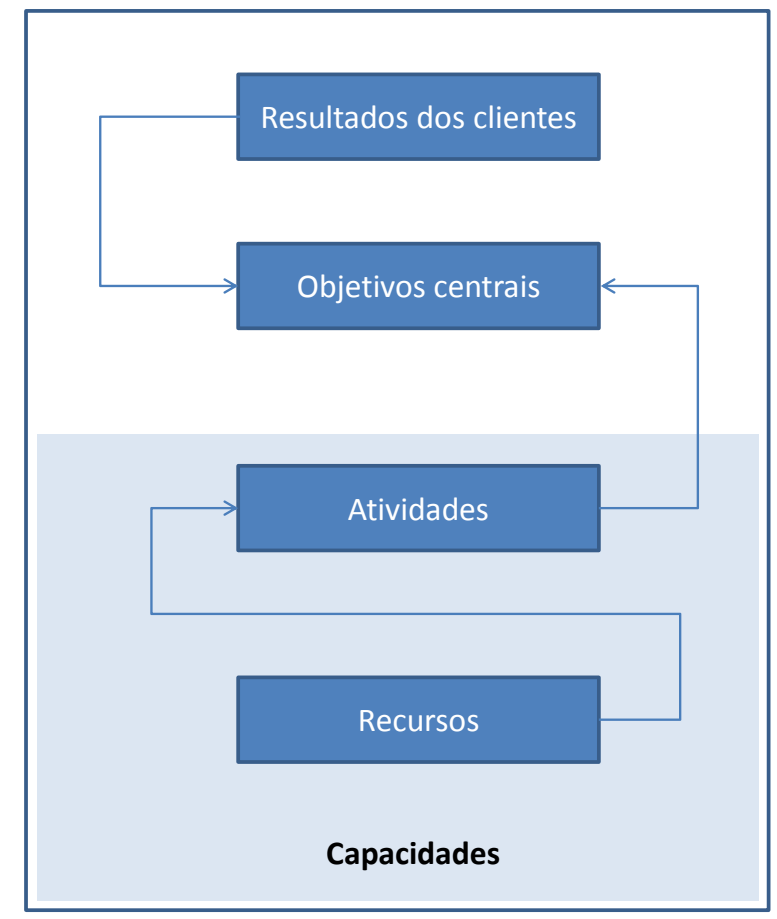

Figura 14 - O modelo COAR

FONTE: Chatterjee (2005).

Os objetivos essenciais devem entregar os resultados desejados pelo consumidor. Essa entrega será feita pela realização das atividades adequadas e pelos recursos corretos. As empresas bem sucedidas focam em poucos itens críticos, pois controlam o que devem (e não o que podem). Os objetivos essenciais das empresas mostram, em poucas métricas, seu retorno imediato de como eles estão indo. Portanto, a quantidade de tempo e o número de intermediários envolvidos no processo de mensuração e ação é reduzido. 


\section{iii) Fatores críticos de sucesso}

O uso de FCS (Fatores Críticos de Sucesso ou Critical Success Factor) e de KPIs (Key Performance Indicators ou Indicadores chave de desempenho - mantenha o padrão) auxilia o alinhamento com a missão organizacional e com a definição de objetivos estratégicos. A Figura 15 representa, graficamente, a sequência de desdobramentos entre os itens. O uso de FCS e de KPI está relacionado à determinação em detalhe, onde a empresa deseja alocar seus esforços para alcançar sua missão, visão e objetivos estratégicos.

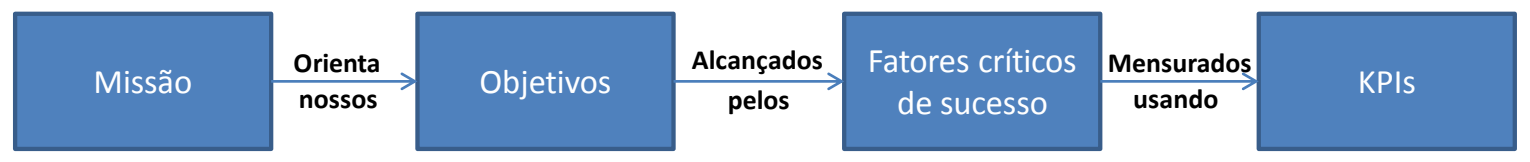

Figura 15 - Processo de definição de objetivos, FCS e KPIs, a partir da missão FONTE: Clark (2008).

De acordo com Clark (2008), a declaração de missão auxilia a organização a definir os objetivos de alto nível apropriados. Enquanto uma organização tem uma declaração de missão, geralmente tem uma série de objetivos. Enquanto a missão possui um texto mais abrangente, os objetivos precisam ser específicos e o autor recomenda que sigam os preceitos do SMART. Após definir os objetivos, é necessário estabelecer o que é preciso para atingi-lo (estes são os considerados FCS).

De acordo com Souza (2005), a proposta de abordagem de um FCS é determinação de um conjunto de fatores que os gestores consideram críticos em seu sucesso. Uma vez identificados, estes fatores são alinhados a seus objetivos e a informação necessária para monitorar seu desempenho é também identificada.

Os KPI, por sua vez, representam um conjunto de medidas focadas em aspectos de desempenho organizacional, que são mais críticos para o sucesso atual e futuro de uma empresa. Elas são especialmente críticas para atingir um conjunto de resultados. De acordo com Baker (1995), a maior contribuição para os KPI, no nível de equipes, é que ele gera um sentimento de propriedade do processo de melhoria da organização, pois quando os próprios colaboradores definem seus KPI a partir de um contexto mais amplo, definido por um FCS, eles têm a confirmação de que o que eles acreditam é importante. 
Adicionalmente, Souza (2005) lista alguns benefícios dos KPI para os funcionários:

- Clarifica os objetivos do grupo

- Define os objetivos e metas do grupo

- Provê uma base que compartilha papéis e responsabilidades entre o time

- Focaliza em processos-chave para uma potencial melhoria

- Identifica áreas problemáticas e determina prioridades de melhoria

- Mensura o sucesso de suas ações

- Provê uma base para reconhecimento e celebração das metas alcançadas pelo grupo

$\mathrm{O}$ atingimento de um FCS é medido por um KPI, que, como um objetivo, também precisa ser SMART. Um KPI é um conjunto de indicadores que uma organização usa para medir seu desempenho para alcançar seus FCS. O FCS é definido com uma característica do aspecto interno ou do ambiente externo de uma organização, que tem uma grande influencia no atingimento dos objetivos da organização.

Existem três níveis que expressam os objetivos de uma organização: visão e missão, metas, e objetivos estratégicos - que a empresa deve alcançar nos próximos anos (isso deveria ser foco da organização e deve estar inserido na visão). As metas estratégicas têm natureza de ser de grande expressão, grandes ideias, e de alto nível. Esses objetivos precisam ser quebrados em algo mais concreto e específico: assim, planos táticos podem ser feitos, orçamentos delineados, responsabilidades distribuídas e medidas estabelecidas. Os objetivos estratégicos são analisados para determinar os fatores que afetam seu alcance (FCS).

Os três níveis talvez não sejam aplicados em todas as empresas, mas o conceito principal é estabelecer uma hierarquia de objetivos, de forma que algo vago e ambicioso vire concreto e mensurável.

Não existem garantias de que os fatores críticos de sucesso escolhidos sejam os adequados. No entanto, as empresas conseguem aprender com a experiência, e por isso, as organizações devem revistar constantemente os FCS e seus KPI, para determinar se esses aspectos realmente estão alinhados ao negócio, e para a direção que a empresa deseja. 
Os passos para determinarem-se os FCS e os KPI são:

1. Estabelecer a Missão e a Visão Estratégica

2. Determinar os objetivos estratégicos

3. Analisar, para cada objetivo, quais os fatores que o influenciam

4. Determinar pelo menos uma medida para cada fator (KPI)

5. Determinar a meta

Tanto os FCS quanto os KPI são técnicas independentes que podem ser usadas em conjunto para buscar o alinhamento com a missão organizacional. Autores que estudaram esses conceitos, como Souza (2005) e Clark (2008), sugerem que outros conceitos como os indicadores SMART ou o BSC possam ser complementares ao conjunto FCS e KPI.

\section{iv) Definição de objetivos de Alogan e Yetis}

Para Alogan e Yetis (2006), visão sem ação é somente um sonho. Historicamente, a razão para os planos continuarem no papel é porque eles não se transformaram em ação. Os autores também reforçam que a terminologia de objetivos ou metas estratégicas não está padronizada.

Os objetivos são itens de ação de nossa agenda, em um horizonte médio (1 a 5 anos). Para preencher esse papel, os objetivos estratégicos precisam ser explícitos, mensuráveis e viáveis. Para os autores, definir objetivos estratégicos deve vir após oito passos. Deve-se destacar uma etapa zero de planejamento (o plano do plano), a definição de missão, visão e valores, a análise ambiental (análise PEST - política, econômica, social e tecnológica) e a aplicação da análise ambiental em uma análise SWOT (strengths, weaknesses, opportunities e threats pontos fortes, fracos, oportunidades e ameaças) em um grande workshop. Após o workshop SWOT, que envolve as principais cabeças da organização (até nível abaixo da gerência, com mais de cem pessoas), é definida uma linha de sugestões do que a empresa deve fazer a partir da análise SWOT e, por fim, é obtida uma lista preliminar de ações a serem feitas (Figura 16).

Esta lista preliminar é avaliada por um grupo menor de tomadores de decisão (máximo de trinta), que vão alinhar a lista de ações preliminares com a visão da empresa e das medidas críticas de desempenho. 
A partir disso, os objetivos estratégicos são formulados avaliando-se todo o material gerado na etapa anterior. Após uma reunião de alinhamento e avaliação do que foi produzido nas etapas anteriores, são feitas análises das ideias geradas para o detalhamento dos objetivos estratégicos.

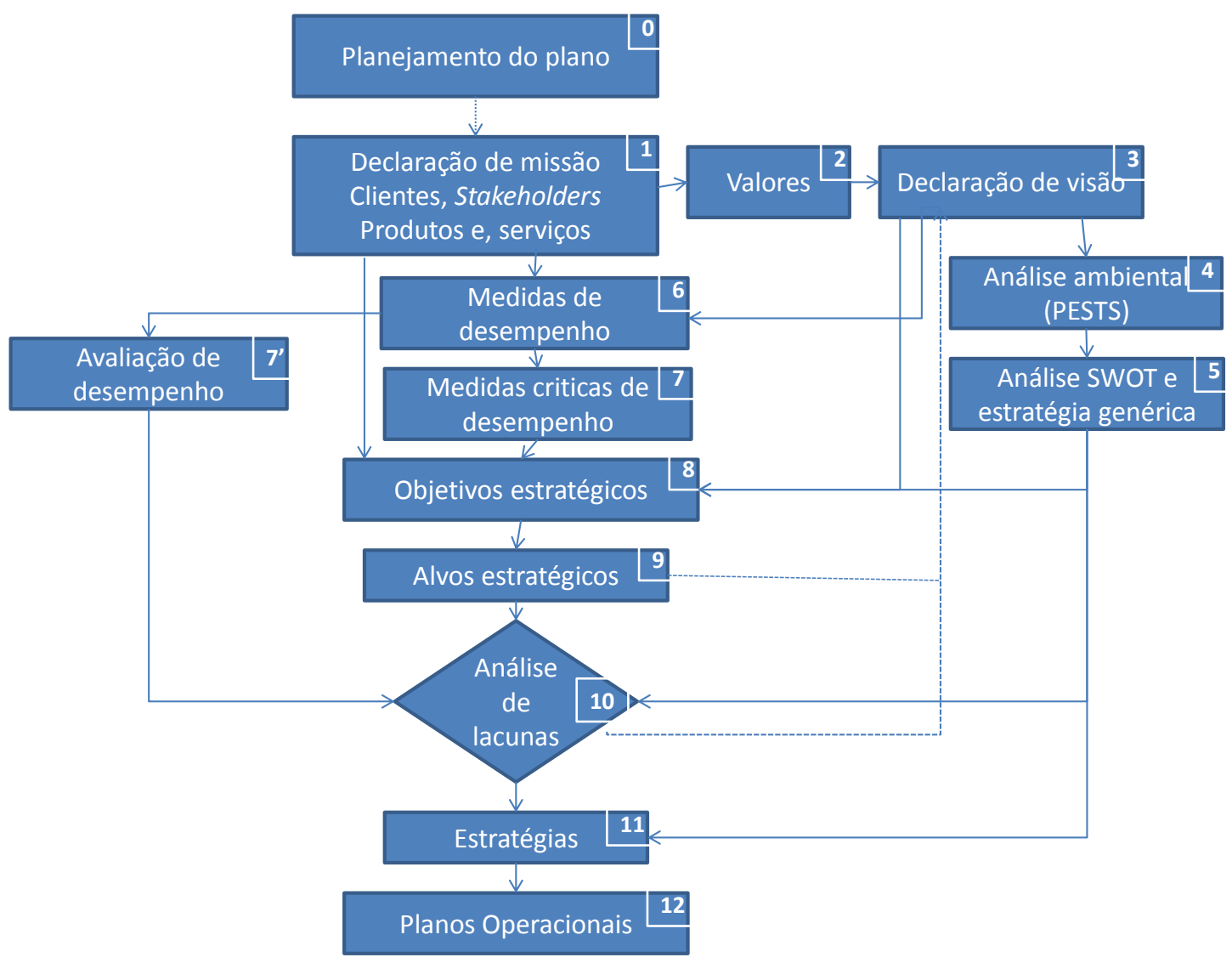

Figura 16 - Fluxo do processo de gestão estratégica

FONTE: Alogan e Yetis (2006).

A geração das ideias que gerarão os objetivos estratégicos será avaliada pelo moderador e cadastrada para discussão em grupo. E de acordo com os autores, deverá responder as seguintes questões relacionadas ao alinhamento entre visão, SWOT e facilidade de comunicação.

Os autores apresentam uma sequência de passos, para efutar o planejamento estratégico, que inclui refletir sobre:

- Declaração de visão da organização: quais são os passos que devem ser efetuados, para que 
a visão não seja apenas um sonho?

- Missão da empresa e nas áreas de atividades futuras (ou linhas de negócios): quais são as coisas que vocês coletivamente pensam, que deveriam fazer por causa da visão, e ainda não estão fazendo?

- Pontos fortes e oportunidades externas da organização: o que você deveria estar fazendo para tomar vantagem destas oportunidades, usando suas fortalezas por meio da visão?

- Pontos fracos e oportunidades externas: que passos podem ser dados para corrigir as fraquezas e obter vantagens das oportunidades identificadas na visão?

- Fraquezas e ameaças: o pode ser feito para corrigir as fraquezas que colocam sua empresa em perigo perto dessas ameaças?

- O que é necessário para aprimorar as medidas críticas de desempenho?

- Que passos podem ser descritos para justificar as etapas que serão seguidas para alcançar já a sua visão de futuro?

\section{v) O processo hoshin kanri}

De acordo com Akao (1991), o hoshin kanri é um conjunto de processos coordenados que ajudam no direcionamento e na gestão para atingir os objetivos traçados pela organização. Para Turrioni et al. (1999), a prática desta técnica está voltada para o alinhamento da organização e negociação de resultados. Sua origem está ligada à gestão da qualidade total e é usado em parceria com ferramentas Lean.

Segundo Turrioni et al. (1999), o hoshin kanri foi desenvolvido a partir da APO e pelo ciclo PDCA de Deming. A técnica é tida como mais reflexiva e participativa que a administração por objetivos, pela inclusão do funcionário no planejamento. Essa técnica começou a ser praticada para permitir o direcionamento da gestão da qualidade em relação aos resultados que a organização tem que atingir para tornar-se e manter-se competitiva.

De acordo com Lopez (2010), para aplicar o hoshin kanri e desdobrar a estratégia, é necessário seguir alguns pré-requisitos, como a definição da visão, missão, valores e como a empresa fará a gestão dos processos.

Lopez (2010) diz que esta técnica é democrática e torna comum as informações em todos os escalões da empresa, uma vez que todos devem entender as metas da empresa e de que forma 
podem colaborar para isto.

De acordo com Akao (1991), a prática do hoshin kanri possibilita: alinhar as metas departamentais e as metas individuais, com os objetivos corporativos, de forma a eliminar esforços em duplicidade; comunicar aos empregados seus papéis para alcançar a visão organizacional; monitorar o desempenho de forma próxima.

Para Akao (1991), a técnica tem a seguinte estrutura básica: diagnóstico, formulação, desdobramento e implementação da estratégia e funciona com a interação de três grandes agrupamentos da empresa: a alta gerência, a média gerência e a equipe designada para fazer a implementação da estratégia. A interação entre estas equipes e a técnica é mostrada na Figura 17.

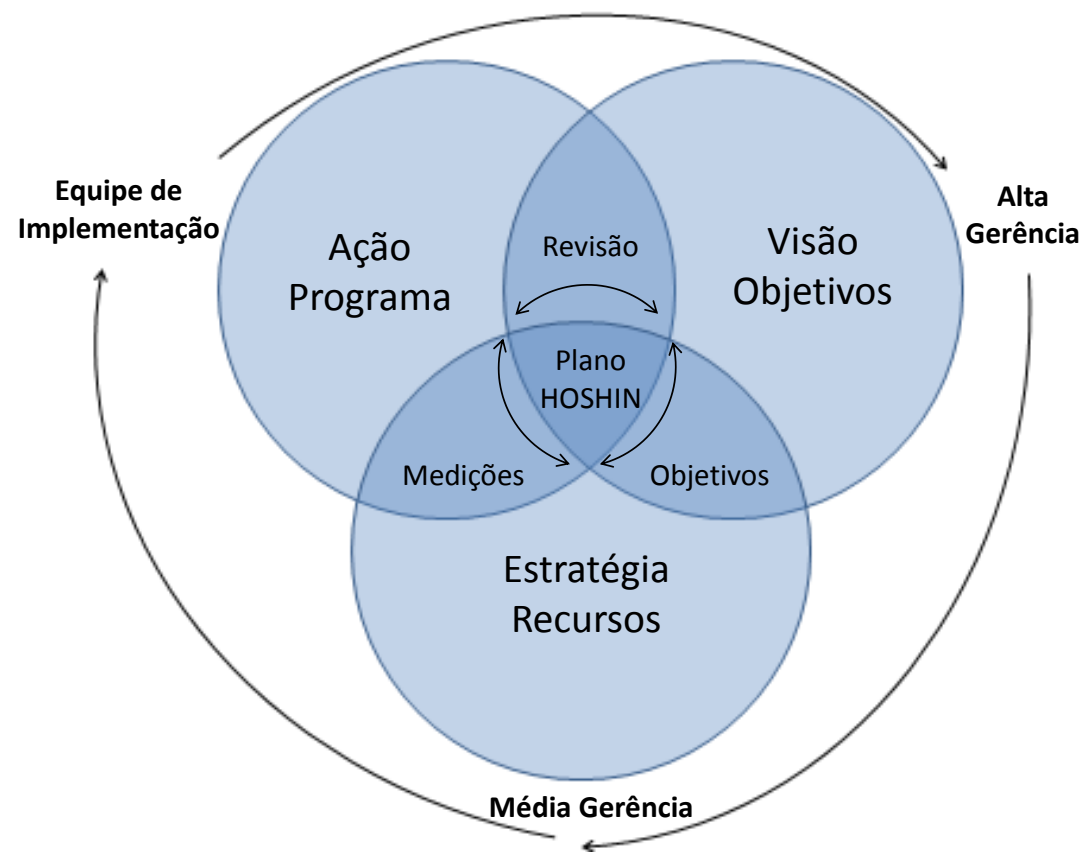

Figura 17 - Esquema do processo hoshin kanri

FONTE: Baseado em Akao (1991) e Turrioni et al. (1999).

O processo hoshin kanri inicia com a especificação dos objetivos, da alta gerência para a média gerência, e depois, dos projetos para a equipe de implementação. Este processo é negociado entre estes três grupos. Estes grupos negociam, até concordar com as metas e o plano de ação.

De acordo com Akao (1991), o hoshin kanri proporciona um processo passo a passo para o 
planejamento, a execução e a revisão das mudanças, além de determinar os objetivos da organização por meio do planejamento estratégico. Permite o seu desdobramento em todos os níveis da organização, atingindo todos os níveis hierárquicos, sem desviar-se do rumo estratégico estabelecido pela empresa. Essa técnica é capaz de desdobrar os objetivos globais da empresa em objetivos individuais, de forma que as pessoas consigam atingi-los.

Para Akao (1991), a técnica possui algumas limitações. A principal é que necessita de uma execução rígida (algo mais difícil de conseguir, fora da cultura japonesa). A técnica requer uma dedicação de longo prazo, especialmente da alta gerência. E, por fim, é uma técnica relativamente estática: Akao (1991) recomenda que o ciclo de planejamento seja de cinco anos, para o alcance dos objetivos estratégicos. Nesta mesma linha de raciocínio, apesar de destacar o fácil entendimento da técnica, Lopes (2010) destaca a dificuldade de se possuir a disciplina necessária para sua implementação e execução na totalidade. É necessário evitar pular etapas, ter disciplina no controle e monitorar o processo de perto, para que a implementação e o desdobramento das metas não caiam em descrédito.

\section{c)}

\section{O uso de Objetivos essencialmente Financeiros}

A área financeira da empresa é tida como parte prioritária da empresa, e frequentemente é vista como ponto de principais preocupações, no que concerne à gestão, justamente por estar mais próxima de objetivos primordiais da empresa como lucro, resultado, valor para o acionista, dentre outros. Gitman (1997) destaca que, para uma gestão financeira eficiente, uma empresa necessita gerenciar quatro categorias de indicadores, liquidez, ativo, endividamento e lucratividade. Apesar de existir uma série de ferramentas que sugerem a gestão organizacional por meio do acompanhamento de diversas áreas da empresa, não é raro encontrar empresas que baseiam sua gestão pelo acompanhamento de medidas essencialmente financeiras. Para Luecke (2009) a força ou fraqueza da estratégia é refletida nas declarações financeiras da empresa.

De acordo com Silva (2009), os gestores buscam uma análise mais abrangente em termos da situação econômico-financeira da empresa, além da análise de sua rentabilidade. Já os credores buscam evidências de solvência, de liquidez, da capacidade financeira da empresa e de garantias de que as dívidas serão pagas. Os investidores, por sua vez, procuram avaliar a empresa em seu potencial de lucro futuro, geração de caixa e lucro imediato, e capacidade de liquidação de juros e títulos, sem contar, funcionários, governo, fornecedores, órgãos setoriais 
que possuem outros interesses, e possivelmente outras demandas para obter uma visão da situação financeira da empresa e das suas possibilidades para o futuro.

Dentre as técnicas de análise financeira, destaca-se a análise por meio de índices ou indicadores (MATARAZZO, 2003). Este autor afirma que a avaliação por meio de indicadores de desempenho é adequada para análises históricas e também para análises comparativas entre organizações. Assim, como existem índices que são interessantes apenas em determinadas análises e para determinados usuários, sejam esses investidores, fornecedores, clientes ou governo (dentre outros), a quantidade de índices a ser utilizada na análise da organização dependerá dos objetivos e da profundidade da análise desejada pelo usuário (MATARAZZO, 2003). Para Morante (2007), há certa liberdade de criação de índices, já que, de posse das informações, é possível estabelecer quantas relações considerarmos valiosas.

Para Gitman (1997), as demonstrações contábeis e financeiras constituem uma importante fonte de informação para os acionistas, credores e administradores que necessitam normalmente dispor de medidas relativas da eficiência operacional e situação econômica e financeira da organização. Sobre estas medidas relativas, existem várias abordagens dentro da literatura. Matarazzo (2003) denomina os indicadores de índices, como a relação entre contas das demonstrações financeiras, com o objetivo de evidenciar aspectos da situação econômica e financeira de uma empresa. Nesse sentido, Gitman (1997) salienta que as utilizações de índices envolvem métodos de cálculos e interpretação para avaliar o desempenho financeiro da organização. É ponto crucial para compreender uma empresa, uma via rápida para monitorar as condições de uma empresa, apesar de permitirem um exame apenas superficial.

De acordo com Gitman (1997), os insumos básicos para a análise baseada em índices são a demonstração do resultado e o balanço patrimonial da empresa, referentes aos períodos examinados. Para Morante (2007), a quantidade de índices está condicionada ao objetivo das análises e podem ser agrupados de diversas maneiras, conforme apurado em sua pesquisa. Gitman (1997) afirma que na análise de índices não vale apenas, a aplicação de fórmulas: o mais importante é a interpretação do valor do índice. Para conseguir interpretar um índice, este autor sugere dois tipos de comparação: a análise cross-sectional, ou análise vertical, que é a análise e comparação de índices financeiros de diferentes empresas, em um mesmo instante (comparação com a principal empresa do setor ou com as médias da indústria), e a 
análise de série temporal, que avalia o desempenho financeiro da empresa ao longo do tempo, por meio dos índices. Pela análise da série temporal, é possível analisar a formação de tendências, e avaliar se a empresa está progredindo de acordo com o planejado, além de ser possível analisar se as demonstrações financeiras projetadas são razoáveis. De acordo com Gitmann (1997), a abordagem mais afirmativa é aquela que combina as análises crosssectional e de séries temporais. A visão combinada pode avaliar a tendência no comportamento do índice em relação à tendência da indústria.

Gitmann (1997) destaca algumas recomendações e precauções, em relação ao uso de índices:

- Deve-se usar um grupo de índices para fornecer uma visão global do desempenho de uma empresa; um único índice geralmente não oferece informações suficientes, a não ser que seja para examinar aspectos específicos.

- As demonstrações financeiras devem ser comparadas com mesma data ou mês de encerramento: medida para evitar que o efeito de sazonalidade leve a conclusões ou decisões errôneas.

- Melhor usar demonstrações financeiras auditadas, para fins de análise. Se não forem auditadas não há razão para crer que os dados ali contidos estão mostrando a real situação financeira da empresa.

- Os dados a serem comparados devem ter sido elaborados com os mesmos critérios. O uso de tratamentos diferentes para apurar o índice pode distorcer os resultados da análise.

- Deve-se tomar cuidado ao comparar empresas mais antigas com mais novas, ou fazer comparações da própria empresa em um longo período de tempo, por conta de eventuais distorções causadas pela inflação, que pode fazer com que os valores contábeis sejam muito diferentes dos valores verdadeiros.

Para Gitman (1997), os índices financeiros podem ser divididos em quatro categorias, conforme a Figura 18: índices de liquidez, índices de atividade, índices de endividamento e índices de lucratividade. Os índices de liquidez, atividade e de endividamento medem, fundamentalmente, risco, enquanto que os de lucratividade medem retorno. Para prazos curtos, os mais importantes são liquidez, atividade e lucratividade. Para Gitman (1997), os índices de endividamento são importantes, quando se tem a certeza de que a empresa será bem sucedida no curto prazo. 


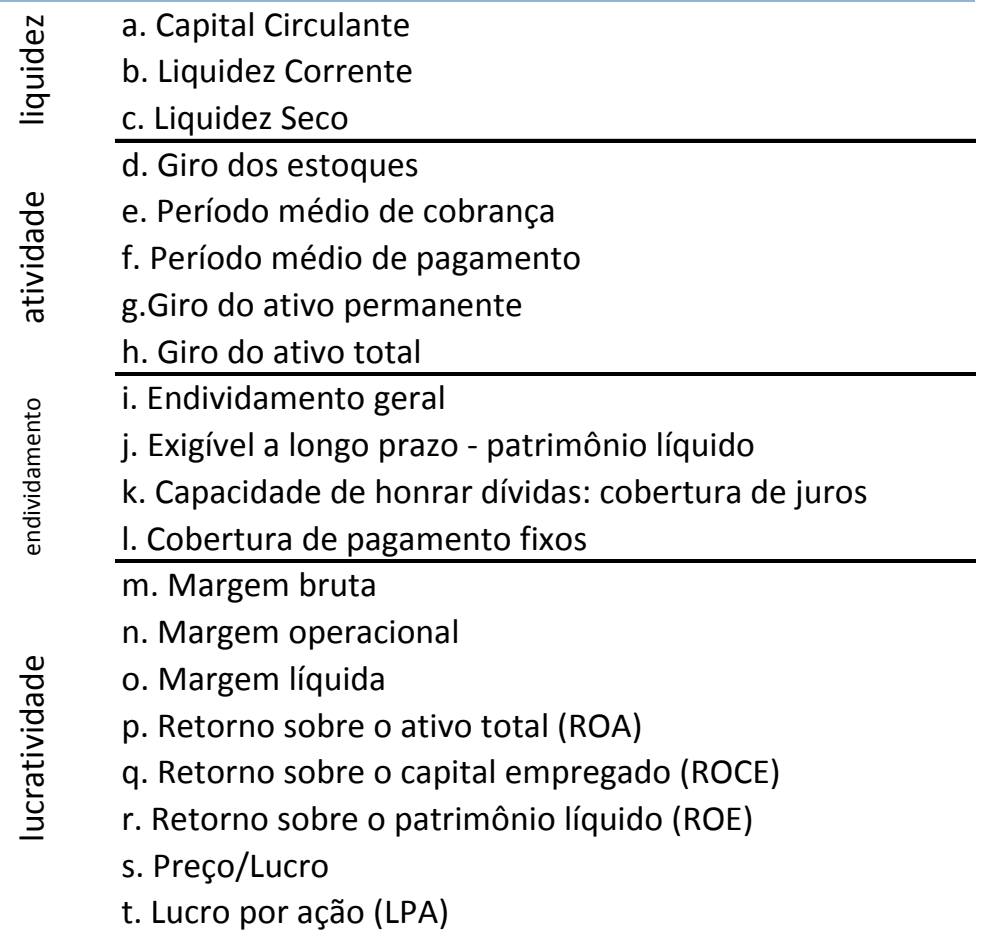

Figura 18 - Indicadores financeiros FONTE: Gitman (1997).

A liquidez de uma empresa é medida por sua capacidade de satisfazer suas obrigações de curto prazo na data do vencimento. As três medidas básicas de liquidez são: capital circulante líquido, índice de liquidez corrente e índice de liquidez seco. Para Matarazzo (2003), os índices de liquidez não são índices extraídos do fluxo de caixa que comparam as entradas com as saídas de dinheiro. São índices, que, a partir do confronto dos ativos circulantes com as dívidas, procuram medir quão sólida é a base financeira da empresa. Uma empresa com bons índices de liquidez tem condições de ter boa capacidade de pagar suas dívidas, mas não estará, obrigatoriamente, pagando suas dívidas em dia, em função de outras variáveis, como prazo, renovação de dívidas etc.

A liquidez corrente mede a capacidade da sociedade em saldar suas obrigações de curto prazo e a liquidez seca é semelhante à liquidez corrente, com a exclusão dos estoques. Gitman (1997) tem o mesmo entendimento ao relatar que o índice de liquidez seca fornece uma medida melhor da liquidez, quando o estoque de uma sociedade não pode ser facilmente convertido em dinheiro. Se o estoque for líquido, o índice de liquidez corrente será uma medida preferível de liquidez. 
Para Morante (2007) os índices de atividade medem o que existe de mais operacional na empresa: sua atividade propriamente dita. Os índices de atividade podem ser usados para medir a rapidez em que as contas circulantes, estoques, duplicatas a receber e duplicatas a pagar são convertidas em caixa ou em venda. De acordo com Gitman (1997), as medidas de liquidez global são insuficientes para medir a liquidez das contas circulantes específicas. Os índices existentes para medir as contas circulantes mais importantes estão relacionados a estoques, duplicatas a receber e duplicatas a pagar. Alguns índices relacionados a esta categoria são: giro dos estoques, período médio de cobrança, período médio de pagamento, giro do ativo permanente e giro do ativo total.

A situação de endividamento de uma empresa pode ser gerida por meio de seu grau de endividamento ou de sua capacidade de pagar as dívidas. De acordo com Gitman (1997), a situação de endividamento de uma empresa indica o montante de recursos de terceiros que está sendo usado na tentativa de gerar lucros. Quanto maior sua alavancagem, isto é, seu endividamento a custos fixos, tanto maior serão o seu risco e retorno potenciais. O grau de endividamento mede o montante da dívida, em relação a outras grandezas significativas do balanço patrimonial; as mais usadas: índices de endividamento e índice exigível-patrimônio líquido. Já, a capacidade de honrar dívidas refere-se à capacidade da empresa para efetuar os pagamentos contratuais requeridos, ao longo da vida da dívida.

A lucratividade da empresa pode ser avaliada em relação a suas vendas, ativos, patrimônio líquido e ao valor da ação. Para Gitman (1997), sem lucros uma empresa não atrairá capital de terceiros e seus atuais investidores e credores poderão ficar preocupados com o futuro da empresa. $\mathrm{O}$ autor recomenda o sistema Dupont, que relaciona a margem líquida e o giro do ativo total à taxa de retorno sobre o ativo total (ROA), ou a análise geral de vários índices. Já, para Morante (2007), estes índices possuem a responsabilidade de mostrar o retorno para os “donos do negócio". Os índices mais usados são margem bruta, margem operacional, margem líquida, taxa de retorno sobe o ativo total (ROA), taxa de retorno sobre o patrimônio liquido (ROE), lucro por ação e índice preço / lucro.

Gitman (1997) enfatiza que uma análise completa dos índices inclui um grande número de indicadores de liquidez, aditividade, endividamento e lucratividade. Para Luecke (2009) o desempenho da estratégia pode ser verificado especialmente pelo balanço e a demonstração 
do resultado do exercício (DRE). Apesar de ressaltar que a gestão por essas informações pode ser incompleta, na visão de Luecke (2009), um gestor pode ter insights analisando os principais índices retirados do balancete e da declaração de rendimentos, pois estes ajudam a formar uma história sobre a organização, suas condições atuais e seu possível futuro.

\section{d) Processo Intuitivo / Criativo desenvolvido a partir da alta direção}

Oliveira e Souza Neto (2008) destacam que após um grande período usando apenas técnicas quantitativas na tomada de decisão as empresas perceberam que estes métodos racionais não conseguiam lidar com decisões não programadas. A intuição se torna elemento chave para a criação de uma visão estratégica para orientar a natureza de um negócio e seu futuro. De acordo com Quinn (2006), embora a criação de uma estratégia geralmente siga um processo, alguns estágios normalmente não são ordenados ou distintos. De acordo com esses autores, esses estágios geralmente estão integrados na mente dos principais executivos. De acordo com Gaj (1987) o sucesso de empresários (empreendedores) muitas vezes é obtido por um processo não-formal baseado em percepções e premissas oportunas. Por isso, na opinião de Gaj (1987) não se deve desconsiderar o Processo Intuitivo. Andrews (2006), por sua vez, reforça que a determinação de uma estratégia exige a consideração de um presidente de empresa e que valores pessoais, aspirações ideais podem (ou devem) influenciar a escolha final de objetivos.

Para Mintzberg (2004), os gestores, em muitas situações, devem ver o "quadro geral” e criar "visões" estratégicas a partir de informações intangíveis, especulativas. E muitas dessas informações são de fontes orais, e isto as torna inacessíveis, em um segundo momento. Daí, a necessidade de processá-las no subconsciente, e de acordo com Mintzberg, provavelmente de maneira intuitiva. Na verdade, de acordo com ele, toda a natureza da formação de estratégia força os gestores a preferir a intuição devido às características do processo estratégico, sua dinâmica, irregularidade, descontinuidade, ênfase na síntese etc.

De acordo com Lobato et al. (2006), o pensamento estratégico postula um comportamento de gestão empresarial mais criativo. Eles destacam a necessidade de os estrategistas serem criativos, especialmente em ambientes de alta descontinuidade. Para os autores, deve-se buscar a adesão intelectual e emocional de todos os seus colaboradores, por meio de um ambiente propício à criatividade. 
A partir de todas essas definições, chega-se a uma técnica que também organiza objetivos estratégicos a partir da experiência, da visão do indivíduo, que pode tomar decisões criativas, mas que, sempre, advêm de um processo mais intuitivo.

Pontes (2009) abordou o estudo conduzido por Weston Agor, que revelou que a intuição ocupa um papel importante no planejamento, na tomada de decisão e na resolução de problemas. Pontes destacou que, quanto maior o nível hierárquico do executivo, mais eles consideravam dispor de capacidades intuitivas e de utilizá-las. Isso deve ocorrer devido à experiência já adquirida pelo executivo, e especialmente, pelo fato do executivo não precisar justificar suas decisões, como os que ocupam cargos de menor nível hierárquico.

Pontes (2009), em sua pesquisa, revelou que os administradores mais velhos (grupos de idade acima de 59 anos) mostraram-se mais intuitivos do que os mais jovens (grupo de idade abaixo de 35 anos). Os executivos pesquisados também apontaram, no quesito percepção da relevância da intuição, que áreas como estratégia e planejamento empresarial, marketing, e pesquisa e desenvolvimento são as principais áreas de aplicação da intuição, no campo de atividades empresariais.

Mintzberg et al. (2006), analisando organizações empreendedoras, destacam que a tomada de decisão é flexível, assim como a comunicação. Os controles formais são desencorajados como uma ameaça à flexibilidade do presidente ou do proprietário. Por certo, podemos considerar essas empresas flexíveis, pois, apesar de o sistema de poder ser altamente centralizado, permite uma resposta rápida. De acordo com Mintzberg et al. (2006), para organizações com essas características, a estratégia é, evidentemente, responsabilidade do presidente, e o processo é altamente intuitivo, e sempre orientado para a busca agressiva de oportunidades. Para eles, não é surpresa que a estratégia resultante tende a refletir a visão implícita de mundo do presidente.

Segundo Quinn (2006), os executivos envolvidos com a criação de uma estratégia tentam focar em poucos (entre seis e dez) "temas centrais", ou seja, nas ações da empresa, de modo a facilitar a discussão e o monitoramento. Dessa maneira, evitam-se modelos excessivamente formais, que tendem a ficar presos em burocracia rígida. Ele incentivam a aplicação do chamado "incrementalismo lógico", como forma de trabalho para reduzir o nível de incerteza nas organizações, e trabalhar melhor com as informações disponíveis no mercado. Desta 
forma, as mudanças estratégicas são testadas aos poucos, de maneira incremental, com o acompanhamento de perto dos executivos, que analisam a implementação da mudança e ajustam a direção da organização, passo a passo.

Albuquerque (2004) destaca que o método Intuitivo é característico de pequenas empresas e lista razões, como a incerteza para monitorar o ambiente externo, que afeta o comportamento estratégico de uma pequena empresa, fazendo com que o dirigente centralize suas decisões. Para ele, isso define a decisão centralizada, quando os dados necessários nem sempre estão disponíveis, o que faz o proprietário decidir sua estratégia de acordo com a sua experiência e intuição.

De acordo com Albuquerque (2004), outra característica da pequena empresa é a informalidade: a estratégia é intuitiva e a proximidade com os funcionários faz com que as decisões de mudanças estratégicas sejam comunicadas até verbalmente, quando o são.

Como alerta ao Processo Intuitivo, centrado no proprietário (ou em poucas pessoas), temos os resultados da pesquisa de Barbero (2008) em que as empresas que centralizam as decisões nos principais executivos não foram as que mais cresceram, em termos de faturamento, no período de três anos analisados. Por isso, o autor recomenda a descentralização da tomada de decisão.

Em uma análise e proposição de estereótipos de executivos de Pitcher (2006), o tipo em que se encaixa a técnica Intuitiva é o artista. De acordo com a autora, esse executivo é descrito, por seus pares e colegas, como algum corajoso, fascinante, intuitivo, empreendedor, inspirador e imprevisível, dentre outros atributos. Também, pode ser visto como volátil, imaginativo, ou, até, "lunático". Geralmente, suas apresentações são um pouco soltas, com poucos detalhes (que possivelmente estão em sua cabeça). Sua tarefa é vender um sonho ou criar uma visão para a organização, que, depois, encarregar-se-á de implementá-la. A organização, como um todo, liderada por um artista é descrita como um local empolgante para estar, mas, que, ao mesmo tempo, pode ser confusa ou atordoante para aqueles que precisam de mais detalhes para sentirem-se confortáveis.

As alternativas ao executivo artista seriam o tecnocrata, alguém caracterizado como sério, analítico, objetivo, metódico, etc, e o artesão, descrito como um executivo ligado à tradição 
da empresa, que possui grande experiência adquirida por um longo tempo na organização, alguém que está familiarizado com o passado da organização e quer contribuir para preservar sua identidade em meio às mudanças.

Para Pitcher (2006), esses três tipos não conseguem comunicar-se entre si, vivem em mundos diferentes com valores e metas diferentes. Embora a autora ressalte que esses três tipos não existem como tal, pois são arquétipos, e pessoas são mais complexas que isso, podemos, para o nosso estudo, entender que para este tipo de técnica intuitiva, é conduzida por um líder que possui a maior parte de um perfil de artista.

e)

Processo Participativo por meio da discussão em grupos de baixo pra cima (bottom-up)

Apesar de existir uma série de ferramentas que sugerem a gestão organizacional por meio estruturado e top-down, Hamel (2006) alerta para um possível problema de uma estratégia hierarquizada: ela pode minar a competitividade ao promover uma visão elitista da gestão, pois os funcionários podem não conseguir visualizar as metas corporativas.

Um aspecto a ser trazido para essa discussão é o caráter "popular" e participativo de uma estratégia emergente, conforme apresentado por Mintzberg et al. (2006). Essa estratégia tem por característica surgir da apreciação de qualquer nível hierárquico/funcional e ser levada aos superiores ou identificada. Mintzberg et al. (2006) alerta que, às vezes, é necessário deixar padrões emergirem de qualquer lugar ou pessoa. Os autores afirmam que um conjunto de ações pode levar a um novo tema estratégico, por meio de um ajuste mútuo de várias pessoas. E este ajuste pode ser gradual, ou, até mesmo, espontâneo.

Mintzberg et al. (2006) destacam que essas estratégias tornarnam-se organizacionais, quando passam a ser coletivas: o novo padrão prolifera e permeia a organização como um todo. $\mathrm{O}$ processo inicial não precisa ser conscientemente desejado pelos líderes; às vezes, as ideias iniciais encontram sozinhas seus caminhos, espalhando-se pela ação coletiva. Quando a estratégia é reconhecida como valiosa, os processos pelas quais ela se prolifera podem ser administrados. Mintzberg (2004) destaca que administrar esses processos não significa préconceber estratégias, mas, reconhecer o surgimento delas, e intervir, quando apropriado.

Para Mintzberg et al. (2006), este modelo é “popular”, pois as estratégias desenvolvem-se a 
partir da base da organização, crescendo e espalhando-se pela ação coletiva. Por fim, Mintzberg ressalta que nenhuma organização pode funcionar apenas com estratégias emergentes, pois significaria a abdicação da vontade, da liderança e do raciocínio consciente. Por outro lado, Mintzberg ressalta que a empresa também não pode funcionar apenas com estratégias que sejam sempre deliberadas, pois isto pode significar uma indisposição para aprender e falta de flexibilidade a qualquer coisa inesperada. Desta forma, poucas estratégicas são puramente emergentes, do mesmo jeito que poucas estratégias são totalmente deliberadas.

Hamel (2006) cita algumas razões e ações para tornar a estratégia mais participativa. Ouvir novas vozes (tirar a monopolização da estratégia apenas nas mãos da alta gerência) é importante para iluminar as novas estratégias. Especificamente, para Hamel (2006), pessoas jovens, recém-chegadas, as que atuam na periferia geográfica da organização, devem ter voz maior. De acordo com Hamel (2006), a criação da estratégia deve ser um processo pluralista, profundamente participativo. Criar diálogo que atravesse as fronteiras usuais da organização aumenta as probabilidades de que surjam ideias para a nova estratégia. Frequentemente, as conversas, nas organizações, tornam-se intrínsecas. Depois de um tempo, com as mesmas pessoas conversando entre si sobre os mesmos assuntos, oferecem pouco para que aprendam umas com as outras.

De acordo com Hamel (2006), há três aspectos participativos que ajudam em uma estratégia:: envolver as pessoas na mudança - as pessoas aceitam, animadamente, a mudança, quando têm uma parcela de voz na invenção do futuro da organização; criar novas perspectivas, com os profissionais buscando novas lentes para redefinirem a si mesmas, seus clientes, concorrentes e oportunidades; elaborar novos experimentos, lançando pequenos experimentos sem risco no mercado ajuda a entender, na prática, como novas estratégias podem funcionar, aumentando o aprendizado da empresa.

De maneira mais específica, Bower (1970 apud BARBERO, 2008) sugere uma forma participativa, envolvendo a gerência operacional interagindo com a alta direção da organização. Na visão deste autor, deve-se admitir que a gerência operacional participe da definição de estratégias, a partir da visão geral da estratégia definida pela alta direção. Primeiramente, identificam-se projetos estratégicos, originados da identificação da mudança no ambiente competitivo que oferecem novas oportunidades para a empresa; esses projetos são pré-selecionados pela gerência de nível intermediário, para, então, serem submetidos à 
apreciação da alta direção, que pode confirmá-los e endossá-los, se estiverem de acordo com a estratégia corporativa, ou adaptá-los, para acomodá-los na estratégia vigente. A síntese dessa discussão é apresentada na Figura 19.

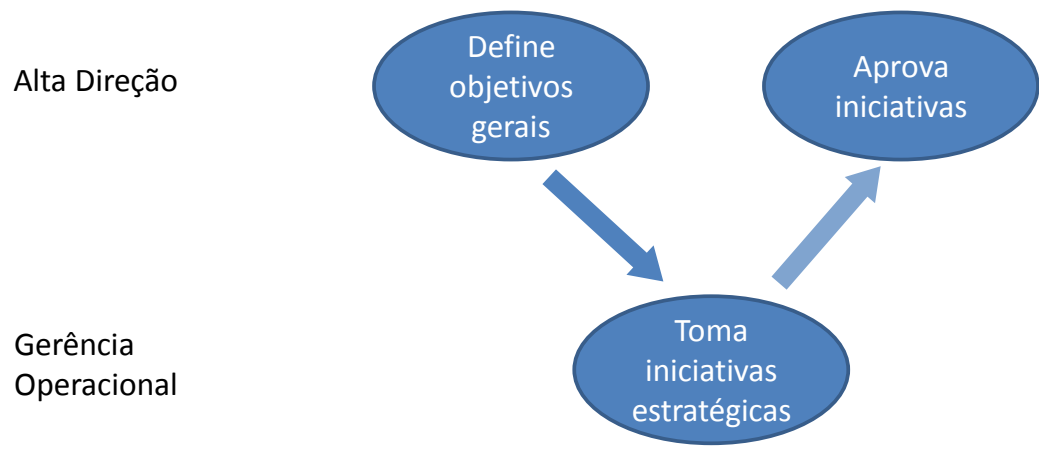

Figura 19 - Esquema da discussão apresentada por Bower FONTE: Bower (1970 apud BARBERO, 2008).

Williams et al. (2013) apresentam um caso estudado com alta participação dos envolvidos na concepção estratégica do conjunto de Bibliotecas da UC San Diego, que tem aproximadamente trezentos funcionários. Foi criado um grupo de trabalho com 22 membros, para o planejamento estratégico. Este grupo contemplou ideias e sugestões dos funcionários, usuários e parceiros. Williams et al. (2013) ressaltam que algumas reuniões foram com mais de cem stakeholders presentes. O grupo de trabalho transformou os inputs recebidos em seis temas estratégicos, que foram validados pela alta administração e se tornaram a base do plano estratégico.

A abordagem Participativa continuou no desenvolvimento de planos de ação alinhados ao plano estratégico. Todos eram avaliados pelos funcionários, que poderiam fazer parte da equipe de implementação. Os benefícios citados por Williams et al. (2013) incluem o engajamento dos funcionários, o alto senso de propriedade do plano estratégico e o desenvolvimento de ideias de ação. Pontos a tomar cuidado também foram destacados: o grande investimento de tempo e o esforço para evitar formalizar demais partes do processo. $\mathrm{O}$ resultado principal foi construir uma equipe integrada, motivada e engajada com o futuro da biblioteca. 


\subsection{Proposição de uma tipologia de organização de objetivos estratégicos corporativos}

O item anterior apresentou as definições de diversos autores sobre técnicas para trabalhar com objetivos estratégicos e como estes podem ser organizados. Pôde-se notar que as diversas visões apresentadas traziam semelhanças e diferenças entre as técnicas, o que nos permite agrupar as diferentes formas de trabalhar-se com objetivos estratégicos em grandes blocos, com ideias equivalentes, conforme a proposta apresentada no Quadro 4.

Quadro 4 - Técnicas que organizam objetivos estratégicos

\begin{tabular}{|c|c|c|c|}
\hline Técnica & Principais autores & Características principais & Como estrutura objetivos \\
\hline Balanced Scorecard & $\begin{array}{l}\text { Kaplan e Norton (1997, } \\
2000,2004 \text { e 2008), Bourne e } \\
\text { Bourne (2011), Niven (2005) e } \\
\text { Papalexandris et al (2005) }\end{array}$ & $\begin{array}{l}\text { Objetivos e indicadores } \\
\text { distribuídos em perspectivas } \\
\text { organizacionais que não enfatizam } \\
\text { somente a parte financeira }\end{array}$ & $\begin{array}{l}\text { Definição do Mapa Estratégico com } \\
\text { relação bem definida de causa-e- } \\
\text { efeito entre objetivos estratégicos e } \\
\text { organizados em perspectivas que } \\
\text { contemplam os elementos mais } \\
\text { críticos da organização }\end{array}$ \\
\hline $\begin{array}{c}\text { Administração por } \\
\text { Objetivos }\end{array}$ & $\begin{array}{l}\text { Drucker (1981), Akao (1991), } \\
\text { Al ogan e Yetis (2006), } \\
\text { Ansoff(1965, 1991), Chatterjee } \\
(2005), \text { Clark (2008) e Lodi } \\
(1977)\end{array}$ & $\begin{array}{l}\text { Definição de poucos objetivos } \\
\text { essenciais, indicadores "smart" e } \\
\text { metas em comum para todos os } \\
\text { níveis da organização }\end{array}$ & $\begin{array}{l}\text { Cascata de objetivos de cima pra } \\
\text { baixo (estratégicos, táticos e } \\
\text { operacionais) como sugestão de } \\
\text { alocação para diferentes áreas da } \\
\text { empresa }\end{array}$ \\
\hline Objetivos Financeiros & $\begin{array}{l}\text { Gitmann (1997), Matarazzo } \\
\text { (2003), Morante (2007) e Silva } \\
(2009)\end{array}$ & $\begin{array}{l}\text { Objetivos e indicadores } \\
\text { financeiros são o ponto central de } \\
\text { atenção da organização }\end{array}$ & $\begin{array}{l}\text { Existe categorização de } \\
\text { objetivos/indicadores (liquidez, } \\
\text { endividamento etc) e definições } \\
\text { claras em como medi-los. Mas não } \\
\text { há preocupação explícita em } \\
\text { estruturar objetivos }\end{array}$ \\
\hline Participativa & $\begin{array}{l}\text { Mintzberg et al. (2006), Hamel } \\
(2006) \text {, Bower (1970), Williams } \\
(2013)\end{array}$ & $\begin{array}{l}\text { Lista de objetivos baseada na } \\
\text { discussão entre toda a } \\
\text { organização. }\end{array}$ & $\begin{array}{l}\text { Objetivos definidos em conjunto. Há } \\
\text { pouca formalidade para apresentar } \\
\text { e discutir objetivos no processo } \\
\text { estratégico }\end{array}$ \\
\hline Intutiva/Criativa & $\begin{array}{l}\text { Al buquerque (2004), Andrews } \\
\text { (2006), Mintzberg (2004, } \\
\text { 2006), Quinn e Vayer (2006), } \\
\text { Pontes (2009) }\end{array}$ & $\begin{array}{l}\text { Lista de objetivos baseada nas } \\
\text { prioridades definidas pelo } \\
\text { proprietário e/ou diretoria da } \\
\text { organização }\end{array}$ & $\begin{array}{l}\text { Objetivos são definidos por poucas } \\
\text { pessoas sem formalidade ou } \\
\text { organização explícita. Usualmente } \\
\text { não há preocupação em divulgar } \\
\text { formalmente para o restante da } \\
\text { organização }\end{array}$ \\
\hline
\end{tabular}

No primeiro bloco estão os conceitos relacionados ao Balanced Scorecard e ao mapa estratégico. Os autores trabalham como uma lista numerosa de objetivos, que está dividida em perspectivas organizacionais e que contribuem para a realização dos objetivos principais de crescimento e/ou rentabilidade. A definição das perspectivas (geralmente quatro), que representam as atividades críticas e as áreas da empresa, juntamente com a relação de causa e 
efeito entre os objetivos, apresenta uma estrutura mais detalhada e com mais informações a respeito do plano estratégico definido, em relação ao nível de detalhamento das demais perspectivas estudadas.

O segundo grande bloco diz respeito aos conceitos relacionados às definições da Administração por Objetivos. Estes conceitos sustentam que a organização deve ter poucos objetivos, para facilitar o foco e o gerenciamento da empresa, que atendem aos requisitos do SMART, ou seja, devem ser específicos, mensuráveis, alcançáveis, realistas e definidos no tempo. Estes objetivos também devem atender a uma cascata que define sua hierarquia entre estratégicos, táticos e operacionais, e assim, atender a todas as áreas da organização.

A terceira opção da lista está relacionada aos Objetivos essencialmente Financeiros que uma organização pode optar por gerenciar. Essa opção pode ser feita em empresas voltadas à gestão financeira, deixando o acompanhamento de outras áreas com a respectiva gerência, sem maiores preocupações com uma gestão sistêmica da organização e com relação entre áreas. Nesse caso, o foco da organização está voltado para a liquidez da empresa, seu endividamento e sua lucratividade.

O quarto bloco diz respeito a técnicas Participativas, que se caracterizam pela inclusão dos colaboradores no processo estratégico. A característica principal desta técnica pressupõe que, com a participação do funcionário, a disseminação da estratégia e sua consequente implementação seja facilitada e alcançada com maior êxito.

A técnica Intuitiva / Criativa diz respeito ao que pode ocorrer em empresas com a gestão mais centralizada na figura do proprietário. Este gerencia a empresa e delega a gestão operacional dos departamentos, mas, geralmente, não compartilha a visão de futuro nem os objetivos estratégicos que a empresa deve alcançar como meta. Geralmente, as metas e objetivos ficam na cabeça dos donos, ou quando são compartilhadas, isso é feito, informalmente, com outros gestores. A visão não é compartilhada para os demais funcionários, mesmo porque não está formalizada em nenhum documento que possa ser divulgado, da mesma forma que os objetivos estratégicos mais implícitos também não estão registrados, segundo a orientação de algum conceito ou técnica.

A análise dessas cinco técnicas, base para esta tese, nos permite propor uma tipologia 
organizada em dois eixos que é apresentada a seguir e ilustrada na Figura 20. No eixo horizontal as técnicas estão alinhadas de acordo com o nível de participação na definição dos objetivos estratégicos: em um extremo, se o processo inclui diversos níveis organizacionais, ou seja, é mais participativo. No outro extremo do eixo, se a técnica é mais impositiva pela alta-direção da organização, ou seja, top-down.

No eixo vertical as técnicas estão posicionadas de acordo com sua formalização para organizar objetivos estratégicos, o que inclui a capacidade da técnica em possibilitar uma estruturação formal entre os objetivos estratégicos a serem organizados. No extremo superior, estão as técnicas mais estruturadas, aquelas que possuem mais ferramental para organizar os objetivos estratégicos, enquanto que, no extremo inferior, estão as técnicas menos estruturadas, ou seja, aquelas que possuem técnicas de organizar objetivos, mas, de maneiras menos formais.

A Figura 20, a seguir, apresenta-nos as cinco técnicas enquadradas segundo os dois eixos:

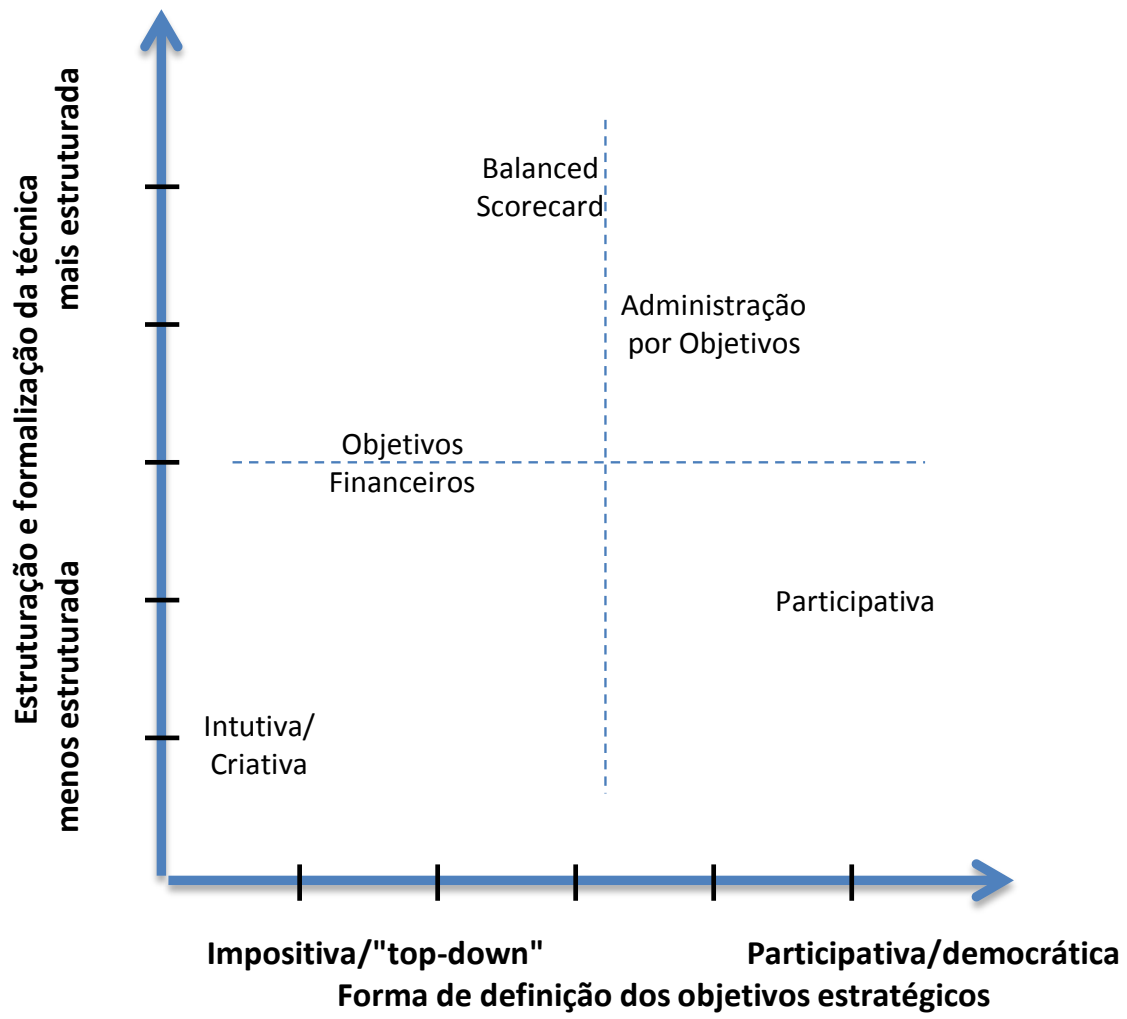

Figura 20 - Tipologia de estruturação de técnicas de organização de objetivos estratégicos

Na combinação "mais estruturada-impositiva", temos o BSC, que, por meio das perspectivas 
e do mapa estratégico, ajuda a criar a relação de causa e efeito dos objetivos, estruturando uma visão da estratégia corporativa em uma página. Além disso, existem referências detalhando a técnica. O BSC é tipicamente uma técnica top-down, já que a diretriz estratégica é vinda de alta direção, e no máximo, é estimulado o desenrolamento dos objetivos corporativos em objetivos pessoais para garantir o alinhamento da empresa com a estratégia.

A técnica APO se coloca na combinação "mais estruturada-participativa", já que em suas referências disponíveis, em sua maioria há mais tempo do que qualquer outra técnica, detalha características como estabelecer objetivos, e em algumas ocasiões, chega a mencionar como ordenar uma hierarquia de objetivos. A APO foi criada para prover maior alinhamento entre colaborador e supervisor para negociar metas e objetivos, em que se pressupõe que haja espaço para discutir estratégia, ao menos, em alguns níveis, além de prover maior alinhamento entre os colaboradores e a estratégia.

$\mathrm{Na}$ técnica dos Objetivos Financeiros, cada objetivo tem muito bem formalizados os seus critérios de cálculo e avaliação, mas a relação entre eles não é discutida. Esta é a razão de posicionar a técnica de Objetivos Financeiros em uma posição intermediária, em termos de estruturação, quase que como uma técnica semiestruturada, se compararmos com o BSC, ou com APO, já que estas técnicas tratam com mais profundidade da definição e organização de seus objetivos, e o impacto na estratégia corporativa. Em termos da participação dos colaboradores da organização, temos que a definição e uso dos objetivos financeiros, geralmente, é decidida de forma centralizada pelos especialistas da área.

A técnica Intuitiva / Criativa está no quadrante "menos estruturada-impositiva". Essa técnica se caracteriza por centralizar a decisão estratégica em poucas pessoas, muitas vezes, apenas no proprietário da empresa, que pode até ter uma visão lógica da estratégia em sua cabeça. Mas, não há formalização para levar adiante e compartilhar a estratégia para o restante da empresa. Esta técnica, dadas as características mencionadas anteriormente, é mais impositiva, fortemente top-down.

Na combinação "menos estruturada-participativa" temos a técnica Participativa, que é pouco estruturada perto das demais, porém, consideramos que seja uma técnica mais estruturada que a Intuitiva, pois deve apresentar um mínimo de ordem, para que os objetivos sejam apresentados e discutidos pelos participantes do processo estratégico. Essa técnica pressupõe 
um envolvimento maior de toda a organização para a definição e organização dos objetivos estratégicos, o que aumenta o alinhamento estratégico, por consequência.

Os itens estudados neste referencial teórico nos leva a reinterpretar o tema, atualizando a Figura 1 apresentada no início desta tese para a Figura 21, exibindo o importante papel dos objetivos estratégicos na ligação entre planejamento e implementação da estratégia.

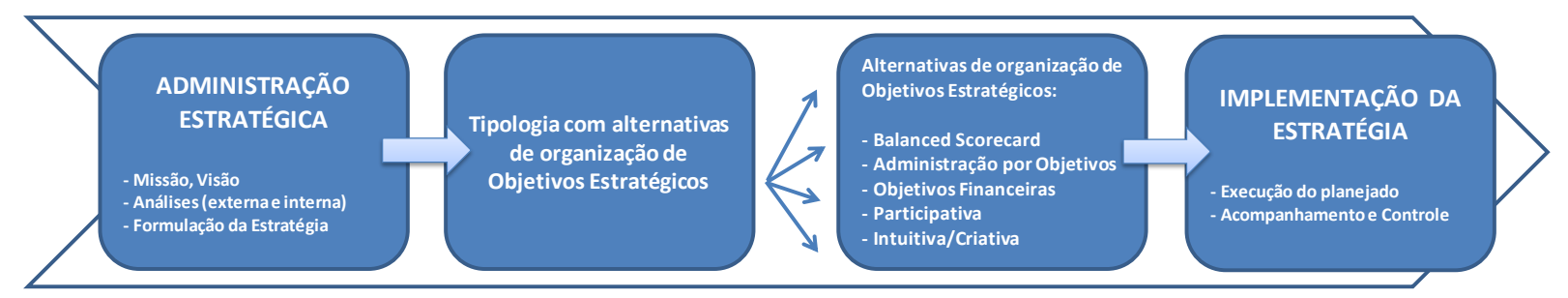

Figura 21 - O papel da definição de objetivos estratégicos, do planejamento à implementação

\subsection{Modelo teórico desta tese}

Após a apresentação dos objetivos desta pesquisa, no capítulo 1, e da discussão do referencial teórico, neste capítulo, propomos o seguinte modelo teórico da tese conforme a Figura 22: 


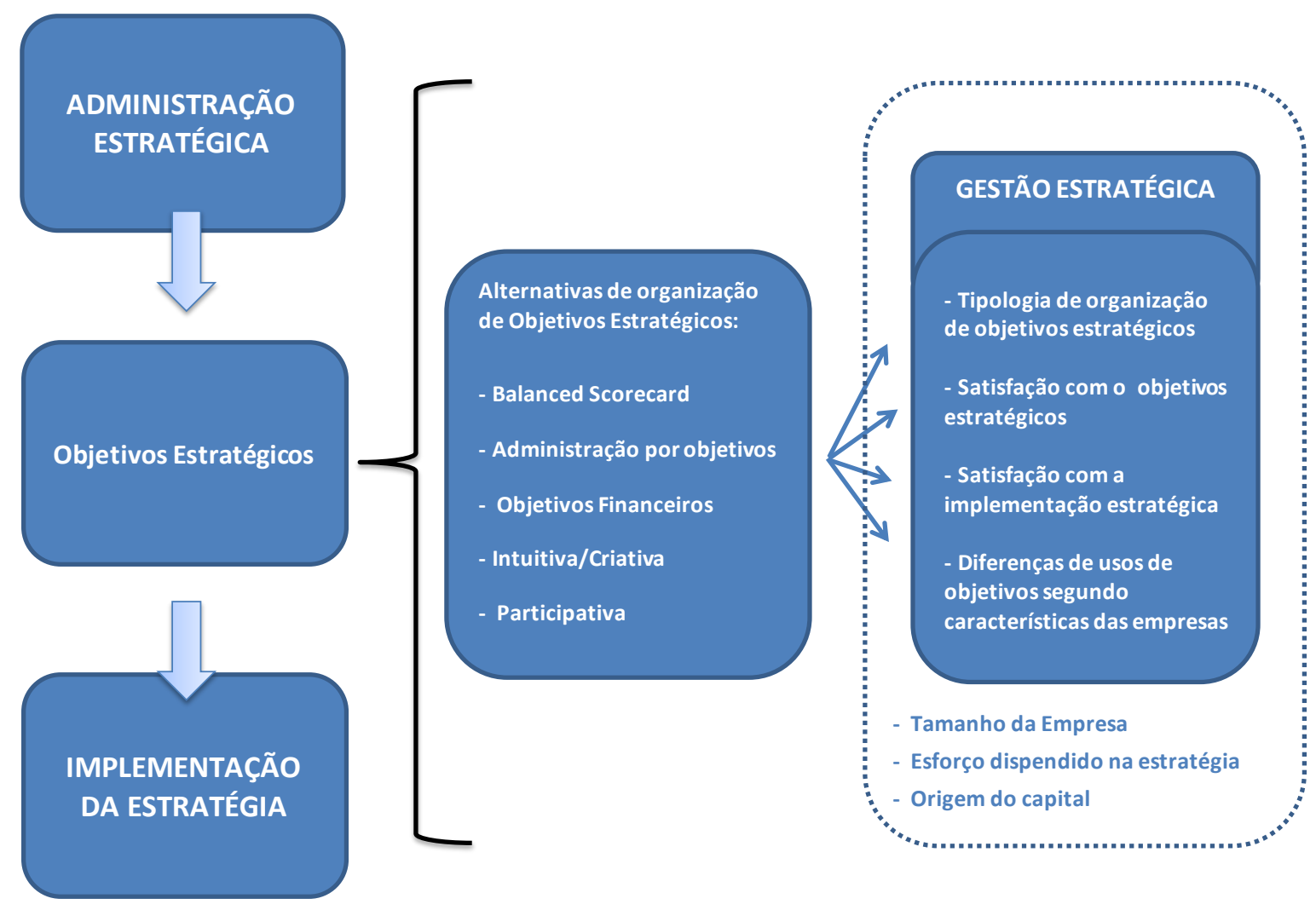

Figura 22 - Modelo teórico da pesquisa

Esta pesquisa está estruturada de maneira a investigar as alternativas de organização de objetivos estratégicos. Consideramos esta etapa como a ligação entre a formulação e a implementação da estratégia. Serão analisadas a satisfação com a implementação, com os objetivos estratégicos, e investigadas as diferenças de usos de objetivos estratégicos de acordo diferentes características de empresas.

O plano de pesquisa, apresentado na Figura 23, é direcionado à área de administração estratégica, que contempla uma pesquisa bibliográfica relacionada ao tema e uma pesquisa de campo realizada por meio de um levantamento de dados. A análise dos resultados fornecidos ajudará a pesquisa a alcançar suas conclusões.
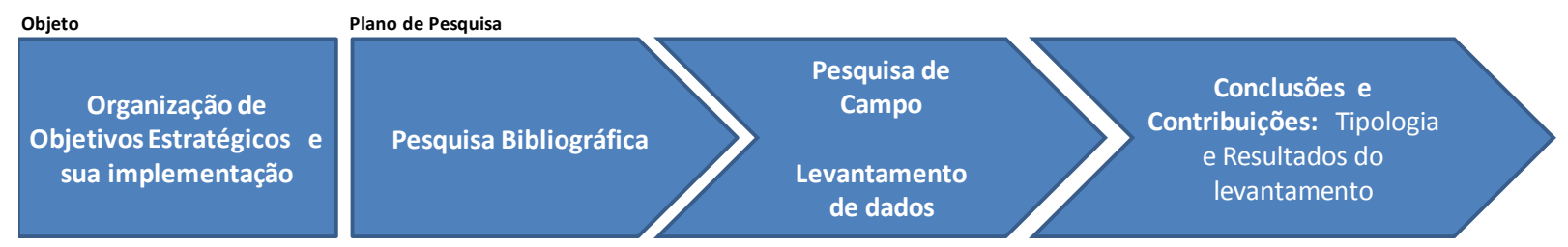

Figura 23 - Plano de pesquisa 
Após a discussão dos conceitos que embasam esta tese, da apresentação do modelo teórico e do plano de pesquisa, a seguir será apresentada a abordagem metodológica da pesquisa de campo. 


\section{ABORDAGEM METODOLÓGICA}

Este item tem o objetivo de delinear a metodologia de pesquisa desta tese. A organização de objetivos estratégicos tem sido pouco discutida no campo da administração estratégica, o que nos faz optar pelo estudo de campo exploratório-descritivo.

\subsection{Caracterização da pesquisa}

No capítulo anterior, foi feita a revisão do referencial teórico dos conceitos que permeiam esta pesquisa e seus objetivos. De acordo com Baker (2001), uma vez definido o que se busca de informação, é possível determinar o método mais apropriado para coletar tais informações. Para Marconi e Lakatos (2010), a seleção do instrumental metodológico está diretamente relacionada ao problema estudado. De acordo com as autoras, os métodos e as metodologias devem adequar-se ao problema a ser estudado e aos tipos de informação com que se entrará em contato.

Gil (2010) afirma que é possível classificar uma pesquisa de diferentes maneiras. Em relação a seus propósitos, as pesquisas podem ser classificadas em exploratórias, descritivas ou explicativas:

- Exploratórias - tem o propósito de obter maior familiaridade com o problema, com vistas a torná-lo mais explícito, ou a construir hipóteses. Em virtude dessa flexibilidade, torna-se difícil "rotular" os estudos exploratórios, mas, segundo Gil (2010), é possível identificar pesquisas bibliográficas, estudos de caso e mesmo levantamentos de campo, que podem ser considerados estudos exploratórios. Para Severino (2007), a pesquisa exploratória busca levantar informações sobre um determinado objeto, delimitando um campo de trabalho, mapeando as condições de manifestação desse objeto.

- Descritivas - tem como objetivo a descrição das características de uma determinada população ou amostra. Podem ser elaboradas, também, com a finalidade de identificar relações entre as variáveis. Entre as pesquisas descritivas, destacam-se aquelas que têm por objetivo estudar as características de um grupo. 
- Explicativa - Identificar fatores que determinam ou contribuem para ocorrência de fenômenos. Busca, também, identificar suas causas (por meio da aplicação do método experimental ou por interpretação dos métodos qualitativos).

A partir do problema e dos objetivos desta tese a pesquisa adotada neste estudo tem um caráter exploratório-descritivo. De acordo com Gil (2010) a pesquisa exploratória tem o objetivo de proporcionar maior familiaridade com o problema para torná-lo mais explícito ou para constituir hipóteses. Segundo Migueles (2005), a pesquisa exploratória é utilizada, quando o pesquisador requer informações ou conhecimentos para elaborar hipóteses pertinentes, ou para desenhar estratégias mais rebuscadas, que permitam alcançar objetivos específicos. De acordo com Gil (2010) as pesquisas descritivas são, juntamente com as exploratórias, o tipo aplicado por pesquisadores preocupados com a atuação prática. Ainda para ele, o planejamento de uma pesquisa exploratória tende a ser bastante flexível, pois interessa considerar os mais variados aspectos relativos ao fato ou fenômeno estudado. Envolve levantamento bibliográfico, consulta a pessoas que tiveram experiência prática com o assunto e análise de exemplos que estimulem a compreensão.

Os objetivos de uma pesquisa exploratória, de acordo com Cooper e Schindler (2003), podem ser alcançados com diversas ferramentas, tanto qualitativas quanto quantitativas, e que são aplicáveis, conforme a ocasião. Já, para Flick (2006), a pesquisa qualitativa oferece uma sensibilidade para o estudo empírico, pois apresenta maior interação de procedimentos de cunho racional e intuitivo, capaz de contribuir para a melhor compreensão dos fenômenos.

Para que se possa avaliar a qualidade dos resultados de uma pesquisa, torna-se necessário saber como os dados foram obtidos, bem como os procedimentos adotados em sua análise e interpretação. Neste ponto, sugere-se classificar a pesquisa segundo o seu delineamento, que leva em consideração o ambiente da pesquisa, a abordagem teórica, e as técnicas de coleta e análise de dados.

Tendo em vista a definição do problema de pesquisa apresentado anteriormente, a primeira etapa da metodologia de trabalho consiste na coleta de dados secundários, por meio de pesquisa bibliográfica; já a pesquisa de campo, para a coleta de dados primários, baseou-se em levantamento por meio de questionário eletrônico, estruturado sob os conceitos de uma pesquisa qualitativa exploratória e de uma amostra intencional. Para Gil (2010), a pesquisa 
bibliográfica é elaborada com base em material já publicado. Praticamente, toda pesquisa acadêmica requer, em algum momento, a realização de trabalho que pode ser caracterizado como pesquisa bibliográfica, uma vez que em teses e dissertações um capítulo é dedicado à revisão bibliográfica, com o propósito de fornecer fundamentação teórica ao trabalho, bem como a identificação do estágio atual do conhecimento referente ao tema. De acordo com Gil (2010), um levantamento é a interrogação direta das pessoas cujo comportamento se deseja conhecer. É a solicitação de informações a um grupo significativo de pessoas acerca do problema de estudo, para obter as conclusões correspondentes aos dados coletados.

\subsection{Definição do universo e amostra de pesquisa}

Para a busca do objetivo desta tese, que é a proposição de uma tipologia de organização de objetivos estratégicos corporativos e a análise de seu uso na implementação estratégica, esperar-se obter diversos setores e portes de empresas com uma abordagem que não delimitasse a população a ser pesquisa por meio desses parâmetros. Por isso, a escolha de uma amostra intencional, relacionada ao público envolvido com a discussão e atuação prática de concepção e implementação de estratégias empresariais, que, em geral, são os profissionais de nível executivo.

Dada a impossibilidade da participação de todos os indivíduos, nessa condição, optou-se por uma amostra não-probabilística, ou, por conveniência. Cooper e Schindler (2003) definem como amostras por conveniência aquelas amostragens não-probabilísticas que são irrestritas. Normalmente, usa-se este tipo de amostragem quando não é viável obter uma amostra probabilística, pois a população total não está disponível. Também, deve-se destacar outra razão da amostragem não-probabilística: em razão da forma de coleta de dados (via Internet), em que os convidados respondem, se quiserem, não há uma seleção prévia aleatória de respondentes. A amostra não-probabilística, entretanto, de acordo com a teoria estatística, permite conclusões, apenas, quanto à amostra obtida, e não em relação à população.

Para Martins e Theóphilo (2009), os métodos de amostragem não-probabilísticos são amostragens em que há uma escolha deliberada dos elementos da amostra. Não é possível generalizar os resultados da amostra para a população, pois não se sabe a probabilidade de seleção do elemento da amostra. 


\subsection{Estratégia de coleta dos dados}

A coleta de dados foi realizada por meio de um questionário eletrônico, elaborado pela plataforma QuestionPro.com. Tão logo o questionário foi redigido, passou-se ao pré-teste. De acordo com Gil (2010), o pré-teste não visa a captar qualquer dos aspectos que constituem os objetivos do levantamento. Ele está centrado na avaliação do instrumento, visando a garantir que meça, exatamente, o que pretende medir.

Gil (2010) ensina que se deve selecionar indivíduos que sejam típicos do universo pesquisado e que aceitem dedicar mais tempo para responder às questões do que os que serão escolhidos para o levantamento. Para Marconi e Lakatos (2010), a análise de dados, após a tabulação do pré-teste, evidenciará possíveis falhas: ambiguidade ou linguagem inacessível, complexidade das questões, tamanho exagerado do questionário etc. Verificadas as falhas, deve-se reformular o questionário, explicitando questões que mereçam modificações, incluindo ou excluindo itens.

No caso do pré-teste deste questionário, foi solicitado a nove contatos do pesquisador a que respondessem a primeira versão do questionário. Todos os convidados do pré-teste possuíam o perfil esperado do respondente da pesquisa: experiência na gestão de empresas e com assuntos estratégicos. Todos os convidados possuem, no mínimo, pós-graduação, experiência profissional estimada de no mínimo quinze anos e passaram por multinacionais ou empresas nacionais ou multinacionais.

Com o feedback de sete desses contatos, no pré-teste, ajustes foram providenciados quanto à redação de algumas questões (para deixar o objetivo de cada questão o mais claro possível), e também, a ordem de algumas questões foram revistas (buscando um encadeamento lógico e trazendo as questões principais à frente), sem, no entanto, interferir na estrutura ou exigir uma reformulação completa do mesmo.

O convite para participar da pesquisa foi realizado, prioritariamente, a partir de uma lista de alunos, ex-alunos e contatos do Programa de Estudos do Futuro da Fundação Instituto de Administração, e adicionalmente, contatos pessoais do pesquisador e contatos do Laboratório 
de Gestão da Tecnologia e Sistemas de Informação da USP. A divulgação do convite foi realizada por meio da Internet, prioritariamente por e-mail, e com reforço via redes sociais, notadamente LinkedIn e Facebook.

O preenchimento do questionário era voluntário, o que caracterizou uma amostra nãoprobabilística. Posteriormente, conforme será descrito no capítulo a seguir, a amostra dos respondentes foi avaliada, e foram selecionados aqueles que tinham o perfil esperado para esta pesquisa - participar do processo estratégico da organização do qual faz parte.

O Quadro 5 apresenta a estrutura de questões que formaram o questionário aplicado. Está disponível, no Apêndice I, o questionário completo aplicado, segundo as premissas definidas neste capítulo.

Quadro 5 - Blocos de questões do levantamento

- Perfil da organização

$\circ \quad$ Origem da empresa

○ Setor

- Faturamento

- Aspectos estratégicos

- Característica fundamental da estratégia

- Responsáveis pela definição da estratégia

- Quantidade de reuniões para definição da estratégia

- Etapas do processo estratégico

- Objetivos estratégicos

○ Técnica utilizada

- Pontos positivos/negativos/aprimoramentos das técnicas

- Divulgação dos objetivos

- Quantidade de objetivos definidos

- Quantidade de objetivos implementados com sucesso

- Satisfação quanto aos resultados alcançados

- Categorias de objetivos utilizados

- Perfil do respondente

- Nível de participação na definição da estratégia

- Departamento funcional

- Nível de decisão

- Formação

- Opcionais

- Nome, empresa, contato para recebimento dos resultados. 


\subsection{Escalas de mensuração e técnicas de tratamento estatístico dos dados}

A escolha das técnicas para a análise de dados relaciona-se aos objetivos a serem atingidos e à natureza dos dados (nível de mensuração das variáveis), além dos requisitos exigidos pela técnica. Dessa forma, segue, a metodologia estatística empregada.

- Análise descritiva

- Análise inferencial

○ Prova do Qui-quadrado

○ Prova não-paramétrica de Kruskal-Wallis; equivalência aos testes paramétricos (teste F, Anova etc.)

- Análise multivariada

○ Análise Fatorial

Para a análise descritiva, foram realizados:

- Tabela de frequência ou gráfico de barras, para variáveis com mensuração nominal ou ordinal

- Estatística de medidas de tendência central e de dispersão, para variáveis quantitativas (discretas ou contínuas): média, mediana, mínimo, máximo, desvio-padrão e coeficiente de variação

A inferência estatística visa a elaborar conclusões acerca de uma população a partir de uma amostra, por meio de testes de hipóteses. Pelos testes de hipótese, é possível comprovar, com certa probabilidade, se os dados amostrais trazem evidências que dão sustentação ou não a uma hipótese formulada sobre a população.

Prova do Qui-quadrado - Para Siegel (1981), essa prova é empregada para comprovar se existe diferença significativa entre o número observado de respostas e o respectivo número esperado, baseado na hipótese de nulidade. Nesta prova, deseja-se rejeitar a hipótese (de nulidade) de que as técnicas para organizar os objetivos estratégicos têm a mesma distribuição de frequência em relação à variável em questão (com mensuração nominal). Ou, de outra forma, pretende-se, com esta prova, comprovar a associação entre Técnica e outra variável, como: origem do capital, setor de atuação, característica fundamental da estratégia etc. 
Prova não-paramétrica de Kruskal-Wallis com comparações múltiplas: de acordo com Siegel (1981), essa prova estatística (ou testes de hipóteses) é útil para decidir se as diferenças encontradas entre as técnicas são apenas devido a variações casuais da amostra, ou se são efetivas. A prova de Kruskal-Wallis rejeita (ou não), neste estudo, a hipótese de nulidade de que as técnicas são iguais com relação à média da variável em questão. A prova exige mensuração no mínimo ordinal da variável em questão (ex: faturamento, número de objetivos, satisfação medida em escala Likert etc.).

Como estatística do teste de Kruskal-Wallis, é fornecida a média de postos. De acordo com a resposta, para toda a amostra, é atribuído um posto de 1 (para o maior valor), até o tamanho da amostra (para o menor valor); para respostas empatadas, atribui-se um posto médio.

As provas estatísticas foram realizadas ao nível de significância de $0,05(\alpha=0,05)$. Nível de significância refere-se a um tipo de erro: probabilidade de rejeitar a hipótese (de nulidade) quando ela é verdadeira. Testes de hipótese fornecem como resultado uma estatística do teste e o nível descritivo, ou valor-p (tradução do inglês, $p$-value). Assim, se o nível descritivo do teste é menor que o nível de significância, isso significa que a probabilidade de rejeitarmos $\mathrm{H}_{0}$, quando é verdadeira é baixa. Ao tomarmos essa decisão, sabemos que o erro que estamos cometendo é, no máximo, igual ao nível de significância estabelecido. Se o nível descritivo é maior ou igual ao nível de significância, então tomamos a decisão de não rejeitar $\mathrm{H}_{0}$.

Para a análise multivariada, optou-se por usar uma Análise Fatorial que, de acordo com Hair (2005), analisa a estrutura das inter-relações entre um grande número de variáveis definindo um conjunto de dimensões latentes comuns, ou seja, em um número menor de fatores. Para este autor, o pesquisador pode primeiro identificar as dimensões em separado e então determinar o grau que cada variável é explicada por cada dimensão. De acordo com Latif (1994) a Análise Fatorial tem quatro grandes etapas para sua elaboração: o cálculo da matriz de correlação das variáveis em estudo para verificar o grau de associação entre elas (com isso verifica-se a adequação da aplicação da ferramenta); extração dos fatores mais significativos que representarão os dados (para saber quão bem o modelo representa os dados); aplicação de rotação nos fatores (para facilitar o entendimento) e; geração de escores fatoriais para utilização em outras análises. 


\subsection{Quadro de integração metodológica}

O Quadro 6 a seguir apresenta a integração metodológica entre os diversos elementos da tese. São apresentados lado-a-lado os objetivos desta tese e os elementos correspondentes ao levantamento realizado na pesquisa de campo e ferramental estatístico utilizado.

Quadro 6 - Integração metodológica entre os elementos da tese

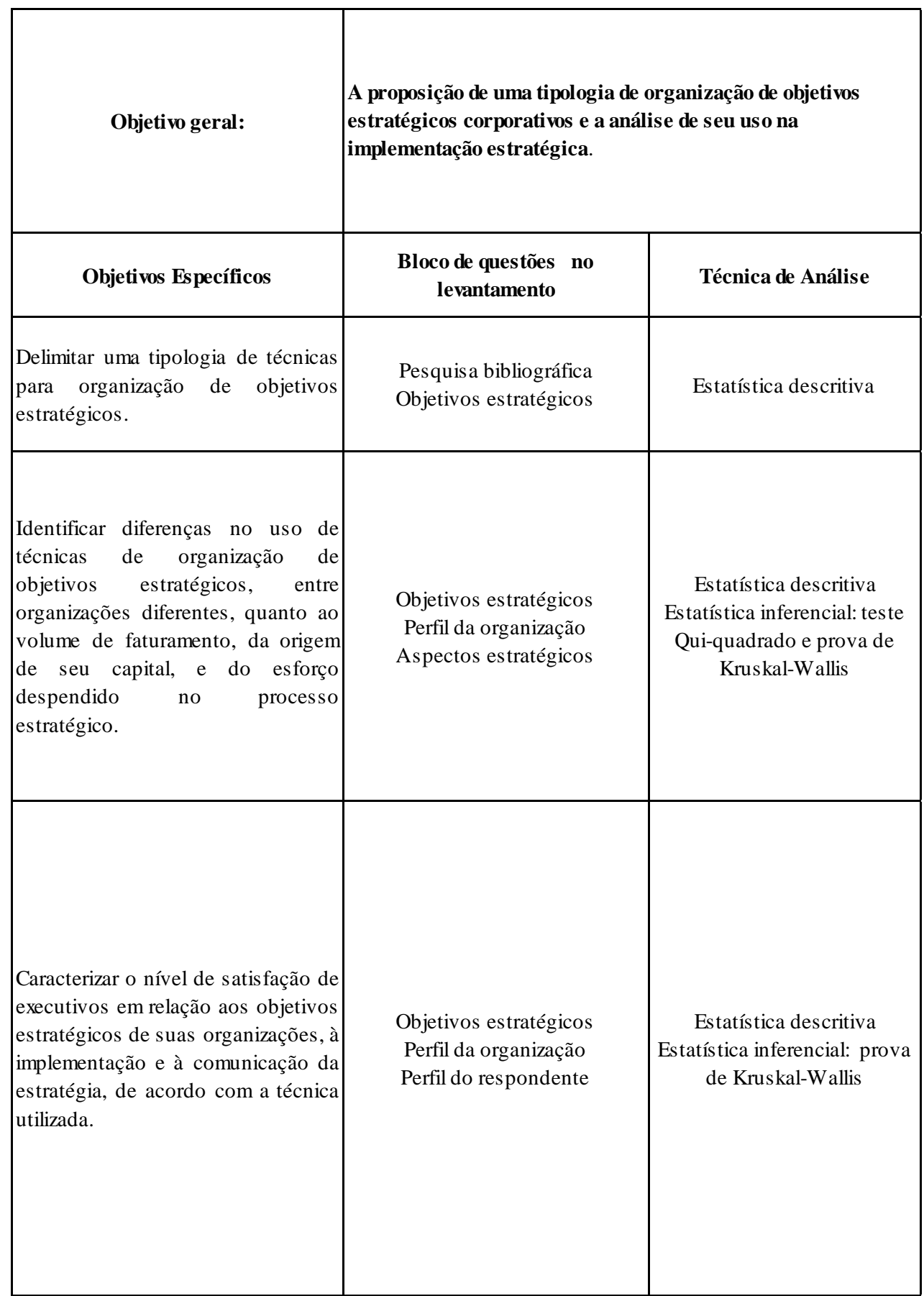




\subsection{Limitações do método de pesquisa}

Não se pode generalizar os resultados desta pesquisa, de forma que se garanta que permanecerão os mesmos para todo o universo de pesquisa, tampouco para qualquer posição hierárquica de uma empresa. Para Cooper e Schindler (2003), a generalização de amostragens não-probabilísticas pode representar problemas em relação à interpretação de resultados de uma pesquisa.

Para Gil (2010), entre as principais limitações dos levantamentos, estão:

a) Ênfase nos aspectos perceptivos: os levantamentos recolhem dados referentes à percepção que as pessoas tem acerca de si mesmas. A percepção é subjetiva, o que pode resultar em dados distorcidos.

b) Pouca profundidade no estudo da estrutura e dos processos sociais: no caso de fenômenos sociais, que são determinados sobretudo por fatores interpessoais e institucionais, os levantamentos mostram-se pouco adequados para investigação profunda desses fenômenos.

c) Limitada apreensão do processo de mudança: o levantamento, oferece, de modo geral visão estática do fenômeno estudado. Oferece uma fotografia de determinado problema, mas, não indica suas tendências à variação e muito menos as possíveis mudanças estruturais.

Para Marconi e Lakatos (2010), também são vistas como limitações aos levantamentos:

- Percentagem pequena dos questionários que voltam

- Grande número de perguntas sem respostas

- Influência de uma questão na resposta de outra

- Devolução tardia prejudica cronograma de pesquisa ou sua utilização

- Exigência de um universo mais homogêneo

Deve-se destacar que, para Marconi e Lakatos (2010), não são adequados para estudos explicativos. São inapropriados para o aprofundamento dos aspectos psicológicos e psicossociais, mas, úteis para o estudo de opiniões e atitudes. 


\section{APRESENTAÇÃO DOS RESULTADOS}

Apresentamos, aqui, os resultados encontrados após a aplicação e análise do questionário de pesquisa. A pesquisa, disponibilizada no site QuestionPro.com, gerou 982 visualizações. Dessas, 322 iniciaram a pesquisa e 320 chegaram até o final do questionário.

Do total de 320 respostas recebidas, procedeu-se duas análises prévias para o aproveitamento da amostra a partir de duas questões apresentadas no questionário. Essas questões serão apresentadas, com mais detalhe, nos próximos itens, mas, neste momento, destaca-se a contribuição dessas questões para selecionar a amostra analisada.

Devido ao tema da pesquisa, foram considerados, para efeitos de análise da amostra, apenas os respondentes que indicaram participar de alguma forma no processo estratégico das empresas em que trabalham. Com isso, as respostas de dezoito participantes que indicaram não possuir acesso à estratégia corporativa e de um que não indicou sua resposta nesta questão foram desprezadas da análise realizada.

O segundo ajuste para viabilizar a análise da amostra foi realizado para considerar apenas aqueles respondentes que indicaram trabalhar com alguma técnica de organização de objetivos estratégicos listados no questionário. Com isso, seis respondentes, que indicaram outras técnicas e seis participantes que não responderam a essa questão, foram excluídos da

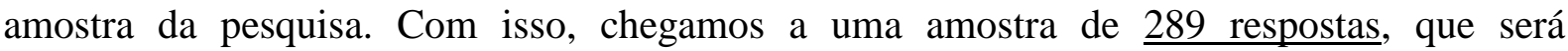
apresentada, em detalhe, a seguir.

\subsection{Perfil dos respondentes}

\section{a) Formação dos respondentes}

Em termos de formação, a maior parte dos respondentes declarou que possui uma pósgraduação (MBA) como grau mais alto cursado (56,7\% das respostas válidas). Também, podemos incluir no grupo dos pós-graduados os que fizeram cursos lato-sensu, 17,3\%, conforme mostra a Tabela 1. 
Destaca-se, também, o grupo que possui formação stricto-sensu: 23,5\% dos respondentes com Mestrado, Doutorado e / ou Pós-doutorado. Com isso, é evidenciado o alto nível de formação dos respondentes da pesquisa, já que $89,2 \%$ dos participantes possuem pós-graduação. A qualidade da formação dos respondentes também é evidenciada pela baixa quantidade respostas nas demais opções: $8,3 \%$ dos respondentes declararam possuir somente o curso de graduação, e apenas dois dos respondentes $(0,7 \%)$ declararam possuir graduação incompleta.

Tabela 1 - Formação dos respondentes

\begin{tabular}{lcc}
\hline Formação dos respondentes & Frequência & $\%$ \\
\hline MBA & 164 & 56,7 \\
\hline Pós-graduação lato-sensu & 50 & 17,3 \\
\hline Mestrado & 29 & 10 \\
\hline Graduação & 24 & 8,3 \\
\hline Doutorado & 10 & 3,5 \\
\hline Pós-doutorado & 5 & 1,7 \\
\hline Graduação incompleta & 2 & 0,7 \\
\hline Total & 284 & 98,3 \\
\hline sem resposta & 5 & 1,7 \\
\hline Total & 289 & 100
\end{tabular}

Quanto aos dois respondentes que declararam não possuir um curso de graduação completo, deve-se destacar que ambos são participantes do processo estratégico das respectivas empresas, e por isso foram mantidos na amostra.

\section{b) Nível de decisão}

Apresentamos, na Tabela 2, as informações do nível de decisão dos respondentes. Das diversas posições apresentadas, destaca-se o maior número de respondentes no nível gerencial, com $37,7 \%$ dos participantes. Deve-se mencionar, também, o alto percentual de Diretores na pesquisa, que correspondem a $29,4 \%$ dos respondentes.

Sócios, Proprietários, Presidentes e Membros de Conselho de organizações correspondem a $14,8 \%$ do total de respondentes. A pesquisa também recebeu contribuições de Superintendentes, Coordenadores, Consultores e Analistas. 
Tabela 2 - Nível de decisão dos respondentes

\begin{tabular}{lcc}
\hline & Frequência & $\%$ \\
\hline Gerente & 109 & 37,7 \\
\hline Diretor & 85 & 29,4 \\
\hline Proprietário/Sócio & 31 & 10,7 \\
\hline Analista & 14 & 4,8 \\
\hline Superintendente & 9 & 3,1 \\
\hline Presidente & 9 & 3,1 \\
\hline Coordenador/Supervisor & 9 & 3,1 \\
\hline Outro & 4 & 1,4 \\
\hline Consultor & 4 & 1,4 \\
\hline Conselheiro & 3 & 1 \\
\hline Vice-Presidente & 3 & 96,9 \\
\hline Total & 280 & 3,1 \\
\hline sem resposta & 9 & 100 \\
\hline
\end{tabular}

\subsection{Perfil das organizações}

\section{a) Origem do capital}

Em termos de origem de capital, temos um predomínio de empresas com origem brasileira, com $60,9 \%$ das empresas estudadas, conforme a Tabela 3.

Tabela 3 - Empresas de origem brasileira

\begin{tabular}{lcc}
\hline & Frequência & $\%$ \\
\hline Sim & 176 & 60,9 \\
\hline Não & 113 & 39,1 \\
\hline Total & 289 & 100 \\
\hline
\end{tabular}

As empresas estrangeiras, com 113 elementos da amostra, correspondem a 39,1\% do total de corporações da pesquisa. Os maiores representantes são as empresas de origem americana e de origem alemã, como nos mostra a Tabela 4.

Tabela 4 - Empresas estrangeiras

\begin{tabular}{lcc}
\hline País & Frequência & $\%$ \\
\hline Estados Unidos & 36 & 31,9 \\
\hline Alemanha & 23 & 20,4 \\
\hline França & 12 & 10,6 \\
\hline Espanha & 8 & 7,1 \\
\hline Japão & 7 & 6,2 \\
\hline Suíça & 6 & 5,3 \\
\hline Reino Unido & 5 & 4,4 \\
\hline Coréia do Sul & 2 & 1,8 \\
\hline Itália & 2 & 1,8 \\
\hline
\end{tabular}


Empresas com origem em países como Áustria, Bélgica, Camarões, Canadá, Cuba, Finlândia, Holanda e Suécia tiveram um respondente, assim como duas empresas binacionais (Brasil / Paraguai e Suécia / EUA) também representadas por um respondente cada.

Do total de empresas, temos que 66 corporações, 23,0\% do total, possuem capital aberto no Brasil (Tabela 5). Desse valor, 17,7\% são de empresas Brasileiras e o restante $(5,4 \%)$ são de empresas estrangeiras.

Tabela 5 - Origem das empresas $x$ capital aberto no Brasil

\begin{tabular}{lcc}
\hline & Frequência & $\%$ \\
\hline Não & 221 & 77 \\
\hline Sim & 66 & 23 \\
\hline Total & 287 & 100 \\
\hline
\end{tabular}

\section{b) Setor de atuação das organizações}

A Tabela 6 apresenta os setores onde a organização do respondente atua, evidenciando uma grande diversidade. Mesmo os setores com maior representação, como Financeiro e Farmacêutico, correspondem a menos de $10 \%$ da amostra cada.

Tabela 6 - Detalhamento do setor de atuação do respondente

\begin{tabular}{lcc}
\hline & Frequência & $\%$ \\
\hline Financeiro & 24 & 8,3 \\
\hline Farmacêutico & 22 & 7,6 \\
\hline Serviços & 20 & 6,9 \\
\hline Indústria da construção & 18 & 6,2 \\
\hline Bens de capital & 17 & 5,9 \\
\hline Química e Petroquímica & 17 & 5,9 \\
\hline Software/TI & 16 & 5,5 \\
\hline Telecomunicações & 15 & 5,2 \\
\hline Autoindústria & 13 & 4,5 \\
\hline Energia & 13 & 4,5 \\
\hline Consultoria/auditoria & 12 & 4,2 \\
\hline Bens de consumo & 10 & 3,5 \\
\hline Outros & 9 & 3,1 \\
\hline Transporte/logística & 9 & 3,1 \\
\hline Varejo & 8 & 2,8 \\
\hline Alimentos e bebidas & 7 & 2,4 \\
\hline Eletroeletrônico & 7 & 2,4 \\
\hline Mídia/Comunicação & 7 & 2,4 \\
\hline Mineração & 7 & 2,4 \\
\hline Produção agropecuária & 6 & 2,1 \\
\hline Governo & 5 & 1,7 \\
\hline Papel e Celulose & 5 & 1,7 \\
\hline Educação & 4 & \\
\hline & & \\
\hline
\end{tabular}




\begin{tabular}{lcc}
\hline Indústria Digital & 4 & 1,4 \\
\hline Siderurgia e Metalurgia & 4 & 1,4 \\
\hline Aeronáutico & 3 & 1 \\
\hline Terceiro Setor & 3 & 1 \\
\hline Têxteis & 3 & 1 \\
\hline Total & 288 & 99,7 \\
\hline sem resposta & 1 & 0,3 \\
\hline Total & 289 & 100 \\
\hline
\end{tabular}

Analisando os setores de maneira agrupada, as organizações foram divididas em grandes categorias, como indústria ou serviço, resultando na Tabela 7. Esta tabela apresenta um equilíbrio na amostra entre as duas grandes categorias já que os setores catalogados como Indústria correspondem a 51,4\% da amostra enquanto que Serviços correspondem a 48,6\%.

Tabela 7 - Agrupamento dos setores entre indústria e serviços

\begin{tabular}{lcc}
\hline & Frequência & $\%$ \\
\hline Indústria & 148 & 51,4 \\
\hline Serviços & 140 & 48,6 \\
\hline Total & 288 & 100 \\
\hline
\end{tabular}

c)

\section{Faturamento}

O maior grupo de organizações representadas da pesquisa são as de faturamento (receita operacional bruta anual) acima de $\mathrm{R} \$ 1$ bilhão que correspondem a $48,1 \%$ do total pesquisado.

As demais faixas tem percentuais semelhantes entre 15 e $20 \%$. Com $18,8 \%$ do total, temos respondentes que trabalham nas micro ou pequenas empresas, que, no conceito do BNDES, são aquelas com até 16 milhões de reais de faturamento anual.

Com 16,7\%, temos as empresas consideradas médias, que possuem faturamento entre 16 milhões e 300 milhões de reais (Tabela 8). E por fim, temos a faixa das empresas entre R\$ 300 milhões e R\$ 1 bilhão de receita operacional bruta anual (16,4\% da amostra). Para o BNDES, empresas com faturamento acima de 300 milhões de reais são consideradas grandes. Deve-se comentar que, das empresas informadas pelos respondentes, $33 \%$ fazem parte do "Ranking Valor1000 2013",

\footnotetext{
${ }^{1}$ Dos setores pesquisados, nesta tese, somente Bancos e Seguradoras (de todas as categorias) não figuram no ranking geral do Valor1000 — estas instituições estão em rankings específicos para área Financeira. Disponível em: http://www.valor.com.br/valor1000/2013
} 
Tabela 8 - Faturamento das organizações

\begin{tabular}{lcc}
\hline & Frequência & $\%$ \\
\hline Até $\mathrm{R} \$ 16$ milhões & 54 & 18,8 \\
\hline $\mathrm{R} \$ 16$ milhões a 300 milhões & 48 & 16,7 \\
\hline $\mathrm{R} \$ 300$ milhões a $\mathrm{R} \$ 1$ bilhão & 47 & 16,4 \\
\hline Acima de R $\$ 1$ bilhão & 138 & 48,1 \\
\hline Total & 287 & 100 \\
\hline
\end{tabular}

\subsection{Características da estratégia corporativa}

a)

\section{Estratégia fundamental}

As respostas assinaladas foram agrupadas de acordo com as estratégias genéricas de Porter, para viabilizar um numero de elementos que possibilite aplicar teste estatístico (a ver nos itens posteriores). Desta forma, verifica-se que a maioria dos respondentes trabalha em empresas que buscam diferenciar-se, seja em produto ou serviço, perante seus concorrentes. A estratégia genérica de diferenciação (agrupada com seus equivalentes das disciplinas de valor) obteve a maior parte das respostas com $56,9 \%$.

A estratégia de liderança em custos (e também a de excelência operacional) ficou com 25,3\%, enquanto que a estratégia de foco foi indicada por 17,8\% dos respondentes (Tabela 9).

Tabela 9 - Estratégia Fundamental

\begin{tabular}{lcc}
\hline & Frequência & $\%$ \\
\hline Diferenciação (Intimidade com cliente e Melhor produto) & 160 & 56,9 \\
\hline Liderança em custos/ Excelência operacional & 71 & 25,3 \\
\hline Foco em um nicho/segmento específico & 50 & 17,8 \\
\hline Total & 281 & 100 \\
\hline
\end{tabular}

\section{b) Nível de participação do respondente na definição da estratégia}

Em termos de participação na definição da estratégia corporativa, conforme a tabela 10 apresenta, a alternativa mais assinalada foi a de participação em partes do processo estratégico, com $31,8 \%$. A seguir, com $23,5 \%$, foi mais indicada a alternativa em que o participante define todo o processo estratégico na estratégia, contribuindo com a tomada de decisão (Tabela 10). Na sequência, com $21,8 \%$, temos a alternativa em que os respondentes da pesquisa participam de todo o processo estratégico.

As demais alternativas escolhidas indicam que esta parte dos respondentes não possui uma 
visão sistêmica, sobre analisar e definir uma nova estratégia, uma vez que a alternativa "sou informado da estratégia ao final do processo" possui $12,1 \%$ do total de respostas, enquanto que a opção "forneço informações para o processo estratégico" ficou com 10,7\%.

Tabela 10 - Nível de participação do respondente na definição da estratégia

\begin{tabular}{lcc}
\hline & Frequência & $\%$ \\
\hline Participo em partes/sou consultado no processo estratégico & 92 & $31,8 \%$ \\
\hline Defino e participo de todo o processo estratégico, inclusive decisão & 68 & $23,5 \%$ \\
\hline $\begin{array}{l}\text { Participo de todo o processo estratégico (análises, concepção de } \\
\text { objetivos, implementação etc.) }\end{array}$ & 63 & $21,8 \%$ \\
\hline Forneço informações para o processo estratégico & 31 & $10,7 \%$ \\
\hline Sou informado da estratégia ao final do processo & 35 & $12,1 \%$ \\
\hline Total & 289 & $100,0 \%$ \\
\hline
\end{tabular}

c) Técnicas que organizam os objetivos estratégicos corporativos

Os participantes da pesquisa foram indagados a respeito de técnicas que auxiliam a organização de objetivos estratégicos usadas nas corporações que fazem parte. Da lista fornecida, a técnica mais citada foi a do BSC (Balanced Scorecard) por 31,8\% dos respondentes, conforme apresenta a tabela 11. A seguir, sem predominância de uma técnica específica, o uso prioritariamente de Objetivos Financeiros foi a opção de $26 \%$ dos participantes da pesquisa.

Na sequência, foi indicado por 19,7\% dos respondentes que a técnica usada em suas organizações é parte de um processo Intuitivo / Criativo desenvolvido a partir da alta direção. A APO (Administração por Objetivos) foi a opção de 15,2\% dos participantes da pesquisa. Por fim, $7,3 \%$ dos respondentes indicaram que o método usado pelas organizações de que fazem parte é um processo Participativo (Tabela 11).

Tabela 11 - Técnicas para organização de objetivos estratégicos corporativos

\begin{tabular}{lcc}
\hline & Frequência & $\%$ \\
\hline BSC - Balanced Scorecard & 92 & 31,8 \\
\hline São definidos objetivos de desempenho Financeiro & 75 & 26,0 \\
\hline Processo Intuitivo/Criativo desenvolvido a partir da alta direção & 57 & 19,7 \\
\hline APO - Administração por objetivos & 44 & 15,2 \\
\hline $\begin{array}{l}\text { Processo Participativo por meio da discussão em grupos de baixo } \\
\text { pra cima (bottom-up) }\end{array}$ & 21 & 7,3 \\
\hline Total & 289 & 100 \\
\hline
\end{tabular}


Cabe destacar que para adequar a amostra desta pesquisa e possibilitar os testes de associação estatística apenas $2 \%$ da amostra (seis respondentes), que indicaram aplicar outras técnicas, foram descartados das análises disponíveis no item 4.4. Cabe mencionar que estes respondentes, que se referem a outras técnicas de organização de objetivos estratégicos, indicaram usar, em sua maioria, métodos híbridos que adaptam as técnicas acima citadas, conforme podemos ver no Quadro 7 a seguir.

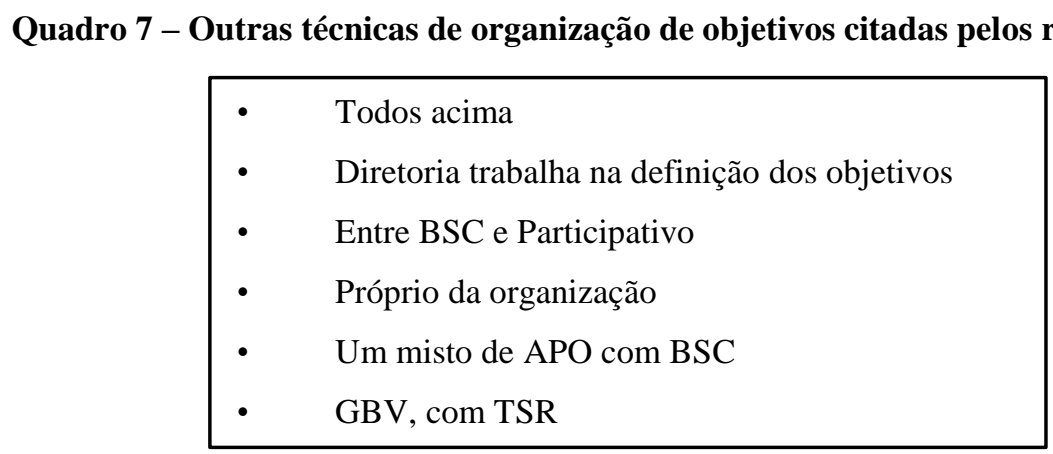

O quadro acima apresenta, além das indicações de técnicas que mesclam as estudadas nessa tese, um comentário sobre a "diretoria da empresa trabalha nos objetivos" o que talvez seja um indício de uma técnica semelhante à Intuitiva. Deve-se comentar também a indicação do uso de GBV com TSR. O Gerenciamento Baseado no Valor (GBV) é uma abordagem voltada à geração de riqueza ao acionista da empresa. Para Muniz (2009) a criação de valor ao acionista ocorre quando um capital investido gera um retorno maior que o custo desse capital. Já o Total Shareholder Return (TSR) é um forma de apuração do desempenho da empresa sob a perspectiva do acionista, contemplando dividendos e valorização da ação. Com essa abordagem, esses conceitos poderiam ser incluídos na técnica de Objetivos Financeiros mesmo com o foco totalmente voltado ao acionista.

\section{d) Pontos fortes e recomendações de aprimoramento das técnicas: análise qualitativa}

Cada respondente da pesquisa analisou os pontos fortes, fracos e sugeriu aprimoramentos para a técnica que indicou usar na organização da qual faz parte. É apresentada a seguir uma compilação dos comentários para cada técnica e, na sequência, um quadro fazendo a comparação entre elas. 


\section{$\underline{\text { A técnica APO }}$}

Como principais pontos positivos para a APO foi destacado, por 11 respondentes, o efeito de envolvimento e comprometimento dos diversos níveis que a técnica estabelece para a organização. A seguir, a clareza que a técnica apresenta para comunicar seus objetivos foi destacada por 7 respondentes. Outros pontos positivos foram lembrados, por uma quantidade menor de participantes da pesquisa, como:

- Transparência (3 comentários)

- Metodologia bem definida (3 comentários)

- Possibilidade de mensuração (3 comentários)

- $\quad$ Autonomia

Como pontos negativos os respondentes que afirmam usar a APO nas organizações em que trabalham destacaram principalmente a dificuldade no alinhamento e na comunicação sobre os objetivos corporativos (7 considerações). Dificuldades com a implementação também foram citadas (7 comentários), especialmente na demora da implantação, falhas na definição de abrangência da ferramenta e desdobramentos de objetivos. Outras características, citadas em menor número também foram lembradas:

- $\quad$ Falta de qualificação do pessoal (4 comentários)

- Dificuldades de mensuração dos objetivos (3 comentários)

- Demora nas decisões quanto aos desvios (2 comentários)

- $\quad$ Foco em problemas atuais

Em termos de aprimoramento, para a APO se destacou a sugestão de buscar alternativas para aumentar o envolvimento e a participação dos membros da organização (7 comentários). A seguir foi destacada a necessidade de capacitação para melhor uso da técnica (6 considerações). Além destes, outros aprimoramentos mencionados foram:

- Buscar maior alinhamento e integração entre áreas e objetivos (5 comentários)

- Definir os objetivos de maneira mais clara (4 comentários)

- Trabalhar a comunicação (3 comentários)

- Reduzir número de objetivos 


\section{A técnica BSC}

Os participantes que indicaram usar o BSC em suas organizações apontaram seus pontos positivos. A maioria dos respondentes apontou a clareza da técnica, e de seus objetivos, metas e indicadores, como ponto positivo. Na opinião desses respondentes, isso facilita a comunicação da estratégia e contribui para o engajamento e alinhamento de toda a organização (43 comentários). Alguns participantes destacaram a característica multidisciplinar da técnica - que busca integrar todas as áreas da empresa (7 comentários). Outros comentários foram elaborados sobre pontos positivos do BSC:

- Bom desdobramento da estratégia em objetivos estratégicos, indicadores e metas (4 comentários)

- Foca em poucos objetivos (2 comentários)

- Garantia dos objetivos financeiros

- Identificação de oportunidades de melhoria

- Velocidade de reação é alta

- Visão sistêmica do ambiente de negócios

- $\quad$ Encadeamento lógico das relações de causa e efeito

O BSC tem os seguintes pontos negativos, na visão daqueles que usam esta técnica: processo de concepção e implantação lento, com problema da ferramenta (16 comentários). O entendimento da técnica, que pode não ser claro para todos na organização também foi citado (15 comentários). A quantidade de objetivos e a complexidade para a definição de critérios para apuração de indicadores e metas (8 comentários) e a definição centralizada, sem considerar adequação para aspectos específicos de mercados locais (6 comentários), também foram itens citados pelos respondentes. Além desses, outros comentários realizados foram:

- Mensuração de riscos ou imprevistos que podem afetar a não implantação dos objetivos estratégicos (2 comentários)

- $\quad$ Alta rotatividade de pessoal (2 comentários)

- $\quad$ Falta de sistematização

- $\quad$ Não aponta as reais causas de ineficiência

Para o aprimoramento do uso do BSC os respondentes indicaram: intensificar a comunicação para todos da corporação e melhorar o engajamento e comprometimento de todos os 
colaboradores, especialmente, de nível inferior (13 comentários). Comentários acerca do aprimoramento do processo estratégico e da técnica em geral também foram feitos (7 comentários). Intensificar o foco na execução e implementação da estratégia também foi lembrando (8 comentários). Aumentar objetividade e agilidade do processo (8 comentários). E, por fim, aumentar a autonomia local (6 comentários). Também foram citados os seguintes aspectos:

- Contemplar contribuições bottom-up (2 comentários)

- Implementar processos de governança corporativa

- Softwares de gestão com alto potencial de análise e estruturação de uma área específica de gestão da informação e do conhecimento.

\section{A técnica Objetivos Financeiros}

Como pontos positivos da técnica de objetivos financeiros temos em primeiro lugar os aspectos de comunicação, envolvimento e alinhamento (27 comentários). De acordo com os comentários, a facilidade de se medir os indicadores possibilita um entendimento e integração entre as áreas de negócio. A objetividade da técnica, com seus indicadores definidos de forma simples, também foi citada pelos respondentes (11 comentários). Por fim, a flexibilidade e agilidade no acompanhamento e gestão dos objetivos financeiros também foram destacadas (10 comentários)

Em termos de pontos negativos da técnica de objetivos financeiros o item mais citado foi a natureza top-down da ferramenta com a consequente falta de integração com outras áreas da empresa (25 comentários). Em seguida, o processo de construção e operação da técnica também foi indicado pelos respondentes (19 comentários). A seguir, foi indicada a excessiva centralização da definição e acompanhamento da técnica em poucas pessoas que possuem o conhecimento dela (14 comentários). De acordo com os respondentes, este aspecto impacta a comunicação e o alinhamento com os colaboradores. Críticas adicionais em relação à falta de formalização do processo suscetível a muitas variações, assim como a falta de formalização de indicadores, resultam em impacto na comunicação e engajamento, também foram realizadas.

Sobre aprimoramentos para a técnica de Objetivos Financeiros, o maior número de comentários foi para os aspectos relacionados a ajustes de processo com sugestões para 
formalizar etapas, alterar o número de reuniões e aumentar a participação de outros colaboradores da organização (22 comentários). O segundo maior número de comentários estão relacionados com o aumento de escopo dos indicadores contemplando outras áreas da empresa (16 comentários). Por fim, aprimorar a comunicação para aumentar engajamento foi destacado por 13 respondentes.

\section{A técnica Participativa}

Para os respondentes que indicaram usar a técnica Participativa o maior ponto positivo desta técnica é a sua característica democrática onde todos os níveis são envolvidos e participam da construção da estratégia (10 comentários). Também houve destaque para a objetividade da técnica (4 comentários) e para a facilidade de comunicação (2 comentários).

Como pontos negativos da técnica Participativa os respondentes ressaltam a dificuldade de se colocar foco na discussão e no processo ( 7 comentários) o que causa lentidão na definição dos objetivos e pode deixar o processo confuso. A dificuldade de se reunir toda empresa e fazer com que todos participem também foi destacada (4 comentários) e, por fim, a dificuldade de contemplar todas os pontos levantados pelos participantes (3 comentários) também foi apontado.

Como pontos para aprimorar a técnica Participativa, os respondentes sugeriram criar mecanismos para melhorar a comunicação e garantir o engajamento de todos os participantes (8 comentários). Outros respondentes sugeriram dar mais foco no processo e facilitar a implementação da estratégia (8 comentários).

\section{A técnica Intuitiva}

Como pontos positivos da técnica Intuitiva temos a participação ativa da diretoria (ou proprietários) da empresa que conhece as condições competitivas e tem visão de longo prazo para estabelecer a estratégia (15 comentários). A flexibilidade e a agilidade para responder criativamente ao mercado também foram destacadas (14 comentários). Somado a esses pontos, a facilidade de comunicação da estratégia (3 comentários) também foi ressaltada.

Como pontos negativos da técnica Intuitiva temos que a falta de uma metodologia mais clara para estabelecer os objetivos gera uma falta de foco e de critérios de avaliação (22 comentários). A centralização das informações leva a problemas de comunicação da estratégia 
e também do engajamento da equipe para a execução (11 comentários). Outra questão está relacionada ao engessamento pautado na centralização da decisão na alta direção ou dos proprietários da empresa, o que leva a um gasto de tempo visto como excessivo pelos respondentes (8 comentários).

Para o aprimoramento da técnica Intuitiva os participantes que indicaram usar essa técnica em suas organizações recomendaram os seguintes aspectos: conduzir um processo melhor estruturado com organização mais explícita, contando com metas, indicadores e comunicação mais formal para além dos diretores da empresa (17 comentários). A seguir ressaltaram aprimorar a comunicação dos itens estratégicos e com isso buscar um melhor engajamento de toda a organização (15 comentários). Outros comentários também foram feitos e seguem abaixo:

- Ampliar visão e integrar com clientes (2 comentários)

- Basear a estratégia no Balanced Scoredcard

- $\quad$ Adequar prazos para a implementação

- Discussão mais ampla de baixo para cima.

- Descentralização da Diretoria e abertura para implantação de novas metodologias.

\section{Comparação entre as técnicas}

O quadro 8 apresenta os comentários mais presentes em cada categoria (pontos positivos, negativos e sugestões de aprimoramento) para cada técnica. O quadro apresenta os dois comentários que mais se repetiram para cada técnica com a quantidade de vezes que os comentários surgiram na compilação entre parênteses.

Dos pontos positivos destacados é possível notar destaque para características como: envolvimento dos participantes, clareza e objetividade da técnica para organização e, especialmente, comunicar os objetivos. Estes pontos aparecem com destaque para a APO, BSC, Objetivos Financeiros e Participativa. A técnica Intuitiva foi a única que destoou deste grupo já que os dois principais pontos positivos lembrados foram a participação ativa da diretoria da empresa e flexibilidade para responder a mudanças - características bem típicas desta técnica que é centrada em poucas pessoas. 
Quadro 8 - Principais pontos fortes, fracos e sugestões de aprimoramento para as técnicas

* Entre parênteses a quantidade de vezes que o item foi citado pelos participantes da pesquisa

\begin{tabular}{|c|c|c|c|c|c|}
\hline Técnica & APO & BSC & Financeiros & Participativa & Intuitiva \\
\hline \multirow{2}{*}{$\begin{array}{l}\text { Principais } \\
\text { pontos } \\
\text { fortes }\end{array}$} & $\begin{array}{l}\text { Envolvimento } \\
\mathrm{e} \\
\text { comprometim } \\
\text { ento dos } \\
\text { diversos níveis } \\
\text { (11) }\end{array}$ & $\begin{array}{l}\text { Clareza na } \\
\text { definição de } \\
\text { objetivos, metas } \\
\text { e indicadores } \\
\text { (43) }\end{array}$ & $\begin{array}{l}\text { Comunicação, } \\
\text { envolvimento } \\
\text { e alinhamento } \\
(27)\end{array}$ & $\begin{array}{l}\text { Envolvimento } \\
\text { de todos os } \\
\text { níveis e } \\
\text { participam da } \\
\text { construção (10) }\end{array}$ & $\begin{array}{l}\text { A participação } \\
\text { ativa da } \\
\text { diretoria/proprie } \\
\text { tários da } \\
\text { empresa (15) }\end{array}$ \\
\hline & $\begin{array}{l}\text { Clareza para } \\
\text { comunicar } \\
\text { seus objetivos } \\
\text { (7) }\end{array}$ & $\begin{array}{l}\text { Característica } \\
\text { multidisciplinar } \\
\text { (7) }\end{array}$ & $\begin{array}{l}\text { Objetividade } \\
\text { da técnica, } \\
\text { com definição } \\
\text { simples (11) }\end{array}$ & $\begin{array}{l}\text { Objetividade da } \\
\text { técnica (4) }\end{array}$ & $\begin{array}{l}\text { Flexibilidade e } \\
\text { agilidade para } \\
\text { responder ao } \\
\text { mercado (14) }\end{array}$ \\
\hline \multirow[b]{2}{*}{$\begin{array}{l}\text { Principais } \\
\text { pontos } \\
\text { fracos }\end{array}$} & $\begin{array}{l}\text { Dificuldade no } \\
\text { alinhamento e } \\
\text { na } \\
\text { comunicação } \\
\text { sobre os } \\
\text { objetivos (7) } \\
\end{array}$ & $\begin{array}{l}\text { Lentidão na } \\
\text { concepção e } \\
\text { implantação, } \\
\text { com problema } \\
\text { de foco (16) }\end{array}$ & $\begin{array}{l}\text { Natureza top- } \\
\text { down e falta } \\
\text { de integração } \\
\text { com outras } \\
\text { áreas (25) }\end{array}$ & $\begin{array}{l}\text { Dificuldade de } \\
\text { se colocar foco } \\
\text { na discussão e } \\
\text { no processo }(7)\end{array}$ & $\begin{array}{l}\text { Falta } \\
\text { clarificação para } \\
\text { se estabelecer os } \\
\text { objetivos (22) }\end{array}$ \\
\hline & $\begin{array}{l}\text { Dificuldades } \\
\text { com a } \\
\text { implementaçã } \\
\text { o (7) }\end{array}$ & $\begin{array}{l}\text { Entendimento } \\
\text { da técnica, que } \\
\text { pode não ser } \\
\text { clara para todos } \\
\text { na organização } \\
\text { (15) }\end{array}$ & $\begin{array}{l}\text { Processo de } \\
\text { construção e } \\
\text { operação da } \\
\text { técnica (19) }\end{array}$ & $\begin{array}{l}\text { Dificuldade para } \\
\text { reunir toda } \\
\text { empresa e fazer } \\
\text { com que todos } \\
\text { participem (4) }\end{array}$ & $\begin{array}{l}\text { A centralização } \\
\text { das } \\
\text { informações, } \\
\text { com problemas } \\
\text { de comunicação } \\
\text { e de } \\
\text { engajamento } \\
\text { para a execução } \\
(11)\end{array}$ \\
\hline \multirow{2}{*}{$\begin{array}{l}\text { Principais } \\
\text { aprimora } \\
\text { mentos }\end{array}$} & $\begin{array}{l}\text { Aumentar o } \\
\text { envolvimento } \\
\text { e a } \\
\text { participação } \\
\text { dos membros } \\
\text { da } \\
\text { organização } \\
\text { (7) }\end{array}$ & $\begin{array}{l}\text { Intensificar a } \\
\text { comunicação } \\
\text { para todos e } \\
\text { melhorar o } \\
\text { engajamento, } \\
\text { especialmente, } \\
\text { de nível inferior } \\
\text { (13) }\end{array}$ & $\begin{array}{l}\text { Ajustar o } \\
\text { processo } \\
\text { formalizando } \\
\text { etapas, } \\
\text { alterando } \\
\text { número de } \\
\text { reuniões e } \\
\text { aumentando a } \\
\text { participação } \\
(22)\end{array}$ & $\begin{array}{l}\text { Aprimorar a } \\
\text { comunicação e } \\
\text { garantir o } \\
\text { engajamento de } \\
\text { todos os } \\
\text { participantes (8) }\end{array}$ & $\begin{array}{l}\text { Melhorar } \\
\text { processo com } \\
\text { metas, } \\
\text { indicadores e } \\
\text { comunicação } \\
\text { mais } \\
\text { formalizados } \\
\text { para além dos } \\
\text { diretores }(17)\end{array}$ \\
\hline & $\begin{array}{l}\text { Aumentar } \\
\text { capacitação } \\
\text { sobre a técnica } \\
\text { (6) }\end{array}$ & $\begin{array}{l}\text { Intensificar o } \\
\text { foco na } \\
\text { execução e } \\
\text { implementação } \\
\text { da estratégia (8) }\end{array}$ & $\begin{array}{l}\text { Aumentar } \\
\text { escopo dos } \\
\text { indicadores } \\
\text { contemplando } \\
\text { outras áreas da } \\
\text { empresa (16) }\end{array}$ & $\begin{array}{l}\text { Incluir outras } \\
\text { ferramentas no } \\
\text { processo para } \\
\text { facilitar a } \\
\text { implementação } \\
\text { (8) }\end{array}$ & $\begin{array}{l}\text { Aprimorar a } \\
\text { comunicação } \\
\text { dos itens } \\
\text { estratégicos e } \\
\text { buscar um } \\
\text { melhor } \\
\text { engajamento de } \\
\text { toda a } \\
\text { organização } \\
(15)\end{array}$ \\
\hline
\end{tabular}

Os pontos negativos das técnicas não se repetem para cada técnica com a mesma frequência vista nos pontos positivos. Foi destacado o problema de entendimento e falta de alinhamento sobre as técnicas (APO, BSC, Objetivos Financeiros e Intuitiva). Também se destacou dificuldades de implementação (APO e BSC) e desafios para integração (Financeiros e Intuitiva). A técnica Participativa, por sua vez, teve como pontos negativos a falta de foco 
para a discussão da estratégia e dificuldades para fazer com que todos da empresa conseguissem participar das discussões.

Em termos de pontos de aprimoramento, observou-se uma necessidade de incrementar os aspectos que aperfeiçoem a comunicação, em especial, o envolvimento e engajamento das pessoas (APO, BSC, Participativa e Intuitivo). Apesar de ser um ponto também colocado como positivo para essas técnicas os respondentes indicaram que ainda há oportunidades de melhoria.

Também foram mais citadas melhorias para aprimorar os processos estratégicos (BSC, Financeiros, Participativa e Intuitiva) e, especificamente, a capacitação nos conceitos da técnica (APO) e o aumento do escopo dos objetivos (Financeiro).

\section{e) Níveis organizacionais que recebem a divulgação dos objetivos estratégicos}

A maior concentração das respostas $(49,3 \%)$ indicou que os objetivos estratégicos são divulgados para toda a corporação, sem restrições de nível organizacional. Por outro lado, o agrupamento das demais respostas merece ser analisado.

Os respondentes que assinalaram que os objetivos são divulgados aos gerentes e superiores correspondem a 30,9\%. Do total de respondentes, $14,2 \%$ indicaram que os objetivos estratégicos são divulgados apenas entre os sócios ou para diretores e superiores da empresa. Ainda, temos o percentual restante de 5,6\% de respondentes que assinalaram que, na corporação da qual faz parte, cada área recebe somente seus objetivos estratégicos (Tabela 12).

Desta forma, temos que o total de respondentes, 50,6\%, destaca que os objetivos estratégicos são divulgados apenas a determinadas partes das corporações. Neste caso, a pergunta que se coloca é se o desempenho dessas empresas aumentaria se estes objetivos chegassem até os níveis operacionais, aumentando o alinhamento de toda a organização com a estratégia planejada. 
Tabela 12 - Níveis organizacionais que recebem os objetivos estratégicos

\begin{tabular}{lcc}
\hline & Frequência & $\%$ \\
\hline Toda a organização, sem restrição de Cargos/Nível organizacional & 142 & $49,3 \%$ \\
\hline Aos Gerentes e superiores & 89 & $30,9 \%$ \\
\hline Para Sócios/diretores e superiores & 41 & $14,2 \%$ \\
\hline Cada área recebe apenas seus objetivos/outros & 16 & $5,6 \%$ \\
\hline Total & 288 & $100 \%$ \\
\hline
\end{tabular}

As informações destas questões poderão trazer insights mais relevantes, quando analisarmos seus resultados cruzados com respostas de outras questões. No próximo item, serão vistos os estudos de associações entre os diversos itens do questionário, bem como o resultado das provas estatísticas dessas associações.

\subsection{Estudo de elementos de influência na técnica adotada pelas organizações}

Neste item, são analisados se os elementos do questionário de pesquisa têm influência na técnica de organização de objetivos estratégicos adotada pelas corporações. Por isso, aqui, deposita-se o foco em encontrar associações relevantes entre as técnicas e as características do contexto estratégico de uma organização.

\section{a) Origem do capital}

De forma descritiva, é possível ver que a proporção do processo intuitivo e do processo participativo é ligeiramente maior para empresas brasileiras que estrangeiras, conforme apresenta a Tabela 13. As demais técnicas estão com proporções assemelhadas, entre empresas brasileiras e estrangeiras.

Porém, de acordo com a Prova do Qui-quadrado, não há razões para concluir que o uso da principal técnica para organizar os objetivos estratégicos esteja relacionada à origem brasileira ou estrangeira da empresa $\left(\chi^{2}=6,082 ; p=0,193\right)$. 
Tabela 13 - Origem de capital e técnicas de organização de objetivos estratégicos corporativos

\begin{tabular}{|c|c|c|c|c|c|c|c|}
\hline $\begin{array}{l}\text { Empresa de origem } \\
\text { brasileira? }\end{array}$ & & APO & BSC & $\begin{array}{c}\text { Objetivos } \\
\text { Financeiros } \\
\end{array}$ & Intuitiva/Criativa & $\begin{array}{c}\text { Técnica } \\
\text { Participativa } \\
\end{array}$ & Total \\
\hline \multirow[t]{2}{*}{ Sim } & $\mathrm{n}$ & 26 & 50 & 44 & 42 & 14 & 176 \\
\hline & $\%$ & $59,1 \%$ & $54,3 \%$ & $58,7 \%$ & $73,7 \%$ & $66,7 \%$ & $60,9 \%$ \\
\hline \multirow[t]{2}{*}{ Não } & $\mathrm{n}$ & 18 & 42 & 31 & 15 & 7 & 113 \\
\hline & $\%$ & $40,9 \%$ & $45,7 \%$ & $41,3 \%$ & $26,3 \%$ & $33,3 \%$ & $39,1 \%$ \\
\hline \multirow[t]{2}{*}{ Total } & $\mathrm{n}$ & 44 & 92 & 75 & 57 & 21 & 289 \\
\hline & $\%$ & $100 \%$ & $100 \%$ & $100 \%$ & $100 \%$ & $100 \%$ & $100 \%$ \\
\hline
\end{tabular}

\section{b)}

\section{Capital aberto no Brasil}

A Tabela 14 mostra que grande parte (77\%) das empresas em que os respondentes atuam não tem capital aberto no Brasil, e que esse percentual pouco se altera, de acordo com a técnica empregada $\left(\chi^{2}=3,632 ; \mathrm{p}=0,458\right)$.

Tabela 14 - Capital aberto no Brasil e técnicas

\begin{tabular}{ll|c|c|c|c|c|}
\hline $\begin{array}{l}\text { Capital aberto no } \\
\text { Brasil? }\end{array}$ & & APO & BSC & $\begin{array}{c}\text { Objetivos } \\
\text { Financeiros }\end{array}$ & Intuitiva/Criativa & $\begin{array}{c}\text { Técnica } \\
\text { Participativa }\end{array}$ \\
\hline Sim & $\mathrm{n}$ & 6 & 23 & 20 & 11 & 6 \\
\hline & $\%$ & $14,0 \%$ & $25,3 \%$ & $26,7 \%$ & $19,3 \%$ & $28,6 \%$ \\
\hline Não & $\mathrm{n}$ & 37 & 68 & 55 & 46 & $23,0 \%$ \\
\hline Total & $\%$ & $86,0 \%$ & $74,7 \%$ & $73,3 \%$ & $80,7 \%$ & $71,4 \%$ \\
\hline & $\mathrm{n}$ & 43 & 91 & 75 & 57 & 21 \\
\hline
\end{tabular}

c)

\section{Faturamento}

De acordo com a Tabela 15 e com o Gráfico 1, nota-se que o método BSC e a técnica essencialmente focada em objetivos de desempenho financeiro são, relativamente, características mais utilizadas por empresas com faturamento acima de R \$ 1 bilhão, enquanto a técnica de processo intuitivo é, relativamente, mais empregada em empresas de menor porte, conforme resultado de comparações múltiplas efetuada após teste de Kruskal-Wallis.

De acordo com a Prova não-paramétrica de Kruskal-Wallis, conclui-se que o faturamento da empresa varia significativamente com o uso da principal técnica para organizar os objetivos estratégicos $\left(\chi^{2}=20,78 ; \mathrm{p}<0,001\right)$. 
Tabela 15 - Faturamento e técnicas

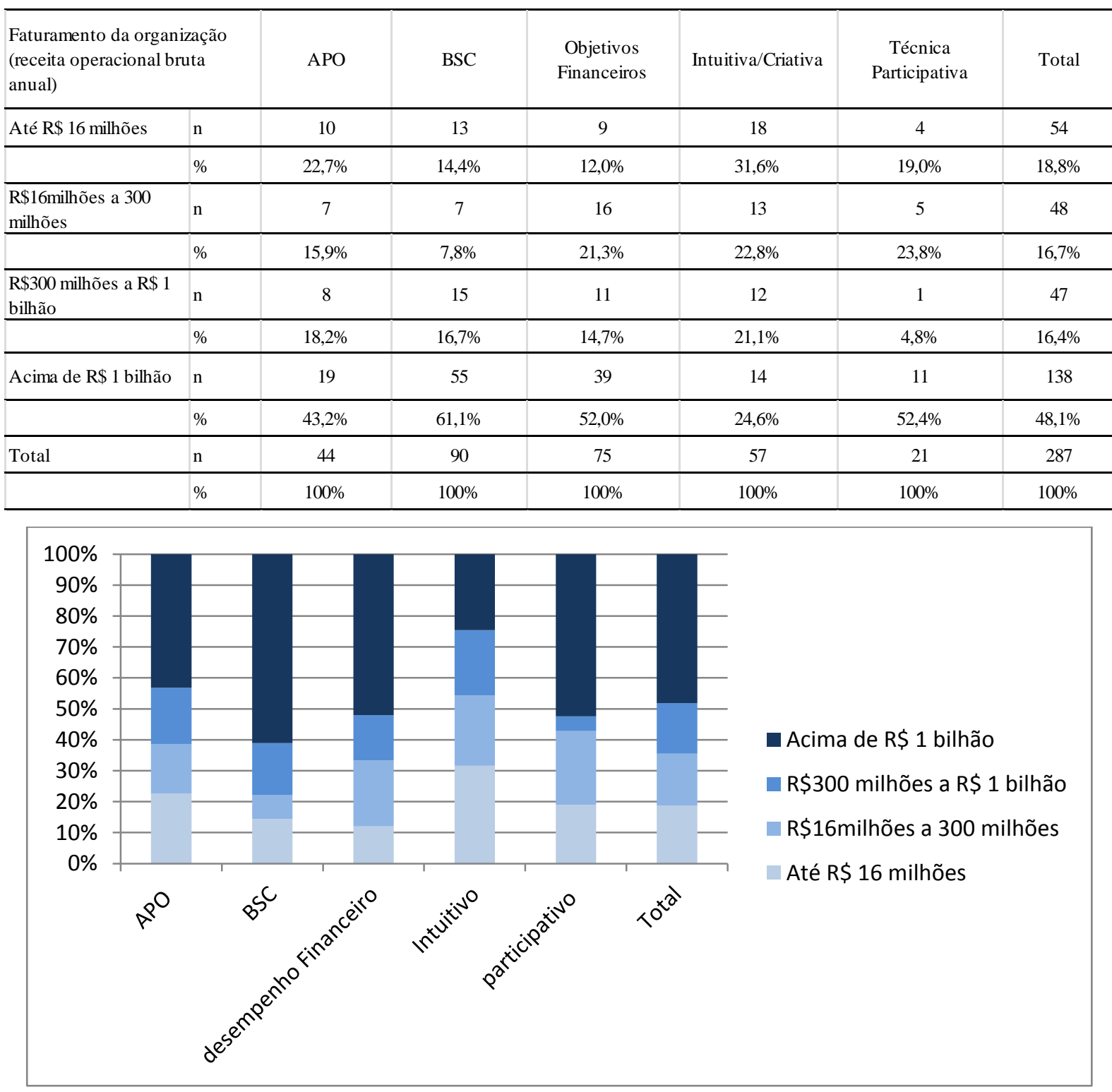

Gráfico 1 - Faturamento das organizações e técnica usada

Como a hipótese nula foi rejeitada, parte-se para a verificação das diferenças estatisticamente significantes (detalhamento disponível no Apêndice II), sendo estas as diferenças encontradas ao nível de $\alpha=0,05$. As diferenças observadas são maiores que as diferenças mínimas significativas (DMS) para a comparação entre BSC e Processo Intuitivo e também para Objetivos Financeiros e Processo Intuitivo.

d) Setor de atuação

Como a distribuição de setores deu-se de maneira pulverizada optou-se por fazer o teste 
estatístico com o agrupamento indústria x serviços, como mostra a Tabela 16. Dessa maneira, foi garantido que cada cruzamento tivesse o número mínimo de observações requeridas pela prova estatística. Pela Prova do Qui-quadrado, não foi possível concluir pela dependência entre técnica empregada e setor de atuação da empresa no agrupamento indústria ou serviços $\left(\chi^{2}=6,104 ; p=0,192\right)$.

Tabela 16 - Setor e técnica

\begin{tabular}{|c|c|c|c|c|c|c|c|}
\hline Indústria ou Serviços & & APO & BSC & $\begin{array}{c}\text { Objetivos } \\
\text { Financeiros }\end{array}$ & Intuitiva/Criativa & $\begin{array}{c}\text { Técnica } \\
\text { Participativa }\end{array}$ & Total \\
\hline \multirow[t]{2}{*}{ Industria } & $\mathrm{n}$ & 29 & 42 & 36 & 28 & 13 & 148 \\
\hline & $\%$ & $65,9 \%$ & $46,2 \%$ & $48,0 \%$ & $49,1 \%$ & $61,9 \%$ & $51,4 \%$ \\
\hline \multirow[t]{2}{*}{ Serviços } & $\mathrm{n}$ & 15 & 49 & 39 & 29 & 8 & 140 \\
\hline & $\%$ & $34,1 \%$ & $53,8 \%$ & $52,0 \%$ & $50,9 \%$ & $38,1 \%$ & $48,6 \%$ \\
\hline \multirow[t]{2}{*}{ Total } & $\mathrm{n}$ & 44 & 91 & 75 & 57 & 21 & 288 \\
\hline & $\%$ & $100 \%$ & $100 \%$ & $100 \%$ & $100 \%$ & $100 \%$ & $100 \%$ \\
\hline
\end{tabular}

e)

\section{Característica fundamental da estratégia}

A Tabela 17 apresenta que a maioria da amostra $(56,9 \%)$ tem como característica fundamental a diferenciação (intimidade com o cliente e melhor produto). Já, 25,3\% da amostra tem como característica fundamental a estratégia de liderança de custos ou excelência operacional, restando $17,8 \%$ que mencionam foco em um nicho ou segmento específico.

Pela Prova do Qui-quadrado, não foi possível concluir pela dependência entre técnica empregada e característica fundamental da estratégia da empresa $\left(\chi^{2}=10,697 ; \mathrm{p}=0,219\right)$. Ou seja, estatisticamente as diferentes técnicas se comportam da mesma forma em relação à característica fundamental. 
Tabela 17 - Característica fundamental da estratégia e técnica

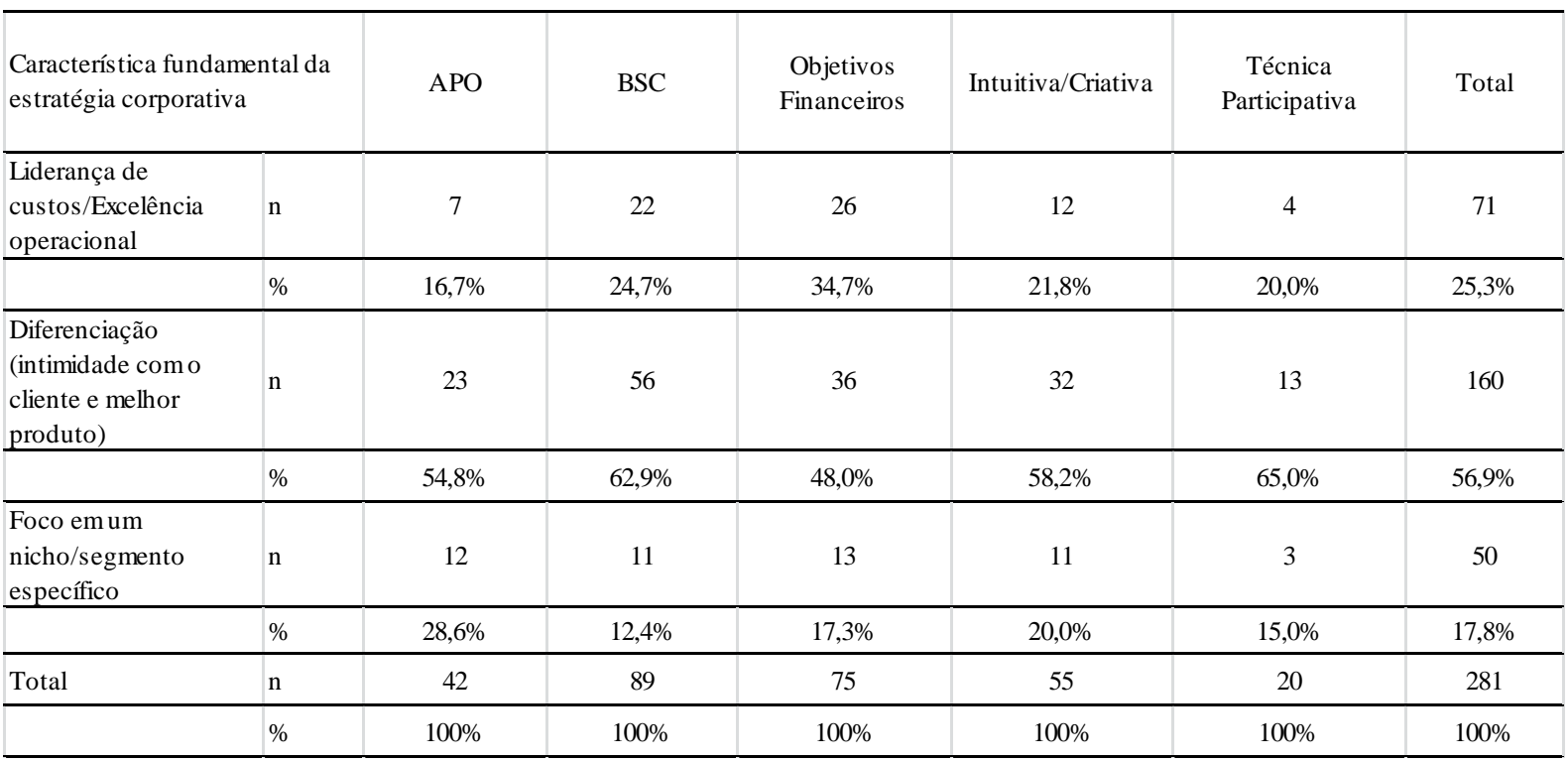

\section{f) Quantidade de reuniões para definição da estratégia}

A Tabela 18 mostra que são realizadas em média 5 reuniões por ano para a definição da estratégia. Quando se analisa a mediana, são 4 reuniões em um ano, possivelmente atrelando essas reuniões a reuniões de avaliação do trimestre. Por outro lado há uma alta dispersão da amostra (coeficiente de variação $=80 \%$ ), onde no extremo temos empresas que não efetuam reuniões e aquelas que efetuam reuniões mensais.

Tabela 18 - Quantidade de reuniões anuais e técnicas (médias e medianas)

\begin{tabular}{|c|c|c|c|c|c|c|}
\hline $\begin{array}{l}\text { Quandidade de reuniões ou eventos utilizados } \\
\text { para a discussão e definição da estratégia }\end{array}$ & APO & BSC & $\begin{array}{c}\text { Objetivos } \\
\text { Financeiros }\end{array}$ & $\begin{array}{l}\text { Intuitiva/ } \\
\text { Criativa }\end{array}$ & $\begin{array}{c}\text { Técnica } \\
\text { Participativa }\end{array}$ & Total \\
\hline Média & 5,2 & 5,0 & 5,6 & 5,3 & 6,0 & 5,3 \\
\hline Mediana & 4,0 & 4,0 & 4,0 & 4,0 & 4,0 & 4,0 \\
\hline Mínimo & 1,0 & 1,0 & 0,0 & 1,0 & 1,0 & 0,0 \\
\hline Máximo & 12,0 & 12,0 & 12,0 & 12,0 & 12,0 & 12,0 \\
\hline Desvio-Padrão & 4,4 & 3,9 & 4,5 & 4,3 & 5,0 & 4,3 \\
\hline Coeficiente de variação & $84 \%$ & $78 \%$ & $80 \%$ & $81 \%$ & $84 \%$ & $80 \%$ \\
\hline
\end{tabular}

Por meio da prova de Kruskal-Wallis, não foi possível distinguir $(\alpha=0,05)$ as várias técnicas quanto à quantidade de reuniões (média de postos muito semelhante qualquer que seja a técnica), com $\chi^{2}=0,289$ e $\mathrm{p}=0,991$.

Analisando a Tabela 19, notamos que a maior parte das respostas flutua entre as reuniões que ocorrem duas vezes por ano às reuniões mensais. 
Tabela 19 - Quantidade de reuniões anuais e técnicas (números absolutos)

\begin{tabular}{|c|c|c|c|c|c|c|c|}
\hline Quantidade de reuniões & & APO & BSC & $\begin{array}{c}\text { Objetivos } \\
\text { Financeiros }\end{array}$ & $\begin{array}{c}\text { Intuitiva/ } \\
\text { Criativa } \\
\end{array}$ & $\begin{array}{c}\text { Técnica } \\
\text { Participativa }\end{array}$ & Total \\
\hline \multirow[t]{2}{*}{ nenhuma } & $\mathrm{n}$ & 0 & 0 & 2 & 0 & 0 & 2 \\
\hline & $\%$ & $0,0 \%$ & $0,0 \%$ & $2,7 \%$ & $0,0 \%$ & $0,0 \%$ & $0,7 \%$ \\
\hline \multirow[t]{2}{*}{1 anual } & $\mathrm{n}$ & 7 & 12 & 8 & 8 & 5 & 40 \\
\hline & $\%$ & $16,3 \%$ & $13,0 \%$ & $10,7 \%$ & $14,0 \%$ & $23,8 \%$ & $13,9 \%$ \\
\hline \multirow[t]{2}{*}{2 por ano } & $\mathrm{n}$ & 12 & 22 & 18 & 16 & 5 & 73 \\
\hline & $\%$ & $27,9 \%$ & $23,9 \%$ & $24,0 \%$ & $28,1 \%$ & $23,8 \%$ & $25,3 \%$ \\
\hline \multirow[t]{2}{*}{1 reunião por trimestre } & $\mathrm{n}$ & 8 & 23 & 15 & 8 & 2 & 56 \\
\hline & $\%$ & $18,6 \%$ & $25,0 \%$ & $20,0 \%$ & $14,0 \%$ & $9,5 \%$ & $19,4 \%$ \\
\hline \multirow[t]{2}{*}{ reuniões bimestrais } & $\mathrm{n}$ & 3 & 12 & 5 & 7 & 1 & 28 \\
\hline & $\%$ & $7,0 \%$ & $13,0 \%$ & $6,7 \%$ & $12,3 \%$ & $4,8 \%$ & $9,7 \%$ \\
\hline \multirow[t]{2}{*}{ reuniões mensais } & $\mathrm{n}$ & 11 & 18 & 21 & 14 & 8 & 72 \\
\hline & $\%$ & $25,6 \%$ & $19,6 \%$ & $28,0 \%$ & $24,6 \%$ & $38,1 \%$ & $25,0 \%$ \\
\hline \multirow[t]{2}{*}{ Outro } & $\mathrm{n}$ & 2 & 5 & 6 & 4 & 0 & 17 \\
\hline & $\%$ & $4,7 \%$ & $5,4 \%$ & $8,0 \%$ & $7,0 \%$ & $0,0 \%$ & $5,9 \%$ \\
\hline \multirow[t]{2}{*}{ Total } & $\mathrm{n}$ & 43 & 92 & 75 & 57 & 21 & 288 \\
\hline & $\%$ & $100 \%$ & $100 \%$ & $100 \%$ & $100 \%$ & $100 \%$ & $100 \%$ \\
\hline
\end{tabular}

\section{g) Dias de preparação prévia para a definição da estratégia empresarial}

A Tabela 20 apresenta alta variabilidade de respostas, variando de zero (5 respondentes) a 360 dias ao ano, variável digna de certa crítica. Porém, em média, se tem 33 dias anuais de preparação prévia a definição ou discussão da estratégia (ou mediana de 20 dias).

Analisando as medianas, verificam-se indícios do processo participativo demandar uma quantidade maior de dias que as outras opções de técnicas. Porém realizada a Prova de Kruskal-Wallis: $\chi^{2}=5,526 ; \mathrm{p}=0,237$; não foi possível rejeitar hipótese de nulidade de que as técnicas são iguais quanto à média do número de reuniões anuais.

Tabela 20 - Dias de preparação prévia e técnicas

\begin{tabular}{|c|c|c|c|c|c|c|}
\hline $\begin{array}{l}\text { Número de dias (por ano) de preparação para } \\
\text { definição da Estratégia }\end{array}$ & APO & BSC & $\begin{array}{c}\text { Objetivos } \\
\text { Financeiros }\end{array}$ & $\begin{array}{c}\text { Intuitiva/ } \\
\text { Criativa }\end{array}$ & $\begin{array}{c}\text { Técnica } \\
\text { Participativa }\end{array}$ & Total \\
\hline Média & 38,9 & 35,2 & 33,6 & 25,0 & 29,7 & 32,9 \\
\hline Mediana & 18,0 & 20,0 & 24,0 & 16,0 & 27,0 & 20,0 \\
\hline Mínimo & 2,0 & 0,0 & 0,0 & 0,0 & 2,0 & 0,0 \\
\hline Máximo & 360,0 & 320,0 & 216,0 & 180,0 & 90,0 & 360,0 \\
\hline Desvio-Padrão & 66,9 & 46,7 & 32,6 & 32,0 & 22,6 & 43,3 \\
\hline Coeficiente de variação & $172 \%$ & $133 \%$ & $97 \%$ & $128 \%$ & $76 \%$ & $132 \%$ \\
\hline
\end{tabular}

\section{h) Divulgação dos objetivos estratégicos para os níveis organizacionais}

Para possibilitar a realização da prova do Qui-quadrado, onde no máximo $25 \%$ das células 
podem ter frequência esperada abaixo de cinco observações, procedeu-se com um ajuste na apresentação dos dados. As respostas foram reunidas em duas grandes categorias, conforme apresenta a Tabela 21, comparando a divulgação dos objetivos estratégicos para toda a organização versus a divulgação segmentada para determinados níveis organizacionais.

Tabela 21 - Divulgação dos objetivos e técnicas

\begin{tabular}{|c|c|c|c|c|c|c|c|}
\hline $\begin{array}{l}\text { Para quem os objetivos } \\
\text { estratégicos corporativos } \\
\text { são divulgados? }\end{array}$ & & APO & BSC & $\begin{array}{l}\text { Objetivos } \\
\text { Financeiros }\end{array}$ & $\begin{array}{l}\text { Intuitiva/ } \\
\text { Criativa }\end{array}$ & $\begin{array}{c}\text { Técnica } \\
\text { Participativa }\end{array}$ & Total \\
\hline \multirow[t]{2}{*}{$\begin{array}{l}\text { Sócios/diretores/gerentes } \\
\text { e superiores }\end{array}$} & $\mathrm{n}$ & 20 & 32 & 39 & 32 & 7 & 130 \\
\hline & $\%$ & $48,8 \%$ & $37,2 \%$ & $54,9 \%$ & $58,2 \%$ & $36,8 \%$ & $47,8 \%$ \\
\hline \multirow[t]{2}{*}{ Toda organização } & $\mathrm{n}$ & 21 & 54 & 32 & 23 & 12 & 142 \\
\hline & $\%$ & $51,2 \%$ & $62,8 \%$ & $45,1 \%$ & $41,8 \%$ & $63,2 \%$ & $52,2 \%$ \\
\hline \multirow[t]{2}{*}{ Total } & $\mathrm{n}$ & 41 & 86 & 71 & 55 & 19 & 272 \\
\hline & $\%$ & $100 \%$ & $100 \%$ & $100 \%$ & $100 \%$ & $100 \%$ & $100 \%$ \\
\hline
\end{tabular}

Pela prova estatística, a $\alpha=0,05$, não foi possível concluir pela associação entre técnica e público da divulgação dos objetivos estratégicos $\left(\chi^{2}=8,618\right.$ e $\left.\mathrm{p}=0,071\right)$. Porém, a $\alpha=0,10$, foi possível constatar a associação entre técnicas e público da divulgação. Pode-se notar, descritivamente, essas informações, na Tabela 21, que BSC e Processo Participativo têm, relativamente, maior divulgação dos objetivos estratégicos para toda a organização $(63,2 \%)$ ante Processo Intuitivo (41,8\%).

\section{i) Nível de participação na definição da estratégia}

Por meio da Prova do Qui-quadrado, a $\alpha=0,05$, não foi possível rejeitar a hipótese de nulidade; mas ao nível de significância de 0,10, foi possível rejeitar a hipótese de independência entre técnica de organização de objetivos estratégicos e nível de participação na definição de estratégia corporativa $\left(\chi^{2}=26,125 ; p=0,052\right)$ (Tabela 22). 
Tabela 22 - Nível de participação e técnica

\begin{tabular}{|c|c|c|c|c|c|c|c|}
\hline $\begin{array}{l}\text { Nível de participação do } \\
\text { respondente na definição da } \\
\text { estratégia corporativa }\end{array}$ & & APO & $\mathrm{BSC}$ & $\begin{array}{l}\text { Objetivos } \\
\text { Financeiros }\end{array}$ & $\begin{array}{l}\text { Intuitiva/ } \\
\text { Criativa }\end{array}$ & $\begin{array}{c}\text { Técnica } \\
\text { Participativa }\end{array}$ & Total \\
\hline \multirow[t]{2}{*}{$\begin{array}{l}\text { Defino e participo de todo o } \\
\text { processo, inclusive decisão }\end{array}$} & $\mathrm{n}$ & 9 & 19 & 16 & 18 & 6 & 68 \\
\hline & $\%$ & $20,5 \%$ & $20,7 \%$ & $21,3 \%$ & $31,6 \%$ & $28,6 \%$ & $23,5 \%$ \\
\hline \multirow[t]{2}{*}{ Participo de todo o processo } & $\mathrm{n}$ & 13 & 16 & 14 & 12 & 8 & 63 \\
\hline & $\%$ & $29,5 \%$ & $17,4 \%$ & $18,7 \%$ & $21,1 \%$ & $38,1 \%$ & $21,8 \%$ \\
\hline \multirow[t]{2}{*}{$\begin{array}{l}\text { Participo em partes do } \\
\text { processo/sou consultado }\end{array}$} & $\mathrm{n}$ & 12 & 28 & 22 & 24 & 6 & 92 \\
\hline & $\%$ & $27,3 \%$ & $30,4 \%$ & $29,3 \%$ & $42,1 \%$ & $28,6 \%$ & $31,8 \%$ \\
\hline \multirow[t]{2}{*}{$\begin{array}{l}\text { Forneço informações para o } \\
\text { processo }\end{array}$} & $\mathrm{n}$ & 4 & 14 & 11 & 1 & 1 & 31 \\
\hline & $\%$ & $9,1 \%$ & $15,2 \%$ & $14,7 \%$ & $1,8 \%$ & $4,8 \%$ & $10,7 \%$ \\
\hline \multirow[t]{2}{*}{$\begin{array}{l}\text { Sou informado da estratégia ao } \\
\text { final do processo }\end{array}$} & $\mathrm{n}$ & 6 & 15 & 12 & 2 & 0 & 35 \\
\hline & $\%$ & $13,6 \%$ & $16,3 \%$ & $16,0 \%$ & $3,5 \%$ & $0,0 \%$ & $12,1 \%$ \\
\hline \multirow[t]{2}{*}{ Total } & $\mathrm{n}$ & 44 & 92 & 75 & 57 & 21 & 289 \\
\hline & $\%$ & $100 \%$ & $100 \%$ & $100 \%$ & $100 \%$ & $100 \%$ & $100 \%$ \\
\hline
\end{tabular}

Neste caso é recomendável refazer a pesquisa com uma amostra maior, para uma conclusão definitiva. Mas, ao menos descrevendo uma tendência, a partir do Gráfico 2, e de dados da Tabela 22, é possível perceber que o processo participativo é relativamente mais presente, quando o respondente participa de todo o processo.

Descritivamente, nota-se que para as técnicas intuitivas e também para a participativa o número de respondentes que são apenas informados é reduzido, enquanto que nas demais é possível ver um percentual de ao menos $13 \%$ dos respondentes que possuem essa participação.

Por outro lado, as técnicas BSC, o APO e Objetivos Financeiros têm maior participação no processo fragmentado. 


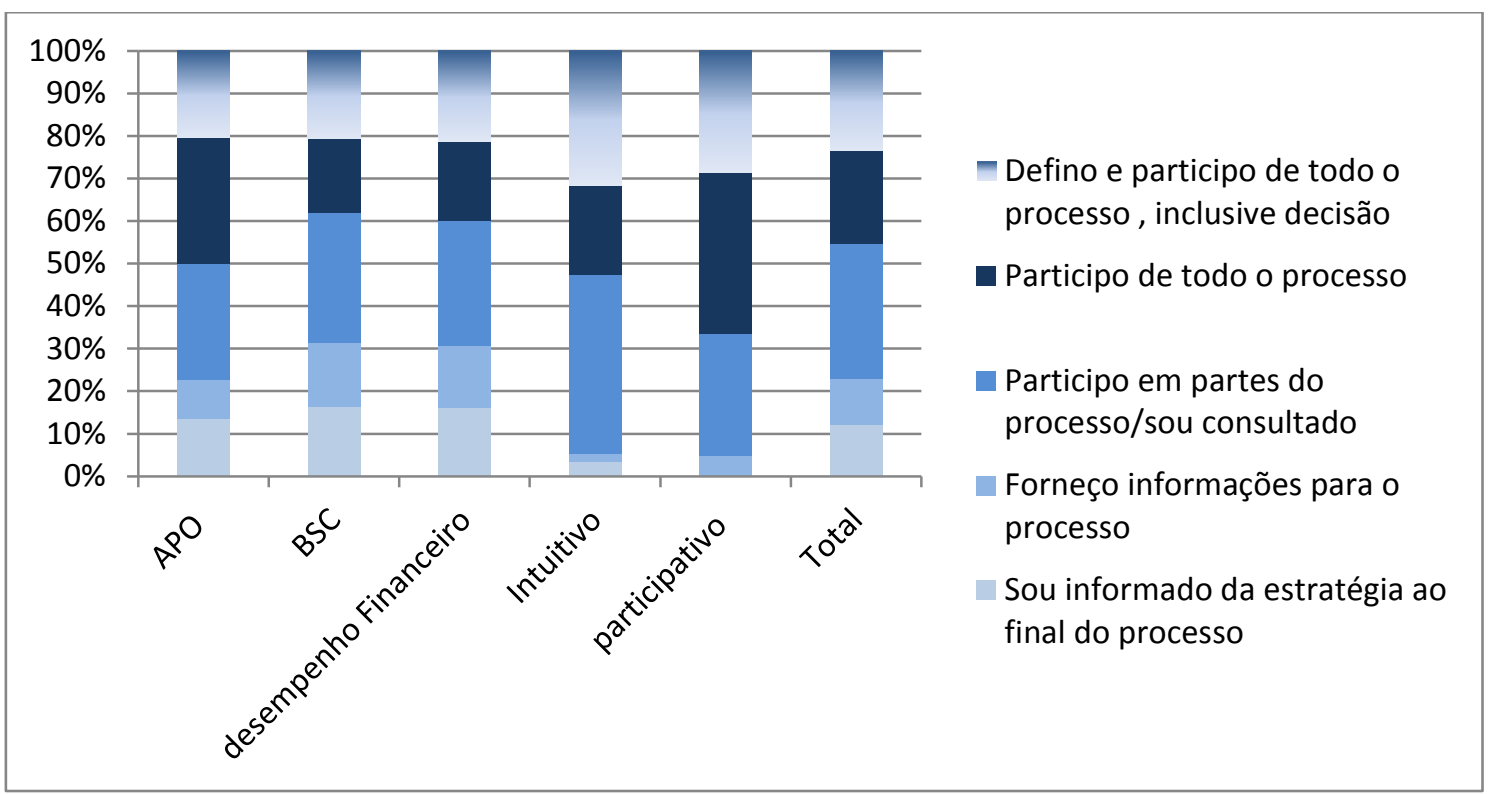

Gráfico 2 - Participação na estratégia e uso da técnica

Diante do exposto (associação entre faturamento e técnica, associação entre participação na estratégia e técnica), levanta-se a hipótese que a participação do respondente relaciona-se ao faturamento da empresa: empresa de alto faturamento a participação é segmentada; empresa de baixo faturamento o respondente participa de todo o processo de definição de estratégias.

De acordo com a Prova do Qui-quadrado, temos $\chi^{2}=45,373 ; \mathrm{p}<0,001$, comprovando-se a hipótese levantada. E descritivamente, na Tabela 23: 50\% dos respondentes de empresas de menor faturamento participam de todo o processo, enquanto apenas 11,6\% dos respondentes de empresas de maior faturamento têm este comportamento. 
Tabela 23 - Nível de participação do respondente e faturamento da organização

\begin{tabular}{|c|c|c|c|c|c|c|}
\hline $\begin{array}{l}\text { Nível de participação do } \\
\text { respondente na definição da } \\
\text { estratégia corporativa }\end{array}$ & & $\begin{array}{l}\text { Até R\$ } 16 \\
\text { milhões }\end{array}$ & $\begin{array}{c}\text { Entre } \\
\text { R\$16milhões e } \\
300 \text { milhões }\end{array}$ & $\begin{array}{c}\text { Entre } \mathrm{R} \$ 300 \\
\text { milhões e } \mathrm{R} \$ 1 \\
\text { bilhão }\end{array}$ & $\begin{array}{l}\text { Acima de R\$ } 1 \\
\text { bilhão }\end{array}$ & Total \\
\hline \multirow[t]{2}{*}{$\begin{array}{l}\text { Defino e participo de todo o } \\
\text { processo, inclusive decisão }\end{array}$} & $\mathrm{n}$ & 27 & 12 & 12 & 16 & 67 \\
\hline & $\%$ & $50,0 \%$ & $25,0 \%$ & $25,5 \%$ & $11,6 \%$ & $23,3 \%$ \\
\hline \multirow[t]{2}{*}{ Participo de todo o processo } & $\mathrm{n}$ & 13 & 11 & 7 & 32 & 63 \\
\hline & $\%$ & $24,1 \%$ & $22,9 \%$ & $14,9 \%$ & $23,2 \%$ & $22,0 \%$ \\
\hline \multirow[t]{2}{*}{$\begin{array}{l}\text { Participo em partes do } \\
\text { processo/sou consultado }\end{array}$} & $\mathrm{n}$ & 8 & 19 & 14 & 51 & 92 \\
\hline & $\%$ & $14,8 \%$ & $39,6 \%$ & $29,8 \%$ & $37,0 \%$ & $32,1 \%$ \\
\hline \multirow[t]{2}{*}{$\begin{array}{l}\text { Forneço informações para o } \\
\text { processo }\end{array}$} & $\mathrm{n}$ & 5 & 3 & 7 & 16 & 31 \\
\hline & $\%$ & $9,3 \%$ & $6,2 \%$ & $14,9 \%$ & $11,6 \%$ & $10,8 \%$ \\
\hline \multirow[t]{2}{*}{$\begin{array}{l}\text { Sou informado da estratégia ao } \\
\text { final do processo }\end{array}$} & $\mathrm{n}$ & 1 & 3 & 7 & 23 & 34 \\
\hline & $\%$ & $1,9 \%$ & $6,2 \%$ & $14,9 \%$ & $16,7 \%$ & $11,8 \%$ \\
\hline \multirow[t]{2}{*}{ Total } & $\mathrm{n}$ & 54 & 48 & 47 & 138 & 287 \\
\hline & $\%$ & $100 \%$ & $100 \%$ & $100 \%$ & $100 \%$ & $100 \%$ \\
\hline
\end{tabular}

\section{j) Número de objetivos estratégicos ${ }^{2}$}

Sobre o número de objetivos estratégicos optou-se por dividir em cinco grandes blocos analisando os objetivos estabelecidos, implementados com sucesso com a comparação entre eles, o número ideal na visão do respondente e os objetivos individuais do respondente associados a estratégia.

\section{1) Número de objetivos estabelecidos pela organização da qual o respondente faz parte}

A Tabela 24 apresenta a quantidade de objetivos estratégicos corporativos, estabelecida pelas organizações. Realizada a prova de Kruskal-Wallis: $\chi^{2}=13,299 ; \mathrm{p}=0,010$, rejeitou-se a hipótese de igualdade $(\alpha=0,05)$ entre técnicas no que diz respeito à quantidade de objetivos estabelecidos.

Com isso, procedeu-se a comparações múltiplas (disponíveis no Apêndice II), que resultaram

\footnotetext{
${ }^{2}$ Retirou-se da análise um caso considerado "outlier", cuja técnica empregada se referia ao processo intuitivo, com as seguintes respostas: objetivos estabelecidos $=200$; número adequado de objetivos $=300$, objetivos implementados com sucesso $=160$.
} 
nas seguintes conclusões: o Processo Intuitivo difere da técnica BSC em relação ao número de objetivos estratégicos. E descritivamente, nota-se que o Processo Intuitivo tem menor número de objetivos estratégicos estabelecidos do que o método BSC. No restante das técnicas, não foi possível diferenciá-las.

Tabela 24 - Número de objetivos estabelecidos e técnicas

\begin{tabular}{lccccc}
\hline $\begin{array}{l}\text { Quantos objetivos são } \\
\text { estabelecidos pela } \\
\text { organização? }\end{array}$ & APO & BSC & $\begin{array}{c}\text { Objetivos } \\
\text { Financeiros }\end{array}$ & $\begin{array}{c}\text { Intuitiva/ } \\
\text { Criativa }\end{array}$ & $\begin{array}{c}\text { Técnica } \\
\text { Participativa }\end{array}$ \\
\hline Média & 6,3 & 7,7 & 5,3 & 6,6 & 6,1 \\
\hline Mediana & 5 & 5 & 5 & 4 & 5 \\
\hline Mínimo & 1 & 1 & 1 & 1 & 1 \\
\hline Máximo & 45 & 32 & 15 & 50 & 17 \\
\hline Desvio-Padrão & 6,7 & 6,3 & 2,7 & 9,4 & 4,1 \\
\hline Coeficiente de variação & $106,4 \%$ & $81,5 \%$ & $52,0 \%$ & $142,5 \%$ & $67,9 \%$ \\
\hline
\end{tabular}

\section{2) Número de objetivos implementados com sucesso}

Para analisar o número de objetivos implementados com sucesso foi realizada a prova de Kruskal-Wallis: $\chi^{2}=20,629 ; \mathrm{p}<0,001$, que rejeitou a hipótese de igualdade entre técnicas no que diz respeito à quantidade de objetivos implementados com sucesso. Procedeu-se a comparações múltiplas, que indicaram que o Processo Intuitivo difere das técnicas BSC, APO e Processo Participativo.

Descritivamente, nota-se que Processo Intuitivo tem menor mediana e média de objetivos estratégicos implementados com sucesso do que o método BSC, APO e Processo Participativo. No restante das técnicas, não foi possível diferenciá-las (Tabela 25).

Tabela 25 - Número de objetivos implementados com sucesso e técnicas

\begin{tabular}{lccccc}
\hline $\begin{array}{l}\text { Número de objetivos } \\
\text { implementados com } \\
\text { sucesso }\end{array}$ & APO & BSC & $\begin{array}{c}\text { Objetivos } \\
\text { Financeiros }\end{array}$ & $\begin{array}{c}\text { Intuitiva/ } \\
\text { Criativa }\end{array}$ & $\begin{array}{c}\text { Técnica } \\
\text { Participativa }\end{array}$ \\
\hline Média & 4,5 & 4,4 & 3,3 & 3,3 & 4,3 \\
\hline Mediana & 3,5 & 3 & 3 & 2,5 & 3 \\
\hline Mínimo & 0 & 0 & 0 & 0 & 0 \\
\hline Máximo & 36 & 20 & 10 & 25 & 10 \\
\hline Desvio-Padrão & 5,3 & 3,5 & 1,9 & 4,4 & 2,7 \\
\hline Coeficiente de variação & $118,8 \%$ & $78,8 \%$ & $57,1 \%$ & $135,9 \%$ & $62,3 \%$ \\
\hline
\end{tabular}

\section{3) Comparação conjunta entre o número de objetivos}

A Tabela 26 apresenta a razão entre objetivos implementados com sucesso e objetivos estabelecidos (indicador de eficiência de objetivos) 
Tabela 26 - Razão entre objetivos implementados com sucesso e objetivos estabelecidos

\begin{tabular}{lcccccc}
\hline & APO & BSC & $\begin{array}{c}\text { Objetivos } \\
\text { Financeiros }\end{array}$ & $\begin{array}{c}\text { Intuitiva/ } \\
\text { Criativa }\end{array}$ & $\begin{array}{c}\text { Técnica } \\
\text { Participativa }\end{array}$ & APO \\
\hline Média & 0,72 & 0,65 & 0,67 & 0,57 & 0,68 & 0,65 \\
\hline Mediana & 0,75 & 0,67 & 0,67 & 0,6 & 0,67 & 0,67 \\
\hline Mínimo & 0 & 0 & 0 & 0 & 0 & 0 \\
\hline Máximo & 1 & 1 & 1 & 1 & 0,29 & 0,27 \\
\hline Desvio-Padrão & 0,25 & 0,26 & 0,27 & 0,30 & $42 \%$ & $42 \%$ \\
\hline $\begin{array}{l}\text { Coeficiente de } \\
\text { variação }\end{array}$ & $35 \%$ & $40 \%$ & $40 \%$ & $53 \%$ & & 1 \\
\hline
\end{tabular}

Os resultados apresentados na tabela acima revelam que, em média, próximo de $2 / 3$ dos objetivos estratégicos corporativos são implementados com sucesso. A dispersão relativa (coeficiente de variação) deste indicador é de $42 \%$, o que não é desprezível.

Realizada a Prova de Kruskal-Wallis: $\chi^{2}=5,756 ; \mathrm{p}=0,218$, não foi possível rejeitar a hipótese de igualdade entre técnicas no que diz respeito ao indicador de eficiência (média) dos objetivos estratégicos implementados.

\section{4) Número adequado de objetivos}

Para esta categoria, não foi possível diferenciar as técnicas quanto ao número de objetivos adequados, na visão do respondente do questionário (realizada prova de Kruskal-Wallis: $\chi^{2}=$ $4,458 ; \mathrm{p}=0,344)$. Nota-se que a estatística mediana do número de objetivos estabelecidos e adequados é semelhante qualquer que seja a técnica (Tabela 27).

Tabela 27 - Número adequado de objetivos e técnicas

\begin{tabular}{lccccc}
\hline $\begin{array}{l}\text { Número adequado de } \\
\text { objetivos na opinião } \\
\text { dos respondentes }\end{array}$ & APO & BSC & $\begin{array}{c}\text { Objetivos } \\
\text { Financeiros }\end{array}$ & $\begin{array}{c}\text { Intuitiva/ } \\
\text { Criativa }\end{array}$ & $\begin{array}{c}\text { Técnica } \\
\text { Participativa }\end{array}$ \\
\hline Média & 4,8 & 6,0 & 5,0 & 6,3 & 5,9 \\
\hline Mediana & 5 & 5 & 5 & 5 & 5 \\
\hline Mínimo & 1 & 1 & 1 & 1 & 1 \\
\hline Máximo & 14,0 & 25,0 & 23,0 & 50,0 & 13,0 \\
\hline Desvio-Padrão & 2,4 & 4,5 & 3,1 & 8,3 & 2,9 \\
\hline $\begin{array}{l}\text { Coeficiente de } \\
\text { variação }\end{array}$ & $50,1 \%$ & $75,0 \%$ & $61,4 \%$ & $132,0 \%$ & $48,8 \%$ \\
\hline
\end{tabular}

5) Número de objetivos organizacionais individuais do respondente associados aos objetivos estratégicos corporativos $^{3}$

A maioria da amostra (76\% dos entrevistados) menciona de 2 a 6 objetivos como objetivos

\footnotetext{
${ }^{3}$ De forma a constituir uma prova estatística, somente nesta questão, foram retirados da amostra respondentes cuja resposta foi "outros" (4 casos).
} 
individuais associados aos objetivos corporativos. Estes estão segmentados em: 45,7\% de respondentes mencionando de 2 a 3 objetivos e outros $29,6 \%$ mencionando de 4 a 6 objetivos. Realizada a prova de Kruskal-Wallis $\left(\chi^{2}=5,863 ; p=0,210\right)$, não foi possível concluir que o número (médio) de objetivos (pessoais) organizacionais relacionados aos objetivos estratégicos seja diferente de acordo com as técnicas (Tabela 28).

Tabela 28 - Número de objetivos individuais e técnicas

\begin{tabular}{|c|c|c|c|c|c|c|c|}
\hline $\begin{array}{l}\text { Número de objetivos } \\
\text { individuais as sociados aos } \\
\text { objetivos estratégicos }\end{array}$ & & APO & BSC & $\begin{array}{c}\text { Objetivos } \\
\text { Financeiros }\end{array}$ & $\begin{array}{l}\text { Intuitiva/ } \\
\text { Criativa }\end{array}$ & $\begin{array}{c}\text { Técnica } \\
\text { Participativa }\end{array}$ & Total \\
\hline \multirow[t]{2}{*}{ "0-1" } & $\mathrm{n}$ & 5 & 7 & 12 & 9 & 1 & 34 \\
\hline & $\%$ & $11,4 \%$ & $7,7 \%$ & $16,2 \%$ & $17,0 \%$ & $5,6 \%$ & $12,1 \%$ \\
\hline \multirow[t]{2}{*}{ "2-3" } & $\mathrm{n}$ & 18 & 39 & 34 & 27 & 10 & 128 \\
\hline & $\%$ & $40,9 \%$ & $42,9 \%$ & $45,9 \%$ & $50,9 \%$ & $55,6 \%$ & $45,7 \%$ \\
\hline \multirow[t]{2}{*}{ "4-6" } & $\mathrm{n}$ & 16 & 32 & 21 & 10 & 4 & 83 \\
\hline & $\%$ & $36,4 \%$ & $35,2 \%$ & $28,4 \%$ & $18,9 \%$ & $22,2 \%$ & $29,6 \%$ \\
\hline \multirow[t]{2}{*}{ "6-10" } & $\mathrm{n}$ & 5 & 13 & 7 & 7 & 3 & 35 \\
\hline & $\%$ & $11,4 \%$ & $14,3 \%$ & $9,5 \%$ & $13,2 \%$ & $16,7 \%$ & $12,5 \%$ \\
\hline \multirow[t]{2}{*}{ Total } & $\mathrm{n}$ & 44 & 91 & 74 & 53 & 18 & 280 \\
\hline & $\%$ & $100 \%$ & $100 \%$ & $100 \%$ & $100 \%$ & $100 \%$ & $100 \%$ \\
\hline
\end{tabular}

k) Nível organizacional responsável pela definição de elementos da Estratégia corporativa

1) Responsáveis pela definição da estratégia corporativa

A Tabela 29 e o Gráfico 3, a seguir, apresentam os responsáveis pela definição da estratégia corporativa segundo os respondentes da pesquisa. 
Tabela 29 - Responsáveis pela definição da estratégia e as técnicas

\begin{tabular}{|c|c|c|c|c|c|c|c|}
\hline $\begin{array}{l}\text { Responsáveis pela } \\
\text { definição da Estratégia } \\
\text { Corporativa }\end{array}$ & & APO & BSC & $\begin{array}{c}\text { Objetivos } \\
\text { Financeiros }\end{array}$ & $\begin{array}{l}\text { Intuitiva/ } \\
\text { Criativa }\end{array}$ & $\begin{array}{c}\text { Técnica } \\
\text { Participativa }\end{array}$ & Total \\
\hline \multirow[t]{2}{*}{ Matriz } & $\mathrm{n}$ & 17 & 38 & 29 & 11 & 5 & 100 \\
\hline & $\%$ & $38,6 \%$ & $42,2 \%$ & $38,7 \%$ & $19,3 \%$ & $23,8 \%$ & $34,8 \%$ \\
\hline \multirow[t]{2}{*}{ Conselho } & $\mathrm{n}$ & 14 & 30 & 24 & 17 & 5 & 90 \\
\hline & $\%$ & $31,8 \%$ & $33,3 \%$ & $32,0 \%$ & $29,8 \%$ & $23,8 \%$ & $31,4 \%$ \\
\hline \multirow[t]{2}{*}{ CEO } & $\mathrm{n}$ & 18 & 38 & 34 & 29 & 7 & 126 \\
\hline & $\%$ & $40,9 \%$ & $42,2 \%$ & $45,3 \%$ & $50,9 \%$ & $33,3 \%$ & $43,9 \%$ \\
\hline \multirow[t]{2}{*}{ Diretoria } & $\mathrm{n}$ & 14 & 22 & 27 & 23 & 9 & 95 \\
\hline & $\%$ & $31,8 \%$ & $24,4 \%$ & $36,0 \%$ & $40,4 \%$ & $42,9 \%$ & $33,1 \%$ \\
\hline \multirow[t]{2}{*}{ Gerência } & $\mathrm{n}$ & 2 & 6 & 8 & 1 & 2 & 19 \\
\hline & $\%$ & $4,5 \%$ & $6,7 \%$ & $10,7 \%$ & $1,8 \%$ & $9,5 \%$ & $6,6 \%$ \\
\hline Total & $\mathrm{n}$ & 44 & 90 & 75 & 57 & 21 & 287 \\
\hline
\end{tabular}

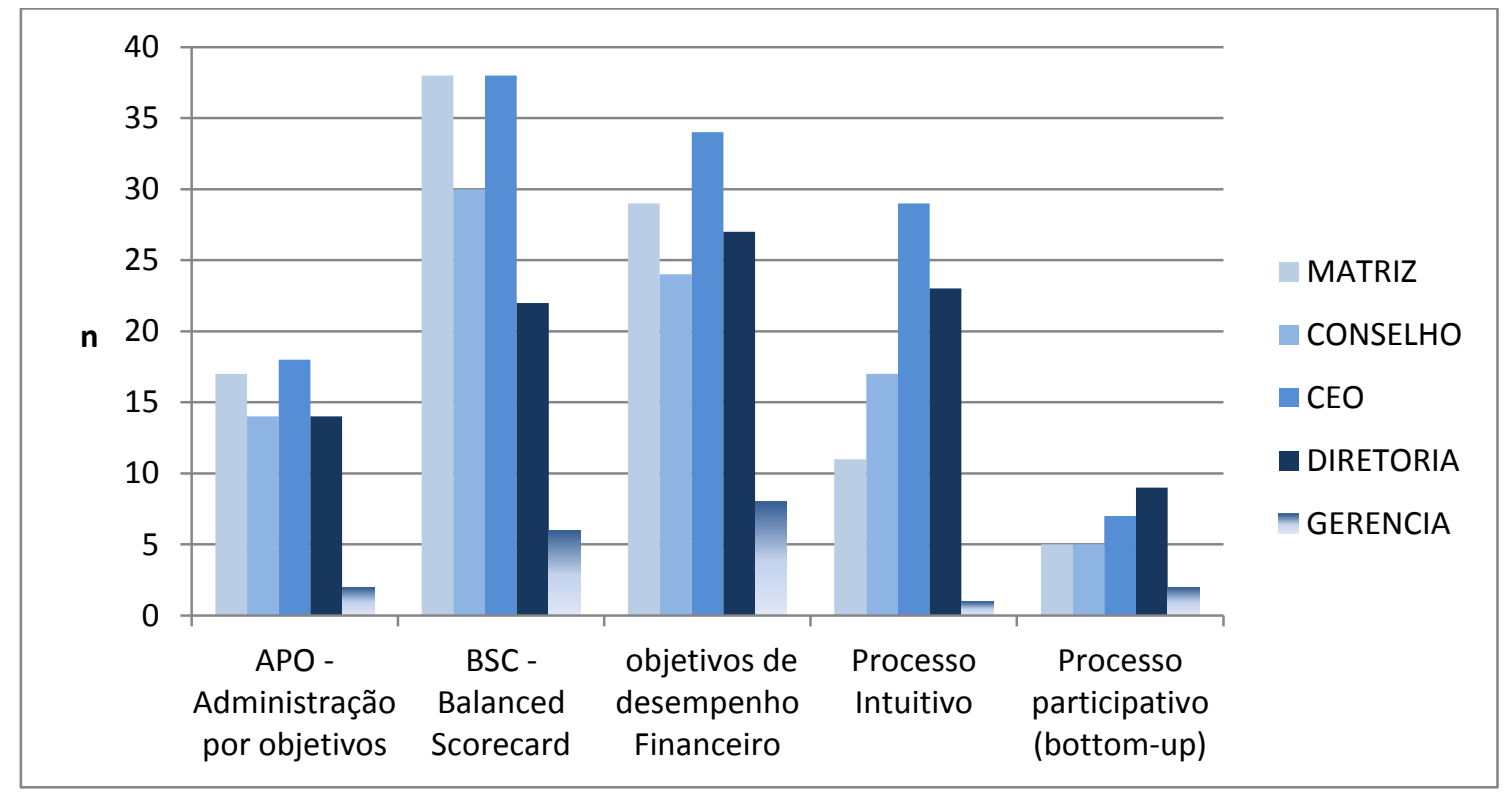

Gráfico 3 - Responsáveis pela definição da estratégia corporativa e as técnicas

\section{2) Responsáveis pela definição da objetivos estratégicos corporativos}

A Tabela 30 e o Gráfico 4 mostram que a definição dos objetivos estratégicos corporativos é, principalmente, responsabilidade do CEO e da diretoria. 
Tabela 30 - Responsáveis pela definição de objetivos estratégicos e as técnicas

\begin{tabular}{|c|c|c|c|c|c|c|c|}
\hline $\begin{array}{l}\text { Responsáveis pela } \\
\text { definição de Objetivos } \\
\text { Estratégicos }\end{array}$ & & APO & BSC & $\begin{array}{c}\text { Objetivos } \\
\text { Financeiros }\end{array}$ & $\begin{array}{l}\text { Intuitiva/ } \\
\text { Criativa }\end{array}$ & $\begin{array}{c}\text { Técnica } \\
\text { Participativa }\end{array}$ & Total \\
\hline \multirow[t]{2}{*}{ Matriz } & $\mathrm{n}$ & 8 & 20 & 15 & 7 & 1 & 51 \\
\hline & $\%$ & $18,6 \%$ & $22,2 \%$ & $20,3 \%$ & $12,3 \%$ & $4,8 \%$ & $17,9 \%$ \\
\hline \multirow[t]{2}{*}{ Conselho } & $\mathrm{n}$ & 5 & 20 & 17 & 10 & 2 & 54 \\
\hline & $\%$ & $11,6 \%$ & $22,2 \%$ & $23,0 \%$ & $17,5 \%$ & $9,5 \%$ & $18,9 \%$ \\
\hline \multirow[t]{2}{*}{ CEO } & $\mathrm{n}$ & 30 & 47 & 40 & 30 & 11 & 158 \\
\hline & $\%$ & $69,8 \%$ & $52,2 \%$ & $54,1 \%$ & $52,6 \%$ & $52,4 \%$ & $55,4 \%$ \\
\hline \multirow[t]{2}{*}{ Diretoria } & $\mathrm{n}$ & 18 & 38 & 38 & 36 & 13 & 143 \\
\hline & $\%$ & $41,9 \%$ & $42,2 \%$ & $51,4 \%$ & $63,2 \%$ & $61,9 \%$ & $50,2 \%$ \\
\hline \multirow[t]{2}{*}{ Gerência } & $\mathrm{n}$ & 5 & 7 & 12 & 6 & 5 & 35 \\
\hline & $\%$ & $11,6 \%$ & $7,8 \%$ & $16,2 \%$ & $10,5 \%$ & $23,8 \%$ & $12,3 \%$ \\
\hline Total & $\mathrm{n}$ & 43 & 90 & 74 & 57 & 21 & 285 \\
\hline
\end{tabular}

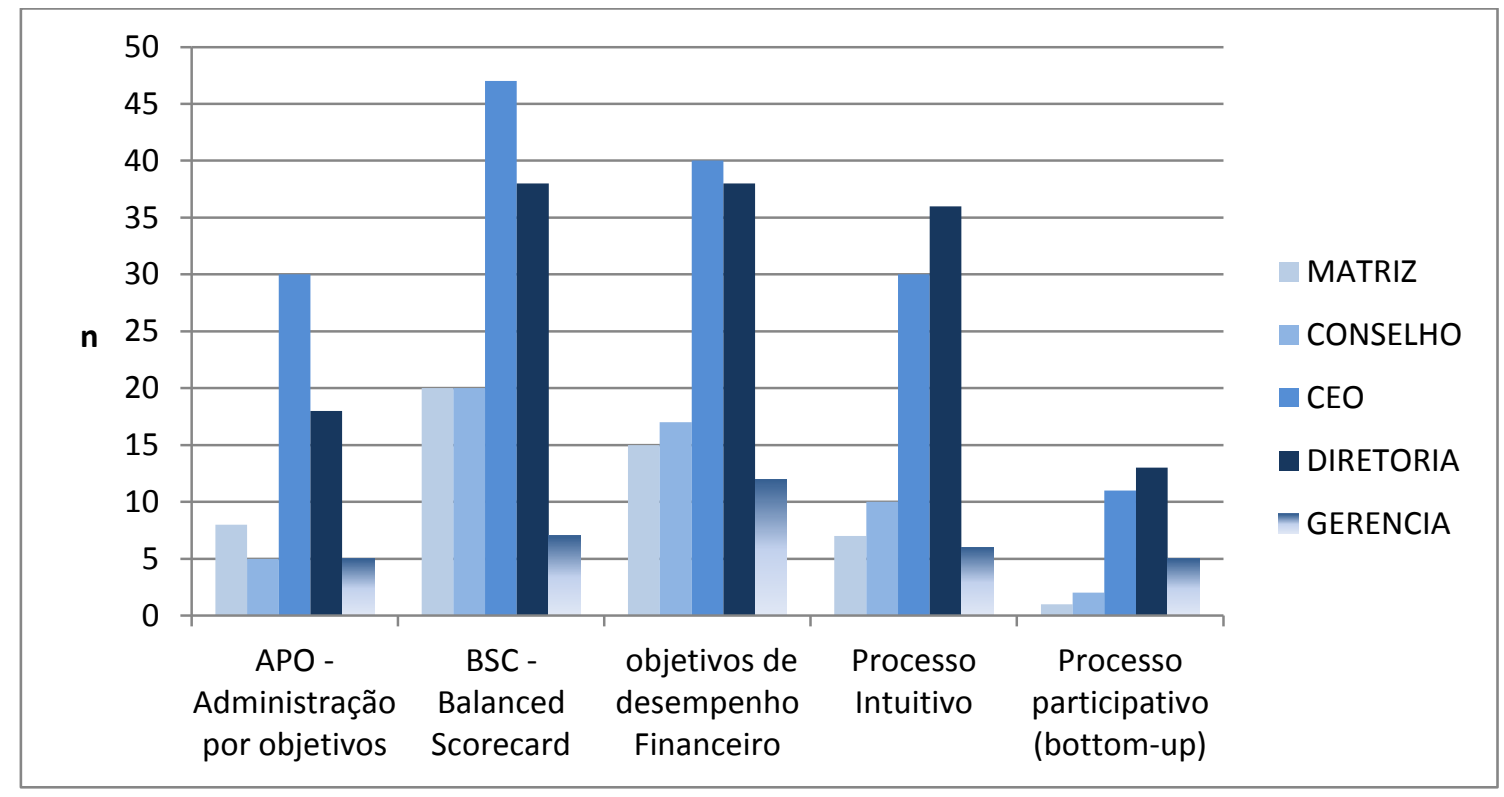

Gráfico 4 - Responsáveis pela definição de objetivos estratégicos e as técnicas

\section{3) Responsáveis pela definição de metas corporativas}

A definição de metas corporativas é uma atribuição, em sua maioria, de diretoria conforme o Gráfico 5 e a Tabela 31. 
Tabela 31 - Responsáveis pela definição de metas e as técnicas

\begin{tabular}{|c|c|c|c|c|c|c|c|}
\hline $\begin{array}{l}\text { Responsáveis pela } \\
\text { definição ds Metas } \\
\text { Estratégia Corporativa } \\
\end{array}$ & & APO & BSC & $\begin{array}{c}\text { Objetivos } \\
\text { Financeiros }\end{array}$ & $\begin{array}{c}\text { Intuitiva/ } \\
\text { Criativa }\end{array}$ & $\begin{array}{c}\text { Técnica } \\
\text { Participativa }\end{array}$ & Total \\
\hline \multirow[t]{2}{*}{ Matriz } & $\mathrm{n}$ & 9 & 22 & 14 & 8 & 1 & 54 \\
\hline & $\%$ & $21,4 \%$ & $24,4 \%$ & $19,2 \%$ & $14,0 \%$ & $4,8 \%$ & $19,1 \%$ \\
\hline \multirow[t]{2}{*}{ Conselho } & $\mathrm{n}$ & 7 & 19 & 12 & 8 & 1 & 47 \\
\hline & $\%$ & $16,7 \%$ & $21,1 \%$ & $16,4 \%$ & $14,0 \%$ & $4,8 \%$ & $16,6 \%$ \\
\hline \multirow[t]{2}{*}{ CEO } & $\mathrm{n}$ & 17 & 35 & 28 & 27 & 7 & 114 \\
\hline & $\%$ & $40,5 \%$ & $38,9 \%$ & $38,4 \%$ & $47,4 \%$ & $33,3 \%$ & $40,3 \%$ \\
\hline \multirow[t]{2}{*}{ Diretoria } & $\mathrm{n}$ & 21 & 49 & 45 & 37 & 13 & 165 \\
\hline & $\%$ & $50,0 \%$ & $54,4 \%$ & $61,6 \%$ & $64,9 \%$ & $61,9 \%$ & $58,3 \%$ \\
\hline \multirow[t]{2}{*}{ Gerência } & $\mathrm{n}$ & 12 & 21 & 21 & 13 & 8 & 75 \\
\hline & $\%$ & $28,6 \%$ & $23,3 \%$ & $28,8 \%$ & $22,8 \%$ & $38,1 \%$ & $26,5 \%$ \\
\hline Total & $\mathrm{n}$ & 42 & 90 & 73 & 57 & 21 & 283 \\
\hline
\end{tabular}

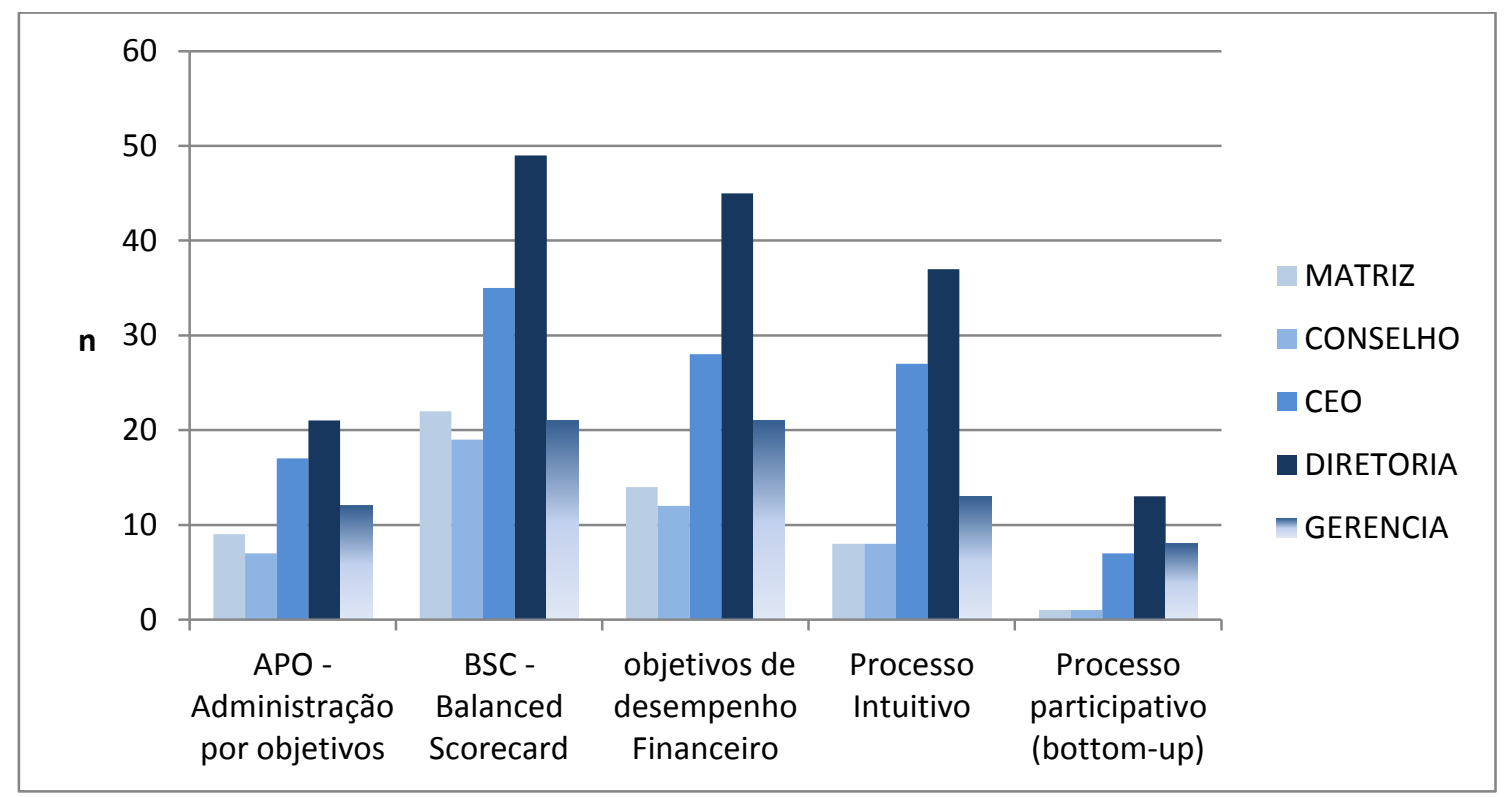

Gráfico 5 - Responsáveis pela definição de metas e as técnicas

\section{4) Em resumo}

O Gráfico 6, a seguir, apresenta o resumo das responsabilidades organizacionais apresentadas anteriormente compilado em um único elemento gráfico. 


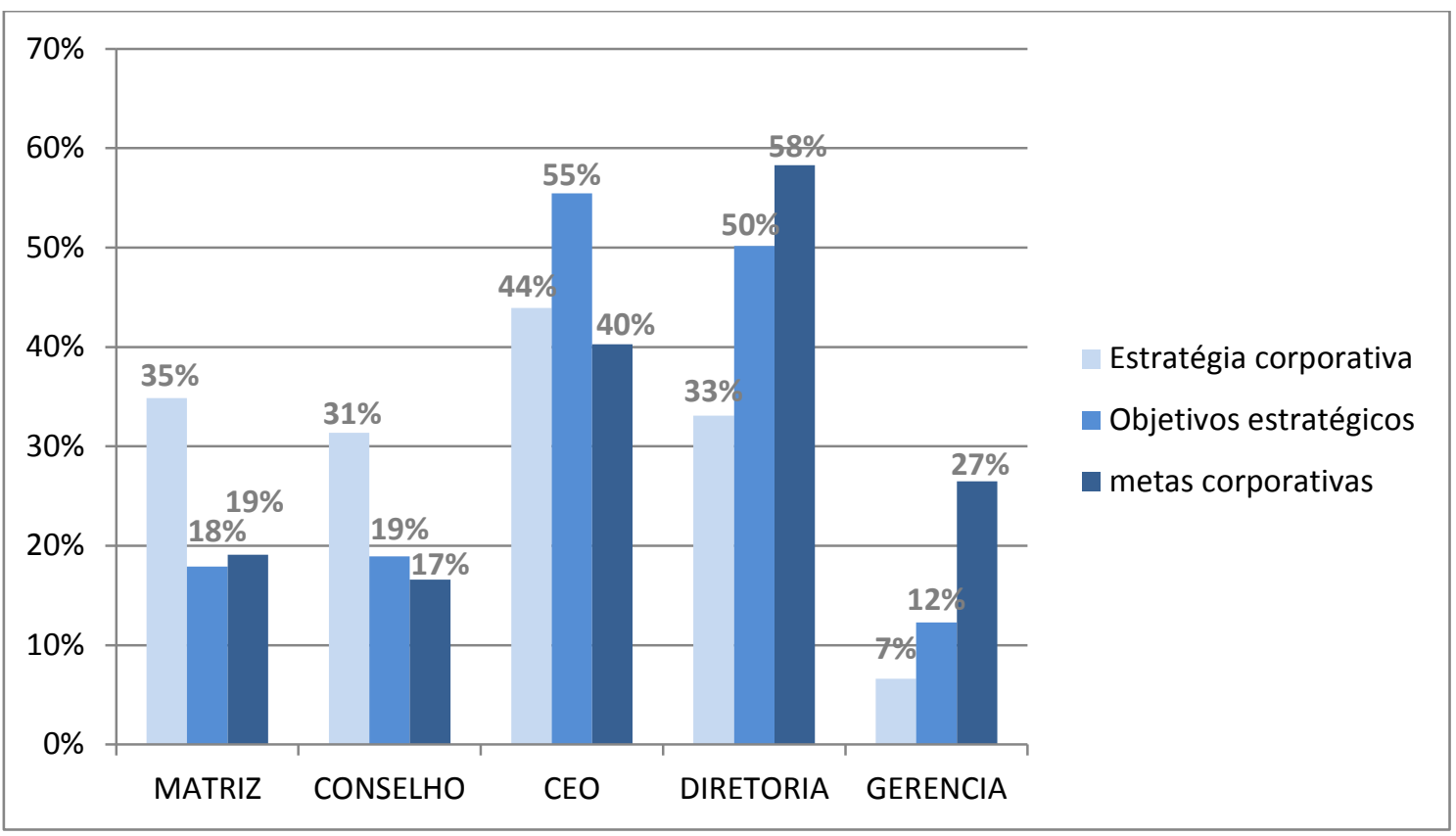

Gráfico 6 - Resumo das responsabilidades

A definição da estratégia corporativa é, relativamente, mais de responsabilidade de CEO, e em seguida, com percentuais semelhantes: matriz, diretoria e conselho. Para os objetivos estratégicos, a responsabilidade é mais concentrada nas mãos do CEO e diretoria, conforme Gráfico 6. Quando se fala de metas corporativas, as maiores indicações, relativamente, estão com as diretorias. E de acordo com a prova do Qui-quadrado (Tabela 32):

Tabela 32 - Responsáveis e $\chi^{2}$ (observado)

\begin{tabular}{lc}
\hline Responsáveis pela definição & $\chi^{2}$ (observado) \\
\hline Estratégia Corporativa & 15,81 \\
\hline Objetivos Estratégicos & 17,94 \\
\hline Metas Corporativas & 11,95 \\
\hline
\end{tabular}

Comparando-se com $\chi^{2}$ (crítico) ao nível de significância de 0,05 e 0,10 (26,30 e 23,54 respectivamente), não foi possível rejeitar a hipótese de independência entre responsável por cada definição e técnica.

\section{l) Percepção de satisfação dos respondentes em relação aos aspectos estratégicos}

Em ordem decrescente de concordância (concorda totalmente ou parcialmente), segue o Gráfico 7, da distribuição das questões avaliadas: 


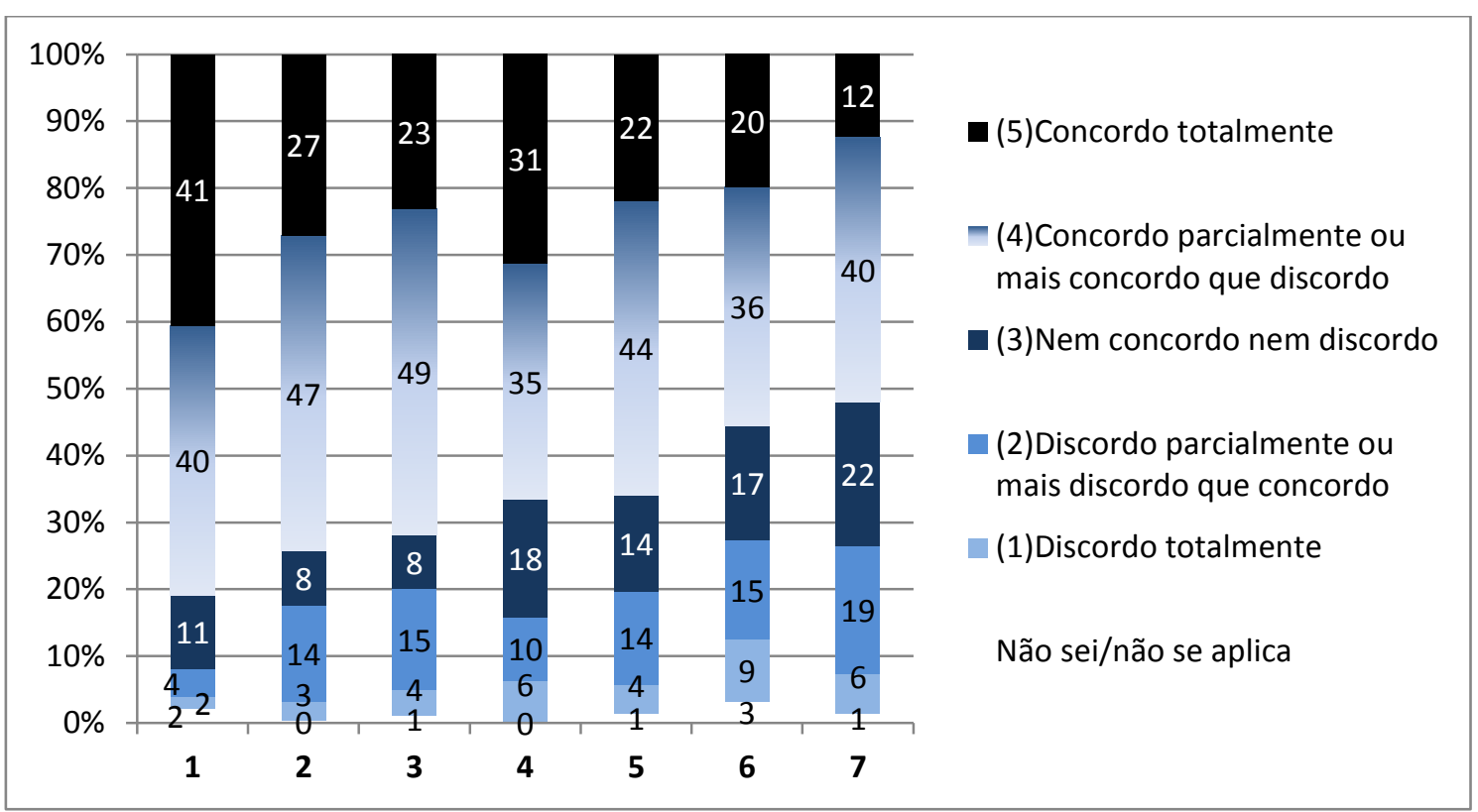

Gráfico 7 - Percepção de satisfação dos respondentes em relação aos aspectos estratégicos

Legenda do Gráfico 7:

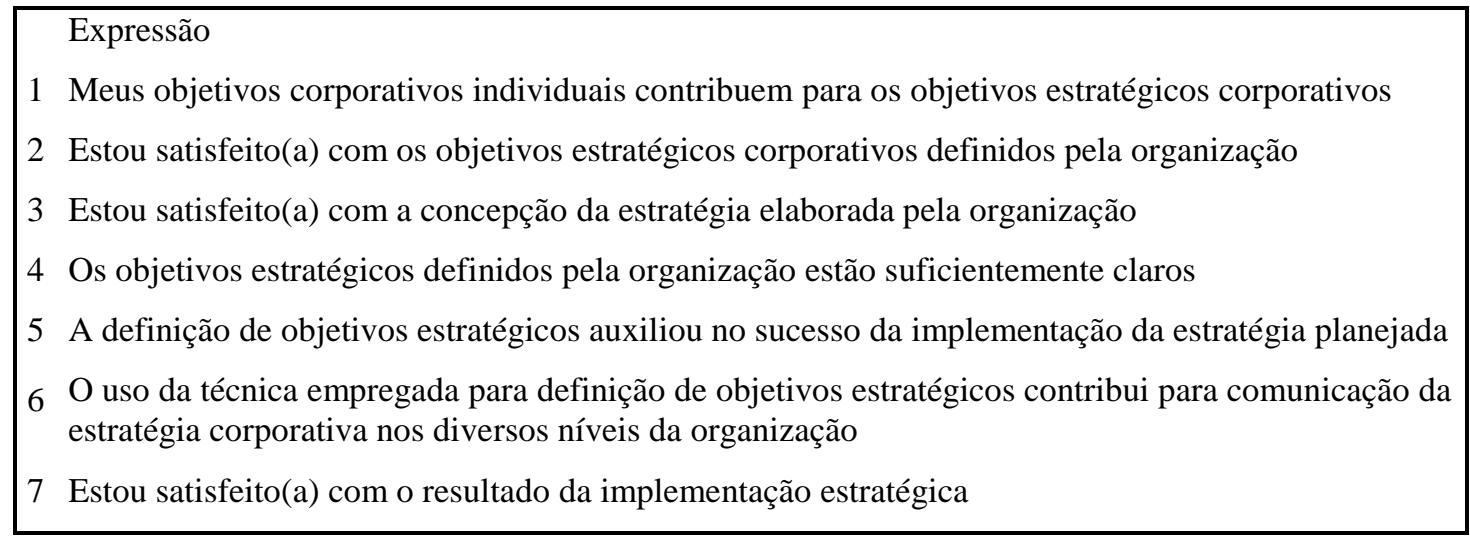

Em geral, descritivamente, pode-se notar que há maior concordância em relação à "Meus objetivos corporativos individuais contribuem para os objetivos estratégicos da corporação"(80,9\% da amostra), porém as expressões com menor concordância se refere à "O uso da técnica empregada contribuiu para comunicação da estratégia corporativa"(55\%) ou à "Estou satisfeito com o resultado da implementação estratégica"(52\%).

E realizada Prova de Kruskal-Wallis, para comparação das técnicas em relação à satisfação resultou nas informações apresentadas na Tabela 33: 
Tabela 33 - Prova de Kruskal-Wallis para comparação das técnicas em relação à satisfação do respondente

\begin{tabular}{lcc}
\hline & $\chi^{2}$ & $\mathrm{p}$ \\
\hline $\begin{array}{l}\text { Estou satisfeito(a) com a concepção (elaboração do plano estratégico) da estratégia } \\
\text { elaborada pela organização }\end{array}$ & 5,81 & 0,214 \\
\hline $\begin{array}{l}\text { Estou satisfeito(a) com os objetivos estratégicos corporativos definidos pela } \\
\text { organização }\end{array}$ & 1,931 & 0,748 \\
\hline Meus objetivos individuais contribuem para os objetivos estratégicos corporativos & 7,416 & 0,115 \\
\hline Os objetivos estratégicos definidos pela sua organização estão suficientemente claros & 3,622 & 0,460 \\
\hline Estou satisfeito(a) com o resultado da implementação estratégica & 2,736 & 0,603 \\
\hline $\begin{array}{l}\text { A definição de objetivos estratégicos auxiliou no sucesso da implementação da } \\
\text { estratégia planejada }\end{array}$ & 4,497 & 0,343 \\
\hline $\begin{array}{l}\text { O uso da técnica empregada para definição de objetivos estratégicos contribui para } \\
\text { comunicação da estratégia corporativa nos diversos níveis da organização }\end{array}$ & 17,451 & 0,002 \\
\hline
\end{tabular}

Apenas a contribuição para a comunicação diferenciou-se entre as técnicas $(\mathrm{p}=0,002<0,05)$. E seguindo com as comparações múltiplas, apenas BSC (com 66\% de concordância) diferencia-se da técnica de Objetivos Financeiros (com $43 \%$ de concordância), e descritivamente, por meio do Gráfico 8, de colunas, ou na tabela de média de postos (disponível no Apêndice II), é possível notar que BSC possui maior concordância com a afirmação "A técnica empregada para a definição de objetivos estratégicos contribuiu para a comunicação da estratégia corporativa".

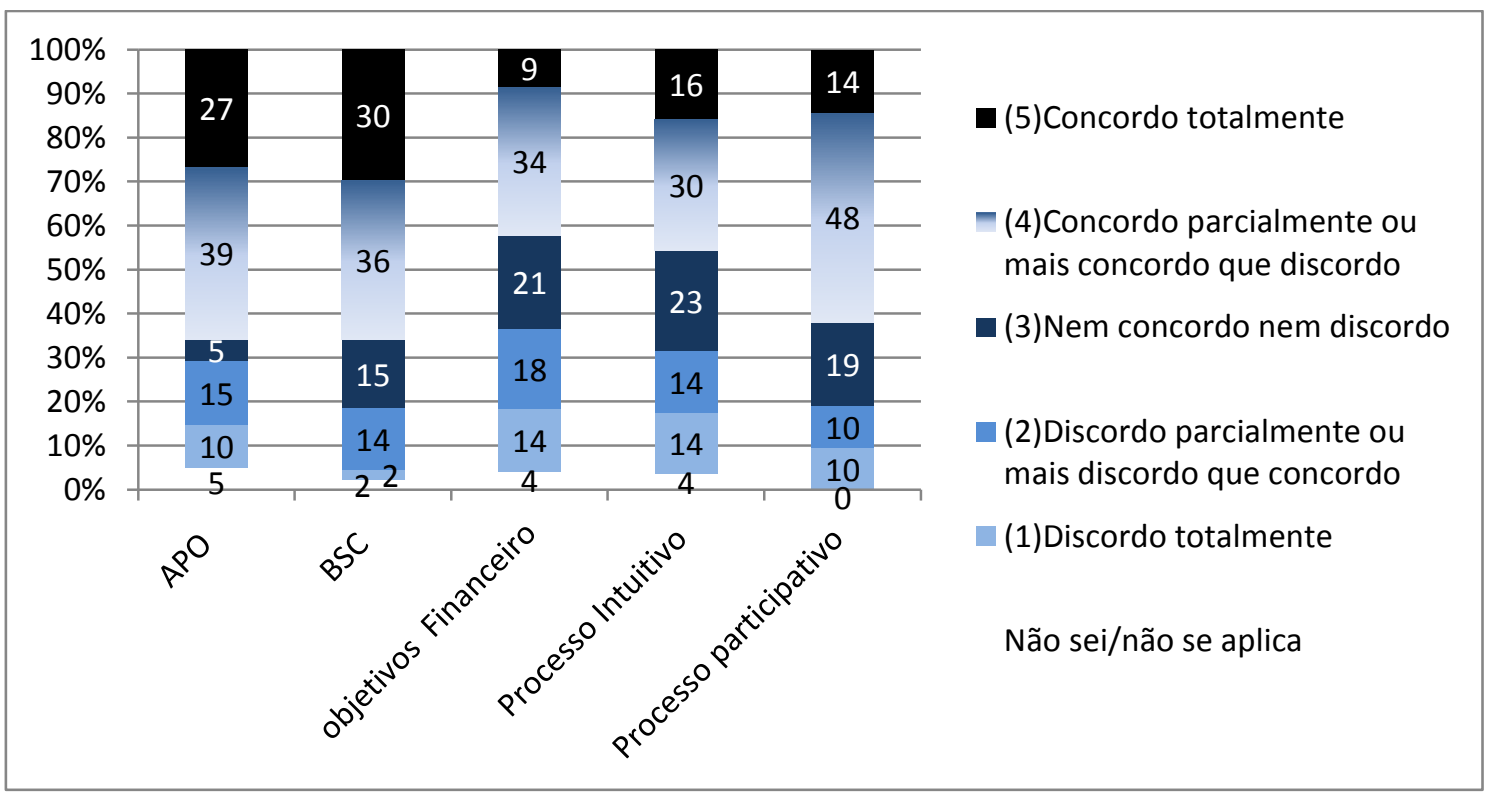

Gráfico 8 - Contribuição da técnica para a comunicação estratégica

\section{m) Uso dos objetivos estratégicos}

O Gráfico 9 apresenta os objetivos mais usados em ordem decrescente. E descritivamente, por meio desse gráfico de colunas, é possível eleger os seis objetivos, relativamente, mais comuns 
entre as empresas, os quais se encontram demarcados no Quadro 9.

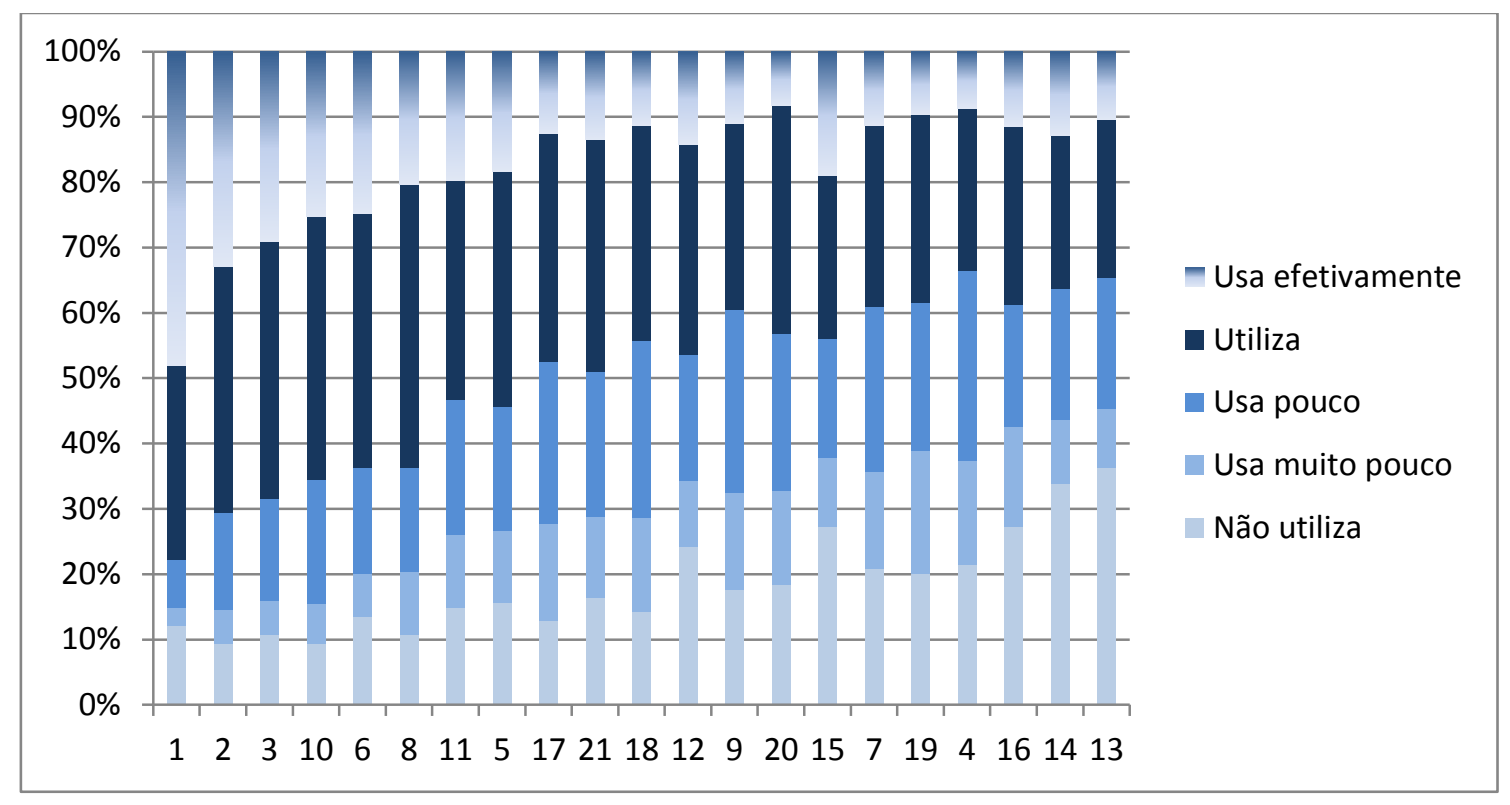

Gráfico 9 - Uso dos objetivos estratégicos

Quadro 9- Objetivos estratégicos mais usados

\begin{tabular}{|ll|}
\hline no. & Expressão \\
1 & Gerar valor para acionista proprietário \\
2 & Melhorar estrutura de custos \\
3 & Aumentar participação de mercado \\
10 & Melhorar Relacionamento com cliente \\
6 & Aumentar Qualidade \\
8 & Melhorar Prestação de Serviços \\
11 & Buscar incremento de Imagem \\
5 & Lançamento de novos produtos \\
17 & Aumentar Alinhamento da equipe com a estrategia \\
21 & Aprimorar Infraestrutura tecnológica \\
18 & Melhorar Trabalho em equipe \\
12 & Aumentar Produção \\
9 & Aumentar Parcerias \\
20 & Incrementar Capacitação \\
15 & Minimizar Impactono Meio ambiente \\
7 & Aprimorar Seleção de clientes \\
19 & Aumentar Retenção de talentos \\
4 & Oferecer Melhor Preço \\
16 & Aprimorar Relacionament ocom comunidade \\
14 & Incrementar Portfólio de P\&D \\
13 & Incrementar Distribuição \\
\hline
\end{tabular}

De forma a sumariar as os objetivos estratégicos corporativos em dimensões latentes, com menor número de itens a avaliar, procedeu-se a análise fatorial por componentes principais. 
A análise fatorial baseia-se nas correlações entre as variáveis constantes na questão analisada. O conjunto de variáveis que estão enquadradas coincide com os fatores resultantes da análise fatorial. A análise fatorial descreve um conjunto de variáveis com um número menor de fatores. Isto é possível quando as variáveis apresentam certo grau de correlação entre si.

O teste de Kaiser-Meyer-Olkin $(\mathrm{KMO}=0,905)$ e o teste de esfericidade de Bartlet (TEB: $\mathrm{p}<$ $0,001)$ comprovam a adequação dos dados à realização da análise fatorial.

Tabela 34 - Comunalidades

\begin{tabular}{|c|c|}
\hline & Comunalidades \\
\hline Q19aGerarvalorparaacionistaproprietário & 0,755 \\
\hline Q19bMelhorarestruturadecustos & 0,706 \\
\hline Q19cAumentarparticipaçãodemercado & 0,629 \\
\hline Q19dOferecerMelhorPreço & 0,702 \\
\hline Q19eLançamentodenovosprodutos & 0,806 \\
\hline Q19fAumentarQualidade & 0,628 \\
\hline Q19gAprimorarSeleçãodeclientes & 0,588 \\
\hline Q19hMelhorarPrestaçãodeServiços & 0,698 \\
\hline Q19iAumentarParcerias & 0,576 \\
\hline Q19jMelhorarRelacionamentocomcliente & 0,699 \\
\hline Q19kBuscarincrementodeImagem & 0,61 \\
\hline Q191AumentarProdução & 0,746 \\
\hline Q19mIncrementarDistribuição & 0,653 \\
\hline Q19nIncrementarPortfóliodeP\&D & 0,724 \\
\hline Q19oMinimizarImpactonoMeioambiente & 0,725 \\
\hline Q19pAprimorarRelacionamentocomcomunidade & 0,741 \\
\hline Q19qAumentarAlinhamentodaequipecomaEstrategia & 0,658 \\
\hline Q19rMelhorarTrabalhoemequipe & 0,756 \\
\hline Q19sAumentarRetençãodetalentos & 0,700 \\
\hline Q19tIncrementarCapacitação & 0,774 \\
\hline Q19uAprimorarInfraestruturatecnológica & 0,550 \\
\hline
\end{tabular}

Comunalidade é o valor que expressa quanto da variância de cada variável pode ser explicada pelos fatores comuns. Qualquer índice de comunalidade é maior do que 0,50, motivo pelo qual esta solução fatorial (6 fatores resultantes) explica todas as variáveis, sendo pertinente a 
entrada de cada uma das variáveis no modelo fatorial, sem qualquer exclusão. Com base na matriz de correlação são calculados os autovalores (eigenvalues), Tabela 35, que representam quanto da variância da estrutura dos dados pode ser atribuída a cada fator.

Tabela 35 - Autovalores

\begin{tabular}{lccc}
\hline Componente & autovalor & \% variância & $\begin{array}{c}\text { \%variância } \\
\text { acumulada }\end{array}$ \\
\hline 1 & 8,417 & 40,079 & 40,079 \\
\hline 2 & 1,651 & 7,861 & 47,94 \\
\hline 3 & 1,349 & 6,425 & 54,365 \\
\hline 4 & 1,172 & 5,581 & 59,946 \\
\hline 5 & 1,017 & 4,842 & 64,788 \\
\hline 6 & 0,816 & 3,884 & 68,672 \\
\hline
\end{tabular}

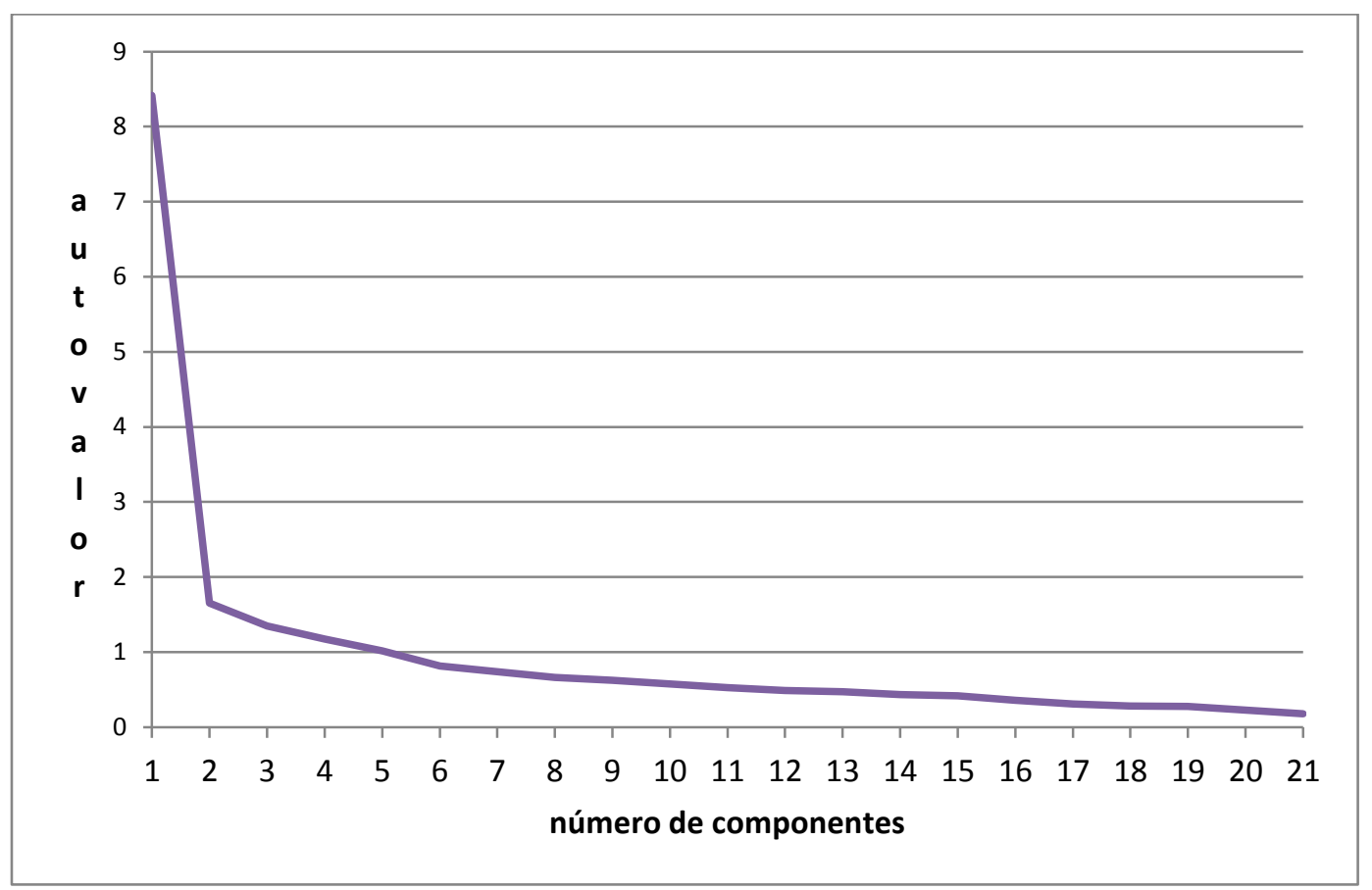

Gráfico 10 - Teste scree para identificação de número de fatores

Para Hair et al. (2005) o teste scree é usado para identificar o número ótimo de fatores que podem ser extraídos para análise. Pelo Gráfico 10 acima, nota-se que após o $6^{\circ}$ fator, os autovalores pouco agregam na explicação da estrutura dos dados. $\mathrm{O}$ primeiro fator explica 40,1\% da variância total (é o fator mais importante na explicação do conjunto de dados), o segundo fator explica 7,9\% da variância total, e assim por diante conforme a Tabela 35, dos autovalores. No conjunto estes 6 fatores explicam 68,7\% da variância dos dados. 
A interpretação dos fatores foi realizada após rotação ortogonal dos eixos (Varimax). Tal procedimento faz com que a variância total permaneça inalterada $(68,7 \%$ de explicação), porém a porcentagem de variância explicada é diferente para cada fato, associando de maneira mais nítida um número de variáveis a cada fator.

Carga fatorial é um dos produtos finais da análise fatorial. Uma carga fatorial é um coeficiente que expressa o quanto uma variável observada está carregada em um fator. Quanto maior for a carga maior a relação entre a variável e o fator, com maior influência na denominação do fator.

Quadro 10 - Variáveis agrupadas em fatores

\begin{tabular}{|c|c|c|}
\hline & Fator & $\begin{array}{c}\text { Carga } \\
\text { fatorial }\end{array}$ \\
\hline Q19tIncrementar Capacitação & \multirow{6}{*}{ equipe } & 0,8 \\
\hline Q19rMelhorar Trabalho em equipe & & 0,785 \\
\hline Q19sAumentar Retenção de talentos & & 0,741 \\
\hline Q19qAumentar Alinhamento da equipe com a estrategia & & 0,714 \\
\hline Q19uAprimorar Infraestrutura tecnológica & & 0,61 \\
\hline Q19fAumentarQualidade & & 0,453 \\
\hline Q19hMelhorar Prestação de Serviços & \multirow{5}{*}{ relacionamento } & 0,742 \\
\hline Q19jMelhorar Relacionamento com cliente & & 0,692 \\
\hline Q19gAprimorar Seleção de clientes & & 0,684 \\
\hline Q19kBuscar incremento de Imagem & & 0,531 \\
\hline Q19iAumentar Parcerias & & 0,521 \\
\hline Q19pAprimorar Relacionamento com comunidade & \multirow{2}{*}{ responsabilidade social corporativa } & 0,767 \\
\hline Q19oMinimizar Impacto no Meioambiente & & 0,755 \\
\hline Q19|Aumentar Produção & \multirow{3}{*}{ fator básico } & 0,786 \\
\hline Q19dOferecer Melhor Preço & & 0,776 \\
\hline Q19mIncrementar Distribuição & & 0,615 \\
\hline Q19eLançamento de novos produtos & \multirow{2}{*}{ novos produtos } & 0,833 \\
\hline Q19nIncrementar Portfólio de P\&D & & 0,628 \\
\hline Q19aGerar valor para acionista proprietário & \multirow{3}{*}{ geração de valor } & 0,828 \\
\hline Q19bMelhorar estrutura de custos & & 0,784 \\
\hline Q19cAumentar participação de mercado & & 0,459 \\
\hline
\end{tabular}

Conforme o Quadro 10 apresenta, "Aumentar qualidade" pode pertencer ao fator "equipe" ou ao fator "relacionamento", a variável "aumentar parcerias" pode pertencer ao fator 
"Relacionamento" ou ao fator "Responsabilidade Social Corporativa". Porém alocou-se estas variáveis em fatores de acordo com sua interpretação.

Os escores fatoriais (factor scores) são os "novos" valores relativos aos fatores, sendo utilizados para análises futuras no lugar das variáveis originais.

Realizada a Prova de Kruskal-Wallis para comparar as técnicas frente ao uso de objetivos agrupados em fatores, resulta na Tabela 36.

Tabela 36 - Prova de Kruskal-Wallis frente aos fatores

\begin{tabular}{lcccccc}
\hline Equipe & Relacionamento & $\begin{array}{c}\text { Responsabilidade } \\
\text { Social } \\
\text { Corporativa }\end{array}$ & $\begin{array}{c}\text { Fatores } \\
\text { básicos }\end{array}$ & $\begin{array}{c}\text { Novos } \\
\text { produtos }\end{array}$ & $\begin{array}{c}\text { Geração } \\
\text { de } \\
\text { Valor }\end{array}$ \\
\hline$\chi^{2}$ & 7,779 & 6,505 & 12,09 & 2,0 & 2,444 & 10,11 \\
\hline $\mathrm{p}$ & 0,100 & 0,165 & 0,017 & 0,736 & 0,655 & 0,039 \\
\hline
\end{tabular}

Apenas o fator Responsabilidade Social Corporativa e Geração de Valor são capazes de diferenciar as técnicas quanto aos fatores de utilização de objetivos. Procedendo-se a comparações múltiplas para estes dois fatores (detalhamento disponível no Apêndice II), resulta:

- Para o fator Geração de Valor — a única diferença significativa é entre Objetivo financeiro e Processo Intuitivo. Descritivamente, este último fazendo menor uso dos objetivos no condizente ao Fator Lucro.

- Para o fator Responsabilidade Social Corporativa - as diferenças entre médias de postos supera a diferença mínima significativa em: Objetivo Financeiro e BSC, Processo Intuitivo e BSC. Descritivamente, nestes dois casos, a técnica BSC difere de Objetivo Financeiro e Processo Intuitivo, por fazer mais uso dos objetivos quanto ao Fator Comunidade.

n) Ordem das etapas do processo estratégico

A Tabela 37 mostra a frequência de respostas sobre as etapas do processo estratégico elencadas pelos participantes. A maioria indicou todas as sete etapas ou seis etapas de processo estratégico. 
Tabela 37 - Quantidade de etapas do processo estratégico

\begin{tabular}{lccc}
\hline Soma postos & Realizadas & Frequência & $\%$ \\
\hline 0 & Nenhuma etapa & 25 & 8,7 \\
\hline 1 & 1 etapa & 1 & 0,3 \\
\hline 3 & 2 etapas & 1 & 0,3 \\
\hline 6 & 3 etapas & 7 & 2,4 \\
\hline 10 & 4 etapas & 10 & 3,5 \\
\hline 15 & 5 etapas & 18 & 6,2 \\
\hline 21 & 6 etapas & 115 & 39,8 \\
\hline 28 & 7 etapas & 112 & 38,8 \\
\hline Total & & 289 & 100 \\
\hline
\end{tabular}

De acordo com a Tabela 37, nota-se que $8,7 \%$ dos respondentes, sequer ordenaram qualquer uma das etapas, e apenas $38,8 \%$ da amostra ordenaram todas as etapas. De forma diversa, leva-se em conta o total da pontuação para cada respondente e procede-se a Prova de KruskalWallis $\left(\chi^{2}=8,476 ; p=0,076\right)$. Não foi possível diferenciar as técnicas quanto ao número de etapas para elaboração da definição da Estratégia corporativa, ao nível de significância de 0,05 , o que foi possível a $\alpha=0,10$. Pelo Gráfico 11 , pelo menos como tendência, é possível destacar que o BSC tem maior média de número de etapas avaliadas do que o processo intuitivo, possivelmente, pelo número maior de empresas estrangeiras que usam o BSC e que recebem orientações da matriz para seu planejamento local.

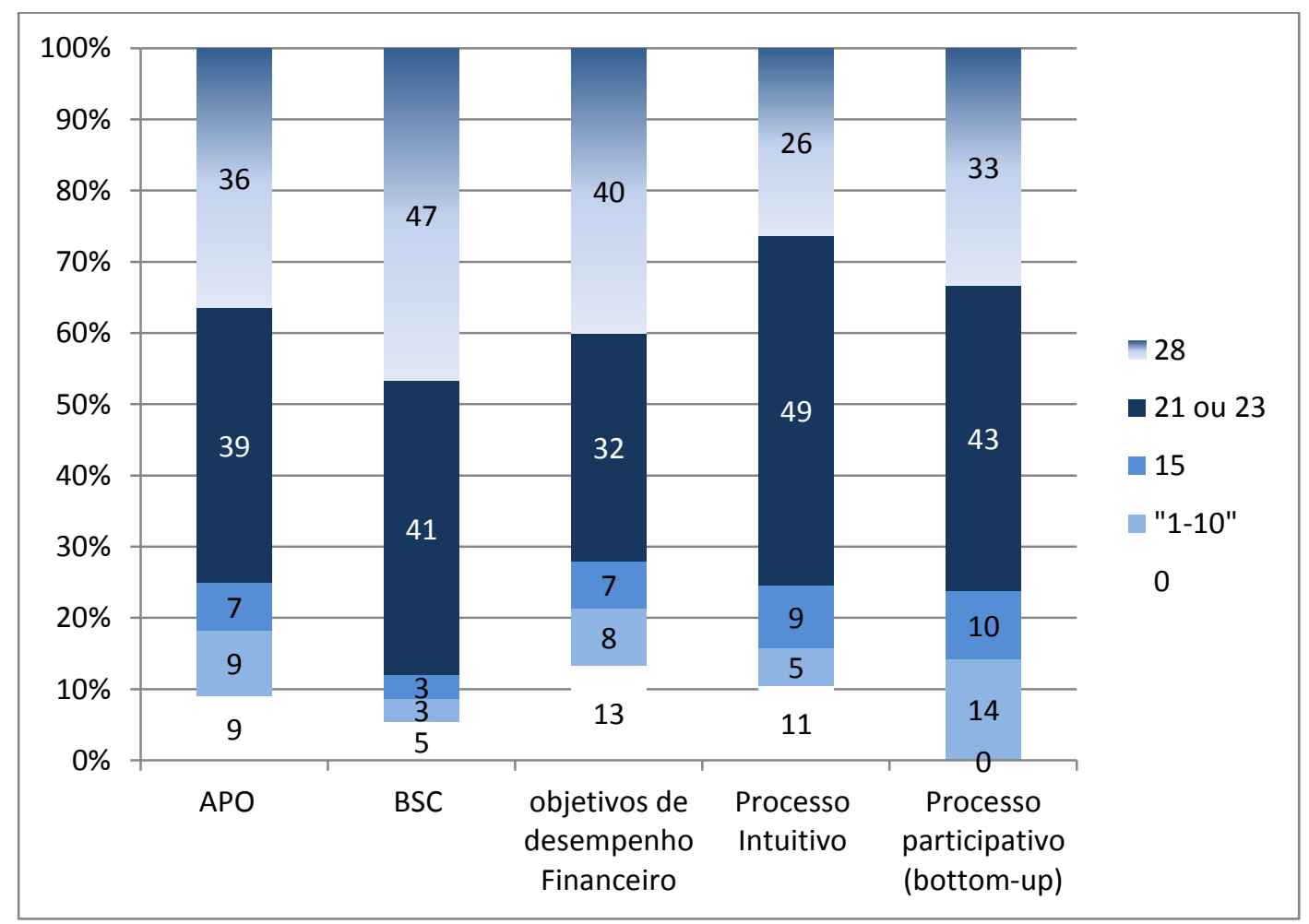

Gráfico 11 - Pontuação das etapas e as técnicas 
Analisando de outra maneira: se o respondente ordenou a etapa, etapa presente; caso contrário a etapa não faz parte do processo de definição da estratégia. De forma específica, realizando a prova de Qui-quadrado, apenas a etapa “Análise dos aspectos Internos" teve sua existência associada à técnica com nível de significância de $0,05(\mathrm{p}=0,032)$, conforme apresenta o Gráfico 12. Análise de diretrizes vindas da matriz teve a conclusão incerta $(p=0,074)$

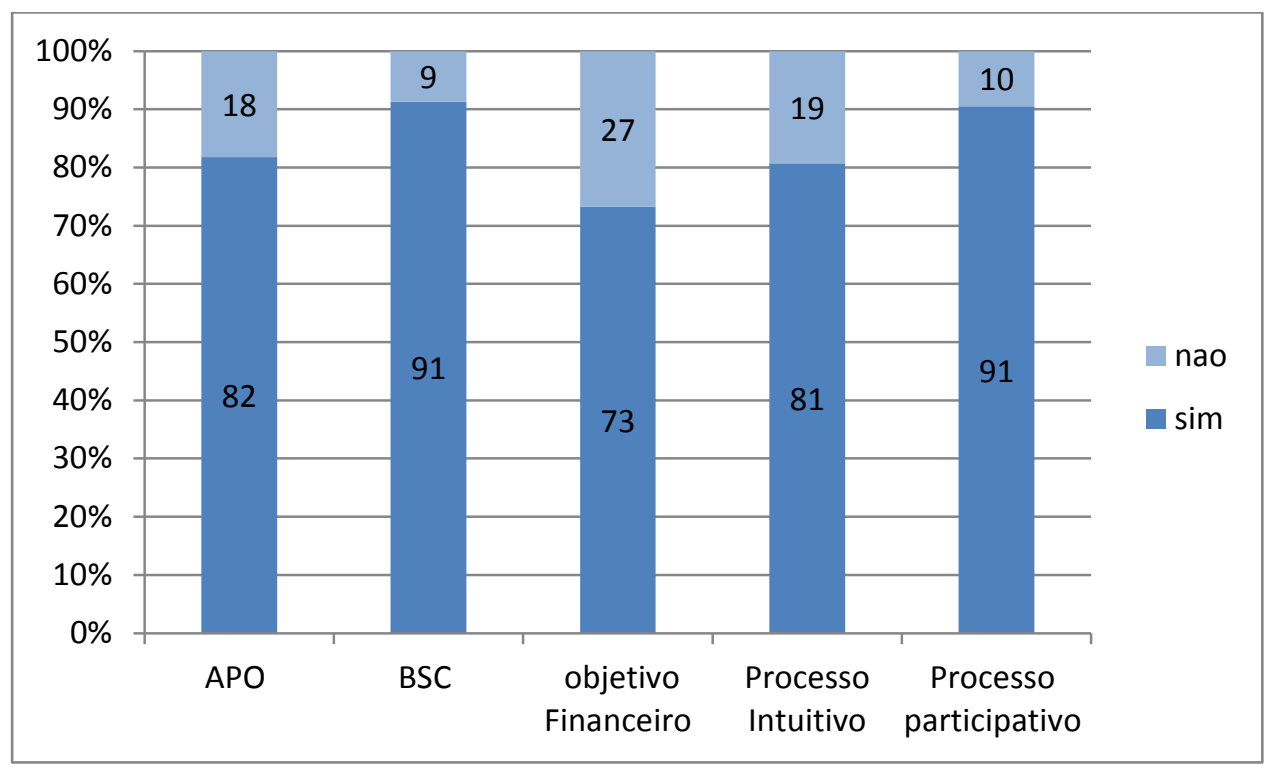

Gráfico 12 - Análise de aspectos internos

Em termos de sequência das etapas do processo estratégico, a tabela 38, apresenta duas situações que refletem os comentários dos parágrafos anteriores. A maior das indicações polarizaram processos estratégicos de seis ou sete etapas. A maior diferença entre esses dois conjuntos de processos se dá pela etapa “Análise de Diretrizes vindas da Matriz" que conjunto de sete etapas se posiciona como etapa número 1. Após essa diferença a sequência de etapas é segue a mesma nos dois casos, como a tabela 38 apresenta. 
Tabela 38 - Sequência das etapas do processo estratégico

\begin{tabular}{|c|c|c|c|c|c|c|c|c|c|c|c|c|c|c|}
\hline & \multicolumn{2}{|c|}{ etapa 1} & \multicolumn{2}{|c|}{ etapa 2} & \multicolumn{2}{|c|}{ etapa 3} & \multicolumn{2}{|c|}{ etapa 4} & \multicolumn{2}{|c|}{ etapa 5} & \multicolumn{2}{|c|}{ etapa 6} & \multicolumn{2}{|c|}{ etapa 7} \\
\hline $\begin{array}{l}\text { Análise de Diretrizes } \\
\text { vindas da Matriz (se } \\
\text { for o caso) }\end{array}$ & 75 & $26,1 \%$ & 15 & $5,3 \%$ & 21 & $7,4 \%$ & 7 & $2,5 \%$ & 7 & $2,6 \%$ & 4 & $1,6 \%$ & 6 & $5,0 \%$ \\
\hline $\begin{array}{l}\text { Análise do Ambiente } \\
\text { Externo }\end{array}$ & 103 & $35,9 \%$ & 77 & $27,0 \%$ & 41 & $14,4 \%$ & 24 & $8,7 \%$ & 9 & $3,4 \%$ & 4 & $1,6 \%$ & 8 & $6,7 \%$ \\
\hline $\begin{array}{l}\text { Análise de Aspectos } \\
\text { Internos }\end{array}$ & 30 & $10,5 \%$ & 99 & $34,7 \%$ & 62 & $21,8 \%$ & 35 & $12,6 \%$ & 18 & $6,8 \%$ & 11 & $4,5 \%$ & 5 & $4,2 \%$ \\
\hline $\begin{array}{l}\text { Concepção da } \\
\text { Estratégia }\end{array}$ & 40 & $13,9 \%$ & 26 & $9,1 \%$ & 71 & $25,0 \%$ & 75 & $27,1 \%$ & 34 & $12,8 \%$ & 14 & $5,8 \%$ & 4 & $3,3 \%$ \\
\hline $\begin{array}{l}\text { Definição de Objetivos } \\
\text { Estratégicos }\end{array}$ & 25 & $8,7 \%$ & 44 & $15,4 \%$ & 54 & $19,0 \%$ & 88 & $31,8 \%$ & 61 & $23,0 \%$ & 7 & $2,9 \%$ & 4 & $3,3 \%$ \\
\hline $\begin{array}{l}\text { Definição de Metas e } \\
\text { indicadores }\end{array}$ & 10 & $3,5 \%$ & 18 & $6,3 \%$ & 25 & $8,8 \%$ & 35 & $12,6 \%$ & 93 & $35,1 \%$ & 85 & $35,0 \%$ & 15 & $12,5 \%$ \\
\hline $\begin{array}{l}\text { Organização da } \\
\text { implementação/ Plano } \\
\text { de ação }\end{array}$ & 4 & $1,4 \%$ & 6 & $2,1 \%$ & 10 & $3,5 \%$ & 13 & $4,7 \%$ & 43 & $16,2 \%$ & 118 & $48,6 \%$ & 78 & $65,0 \%$ \\
\hline
\end{tabular}

A Tabela 38 apresenta as seguintes atividades como as mais votadas para o estabelecimento do processo estratégico, na ordem a seguir:

- Etapa 1 - Ambiente Externo

- Etapa 2 - Aspectos Internos

- Etapa 3 - Estratégia

- Etapa 4 - Objetivos Estratégicos

- Etapa 5 - Metas e indicadores

- Etapa 6 - Implementação

- Etapa 7 - Implementação

Como atividades mais votadas em segundo lugar para cada etapa, temos a seguinte ordem:

- Etapa 1 - Análise das Diretrizes vindas da matriz

- Etapa 2 - Ambiente Externo

- Etapa 3 - Aspectos Internos

- Etapa 4 - Estratégia

- Etapa 5 - Objetivos Estratégicos

- Etapa 6 - Metas e indicadores

- Etapa 7 - Metas e indicadores

Analisando tanto as primeiras como as segundas opções para cada etapa, vemos duas sequências de processo estratégico apresentadas. A principal diferença entre elas se dá na etapa 1 do segundo grupo: este processo estratégico se inicia analisando diretrizes recebidas de organização-matriz. No primeiro grupo (as opções mais votadas) o processo se inicia a 
partir da análise do ambiente externo que é a segunda etapa do segundo grupo. A partir daí as etapas do processo seguem a mesma sequência, em um caminho similar ao processo estratégico usado como referência nesta tese, baseado em Almeida (2010) e Kaplan e Norton (2004).

o)

\section{Resumo das diferenças estatisticamente significativas encontradas entre as técnicas}

O Quadro 11 elenca as diferenças significativas encontradas entre as técnicas estudadas na pesquisa de campo desta tese.

Quadro 11 - Diferenças estatisticamente relevantes entre as técnicas

\begin{tabular}{|c|c|c|c|c|c|}
\hline $\begin{array}{l}\text { Técnicas / } \\
\text { Categoria }\end{array}$ & APO & BSC & Obj. Financeiros & Participativa & Intuitiva/Criativa \\
\hline Faturamento & & Acima de 1 Bilhão & $\begin{array}{c}\text { Acima de R\$ } 1 \\
\text { bilhão }\end{array}$ & & $\begin{array}{c}\text { Abaixo de R\$ } \\
\text { 1bilhão }\end{array}$ \\
\hline Divulgação & & $\begin{array}{c}\text { Divulga para toda } \\
\text { organização }\end{array}$ & & $\begin{array}{l}\text { Divulga para toda } \\
\text { organização }\end{array}$ & $\begin{array}{c}\text { Divulga para } \\
\text { determinados } \\
\text { níveis } \\
\text { organizacionais } \\
\end{array}$ \\
\hline Participação & & $\begin{array}{c}\text { Participa de parte } \\
\text { do processo } \\
\text { estratégico }\end{array}$ & $\begin{array}{c}\text { Participa de parte } \\
\text { do processo } \\
\text { estratégico }\end{array}$ & $\begin{array}{l}\text { Decide ou participa } \\
\text { de todo processo } \\
\text { estratégico }\end{array}$ & \\
\hline $\begin{array}{c}\text { Número de } \\
\text { objetivos } \\
\text { estabelecidos } \\
\end{array}$ & & $\begin{array}{c}\text { Maior número de } \\
\text { objetivos } \\
\text { estabelecidos }\end{array}$ & & & $\begin{array}{c}\text { Menor número de } \\
\text { objetivos } \\
\text { estabelecidos } \\
\end{array}$ \\
\hline $\begin{array}{c}\text { Número de } \\
\text { objetivos } \\
\text { implementados } \\
\text { com sucesso } \\
\end{array}$ & $\begin{array}{c}\text { Maior número de } \\
\text { objetivos } \\
\text { implementados }\end{array}$ & $\begin{array}{c}\text { Maior número de } \\
\text { objetivos } \\
\text { implementados }\end{array}$ & & $\begin{array}{l}\text { Maior número de } \\
\text { objetivos } \\
\text { implementados }\end{array}$ & $\begin{array}{l}\text { Menor número de } \\
\text { objetivos } \\
\text { implementados }\end{array}$ \\
\hline $\begin{array}{c}\text { Concordância da } \\
\text { contribuição para } \\
\text { comunicação da } \\
\text { estratégia } \\
\end{array}$ & & $\begin{array}{c}\text { Maior Contribuição } \\
\text { para comunicação }\end{array}$ & $\begin{array}{c}\text { Menor } \\
\text { contribuição para } \\
\text { comunicação }\end{array}$ & & \\
\hline $\begin{array}{l}\text { Uso de fatores de } \\
\text { objetivos }\end{array}$ & & & $\begin{array}{c}\text { Usa mais os } \\
\text { objetivos de } \\
\text { "Geração de Valor" }\end{array}$ & & $\begin{array}{c}\text { Usa menos os } \\
\text { objetivos de } \\
\text { "Geração de Valor" }\end{array}$ \\
\hline $\begin{array}{l}\text { Uso de fatores de } \\
\text { objetivos }\end{array}$ & & $\begin{array}{c}\text { Usa mais os } \\
\text { objetivos de } \\
\text { "Responsabilidade } \\
\text { Social Corporativa" }\end{array}$ & $\begin{array}{c}\text { Usa menos os } \\
\text { objetivos de } \\
\text { "Responsabilidade } \\
\text { Social Corporativa" }\end{array}$ & & $\begin{array}{c}\text { Usa menos os } \\
\text { objetivos de } \\
\text { "Responsabilidade } \\
\text { Social Corporativa" }\end{array}$ \\
\hline
\end{tabular}

Em relação ao número de objetivos estabelecidos pela corporação foi possível encontrar diferenças entre as técnicas de Processo Criativo / Intuitivo e do BSC. Descritivamente, verifica-se que o Processo Intuitivo apresenta número menor de objetivos estratégicos 
estabelecidos que o BSC.

$\mathrm{Na}$ comparação entre as técnicas, foi possível indicar que o Processo Intuitivo difere das técnicas BSC, APO e Processo participativo por apresentar um número menor de objetivos implementados. O menor número de objetivos usados pelos que aplicam a técnica Intuitiva parece estar mais relacionada à centralização da decisão estratégica do que eficiência do objetivo, visto que a relação entre objetivos implementados com sucesso e objetivos estabelecidos para todas as técnicas estudadas é aproximadamente 2 para 3.

Em relação à satisfação do respondente com os objetivos estratégicos de sua organização temos que as técnicas se diferenciaram na contribuição para a comunicação da estratégia, para os diversos níveis da organização. Neste ponto temos que o BSC se diferencia da técnica de objetivos financeiros (BSC contribui mais pra comunicação que os outros, especialmente a de Objetivos Financeiros). Ou seja, o BSC contribui mais pra a comunicação que as demais técnicas enquanto que a técnica de Objetivos Financeiros contribui menos para a comunicação estratégica que as demais.

Em relação aos objetivos estratégicos mais usados, estes foram agrupados em fatores para possibilitar uma melhor análise e, desta forma, os fatores de Responsabilidade Social Corporativa e de Geração de Valor são capazes de diferenciar as técnicas de organização de objetivos estratégicos corporativos.

O fator Geração de Valor diferencia as técnicas de Objetivos Financeiros e Processo Intuitivo, onde este último usa menos objetivos de "geração de valor" que as técnicas de Objetivos Financeiros.

Já o fator Responsabilidade Social Corporativa consegue diferenciar a técnica do BSC por usar mais objetivos do Fator RSC que as técnicas de Objetivo Financeiro e processo Intuitivo.

Foi constatado pela prova estatística que a técnica de organização de objetivos estratégicos tende a variar em função do faturamento das organizações. Especificamente, foram encontradas diferenças nas comparações entre o BSC e o Processo Intuitivo, e também, na comparação entre Objetivos Financeiros e o Processo Intuitivo. Foi possível notar que as técnicas do BSC e de Objetivos Financeiros concentram a maior parte das respostas com 
empresas que possuem faturamento acima de R\$ 1 bilhão (respectivamente $61 \%$ e 52\%) enquanto que o Processo Intuitivo / Criativo predomina em empresas menores com faturamento até R\$ 1 bilhão, que concentra 75,5\% dos respondentes que indicaram usar essa técnica.

Em relação à divulgação dos objetivos (para toda organização ou fragmentada de acordo o nível organizacional) e as técnicas, foi possível encontrar o indício de que o BSC e processo Participativo possuem maior foco em divulgação dos objetivos estratégicos para toda a organização (63\% cada), enquanto que o Processo Intuitivo tem sua maioria voltada a divulgar seus objetivos de maneira fragmentada a determinados níveis da organização (58\%).

Sobre a participação do respondente na definição da estratégia corporativa foram encontrado indícios ao nível de significância de 0,10 de que existem diferenças entre os grupos de técnicas. É possível destacar que a técnica Participativa se comprova ser a mais inclusiva, ao menos com a amostra pesquisada, pois $66,7 \%$ dos participantes que indicaram usar esta técnica na corporação em que atuam definem e/ou participam de todo o processo estratégico. Por outro lado quando se analisam as técnicas do BSC ou dos Objetivos Financeiros, nota-se que aproximadamente $60 \%$ de seus respondentes indicam participar de partes determinadas do processo estratégico enquanto que os $40 \%$ restantes estão voltados às participações em todo o processo.

Com isso, foi possível sugerir que a participação do respondente pode estar relacionada ao faturamento da empresa. Quanto maior a empresa, mais se participa de partes do processo estratégico (e aumenta percentual do apenas informados), enquanto que nas empresas com faturamento menor o participante contribui para todo processo, conforme a Tabela 39 apresenta. 
Tabela 39 - Nível de participação na definição estratégia e tamanho da organização

\begin{tabular}{|c|c|c|c|c|c|c|}
\hline $\begin{array}{l}\text { Nível de participação do } \\
\text { respondente na definição } \\
\text { da estratégia corporativa }\end{array}$ & & $\begin{array}{l}\text { Até } \mathrm{R} \$ \\
16 \\
\text { milhões }\end{array}$ & $\begin{array}{c}\text { Entre } \\
\text { R\$16milhões } \\
\text { e } 300 \\
\text { milhões }\end{array}$ & $\begin{array}{c}\text { Entre } \\
\text { R\$300 } \\
\text { milhões } \\
\text { e R\$ 1 } \\
\text { bilhão } \\
\end{array}$ & $\begin{array}{l}\text { Acima de } \mathrm{R} \$ \\
1 \text { bilhão }\end{array}$ & Total \\
\hline \multirow[t]{2}{*}{$\begin{array}{l}\text { Defino/participo de todo } \\
\text { o processo estratégico }\end{array}$} & $\mathrm{n}$ & 40 & 23 & 19 & 48 & 130 \\
\hline & $\%$ & $74,1 \%$ & $47,9 \%$ & $40,4 \%$ & $34,8 \%$ & $45,3 \%$ \\
\hline \multirow[t]{2}{*}{$\begin{array}{l}\text { Participo em partes do } \\
\text { processo estratégico/sou } \\
\text { consultado/forneço } \\
\text { informações }\end{array}$} & $\mathrm{n}$ & 13 & 22 & 21 & 67 & 123 \\
\hline & $\%$ & $24,1 \%$ & $45,8 \%$ & $44,7 \%$ & $48,6 \%$ & $42,9 \%$ \\
\hline \multirow[t]{2}{*}{$\begin{array}{l}\text { Sou informado da } \\
\text { estratégia ao final do } \\
\text { processo }\end{array}$} & $\mathrm{n}$ & 1 & 3 & 7 & 23 & 34 \\
\hline & $\%$ & $1,9 \%$ & $6,2 \%$ & $14,9 \%$ & $16,7 \%$ & $11,8 \%$ \\
\hline Total & $\begin{array}{l}\mathrm{n} \\
\% \\
\end{array}$ & $\begin{array}{c}54 \\
100,0 \%\end{array}$ & $\begin{array}{c}48 \\
100,0 \%\end{array}$ & $\begin{array}{c}47 \\
100,0 \%\end{array}$ & $\frac{138}{100,0 \%}$ & $\begin{array}{c}287 \\
100,0 \%\end{array}$ \\
\hline
\end{tabular}

A seguir as informações apresentadas até aqui serão discutidas no próximo capítulo que trata da análise de resultados e das considerações finais desta tese. 


\section{ANÁLISE DE RESULTADOS E CONSIDERAÇÕES FINAIS}

Esta tese teve o intuito de propor uma tipologia de técnicas de organização de objetivos estratégicos corporativos e analisar o uso destas técnicas na implementação estratégica. $\mathrm{O}$ estudo destes aspectos busca oferecer uma contribuição à compreensão da ligação entre as fases de formulação e implementação da estratégia de uma organização que busca atender sua missão e visão.

Em termos de objetivos específicos foram discutidas as diferentes formas de organização de objetivos estratégicos e características da organização e também aspectos relacionados à implementação, comunicação e esforço despendido com a estratégia.

A partir do levantamento bibliográfico, que passou pela visão de evolução dos conceitos de estratégia, suas escolas e principais etapas do processo estratégico, colocou-se foco na discussão conceitual do que são objetivos estratégicos, destacando-se alguns dos principais conceitos abordados por este tema.

A partir deste referencial, buscou-se mapear as principais técnicas de organização de objetivos estratégicos e organizá-las segundo a tipologia proposta no item 2.5. Nesta tipologia, os conceitos foram alinhados de acordo com pressupostos centrais, os quais os autores pesquisados fazem referência, o que permitiu caracterizar cinco técnicas fundamentais de organização de objetivos, que foram a base da pesquisa de campo e da tipologia proposta. As técnicas estudadas foram agrupadas nas seguintes técnicas centrais:

- APO - Administração por objetivos

- BSC - Balanced Scorecard

- Objetivos Financeiros

- Intuitiva / Criativa - elaborada pela alta direção da organização

- Participativa - pressupõe a colaboração aberta dos profissionais da organização com contribuições "bottom-up".

Essas cinco técnicas, investigadas nesta tese, permitiram propor a tipologia organizada em 
dois eixos, conforme é apresentado na Figura 24. O eixo vertical posiciona as técnicas de acordo com sua capacidade em possibilitar uma estruturação formal entre os objetivos estratégicos a serem organizados pela técnica.

O eixo horizontal alinha as técnicas de acordo as características para a definição dos objetivos estratégicos: se é mais participativo por diversos níveis organizacionais, ou, no outro extremo, se é mais impositivo pela alta-direção da organização, ou seja, top-down.

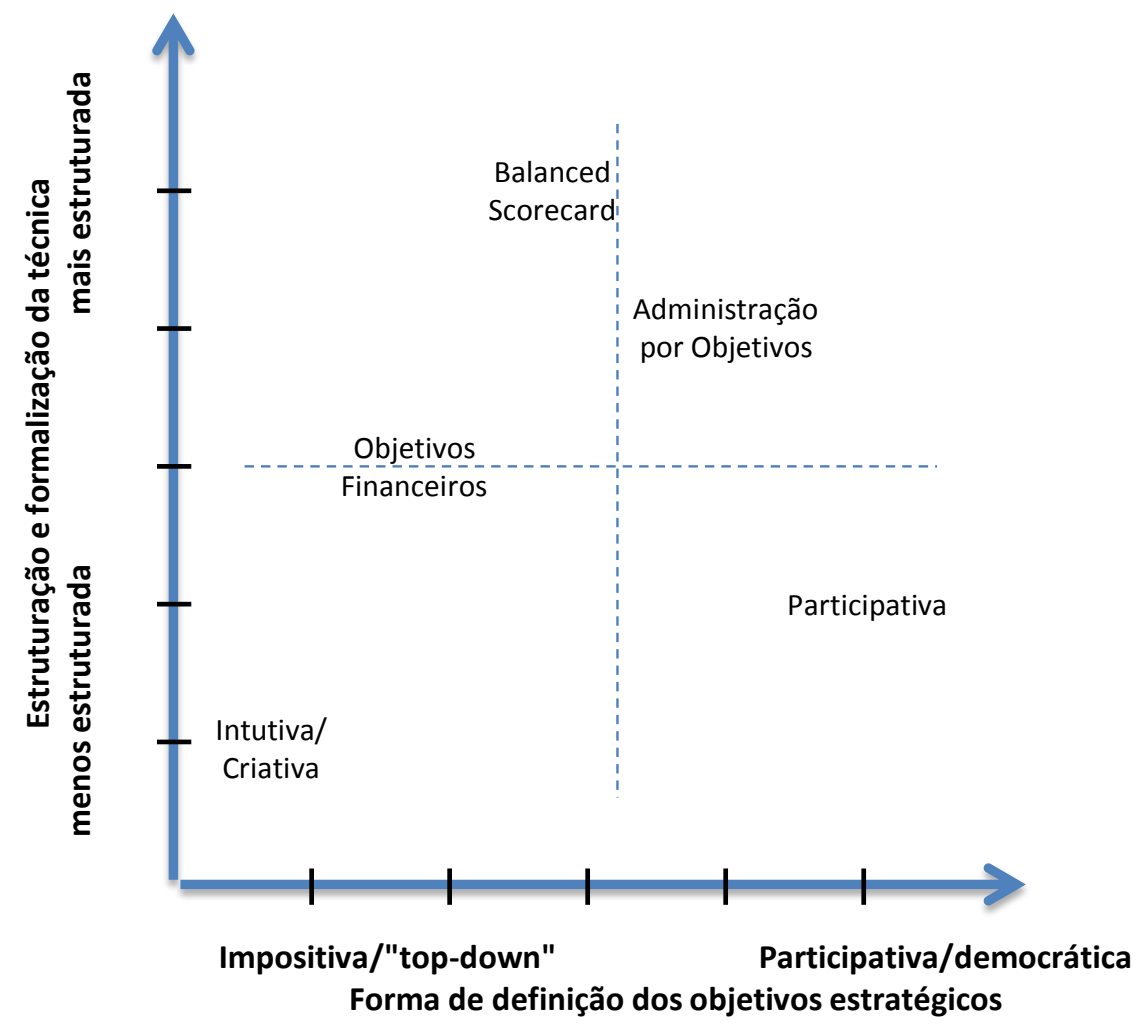

Figura 24 - Tipologia proposta neste estudo

\subsection{Principais resultados encontrados na pesquisa de campo}

Somado ao delineamento da tipologia, outros resultados relevantes foram obtidos a partir da análise da pesquisa de campo que trabalhou com 289 respostas válidas. Primeiramente destacaremos, a seguir, alguns pontos sobre as técnicas de organização de objetivos estratégicos.

Em termos de uso das técnicas, sintetizada pela Tabela 40, vimos que a técnica mais citada foi 
o Balanced Scorecard (BSC), por 31,8\% dos respondentes. A seguir, a técnica com foco em Objetivos Financeiros obteve a indicação de $26 \%$ dos profissionais pesquisados. Em terceiro, foi indicado por $19,7 \%$ dos respondentes, que, na organização em que atuam, é usado um Processo Intuitivo / Criativo desenvolvido a partir da alta direção. Já, a técnica de Administração por Objetivos corresponde a 15,2\% das indicações, enquanto que o processo Participativo, com discussões de baixo para cima, foi indicado por 7,3\% da amostra.

Tabela 40 - Uso das técnicas de organização de objetivos estratégicos corporativos

\begin{tabular}{lc}
\hline Técnica & $\%$ \\
\hline BSC & 31,8 \\
\hline $\begin{array}{l}\text { Objetivos } \\
\text { Financeiros }\end{array}$ & 26,0 \\
\hline Intuitiva/Criativa & 19,7 \\
\hline APO & 15,2 \\
\hline Participativa & 7,3 \\
\hline Total & 100 \\
\hline
\end{tabular}

Cabe destacar, ainda, que na fase de ajuste de amostra somente $2 \%$ dos participantes (6 respondentes) indicaram técnicas diferentes das cinco listadas acima. Ainda assim boa parte desses mencionaram misturas de características das cinco técnicas listadas, conforme discutido no capítulo 4, item 4.3, subitem c.

A Tabela 41 apresenta resultados da pesquisa em termos de porte da empresa. Os dados mostram que predominam as grandes empresas (com faturamento anual acima de R $\$ 1$ bilhão) como maior parte das respostas para BSC e Objetivos Financeiros. Já a maior parte dos respondentes que indicam usar a técnica Intuitiva atuam em empresas com até R \$ 16 milhões de faturamento anual.

Tabela 41 - Porte da empresa e uso da técnica de organização de objetivos estratégicos corporativos

\begin{tabular}{lcccccc}
\hline & APO & BSC & Intuitiva/Criativa & Participativa & $\begin{array}{c}\text { Objetivos } \\
\text { Financeiros }\end{array}$ & Total \\
\hline Até R\$ 16 milhões & $3,2 \%$ & $4,6 \%$ & $6,0 \%$ & $1,9 \%$ & $3,0 \%$ & $18,8 \%$ \\
\hline R\$ 16 - 300 milhões & $2,4 \%$ & $2,5 \%$ & $4,8 \%$ & $1,9 \%$ & $5,1 \%$ & $16,7 \%$ \\
\hline R\$ 300M - R\$ 1 Bi & $2,9 \%$ & $5,4 \%$ & $3,9 \%$ & $0,4 \%$ & $3,9 \%$ & $16,4 \%$ \\
\hline Acima de R\$ 1 Bi & $6,7 \%$ & $19,3 \%$ & $5,0 \%$ & $3,2 \%$ & $13,9 \%$ & $48,1 \%$ \\
\hline Total & $15,2 \%$ & $31,8 \%$ & $19,7 \%$ & $7,4 \%$ & $26,0 \%$ & $100,0 \%$ \\
\hline
\end{tabular}

Sobre a origem do capital das empresas pesquisadas, a tabela 42 apresenta que predominam 
as empresas brasileiras para todas as técnicas. Proporcionalmente a maior ênfase está no uso das técnicas Intuitiva e Participativa em âmbito nacional.

Tabela 42 - Origem do capital das empresas e uso da técnica de organização de objetivos estratégicos

APO BSC Intuitiva/Criativa Participativa $\begin{gathered}\text { Objetivos } \\ \text { Financeiros }\end{gathered}$ Total

\begin{tabular}{lcccccc}
\hline Estrangeira & $6,4 \%$ & $14,4 \%$ & $5,4 \%$ & $2,3 \%$ & $10,6 \%$ & $39,1 \%$ \\
\hline Brasileira & $8,9 \%$ & $17,4 \%$ & $14,3 \%$ & $4,9 \%$ & $15,4 \%$ & $60,9 \%$ \\
\hline Total & $15,2 \%$ & $31,8 \%$ & $19,7 \%$ & $7,2 \%$ & $26,0 \%$ & $100,0 \%$ \\
\hline
\end{tabular}

A respeito da divulgação dos objetivos para a organização a tabela 43 apresenta, que predominantemente, para as técnicas BSC e Participativa os objetivos são divulgados para a organização como um todo. Para as técnicas Intuitiva e Objetivos Financeiros prioritariamente os objetivos são divulgados para determinados níveis organizacionais (como diretoria ou gerência) e seus superiores, ou seja, sem contemplar toda a organização. Para a APO consideramos que não os dados não apresentam uma preferência clara quanto a abrangência da divulgação dos objetivos.

Tabela 43 - Divulgação dos objetivos para a organização e uso da técnica de organização de objetivos estratégicos corporativos

\begin{tabular}{lrrrrrr}
\hline & APO & BSC & $\begin{array}{c}\text { Intuitiva/Cria } \\
\text { tiva }\end{array}$ & Participativa & $\begin{array}{c}\text { Objetivos } \\
\text { Financeiros }\end{array}$ & $\begin{array}{c}\text { Total } \\
\text { Geral }\end{array}$ \\
\hline Empresa como um todo & $7,7 \%$ & $19,9 \%$ & $8,2 \%$ & $4,7 \%$ & $11,7 \%$ & $52,2 \%$ \\
\hline $\begin{array}{l}\text { Determinados níveis } \\
\text { organizacionais }\end{array}$ & $7,4 \%$ & $11,9 \%$ & $11,5 \%$ & $2,7 \%$ & $14,3 \%$ & $47,8 \%$ \\
\hline & $15,2 \%$ & $31,8 \%$ & $19,7 \%$ & $7,4 \%$ & $26,0 \%$ & $100,0 \%$ \\
\hline
\end{tabular}

Com relação à satisfação do respondente quanto à contribuição dos objetivos estratégicos para a comunicação da estratégia corporativa, podemos afirmar que a maioria dos profissionais consultados está satisfeita com esse aspecto. Somando os percentuais de dois dos cinco pontos da escala (concordo totalmente com a afirmação + concordo parcialmente), temos que o BSC, a APO e a técnica Participativa são as que se destacam com os maiores percentuais, conforme a Tabela 44 apresenta. 
Tabela 44 - Satisfação do respondente com relação a contribuição do objetivo para a comunicação estratégica

\begin{tabular}{lccccc}
\hline & \multicolumn{4}{c}{ (valores em \%) } \\
\cline { 2 - 6 } & BSC & $\begin{array}{c}\text { Objetivos } \\
\text { Financeiros }\end{array}$ & $\begin{array}{c}\text { Intuitiva/ } \\
\text { Criativa }\end{array}$ & APO & Participativa \\
\hline $\begin{array}{l}\text { Satisfação com a contribuição do } \\
\text { objetivo para a comunicação } \\
\text { (concorda totalmente + concorda parcialmente) }\end{array}$ & 66,0 & 43,0 & 46,0 & 66,0 & 62,0 \\
\hline
\end{tabular}

Em termos de resultados gerais a respeito das organizações representadas pelos participantes da pesquisa alguns pontos também merecem ser destacados.

Sobre o posicionamento estratégico das empresas as quais os participantes da pesquisa atuam, usando os conceitos de estratégia genérica de Porter, vemos uma preferência pela estratégia de diferenciação com 56,9\%, enquanto a estratégia de liderança em custos ficou com $25,3 \%$, e a estratégia de foco com $17,8 \%$.

A respeito do esforço despendido com a estratégia, os resultados mostram que, em média, são realizadas cinco reuniões por ano, para discussão e definição da estratégia com o alto comando da empresa. Cada reunião demanda uma preparação prévia de 33 dias, em média, dos profissionais envolvidos com a estratégia corporativa.

Com relação à quantidade de etapas do processo estratégico das empresas houve uma polarização entre o planejamento entre 6 ou 7 etapas. No entanto, a diferença entre elas é a etapa de "análise das diretrizes da matriz", e a ordem geral assinalada é igual ao processo estratégico usado como referência para esta tese, baseado em Almeida (2010) e Kaplan e Norton (2004), conforme a figura 25 apresenta.

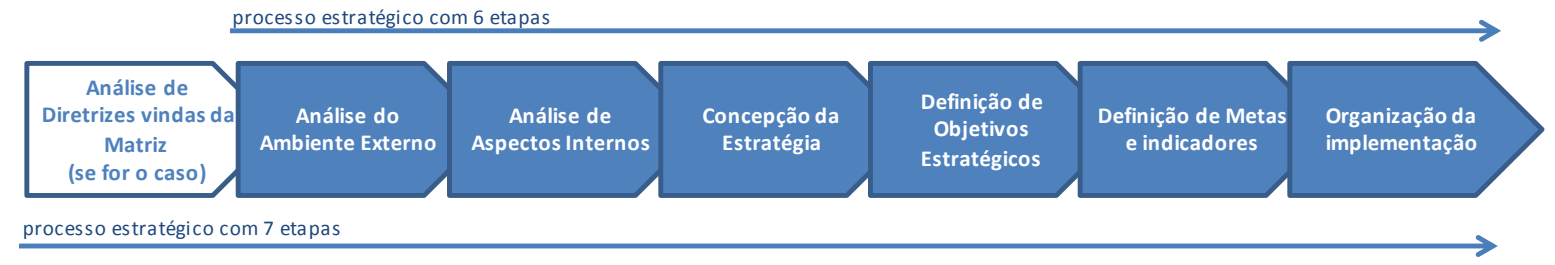

Figura 25 - Ordem das etapas do processo estratégico

A sequência apresentada, na Figura 25, a partir do resultado da pesquisa de campo é equivalente ao modelo de organização industrial (também conhecido como modelo I/O), 
discutido por Hitt et al. (2008), conforme apresentado no capítulo 2, este modelo parte do pressuposto que o ambiente externo exerce pressão no mercado intensificando a concorrência entre empresas que possuem recursos bem parecidos, conforme a sequencia encontrada na pesquisa.

\subsection{Considerações sobre as técnicas de organização de objetivos estratégicos}

$\mathrm{O} \underline{\mathrm{BSC}}$ mostra ser a técnica mais abrangente que as demais, pois contempla aspectos que outras técnicas não tratam. Por ser uma técnica mais formal e estruturada (ferramentas bem definidas para organização dos objetivos, com referências disponíveis que detalham a maioria dos passos para aplicar a técnica), ela se mostra mais versátil para contemplar uma estratégia e divulgá-la de maneira homogênea, especialmente em empresas maiores, onde a complexidade organizacional e a quantidade de pessoas contribuem para dificultar a comunicação e a disseminação da estratégia.

Nesta pesquisa, foi possível comprovar alguns aspectos da ferramenta que é difundida por Kaplan e Norton como a contribuição para a comunicação, a divulgação da estratégia para toda a organização e a representação de uma maior abrangência nos temas dos objetivos, especificamente por usar mais os objetivos de Responsabilidade Social Corporativa.

Entre as cinco técnicas analisadas, o BSC se destacou em termos de contribuição para a comunicação da estratégia, para a organização como um todo, mostrando que, na prática, as premissas de Kaplan e Norton, no que diz respeito à comunicação e ao alinhamento da estratégia, mostram-se adequadas.

Embora seja possível encontrar o uso do BSC em empresas de todos os tamanhos, notadamente, entre todas as técnicas, o BSC é a mais usada por empresas de grande faturamento (acima de $\mathrm{R} \$ 1$ bilhão), com $61,10 \%$ das respostas, cujos participantes indicaram usar essa técnica.

Também, foi constatado que o BSC é a técnica em que seus respondentes mais contribuem para partes do processo estratégico, em vez de contribuir para o processo estratégico como um todo. Como a técnica do BSC também é a mais usada pelas grandes empresas, isso pode 
sugerir que as grandes estruturas organizacionais, com vários colaboradores e áreas, fazem com que seja mais fácil participar apenas de partes do processo estratégico e contribuir de maneira fragmentada. Outra possível razão pode ser a facilidade de identificar e dividir as perspectivas do BSC por áreas da empresa.

Deve-se destacar, também, que o BSC é a técnica que estabeleceu o maior número médio de objetivos, assim como pelo segundo maior número de objetivos implementados com sucesso. Por um lado, essa característica demonstra que o grande número de objetivos pode aumentar as chances de a empresa alcançar todas as áreas da empresa; por outro lado, deve-se ressalvar que um número muito grande de objetivos pode dificultar sua gestão.

Neste ponto, talvez seja possível identificar um possível tema de pesquisa, visando ao ajuste na implementação, buscando a otimização no número de objetivos a ser implementado e acompanhado. Isso abordaria uma das críticas a esta técnica, que é a de, em alguns casos, levar ao uso de objetivos e indicadores em número demasiadamente elevado.

Por fim, o BSC é a técnica que mais usa os objetivos agrupados no fator "Responsabilidade Social Corporativa", destacando a característica abrangente dessa técnica, que permite envolver todas as áreas da administração, inclusive a de Responsabilidade Social, e não apenas aspectos puramente financeiros, mercadológicos e processuais.

A $\underline{\text { APO }}$ apesar de ser um conceito estabelecido na década de 1950, ainda é usada por 15,2\% das organizações da amostra pesquisada. Os conceitos de Drucker contribuíram para inspirar várias outras técnicas que são mais recentes que a APO, mas, seguem características essenciais da técnica original, como os objetivos SMART e a distribuição de objetivos por áreas da organização.

$\mathrm{Na}$ amostra pesquisada, a APO foi uma das técnicas que se destacou em relação aos objetivos implementados com sucesso. Apesar de uma pequena diferença, essa técnica obteve em média, relativamente, o maior número de objetivos implementados com sucesso. Apesar de não haver mais destaques para esta técnica, obtidos na pesquisa, esse aspecto, juntamente com os pontos positivos já destacados, podem ser as justificativas da continuidade da adoção desta ferramenta mesmo com outras técnicas disponíveis atualmente. 
A técnica de Objetivos Financeiros também obteve alta participação na amostra, sendo a segunda mais indicada pelos participantes da pesquisa, apesar de existirem técnicas alternativas para acompanhar a empresa como um todo, além dos aspectos essencialmente financeiros. As preocupações com o curto prazo, fluxo de caixa, endividamento e financiamentos podem ser questões que direcionam as empresas a usar apenas os objetivos financeiros.

$\mathrm{Na}$ pesquisa realizada, essa é a segunda técnica mais utilizada por grandes empresas (faturamento acima de $\mathrm{R} \$ 1$ bilhão), e a segunda técnica em que a maior parte dos respondentes indicou participar, de maneira fragmentada, no processo estratégico, em vez de contribuir para a estratégia como um todo. Esses dois resultados sugerem que se usa intensamente a técnica de Objetivos Financeiros em empresas maiores, onde é usual que se faça a divisão dos objetivos e dos indicadores para áreas ou equipes responsáveis pela apuração e acompanhamento. Desta forma, os colaboradores das organizações que trabalham dessa maneira acabam contribuindo, apenas, para os fragmentos da estratégia com o qual possuem contato.

Considerando o uso de categorias de objetivos, essa técnica trata, predominantemente, dos objetivos de Geração de Valor - de todas as técnicas pesquisadas é a que mais usa esta categoria de objetivos, corroborando sua característica essencialmente financeira. Este aspecto é reforçado, quando se analisa outro agrupamento de objetivos estratégicos, já que essa técnica é das que menos trata os objetivos de Responsabilidade Social Corporativa, confirmando seu foco em aspectos financeiros.

Em termos de comunicação, a técnica de Objetivos Financeiros destacou-se, negativamente, pois é a que menos contribui para a comunicação da estratégia empresarial para a organização como um todo, segundo os resultados da pesquisa.

A técnica Participativa se destaca pela inclusão dos colaboradores da empresa na definição da estratégia e por sua divulgação ampla na organização. Na amostra analisada, é a técnica em que a maioria dos respondentes indicou que a divulgação da estratégia é feita para todos na corporação.

Percentualmente, a técnica participava é a que mais recebeu indicações de respondentes que 
decidem ou participam do processo estratégico, como um todo, reforçando a característica primordial desta técnica.

A técnica participativa é a terceira técnica entre as que possuem o maior número de objetivos estratégicos implementados com sucesso. Desta afirmação, pode-se sugerir uma relação entre a participação dos colaboradores com a construção, comunicação da estratégia, o engajamento das pessoas e resultados positivos em termos de implementação de objetivos com sucesso.

A técnica Intuitiva-Criativa é usada predominantemente em empresas com faturamento inferior a $\mathrm{R} \$ 1$ bilhão, o que sugere que seja a técnica mais utilizada em organizações menores, devido à proximidade com os níveis decisórios, geralmente os proprietários e decisões da estratégia, o que a deixa menos formal.

Em termos de divulgação, essa é a técnica que se caracteriza por divulgar a estratégia apenas para determinados níveis da organização. O que, de certa forma, faz sentido com as características da técnica que centraliza a estratégia nos proprietários, ou em poucos executivos das empresas.

A técnica Intuitiva apresentou na pesquisa números de objetivos estabelecidos e de objetivos implementados com sucesso menores do que as demais técnicas. Isso sugere que a definição da estratégia concentrada em poucas pessoas pode gerar uma lista de objetivos mais enxuta, porém, com menor taxa de sucesso, conforme os resultados apresentaram. Uma questão em aberto é se a taxa de sucesso na implementação de objetivos estratégicos é uma função do tratamento da empresa ou do número de objetivos.

Por outro lado, a técnica Intuitiva caracterizou-se por ser uma das duas técnicas que menos utilizam os objetivos de Geração de Valor e Responsabilidade Social Corporativa, não deixando claro qual seria sua linha de objetivos prioritários a ser conduzida pela técnica. Cabe analisar se esse método realmente é o mais adequado, mesmo para empresas menores, que encontram agilidade e precisam de flexibilidade em suas ações, mas, por outro lado, precisam comunicar melhor seus objetivos e fazer desenvolver sua estratégia. 
Nesta pesquisa, para ajudar a alcançar o objetivo principal da tese, foram caracterizados objetivos específicos para facilitar o estudo do tema em questão. Assim, nos próximos itens são apresentadas as considerações a respeito dos objetivos específicos desta tese e seus respectivos resultados alcançados.

- Objetivo Específico 1: Delimitar uma tipologia de técnicas para organização de objetivos estratégicos

Com base na pesquisa bibliográfica foi proposta uma tipologia de técnicas de organização de objetivos estratégicos. Em um eixo da tipologia, partindo de um extremo, com técnicas altamente estruturadas e técnicas com baixo nível de estruturação. No outro eixo da tipologia, também foram estudas as técnicas de organização de objetivos estratégicos, de acordo com a maneira de definirem-se os objetivos, em um extremo, com técnicas altamente participativas, e técnicas com menores níveis de participação dos colaboradores da empresa, o que nos permite dizer que seriam técnicas que apresentam características mais impositivas dos objetivos e visões da alta direção da organização.

O levantamento bibliográfico permitiu-nos chegar a uma lista de cinco técnicas, que, mesmo que com algumas semelhanças, são, na maior parte de suas características, conceitualmente diferentes. Foi possível identificar, inclusive, que algumas técnicas apresentadas por autores contemporâneos, a bem dizer, eram derivadas de técnicas clássicas, onde o melhor exemplo são os conceitos relacionados à APO.

Neste grupo de cinco técnicas, em um extremo, as técnicas mais estruturadas, como o BSC, que tem referências detalhadas com instruções e exemplos de como construí-lo e implementálo, passamos pela APO, com seus parâmetros da técnica e características SMART, para os objetivos e indicadores - em ambas as técnicas, alguns autores chegam a sugerir montar mapas, demonstrando a cadeia de relações entre os objetivos. O BSC possui características top-down, ou seja, parte da definição da estratégia e de seus objetivos, pela alta direção da organização, antes de ser divulgado. Já, a APO caracteriza-se pelo alinhamento entre o colaborador e seu supervisor imediato para a definição de objetivos e metas a serem 
alcançadas.

Um pouco menos estruturado, mas, fortemente pautado nos padrões e interesses da área contábil-financeira, temos os Objetivos Financeiros, onde a preocupação da corporação é voltada para a gestão de seus recursos financeiros e a geração de valor ao acionista. Esta técnica depende da caracterização dos objetivos, pela alta direção da empresa e da operacionalização pelas áreas especializadas.

No outro extremo da tipologia, em termos de formalização e estruturação, temos duas técnicas pautadas na experiência do(s) envolvido(s) com a estratégia da empresa. A técnica Participativa pressupõe a contribuição de um número maior de pessoas, além do corpo diretivo da empresa no processo estratégico - idealmente de toda a organização. Esta técnica é a mais suscetível para contemplar estratégias emergentes.

A técnica Intuitiva / Criativa pressupõe a participação do presidente da empresa e de poucas pessoas a mais, quando é o caso. Em empresas de tamanho menor, pode ser, apenas, entre os sócios, ou, até mesmo, de uma atividade realizada apenas pelo empreendedor.

A técnica Intuitiva caracteriza-se pela definição da estratégia de maneira pouco formal, baseada em pressupostos e na experiência dos envolvidos, o que pode contribuir para o surgimento de soluções criativas, frente aos padrões do mercado.

Deve-se destacar que após a definição das cinco técnicas da tipologia, foi realizada a pesquisa de campo onde os 289 respondentes analisados indicaram usar uma das técnicas. Apenas $2 \%$ da amostra original (seis participantes da pesquisa) foram retirados por indicar técnicas com nomenclatura diferentes das elencadas na tipologia - mesmo assim, a maioria desses respondentes sugeriu trabalhar com a mescla das técnicas citadas.

- Objetivo Específico 2: Identificar diferenças de usos de técnicas de objetivos estratégicos entre organizações de características diferentes, quanto ao volume de faturamento, da origem de seu capital e do esforço despendido no processo estratégico.

Este item específico buscava encontrar diferenças do uso das técnicas de organização de objetivos estratégicos, por meio das características das organizações que as utilizam. O 
Quadro 12 lista as cinco técnicas com as principais diferenças entre elas levantadas na pesquisa de campo desta tese.

Quadro 12 - Principais diferenças entre as técnicas

\begin{tabular}{|c|c|}
\hline Técnica & Principais diferenças entre as técnicas \\
\hline Balanced Scorecard & $\begin{array}{l}\text { - Empresas com faturamento acima de R\$1Bi } \\
\text { - Divulga a estratégia para toda a organização } \\
\text { - Seus executivos participam de parte do processo estratégico } \\
\text { - Maior número de objetivos estabelecidos } \\
\text { - Segundo maior número de objetivos implementados com sucesso } \\
\text { - Maior concordância quanto a contribuição para a comunicação } \\
\text { - Maior uso dos objetivos de "Responsabilidade Social Corporativa" }\end{array}$ \\
\hline $\begin{array}{c}\text { Administração por } \\
\text { Objetivos }\end{array}$ & - Maior uso de objetivos estratégicos implementados com sucesso \\
\hline $\begin{array}{c}\text { Objetivos } \\
\text { Financeiros }\end{array}$ & $\begin{array}{l}\text { - Segunda mais usada por empresas com faturamento acima de R\$ 1Bi } \\
\text { - Seus executivos participam de parte do processo estratégico } \\
\text { - Menor concordância quanto à contribuição para a comunicação } \\
\text { - Maior uso dos objetivos de "Geração de Valor" } \\
\text { - Menor uso dos objetivos de "Responsabilidade Social Corporativa" }\end{array}$ \\
\hline Participativa & $\begin{array}{l}\text { - Divulga a estratégia para toda a organização } \\
\text { - Decide e participa de todo o processo estratégico } \\
\text { - Terceiro maior número de objetivos estratégicos implementados }\end{array}$ \\
\hline Intuitiva/Criativa & $\begin{array}{l}\text { - Empresas com faturamento abaixo de } \mathrm{R} \$ 1 \mathrm{Bi} \\
\text { - A estratégia é divulgada apenas para determinados níveis organizacionais } \\
\text { - Menor número de objetivos estabelecidos } \\
\text { - Menor número de objetivos implementados com sucesso } \\
\text { - Menor uso de objetivos de "Geração de Valor" } \\
\text { - Menor uso de objetivos de "Responsabilidade Social Corporativa" }\end{array}$ \\
\hline
\end{tabular}

Em termos dos objetivos específicos desta tese, não foi possível diferenciar na amostra as técnicas de acordo com o esforço despendido para cuidar da estratégia ou com a origem de capital. Também, foi visto, nos itens anteriores, que não há relação entre uso de técnicas de organização de objetivos estratégicos corporativos e o país de origem da empresa. Da mesma forma, não foi constatada relação entre as técnicas e o fato das organizações possuírem ou não capital aberto em bolsa, no Brasil.

Já, em termos de faturamento, pôde-se diferenciar o uso das técnicas, de acordo com o tamanho da organização. Neste caso, para a maioria das respostas dadas pelos participantes da pesquisa, temos que as técnicas de BSC e de Objetivos Financeiros diferenciam-se das demais, por serem usadas por empresas grandes, com faturamento acima de 1 bilhão de reais. Já, técnica Intuitiva consegue diferenciar-se, por seu uso concentrado em empresas com 
faturamento abaixo de 1 bilhão.

- Objetivo Específico 3: Caracterizar a satisfação de executivos em relação aos objetivos estratégicos de suas organizações, à implementação e à comunicação da estratégia, de acordo com a técnica utilizada

Em relação à satisfação, em uma visão mais ampla, foi evidenciado um bom nível de satisfação geral dos respondentes em todas as questões. De um modo geral os participantes foram indagados a respeito da sua satisfação sobre a concepção e aplicação do processo estratégico, da definição e uso dos objetivos e da implementação estratégica. Em todas as questões, o menor percentual de concordância alcançou 52\%. Analisando a aplicação de técnicas de objetivos estratégicos não houve diferenciação de técnica específica, em termos de satisfação geral.

Analisando as questões sobre satisfação, de maneira individual, foi possível diferenciar as técnicas em relação à comunicação da estratégia. O BSC foi a técnica que mais contribuiu para a comunicação, enquanto a técnica de Objetivos Financeiros mostrou-se a que menos contribuiu para a comunicação. Desta maneira, os resultados analisados mostram que organizações que seguem um modelo mais estruturado de organização de objetivos comunicam melhor sua estratégia corporativa.

\section{$5.4 \quad$ Limitações da pesquisa e sugestões para estudos futuros}

Como em toda pesquisa algumas delimitações são necessárias para dar-se o foco necessário ao objeto de estudo. A partir desta tese, algumas limitações foram encontradas, assim como sugestões para dar continuidade ao tema desta pesquisa.

Como em toda pesquisa com amostragem não-probabilística, os resultados encontrados não podem ser generalizados. Também, deve-se destacar que não foi objeto do estudo discutir os resultados financeiros alcançados pelas organizações a partir de sua estratégia. $O$ foco de análise desta tese foi o processo de estratégia, especialmente na organização dos objetivos estratégicos. 
Considerando essas limitações, os resultados da pesquisa sugerem outras maneiras de dar continuidade ao tema, listadas, a seguir, aprofundando a investigação realizada.

- Repetir a aplicação do questionário de maneira a verificar a generalização dos resultados a empresas de todo o universo de pesquisa, com base em uma amostra probabilística.

- Aprofundar o estudo da aplicação das técnicas de organização de objetivos estratégicos corporativos, em setores específicos, e investigar se existem técnicas mais adequadas, de acordo com um setor da economia. A partir das características do setor, entender se existem técnicas mais apropriadas para a dinâmica de cada setor. Também, poderiam ser analisadas as técnicas de organização de objetivos estratégicos que seriam mais adequadas, de acordo com a maturidade tecnológica daquele setor.

- Prosseguir o estudo com as percepções de executivos sobre a estratégia da organização em que atuam com uma pesquisa mais aprofundada para analisar qual o alinhamento da estratégia e a satisfação com os diferentes aspectos estudados aqui, como o processo estratégico, a implementação, os objetivos estratégicos, dentre outros.

\subsection{Considerações finais}

Os objetivos estratégicos corporativos possuem um importante papel no processo estratégico, especialmente na ligação entre a formulação e a implementação de uma estratégia. E para desenvolver esta tese, com foco no tema acima, foi utilizada a seguinte pergunta de pesquisa como referência.

\section{Quais são as principais alternativas de organização de objetivos estratégicos corporativos e suas possíveis contribuições para a implementação e administração da estratégia empresarial?}

A partir do estudo de diversos conceitos, foi realizado um agrupamento de cinco técnicas que deram origem a tipologia proposta. A pesquisa de campo permitiu realizar o estudo conjunto e a comparação entre as técnicas, que evidenciaram e confirmaram algumas das principais características. Os resultados mostram que as cinco técnicas elencadas na tipologia mostramse adequadas para a amostra de pesquisa já que apenas $2 \%$ (seis casos) dessa amostra foi retirada por indicar usar outras técnicas que não são exatamente uma das mapeadas na 
tipologia.

O BSC foi a técnica em que mais características puderam ser comprovadas. Apesar de obter destaque na pesquisa pela maior parte de respondentes que atuam em empresas com faturamento acima de R\$ 1 bilhão, os resultados apresentaram que esta técnica é usada em todos os tamanhos de empresa. Características, divulgadas pelos seus criadores (Kaplan e Norton), foram comprovadas na pesquisa: divulgação da estratégia para toda a organização, contribuição para comunicação, uso mais abrangente dos objetivos, dentre outros.

A APO destacou-se pelo maior número de objetivos estratégicos implementados com sucesso, o que sugere explicar a razão desta técnica ser usada, atualmente, mesmo com alternativas mais recentes disponíveis.

Apesar de essencialmente focada, a técnica de Objetivos Financeiros foi a segunda mais indicada pelos respondentes, que a usam nas corporações de que fazem parte. A sua característica principal foi reforçada na pesquisa, sendo a técnica que mais usa os objetivos de “Geração de Valor".

As características principais da técnica Participativa foram comprovadas na pesquisa, destacando a participação dos respondentes em todo o processo estratégico, com a consequente divulgação da estratégia para toda a organização. Adicionalmente esta técnica apresentou, como resultado, um dos maiores números de objetivos estratégicos implementados com sucesso.

Por fim, a técnica Intuitiva, que se caracteriza pela centralização da decisão no proprietário ou em poucos elementos da empresa, resultou em um maior número de respondentes, em empresas com faturamento abaixo de 1 bilhão.

Possivelmente, empresas maiores necessitam de mecanismos mais formais para fazer a divulgação de sua estratégia, enquanto que, em empresas pequenas, ainda é possível imaginar que questões de comunicação, e especialmente, de estratégia serão discutidas e divulgadas diretamente pelos donos da empresa ou seu corpo diretivo. Este argumento ilustra a razão do BSC (a técnica mais estruturada da tipologia) ser a mais usada nas empresas maiores e ajudar na divulgação da estratégia como um todo. De maneira análoga, a técnica Participativa é mais 
útil em empresas de porte menor, dada a sua característica inclusiva para a condução do processo estratégico.

Independente da técnica utilizada é necessário entender, que o nível de exigência competitiva é crescente, e isto pode, inclusive, exigir a avaliação de novas técnicas ou conceitos complementares ao que já existe. Neste sentido, novas iniciativas como a do "relato integrado" são importantes para alinhar a estratégia empresarial, a responsabilidade social corporativa e a geração de valor, trazendo componentes importantes para a gestão de uma organização e que pode complementar, ou funcionar em conjunto com a visão já estabelecida por uma das técnicas de organização de objetivos estratégicos da tipologia estudada nesta tese.

Carvalho e Kassai (2013) definem que o relato integrado é mais do que a junção dos relatórios financeiros com informações não-financeiras. Deve-se incluir uma visão concisa sobre como a estratégia, a governança, o desempenho, seu ambiente externo e a postura diante das externalidades contribuem para a redução de riscos e o aumento do valor da empresa ao longo do tempo. A proposta é que o relato integrado passe a representar um "vídeo" (em vez de um retrato da empresa) orientado, principalmente, à criação de valor ao longo do tempo: como a empresa criou valor no passado, e quais as variáveis críticas, para que continue.

Analisando, por este caminho, os resultados indicam, uma possível vantagem das empresas que já utilizam o BSC, por sua característica plural, onde destacamos os fatores RSC e Geração de Valor, que, notadamente, diferenciaram-se, nesta pesquisa, e que são, justamente, duas das dimensões relevantes do relato integrado. Independente da próxima tendência do futuro ou do surgimento de novas técnicas é importante ter bem estabelecido o que a corporação deseja, em termos de objetivos estratégicos, para que a aplicação da técnica apoie a organização a alcançar o seu futuro desejado.

Nesta tese vimos que o conceito de objetivos estratégicos é, de fato, usado pelas empresas como componente relevante em seu processo estratégico. Foi respondido pelos participantes da pesquisa que os objetivos auxiliam a empresa na implementação estratégica, na participação de colaboradores e na comunicação da estratégia, todos estes aspectos com alto grau de satisfação. A tipologia de organização de objetivos estratégicos evidenciou características das cinco técnicas mapeadas entre participação e nível de estruturação, além 
dos aspectos colhidos na pesquisa. O BSC se mostrou ser a ferramenta mais abrangente, característica especialmente comprovada pelo maior uso de objetivos agrupados no fator de Responsabilidade Social Corporativa. A APO mostrou-se eficaz, com o maior número de objetivos implementados com sucesso, em média. Enquanto que os Objetivos Financeiros se destacaram por ser a que mais objetivos agrupados nos fatores de Geração de Valor. A técnica Intuitiva se caracterizou pelo maior uso em empresas de menor porte, com uma liderança forte e centralizada. Por fim, a técnica Participativa é mais voltada para a disseminação da estratégia e a participação dos colaboradores da empresa que a usam.

Com a proposição da tipologia de organização de objetivos estratégicos e a análise de suas técnicas nesta tese espera-se ter contribuído ao estudo de objetivos corporativos e à área de Administração de Empresas. Os resultados alcançados mostram que a continuidade dessa linha de pesquisa pode trazer contribuições no apoio à estratégia e sua implementação. Estes resultados permitem um entendimento inicial sobre o tema e possibilitam avaliar novas oportunidades de pesquisa para contribuir com o desenvolvimento de estudos sobre objetivos estratégicos corporativos. 


\section{REFERÊNCIAS}

AKAO, Y. Hoshin Kanri: Policy deployment for successful TQM. Cambridge: Productivity Press, 1991.

ALBUQUERQUE, Alexandre Farias. Gestão Estratégica das informações internas na pequena empresa. São Carlos, 2004. Dissertação (Mestrado em Engenharia) - Escola de Engenharia de São Carlos, Universidade de São Paulo.

ALMEIDA, Martinho Isnard Ribeiro de. Manual de Planejamento Estratégico Desenvolvimento de um Plano Estratégico com a Utilização de Planilhas Excel. 3. ed. São Paulo: Atlas, 2010.

ALOGAN, Güldal Büyükdamgaci; YETIS, Nüket. Defining Strategic Objectives: A Methodology Suited for Public Organizations. Total Quality Management. v.17, n.6, p.669684, Jul. 2006.

ANDREWS, Kenneth. O conceito de Estratégia Corporativa In: MINTZBERG, Henry et al. O processo da estratégia. 4. ed. Porto Alegre: Bookman, 2006.

ANSOFF, Igor. Corporate Strategy. Nova York: McGraw-Hill, 1965.

ANSOFF, Igor. A nova Estratégia Empresarial. São Paulo: Atlas, 1991.

BAKER, Michael J. Selecting a research methodology. The Marketing Review, v.1, n.3, p.373-397, 2001.

BARBERO, Edson Ricardo. Formação de estratégias: uma contribuição através de um modelo multidimensional. São Paulo, 2008. Tese (Doutorado em Administração) Faculdade de Economia Administração e Contabilidade. Universidade de São Paulo.

BETHLEM, Agrícola de Souza. Estratégia Empresarial: conceitos, processo e administração estratégica. São Paulo: Atlas, 1998.

BOURNE, Michael; BOURNE, Pippa. Handbook of Corporate Performance Management. Willey, 2011.

BOWER, J. L. Managing the resource allocation process. Boston: Graduate School of Business Administration, Harvard University, 1970. Apud BARBERO, Edson Ricardo. Formação de estratégias: uma contribuição através de um modelo multidimensional. São Paulo, 2008. Tese (Doutorado em Administração) - Faculdade de Economia Administração e Contabilidade, Universidade de São Paulo. 
BRADLEY, Chris, HIRT, Martin; SMIT, Sven. Have you tested your strategy lately? McKinsey Quartely. jan./2011.

CARVALHO, Marly M.; LAURINDO, Fernando J. B. Estratégia Competitiva: dos conceitos à implementação. São Paulo: Atlas, 2007.

CARVALHO, L. Nelson; KASSAI, José Roberto. Relato Integrado. In: LEAL, Ricardo; FONTES FILHO, Joaquim. O Futuro da Governança Corporativa. São Paulo: Saint Paul, 2013.

CERTO, Samuel. Administração Estratégica. Planejamento e implantação de estratégias. Pearson, 2010.

CHATTERJEE, S. Core objectives: clarity in designing strategy. California Management Review. v.47 n.2, p.33-49, winter, 2005.

CLARK, Daniel. Integrated Management. Financial Management.Cima, 2008.

COOPER, Donald R.; SCHINDLER, Pamela. Métodos de Pesquisa em Administração. Porto Alegre: Bookman, 2003.

DAFT, R. L. Management. Orlando: The Dryden Press, 1999.

DRUCKER, Peter F. Prática da administração. São Paulo: Cengage Learning, 1981.

DRUCKER, Peter F. Introdução à administração. 3. ed. São Paulo: Cengage Learning, 1998.

ETZIONI, A. Organizações modernas. 5. ed. São Paulo: Pioneira, 1976

FISCHMANN, Adalberto Américo; ALMEIDA, Martinho Isnard Ribeiro de. Planejamento Estratégico na prática. 2 ed. São Paulo: Atlas, 1991.

FISCHMANN, Adalberto. Implementação de estratégias: identificação e análise de problemas. São Paulo, 1987. Tese (Livre docência em Administração) - Programa de PósGraduação em Administração da Faculdade de Economia, Administração e Contabilidade da Universidade de São Paulo.

FLICK, U. An introduction to qualitative research. 3a. ed. Sage Publications, Inc. 2006.

GAJ, Luis. Administração Estratégica. São Paulo: Ática, 1987. 
GIL, Antonio Carlos. Como elaborar projetos de pesquisa. 5. ed. São Paulo: Atlas, 2010.

GITMAN, L. Princípios da Administração Financeira. São Paulo: Habra, 1997.

HAIR, Joseph F.; ANDERSON, Rolph E.; TATHAM, Ronald L.; BLACK, William C. Análise Multivariada de Dados. 5. ed. Porto Alegre: Bookman, 2005.

HAMEL, Gary e PRAHALAD, C. K. Objetivo Estratégico In: MINTZBERG, Henry et al. O processo da estratégia. 4. ed. Porto Alegre: Bookman, 2006.

HAX, Arnoldo C.; MAJLUF, Nicolas S. The strategy concept and process. New Jersey: Prentice Hall, 1984.

HINDLE, Tim. Management by objectives. In: The Economist Guide to Management Ideas and Gurus. Nova Jersey: John Wiley \& Sons, 2009. Disponível em <http://www.economist.com/node/14299761>. Acesso em 06/01/2014.

HITT, Michael; IRELAND, R. Duane; HOSKINSSON, Robert. Administração Estratégica. São Paulo: Thomson Learning, 2008.

HREBINIAK, Lawrence G. Fazendo a estratégia funcionar. Bookman, 2006.

HREBINIAK, Lawrence G. Implementing Strategy. Notas de aula, 2011.

KALLÁS, David. Balanced Scorecard - Aplicação e impactos. Um estudo com jogos de empresas. São Paulo, 2003. Dissertação (Mestrado em Administração). Programa de PósGraduação em Administração da Faculdade de Economia, Administração e Contabilidade da Universidade de São Paulo.

KAPLAN, Robert e NORTON, David. P. A estratégia em ação - Balanced Scorecard. Rio de Janeiro: Campus, 1997.

KAPLAN, Robert e NORTON, David. P. Having Trouble With Your Strategy? Then map it. Harvard Business Review. v.78, n.5, Sep./Oct. 2000.

KAPLAN, Robert e NORTON, David. P. Mapas Estratégicos: convertendo ativos intangíveis em resultados tangíveis. Rio de Janeiro: Campus, 2004.

KAPLAN, Robert e NORTON, David. P. A Execução Premium: a obtenção de vantagem competitiva através do vincula da estratégia com as operações do negócio. Rio de Janeiro: Elsevier, 2008.

KOTTER, John. P. Liderando Mudança. Rio de Janeiro: Elsevier, 1997. 
KRONMEYER FILHO, Oscar Rudy; KLIEMANN NETO, Francisco José; RIBEIRO, José Luiz Duarte. Gestão Estratégica e BSC: Gaps e Oportunidades de Melhoria. In: ENCONTRO NACIONAL DE ENGENHARIA DE PRODUÇÃO - ENEGEP, 24., 2004, Florianópolis. Anais... Florianópolis: ENEGEP, 2005.

LATIF, S. A. A análise fatorial auxiliando a resolução de um problema real de pesquisa de marketing. Caderno de pesquisas em administração. São Paulo, v.0, n.0, 2.sem.1994.

LOBATO, David M.; MOYSÉS FILHO, Jamil; TORRES, Maria Cândida S.; RODRIGUES, Murilo R. A. Estratégia de empresas. Rio de Janeiro: Editora FGV, 2006.

LODI, João Bosco. Administração por objetivos. 6ed. São Paulo, Pioneira, 1977.

LOPEZ, Cid. Hoshin Kanri — Desdobrando a estratégia em sua organização.11/jan/2010 Disponível em: http://www.lean.org.br/comunidade/artigos/pdf/artigo_125.pdf. Acesso em 25/11/2012.

LUECKE, Richard. Estratégia. 4. ed. Rio de Janeiro: Record, 2009. (Harvard Business Essentials).

LUPOLI JUNIOR, José G. Impactos do comportamento de equipe na tomada de decisão estratégica: um experimento com grupos de trabalho. São Paulo, 2006. Tese (Doutorado em Administração) - Programa de Pós-Graduação em Administração, Faculdade de Economia, Administração e Contabilidade da Universidade de São Paulo.

MAGRETTA, Joan. Understanding Michael Porter. Boston: Harvard Business School Publishing, 2012.

MARCONI, Marina; LAKATOS, Eva Maria. Fundamentos de Técnica Científica. 7. ed. São Paulo: Atlas, 2010.

MARTINS, Giberto de Andrade; THEÓPHILO, Carlos Renato. Metodologia da investigação científica para ciências sociais aplicadas. 2 ed. São Paulo: Atlas, 2009.

MATARAZZO, D. Análise financeira de balanços: abordagem básica e gerencial. São Paulo: Atlas, 2003.

MICHAELIS. Moderno dicionário da língua portuguesa. São Paulo: Melhoramentos, 2009.

MIGUELES, Carmen. Pesquisa: Por Que Administradores Precisam Entender Disso? Rio de Janeiro: e-Papers. 2005. 
MILES, Robert H. Spotlight on Reinvention - Accelerating Corporate Transformations (Don't Lose your Nerve). Harvard Business Review, p.70, Jan./Feb. 2010.

MINTZBERG, H.; AHLSTRAND, B.; LAMPEL, J. Safári de Estratégia. Porto Alegre: Bookman, 2000.

MINTZBERG, Henry. Ascensão e queda do planejamento estratégico. Porto Alegre: Bookman, 2004.

MINTZBERG, Henry; LAMPEL, Joseph; QUINN, James Brian; GHOSHAL, Sumantra. O processo da estratégia. 4. ed. Porto Alegre: Bookman, 2006.

MONTGOMERY, Cynthia A. O Estrategista. Rio de Janeiro: Sextante, 2012.

MORANTE, A. Análise das demonstrações financeiras. São Paulo: Atlas, 2007.

MUNIZ, Sergio Tadeu G. A nova métrica baseada em valor: uma resposta aos antagonismos e conflitos de interesse na empresa moderna. In: ENCONTRO NACIONAL DE ENGENHARIA DE PRODUÇÃO - ENEGEP, 29., 2009, Salvador. Anais... Salvador: ENEGEP, 2009.

NEILSON, Gary L.; MARTIN, Karla L.; POWERS, Elizabeth. The secrets to successful strategy execution. Harvard Business Review. p. 60-70, jun. 2008.

NIVEN, Paul R. Balanced Scorecard passo-a-passo: elevando o desempenho e mantendo resultados. Rio de Janeiro: Qualitymark, 2005.

O’DONNELL, Cyril. Planning Objectives. California Management Review. Winter. 1963.

OLIVEIRA, Murilo; SOUZA NETO, Silvestre. A contribuição de elementos subjetivos nas estratégias emergentes e na criação de cenários: avaliando o perfil intuitivo dos decisores. In: COSTA, Benny Kramer. ALMEIDA, Martinho. Estratégia Contemporânea. Campinas: Akademika, 2008.

PAPALEXANDRIS, Alexandros; IOANNOU, George; PRASTACOS, Gregory; SODERQUIST, Klas Eric. An Integrated Methodology for putting the Balanced Scorecard into Action. European Management Journal. v.23, n.2, 2005.

PITCHER, Patrícia. Artistas, Artesãos e Tecnocratas. In: MINTZBERG, Henry et al. O processo da estratégia. 4. ed. Porto Alegre: Bookman, 2006.

PORTER, Michael E. Estratégia Competitiva. Rio Janeiro: Campus, 1986. 
PORTER, Michael E. Vantagem Competitiva. Rio Janeiro: Campus, 1989.

PORTER, Michael. What is Strategy? Harvard Business Review. nov./dez.,1996.

PORTER, Michael. An interview with Michael Porter. In: MAGRETTA, Joan. Understanding Michael Porter. Boston: Harvard Business School Publishing, 2012.

PONTES, Diana Santos. O uso da intuição e a presença de vieses cognitivos na tomada de decisão. Fortaleza, 2009. Dissertação (Mestrado em Administração). Universidade Estadual do Ceará.

QUINN, James. Estratégias para Mudança. In: MINTZBERG, Henry et al. O processo da estratégia. 4. ed. Porto Alegre: Bookman, 2006.

RAJ, Rhada. Corporate Planning and Strategic Human Resources Management. Pune: Nirali Publication, 2007. Disponível em: http://books.google.com.br/books?id=DJha_WZdk3UC\&lpg=SA4PA15\&ots=OgKNYUdsBr\&dq=Andy\%20Grove\%20MBO\%20\%20Intel\&hl=pt-BR\&pg=PP4\#v=onepage\&q\&f=false Acesso em 03/01/2014.

ROBINSON, John. Paradoxes in planning. Great Britain. Long Range Planning, v.19, n.6, 1986.

ROTH, William F. Is Management by Objectives Obsolete? Global Business and Organizational Excellence. may/jun. 2009.

RUMELT, Richard. Avaliando a estratégia empresarial. In: MINTZBERG, Henry et al. $\mathbf{O}$ processo da estratégia. 4. ed. Porto Alegre: Bookman, 2006.

SA, Yongjin. Elements of Strategic Management Process and Performance Management Systems in U.S. Federal Agencies: Do Employee Managerial Levels Matter? International Journal of Business and Management; v.8, n.9, 2013.

SEVERINO, Antonio Joaquim. Metodologia do trabalho científico. 23 ed. São Paulo: Cortez, 2007.

SIEGEL, Sidney. Estatística não-paramétrica. São Paulo: McGraw-Hill, 1981.

SILVA, M. W. Análise de Demonstrativos Financeiros. Curitiba: IESDE, 2009.

SOUZA, J. M. Definition and analysis of critical success factors for ERP implementation process. Barcelona (2005). Tese (Doutorado). Universitat Politècnica de Catalunya. 
TURRIONI, J. B.; SOUZA, Luiz Gonzaga Mariano de; COSTA NETO, Pedro Luiz de Oliveira. Hoshin Kanri: uma análise da implementação em operações de manufatura no Brasil. In: ENCONTRO NACIONAL DE ENGENHARIA DE PRODUÇÃO - ENEGEP, 19., 1999, Rio de Janeiro. Anais... Rio de Janeiro: ENEGEP, 1999.

VALOR1000. 1000 Maiores Empresas - Edição 2013. Disponível em: <http://www.valor.com.br/valor1000/2013>. Acesso em: 26/12/2013.

WILLIAMS, Jeff; DEARIE, Tammy Nickelson; SCHOTTLAENDER, Brian E. C. BottomUp Strategic Planning: The UC San Diego Libraries Experience. Library Leadership \& Management. v.27, n.3, 2013.

ZACARELLI, Sérgio. Estratégia e sucesso nas empresas. São Paulo: Saraiva, 2003. 


\section{APÊNDICES}

APÊNDICE 1 - QUESTIONÁRIO

APÊNDICE 2 - DETALHAMENTO ESTATIISTICO 


\section{APÊNDICE I - QUESTIONÁRIO}

Prezado(a) colega,

Gostaria de pedir sua ajuda respondendo a este questionário sobre sua percepção com relação à formulação de Objetivos Estratégicos Corporativos. Esta pesquisa, desenvolvida sob orientação do Prof Dr. James Wright, é base para meu Doutorado em Administração pela FEA/USP e visa aprimorar o conhecimento científico sobre o passo entre a concepção da estratégia corporativa e sua implementação.

O preenchimento leva aproximadamente 15 minutos e a análise com os dados consolidados estará à disposição na publicação da minha tese. Adicionalmente, os respondentes deste questionário receberão uma síntese específica dos resultados da pesquisa.

Ressalto que respostas individuais não serão divulgadas e para garantir a segurança dos dados utilizo a ferramenta de pesquisas QuestionPro. Em caso de dúvidas estou a disposição no email dcarvalho@usp.br. Estes dados serão trabalhados apenas por mim com o único objetivo de analisá-los para a minha pesquisa. Somente informações consolidadas serão divulgadas. Agradeço sua atenção - sua contribuição será muito relevante para o sucesso desta pesquisa!

\section{Obrigado!!}

Daniel Estima de Carvalho - Doutorando FEA/USP

Você atua em uma empresa de origem brasileira?

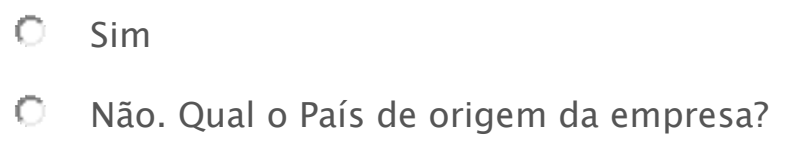

A empresa em que você atua possui capital aberto no Brasil?

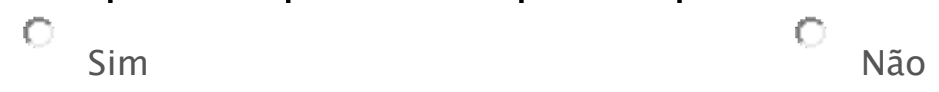

Caso o controle não seja brasileiro, a empresa em que você atua possui capital aberto no país de origem?
Sim
Não
Não se aplica 
Qual o setor de atuação da sua organização?

\begin{tabular}{|c|c|c|c|c|}
\hline C Atacado & $\mathrm{C}$ & Indústria da construção & $\mathrm{C}$ & Serviços \\
\hline Autoindústria & 0 & Indústria Digital & 0 & Siderurgia e Metalurgia \\
\hline Bens de capital & 0 & Mineração & 0 & Transporte \\
\hline Bens de consumo & $\mathrm{C}$ & Papel e Celulose & $\mathrm{C}$ & Telecomunicações \\
\hline Eletroeletrônico & $c$ & Produção agropecuária & 0 & Têxteis \\
\hline Energia & $c$ & Química e Petroquímica & 0 & Varejo \\
\hline Farmacêutico & & & & \\
\hline Outro. Qual? & & & & \\
\hline
\end{tabular}

Qual é o faturamento (receita operacional bruta anual) da sua empresa?
Menor ou igual a $\mathrm{R} \$ 2,4$ milhões
Entre $\mathrm{R} \$ 2,4$ milhões e $\mathrm{R} \$ 16$ milhões
Entre R\$16 milhões e R\$90 milhões
Entre $\mathrm{R} \$ 90$ milhões e $\mathrm{R} \$ 300$ milhões
Entre $\mathrm{R} \$ 300$ milhões e $\mathrm{R} \$ 500$ milhões
Cntre R\$500 milhões e R\$ 1 bilhão
C Maior que R\$1 bilhão

O bloco de questões a seguir possui o intuito de entender como as empresas lidam com seus objetivos estratégicos corporativos para realizar uma estratégia planejada. Consideramos como Objetivos Estratégicos Corporativos aqueles de mais alto nível de uma empresa. São os objetivos que a organização como um todo deve atingir para considerar realizada sua estratégia empresarial.

Qualifique a característica fundamental da estratégia empresa em que você atua (indique a principal): saiba mais
Liderança em custo
Intimidade com o cliente
Foco em um nicho/segmento específico
Diferenciação (em produtos e/ou
Excelência Operacional serviços)
Liderança com "o melhor produto"
Outra. Qual? 
Por favor indique os responsáveis pela definição dos itens abaixo na sua empresa: saiba mais

$\begin{array}{cccc}\text { Matriz } & \text { Conselho de } & \text { CEO/Presidente } & \text { Diretoria } \\ \text { (sede no } & \text { Administração(local) } & \text { (local) } & \\ \text { exterior) } & & & \end{array}$

\begin{tabular}{|c|c|c|c|c|c|}
\hline $\begin{array}{l}\text { Estratégia } \\
\text { Corporativa }\end{array}$ & Г & Г & Г & Г & Г \\
\hline $\begin{array}{l}\text { Objetivos } \\
\text { Estratégicos }\end{array}$ & Г & Г & Г & Г & Г \\
\hline $\begin{array}{l}\text { Metas } \\
\text { corporativas }\end{array}$ & Г & $\Gamma$ & $\Gamma$ & Г & $\Gamma$ \\
\hline
\end{tabular}

\section{Para quem os objetivos estratégicos corporativos são divulgados?}
A Apenas Sócios
Aos Diretores e superiores
Aos Gerentes e superiores
C Toda a organização, sem restrição de Cargos/Nível organizacional
Cada área recebe apenas seus objetivos
Outro. Quem?

Qual o seu nível de participação na definição da Estratégia corporativa da organização em que você atua?

Não possuo acesso à estratégia que é divulgada para poucas pessoas (ex. donos e/ou diretores)

Defino e participo de todo o processo estratégico

Defino a estratégia (decisão de qual estratégia seguir)

Participo de todo o processo estratégico (análises, concepção de objetivos, implementação etc.)

C Participo em partes do processo do processo estratégico

Sou consultado no processo de análise e definição da estratégia

Forneço informações para o processo estratégico

C Sou informado da estratégia ao final do processo 
Quantos objetivos estratégicos corporativos (ou empresariais gerais) são estabelecidos pela sua empresa?

saiba mais

Na sua opinião, qual seria o número adequado de objetivos estratégicos corporativos para sua empresa?

Quantos objetivos estratégicos corporativos da sua organização foram implementados com sucesso?

Quantos dos seus objetivos organizacionais estão associados aos objetivos estratégicos corporativos da organização?
nenhum
C 1
C $2-3$
C $4-6$
C $6-10$
Outros. Quantos?

Indique a técnica que melhor descreve o processo usado para organizar os objetivos estratégicos corporativos na sua empresa: saiba mais
APO - Administração por objetivos
C BSC - Balanced Scorecard
São definidos objetivos de desempenho Financeiro
Processo Intuitivo/Criativo desenvolvido a partir da alta direção
Processo participativo por meio da discussão em grupos de baixo pra cima (bottom-up)
Outra. Qual? 
Indique a quantidade de reuniões/eventos utilizados especificamente para a discussão e definição da Estratégia empresarial corporativa
nenhuma
C 1 reunião por trimestre
C 1 anual
reuniões bimestrais
C 2 por ano
C reuniões mensais
Outro

Para cada reunião assinalada acima quanto dias de preparação prévia são necessários?

Neste bloco pedimos que analise sua satisfação em relação aos resultados alcançados pelos objetivos estratégicos corporativos definidos por sua empresa

$\begin{array}{cccccc}\text { Não } & \text { (1)Discordo } & \text { (2)Discordo } & \text { (3)Nem } & \text { (4)Concordo } & \text { (5)Concordo } \\ \text { sei/não } & \text { totalmente } & \begin{array}{c}\text { parcialmente } \\ \text { ou mais }\end{array} & \begin{array}{c}\text { concordo } \\ \text { se }\end{array} & \begin{array}{c}\text { nem } \\ \text { discordo que } \\ \text { concordo }\end{array} & \text { discordo mais } \\ \text { aplica } & & \begin{array}{c}\text { concordo que } \\ \text { discordo }\end{array} & \text { totalmente } \\ & & & \text { discordo }\end{array}$

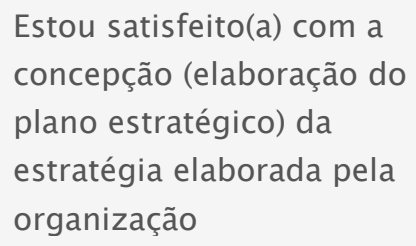


sucesso da implementação

da estratégia planejada

O uso da técnica

empregada para definição

de objetivos estratégicos

contribui para

comunicação da estratégia

corporativa nos diversos

níveis da organização

Com relação à técnica de organização de objetivos estratégicos corporativos indicada anteriormente, quais os pontos positivos desta técnica usada pela sua organização?

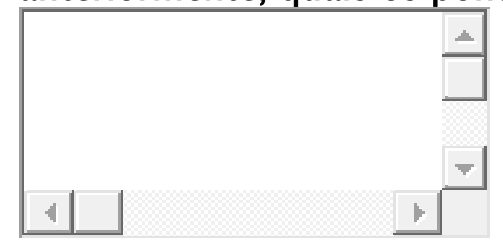

\section{Quais os pontos negativos?}

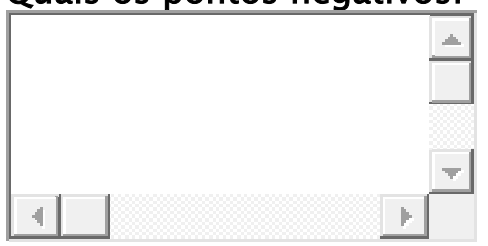

O que você faria para aprimorar a técnica usada pela sua organização? O que falta para implementar os objetivos estratégicos corporativos com sucesso?

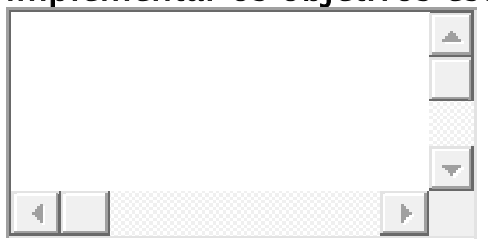

Da lista de objetivos abaixo avalie as categorias que englobam os objetivos estratégicos corporativos prioritários que são utilizados efetivamente na sua organização (Avalie quantos for necessário). Atribua 1 (um) quando a empresa não utilizar o objetivo e 5(cinco) quando usar intensamente estes objetivos estratégicos.

Comentário: A lista abaixo foi elaborada com base em objetivos de diversas organizações. Alguns podem ser mutuamente excludentes. É provável que nenhuma organização trabalhe com todos estes ao mesmo tempo.

$\begin{array}{ccccc}1-\text { Não } & 2 \text { - Usa } & 3 \text { - Usa } & 4 \text { - Utiliza } & 5 \text { - Usa } \\ \text { Utiliza } & \begin{array}{c}\text { muito } \\ \text { pouco }\end{array} & \text { pouco } & & \text { efetivamente }\end{array}$


- Gerar valor para acionista/proprietário

- Melhorar estrutura de custos

- Aumentar participação

(c)

$c$

c

C

c de mercado

- Oferecer Melhor Preço

$6 \quad \mathrm{c}$

$c \quad r$

$c$

- Lançamento de novos produtos

- Aumentar Qualidade

c $C$

- Aprimorar Seleção de clientes

$6 \quad r$

- Melhorar Prestação de Serviços

- Aumentar Parcerias

$6 \quad \mathrm{C}$

C

$\mathrm{c}$

$c$

c

$c$

- Melhorar

Relacionamento com

c

cliente

- Buscar incremento de Imagem

- Aumentar Produção

- Incrementar Distribuição

$6 r$

$c$

c

c

c

c

- Incrementar Portfólio de P\&D

- Minimizar Impacto no Meio ambiente

c $c$

- Aprimorar

Relacionamento com

$6 r$

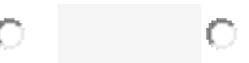

c

c

c

comunidade

- Aumentar Alinhamento da equipe com a

$6 \quad \mathrm{c}$

0

c

$c$ estrategia

- Melhorar Trabalho em equipe

- Aumentar Retencão de

c

$c$

c

C

$0 \quad 0 \quad 00$

C

C

$c$

6

c

C $\quad 0$

c 
talentos

- Incrementar Capacitação

- Aprimorar Infra

estrutura tecnológica

Algum objetivo estratégico não listado? Por favor indique aqueles que a organização usa efetivamente e não estão listados na questão acima

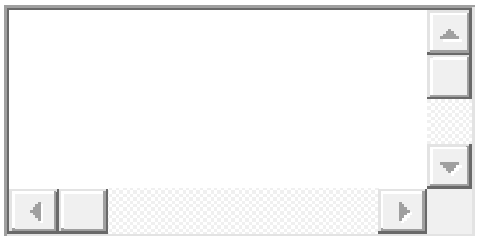

Indique, de forma ordenada sendo 1 a primeira etapa e assim por diante $(2,3,4 \ldots)$, a forma de trabalho para a definição da Estratégia corporativa da organização em que você atua. Deixe em branco caso a etapa não seja realizada pela sua empresa.

Análise de Diretrizes vindas da Matriz (se for o caso)

Análise do Ambiente Externo

Definição de Objetivos Estratégicos

Análise de Aspectos Internos

Organização da implementação/Plano de ação

Concepção da Estratégia

Definição de Metas e indicadores

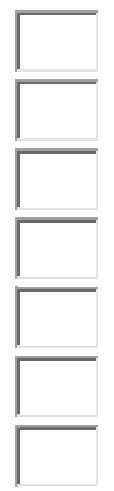

Outro? Por favor, explique:

Qual o seu departamento funcional?
C Planejamento Estratégico
C Gestão de Pessoas
Contabilidade/Controladoria
Operações/Produção
Finanças
C Marketing/Vendas
Gerência Geral
C Tecnologia
Cutro 
Qual seu nível de decisão na organização em que atua?
C. Analista
Gerente
C Diretor
C Presidente
Superintendente
C Proprietário/Sócio
Outro

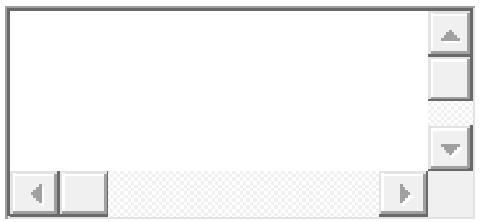

Qual sua formação? Por favor indique o último grau formado.
Graduação incompleta
C. Mestrado
Graduação
Doutorado
C Pós-graduação lato sensu
Pós-doutorado
C MBA
Outro. Qual?

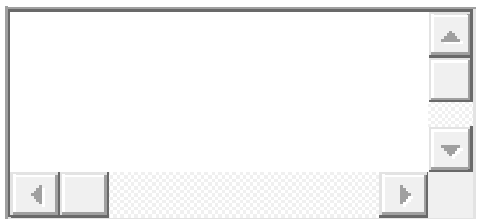

Nome(opcional):

Empresa (opcional) 


\section{APÊNDICE II — DETALHAMENTO ESTATÍSTICO}

\section{4}

\section{c) Faturamento}

\section{Faturamento}

\begin{tabular}{|lcc|}
\hline Técnica & $\mathrm{n}$ & média de postos \\
BSC - Balanced Scorecard & 90 & 164,61 \\
São definidos objetivos de desempenho Financeiro & 75 & 152,15 \\
Processo participativo por meio da discussão em grupos de baixo pra cima & 21 & 144,38 \\
(bottom-up) & 44 & 136,00 \\
APO - Administração por objetivos & 57 & 106,78 \\
Processo Intuitivo/Criativo desenvolvido a partir da alta direção & 287 & \\
Total & & \\
\hline
\end{tabular}

Ao se realizar comparações múltiplas, objetivando indicar quais das técnicas são diferentes frente ao faturamento:

Diferenças entre média de postos (observada)

\begin{tabular}{|lcccc|}
\hline & BSC & Objetivos Financeiros & $\begin{array}{c}\text { Processo } \\
\text { participativo }\end{array}$ & APO \\
Objetivos Financeiros & 12,46 & & & \\
Participativo & 20,23 & 7,77 & 8,38 & \\
Apo & 28,61 & 16,15 & 37,6 & 29,22 \\
Intuitiva & 57,83 & 45,37 & & \\
\hline
\end{tabular}

Diferença Mínima Significativa (DMS)

\begin{tabular}{|lcccc|}
\hline DMS $(\alpha=0,05)$ & BSC & Objetivos Financeiros & $\begin{array}{c}\text { Processo } \\
\text { participativo }\end{array}$ & Apo \\
Objetivos Financeiros & 36,46 & & & \\
Processo participativo & 56,52 & 57,58 & & \\
Apo & 42,9 & 44,29 & 40,16 & \\
Processo intuitivo & 39,48 & 40,98 & 59,53 & 46,80 \\
\hline
\end{tabular}

As diferenças observadas são maiores que DMS para:

- BSC e processo intuitivo

- Objetivo financeiro e processo intuitivo

Sendo estas as diferenças encontradas ao nível de $\alpha=0,05$ 


\section{4}

\section{f) Quantidade de reuniões para definição da estratégia}

Esta variável foi transformada da seguinte forma:

\begin{tabular}{|lc|}
\hline Resposta do questionário & Valor \\
Nenhuma & 0 \\
1 anual & 1 \\
2 por ano & 2 \\
1 reunião por trimestre & 4 \\
Reuniões bimestrais & 6 \\
Reuniões mensais & 12 \\
\hline
\end{tabular}

Considerada então variável quantitativa contínua, pôde proceder-se as estimativas.

Cálculo de postos

\begin{tabular}{|lcc|}
\hline Técnica & Quantidade de reuniões \\
APO & 41 & média de postos \\
BSC & 87 & 131,72 \\
Objetivos Financeiros & 69 & 135,33 \\
Intuitiva & 53 & 139,57 \\
Participativa & 21 & 135,61 \\
Total & 271 & 136,38 \\
\hline
\end{tabular}

\begin{tabular}{|lcc|}
\hline & & $\begin{array}{c}\text { Quantidade de reuniões/eventos utilizados para a } \\
\text { discussão e definição da estratégia corporativa }\end{array}$ \\
Técnica & $\mathrm{N}$ & Média de postos \\
APO - Administração por objetivos & 41 & 131,72 \\
BSC - Balanced Scorecard & 87 & 135,33 \\
Objetivos Financeiros & 69 & 139,57 \\
Processo Intuitivo & 53 & 135,61 \\
Processo participativo (bottom-up) & 21 & 136,38 \\
Total & 271 & \\
$\chi^{2}$ & & \\
$\mathrm{p}$ & 0,289 &
\end{tabular}




\section{4}

\section{g) Dias de preparação prévia para definição da estratégia}

\begin{tabular}{|lcc|}
\hline & & $\begin{array}{c}\text { Número de dias (por ano) de } \\
\text { preparação para definição da } \\
\text { Estratégia }\end{array}$ \\
Técnica que melhor descreve o processo usado para & & Média de postos \\
organizar os objetivos estratégicos corporativos & $\mathrm{N}$ & 122,32 \\
APO - Administração por objetivos & 38 & 126,79 \\
BSC - Balanced Scorecard & 77 & 135,4 \\
Objetivos Financeiros & 62 & 105,51 \\
Processo Intuitivo & 51 & 134,45 \\
Processo participativo (bottom-up) & 20 & \\
Total & 248 & \\
\hline
\end{tabular}

\section{4}

\section{j) Número de objetivos estratégicos}

1) estabelecidos pela organização

\begin{tabular}{|lcc|}
\hline Técnica & N & Média de postos \\
APO & 42 & 135,32 \\
BSC & 83 & 156,61 \\
Objetivos Financeiros & 72 & 128,51 \\
Processo Intuitivo & 52 & 108,56 \\
Processo participativo (bottom-up) & 20 & 136,72 \\
Total & 269 & \\
\hline
\end{tabular}

Diferenças entre média de postos (observada)

\begin{tabular}{|lcccc|}
\hline & Processo & Objetivos \\
Processo participativo & 19,89 & participativo & APO & Financeiros \\
APO & 21,29 & & & \\
Objetivos Financeiros & 28,1 & 1,40 & & \\
Processo Intuitivo & 48,05 & 8,21 & 6,81 & \\
\hline
\end{tabular}

Diferença mínima significatica (DMS)

\begin{tabular}{|lcccc|}
\hline & & Processo & Objetivos \\
DMS $(\alpha=0,05)$ & BSC & participativo & APO & Financeiros \\
Processo participativo & 54,46 & & & \\
APO & 41,40 & 59,39 & & \\
Objetivos Financeiros & 35,21 & 55,26 & 38,86 & 39,78 \\
Processo Intuitivo & 38,66 & 57,52 & 45,35 & \\
\hline
\end{tabular}




\section{4}

\section{j) Número de objetivos estratégicos}

2) implementados

Cálculo de postos

\begin{tabular}{|lcc|}
\hline & & Média de \\
Técnica & $\mathrm{N}$ & postos \\
APO - Administração por objetivos & 40 & 145,05 \\
BSC - Balanced Scorecard & 78 & 142,49 \\
Objetivos Financeiros & 68 & 116,71 \\
Processo Intuitivo/Criativo & 48 & 92,43 \\
Processo participativo & 19 & 149,55 \\
Total & 253 & \\
\hline
\end{tabular}

Diferenças entre média de postos (observada)

\begin{tabular}{|lcccc|}
\hline & $\begin{array}{c}\text { Processo } \\
\text { participativo }\end{array}$ & APO & BSC & Objetivos \\
APO & 4,5 & & & \\
BSC & 7,06 & 2,56 & & \\
Objetivos Financeiros \\
Processo Intuitivo & 32,84 & 28,34 & 25,78 & \\
\hline
\end{tabular}

Diferença mínima significativa (DMS)

\begin{tabular}{|lcccc|}
\hline & $\begin{array}{c}\text { Processo } \\
\text { participativo }\end{array}$ & APO & BSC & $\begin{array}{c}\text { Objetivos } \\
\text { Financeiros }\end{array}$ \\
APO & 57,29 & & & \\
BSC & 52,61 & 39,99 & & \\
Objetivos Financeiros & 53,36 & 40,98 & 34,12 & \\
Processo Intuitivo & 55,74 & 44,02 & 37,72 & 38,77 \\
\hline
\end{tabular}

\section{4}

\section{j) Número de objetivos estratégicos}

3) considerados adequado pelo respondente

\begin{tabular}{|lcc|}
\hline Técnica & N & Média de postos \\
APO & 42 & 126,25 \\
BSC & 81 & 138,09 \\
Objetivos Financeiros & 71 & 127,9 \\
Processo Intuitivo & 51 & 126,25 \\
Processo participativo (bottom-up) & 20 & 161,88 \\
Total & 265 & \\
\hline
\end{tabular}




\section{4}

\section{j) Número de objetivos estratégicos}

4) associados aos objetivos organizacionais do respondente

\begin{tabular}{|lcc|}
\hline Técnica & $\mathrm{N}$ & Média de \\
APO & 44 & postos \\
BSC & 91 & 146,64 \\
Objetivos Financeiros & 74 & 152,87 \\
Intuitiva & 53 & 126,58 \\
Participativa & 18 & 145 \\
Total & 280 & \\
\hline
\end{tabular}

\section{4}

\section{l) Satisfação}

Comunicação

\begin{tabular}{|lcc|}
\hline Técnica & M & Média de \\
APO & 39 & postos \\
BSC & 89 & 150,71 \\
Objetivos Financeiros & 68 & 157,7 \\
Processo Intuitivo & 55 & 111,81 \\
Processo Participativo & 21 & 122,21 \\
Total & 272 & \\
\hline
\end{tabular}

Diferenças entre média de postos (observada)

\begin{tabular}{|lcccc|}
\hline & BSC & APO & $\begin{array}{c}\text { Processo } \\
\text { Participativo }\end{array}$ & $\begin{array}{c}\text { Processo } \\
\text { Intuitivo }\end{array}$ \\
APO & 6,99 & & & \\
Processo Participativo & 20,06 & 13,07 & & \\
Processo Intuitivo & 35,49 & 28,5 & 15,43 & \\
Objetivos Financeiros & 45,89 & 38,9 & 25,83 & 10,4 \\
\hline
\end{tabular}

Diferença mínima significativa

\begin{tabular}{|lcccc|}
\hline DMS $(\alpha=0,05)$ & BSC & APO & Processo & Processo \\
APO & 42,45 & & & \\
Processo Participativo & Intuitivo \\
Processo Intuitivo & 53,63 & 59,83 & & \\
Objetivos Financeiros & 37,91 & 46,27 & 56,70 & \\
\hline
\end{tabular}




\section{4}

m) uso dos objetivos

Em relação ao fator Responsabilidade Social Corporativa

\begin{tabular}{|lcc|}
\hline & & Média de \\
APO & N & Postos \\
BSC & 44 & 148,75 \\
Objetivos Financeiros & 92 & 165,76 \\
Processo Intuitivo & 75 & 129,16 \\
Processo Participativo & 57 & 125,13 \\
Total & 21 & 156,71 \\
\hline
\end{tabular}

Diferenças entre média de postos (observada)

\begin{tabular}{|lcccc|}
\hline & Processo & Objetivos \\
Processo participativo & BSC & Participativo & APO & Financeiros \\
APO & 9,05 & & & \\
Objetivos Financeiros & 17,01 & 7,96 & & \\
Processo Intuitivo & 36,6 & 27,55 & 19,59 & 4,03 \\
\hline
\end{tabular}

Diferença mínima significativa (DMS)

\begin{tabular}{|lcccc|}
\hline & & Processo & Objetivos \\
DMS $(\alpha=0,05)$ & BSC & Participativo & APO & Financeiros \\
Processo participativo & 56,79 & & & \\
APO & 43,04 & 62,29 & & \\
Objetivos Financeiros & 36,53 & 57,98 & 44,59 & 41,27 \\
Processo Intuitivo & 39,58 & 59,95 & 47,13 & \\
\hline
\end{tabular}

As diferenças entre médias de postos supera a diferença mínima significativa em: Objetivos Financeiros e BSC, Processo Intuitivo e BSC. Descritivamente, nestes dois casos, a técnica BSC difere de Objetivos Financeiros e Processo Intuitivo, por fazer mais uso dos objetivos quanto ao Fator Responsabilidade Social Corporativa. 
Em relação ao fator Geração de Valor

\begin{tabular}{|lcc|}
\hline & & Média de \\
APO & N & Postos \\
BSC & 44 & 149,25 \\
Objetivos Financeiros & 92 & 145,88 \\
Processo Intuitivo & 75 & 163,11 \\
Processo Participativo & 57 & 116,87 \\
Total & 21 & 143,95 \\
\hline
\end{tabular}

Diferenças entre média de postos (observada)

\begin{tabular}{|lcccc|}
\hline & Objetivos & & & Processo \\
& Financeiros & APO & BSC & participativo \\
APO & 13,86 & & & \\
BSC & 17,23 & 3,37 & & \\
Processo Participativo & 19,16 & 5,3 & 1,93 & 27,08 \\
Processo Intuitivo & 46,24 & 32,38 & 29,01 & \\
\hline
\end{tabular}

Diferença mínima significativa (DMS)

\begin{tabular}{|lcccc|}
\hline & Objetivos & & Processo \\
DMS $(\alpha=0,05)$ & Financeiros & APO & BSC & participativo \\
APO & 44,59 & & & \\
BSC & 36,53 & 43,04 & & \\
Processo Participativo & 57,98 & 62,29 & 56,79 & 59,95 \\
Processo Intuitivo & 41,27 & 47,13 & 39,58 & \\
\hline
\end{tabular}

A única diferença significativa é entre Objetivos Financeiros e Processo Intuitivo. Descritivamente, este último fazendo menor uso dos objetivos no condizente ao Fator Geração de Valor.

\section{4}

n) ordem das etapas do processo estratégico

\begin{tabular}{|lcc|}
\hline Técnica & N & Média de postos \\
APO & 44 & 139,11 \\
BSC & 92 & 163,58 \\
Objetivos Financeiros & 75 & 140,08 \\
Processo Intuitivo & 57 & 128,17 \\
Processo Participativo & 21 & 139,19 \\
Total & 289 & \\
\hline
\end{tabular}

